\title{
WestVirginiaUniversity
}

THE RESEARCH REPOSITORY @ WVU

Graduate Theses, Dissertations, and Problem Reports

2002

\section{Establishing design vehicles for the hang-up problem}

Amy Lorraine Clawson

West Virginia University

Follow this and additional works at: https://researchrepository.wvu.edu/etd

\section{Recommended Citation}

Clawson, Amy Lorraine, "Establishing design vehicles for the hang-up problem" (2002). Graduate Theses, Dissertations, and Problem Reports. 1222.

https://researchrepository.wvu.edu/etd/1222

This Thesis is protected by copyright and/or related rights. It has been brought to you by the The Research Repository @ WVU with permission from the rights-holder(s). You are free to use this Thesis in any way that is permitted by the copyright and related rights legislation that applies to your use. For other uses you must obtain permission from the rights-holder(s) directly, unless additional rights are indicated by a Creative Commons license in the record and/ or on the work itself. This Thesis has been accepted for inclusion in WVU Graduate Theses, Dissertations, and Problem Reports collection by an authorized administrator of The Research Repository @ WVU. For more information, please contact researchrepository@mail.wvu.edu. 


\title{
Establishing Design Vehicles for the Hang-Up Problem
}

\author{
Amy L. Clawson \\ Thesis submitted to the \\ College of Engineering and Mineral Resources \\ at West Virginia University \\ in partial fulfillment of the requirements \\ for the degree of \\ Master of Science \\ in \\ Civil Engineering \\ Dr. Lloyd Jim French, III, Ph.D. (Chair) \\ Dr. Ronald W. Eck, Ph.D. \\ Dr. David R. Martinelli, Ph.D. \\ Department of Civil Engineering \\ Morgantown, West Virginia \\ 2002
}

Keywords: Hang-Up, Design Vehicles, Ground Clearance, Wheelbase, Front or Rear Overhang 


\section{ABSTRACT \\ Establishing Design Vehicles for the Hang-Up Problem}

\section{Amy Clawson}

Current design vehicles do not address the hang-up problem. The hang-up problem depends on two factors, vehicle geometry and roadway geometry, and occurs at high-profile alignments. There is a need to establish design vehicle characteristics for hang-up prone vehicles to reduce the occurrence of hang-ups.

Roadway geometry and vehicle characteristics relative to the hang-up problem were reviewed. Consideration of these properties by key organizations and associations, and government regulations were studied, and research performed by individuals establishing other design vehicles was analyzed. A general methodology was established:

1. Establish the Design Vehicles to be Developed

2. Determine the Dimensions / Characteristics to be Defined

3. Collect Appropriate Data

4. Use Data to Quantitatively Define Dimensions / Characteristics

The design vehicles developed were chosen to represent the vehicle population. Variation in vehicle population, the ramifications of using a limited number of vehicles, and local conditions were considerations in selecting design vehicle types.

Dimensions important to the hang-up problem (namely wheelbase, front/rear overhang, and ground clearance) were collected through field measurements and contacting manufacturers via telephone or Internet web pages.

After establishing a database of measurements, the HANGUP software program was utilized to produce plots depicting hang-up points on four vertical curves and the spread of the database of dimensions for each design vehicle type with respect to those hang-up points. These plots displayed outliers in the database, allowing the researchers to select design vehicle dimensions that closely represented the vehicle population for each design vehicle type. The worst case dimensions (also plotted on the hang-up graphs) for wheelbase, front/rear overhang, and ground clearance were used as reference points for the establishment of design vehicle dimensions for all the vehicles save one, which utilized the $85^{\text {th }}$ percentile method to establish dimensions. Comparisons with AASHTO design vehicles were made.

Constraints and considerations in establishing design vehicles were identified. Limitations found during the research included the geographic area and the infinite combinations of vehicles. 


\section{Acknowledgments}

The author would like to express her thanks to the many people who provided guidance and support in completing this thesis. Many thanks are given to Dr. Jim French, graduate advisor and committee chairperson, for guidance and assistance in the preparation of this thesis. For his participation on the committee and help with the revision process of the thesis, the author would like to express her thanks to Dr. Ronald Eck. Finally, the author wishes to extend her appreciation to Dr. Martinelli, the third member of the Examination Committee. The author would also like to thank Ray Lewis for his support and knowledge.

The author expresses her thanks Scott Nale and Jacob D'Angelo for their help in the data collection. For Scott Nale, additional thanks are expressed for help with data reduction. The help and support of friends and family was also greatly and dearly appreciated.

Finally, much gratitude and acknowledgements are extended to the West Virginia Department of Transportation and the Mid-Atlantic Universities Transportation Center for their financial support of this project. 


\section{Table of Contents}

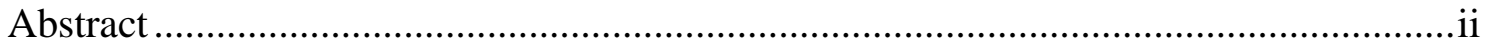

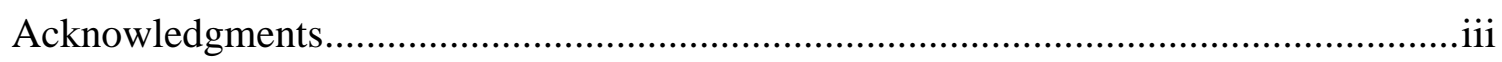

Table of Contents ................................................................................................

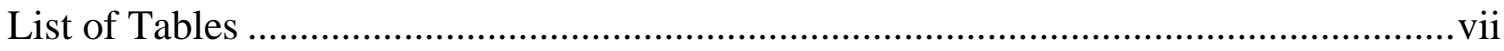

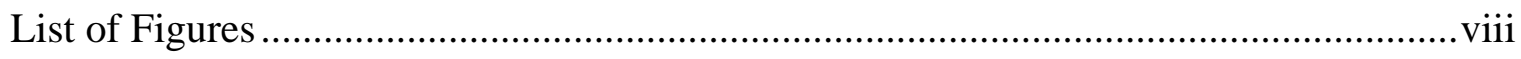

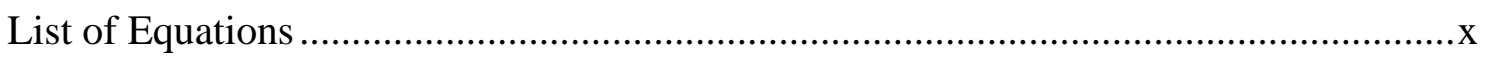

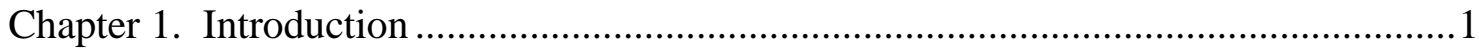

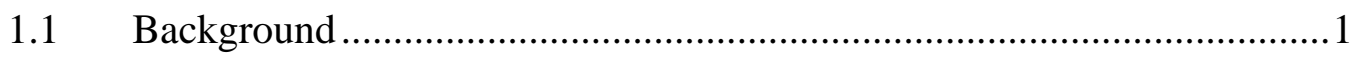

1.1.1 Issues to Consider ................................................................. 3

1.1.2 Requirements and Approaches to Addressing the Problem..........4

1.2 Problem Statement .................................................................6

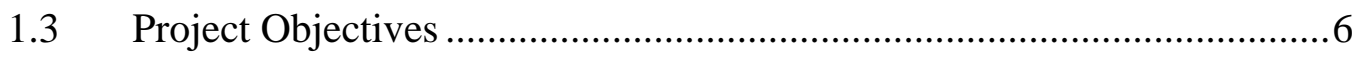

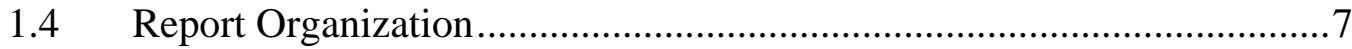

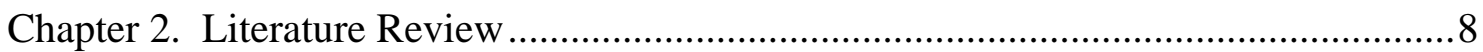

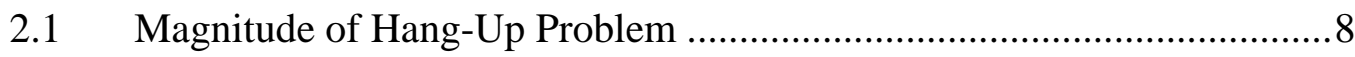

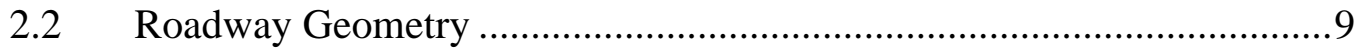

2.2.1 Roadway Properties and Characteristics..................................9

2.2.2 Design Guidance............................................................... 13

A. Early Research ...................................................... 13

B. Policies of Highway and Railway Organizations ............ 14

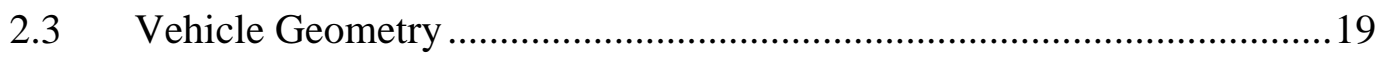

2.3.1 Vehicle Properties and Characteristics ..................................... 19

2.3.2 Standards and Regulations .................................................23

A. Guidelines from Truck / Trailer Manufacturer Trade Groups ..................................................................23

B. Government Regulations ........................................25

C. Special Permit Vehicles ..............................................26

D. Driver and Escort Licensing ......................................28

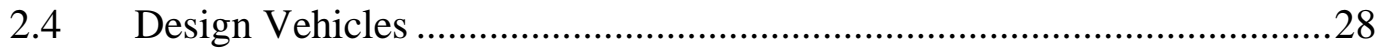

2.4.1 AASHTO Design Vehicles ...............................................28 
2.4.2 The Process of Establishing Semitrailer Combination Design

Vehicles and a School Bus Design Vehicle ........................32

2.4.3 Design Vehicle Efforts Directly Related to the Hang-Up Problem

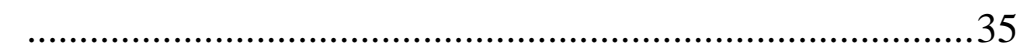

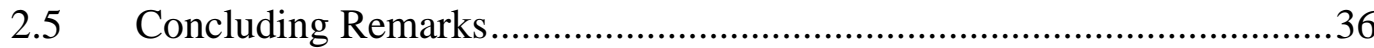

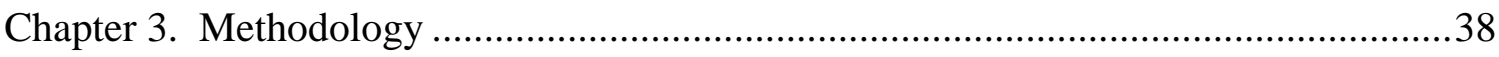

3.1 Establish the Design Vehicles to be Developed ..........................................38

3.2 Determine the Dimensions / Characteristics to be Defined ........................42

3.2.1 Dimensions / Characteristics Important to the Hang-Up Problem

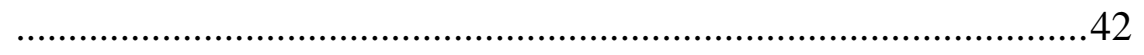

A. Ground Clearance, Wheelbase, Front / Rear Overhang ............43

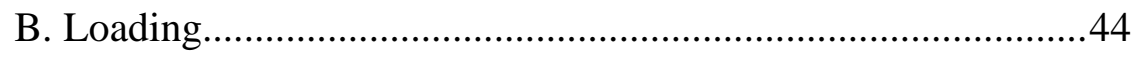

C. Tire Size, Inflation, and Wear .................................................44

D. Angles of Approach and Departure, Breakover Angle .............45

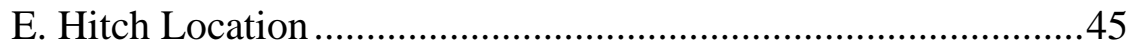

3.2.2 Dimensions / Characteristics to be Measured ..................................46

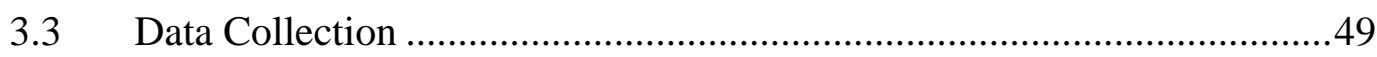

3.3.1 Data Collection Techniques Overview ………………………......49

3.3.2 Field Data Collection ..................................................................52

3.3.3 Manufacturer Data Collection.....................................................52

3.3.4 Concluding Remarks...............................................................53

3.4 Using Data to Quantitatively Define Dimensions / Characteristics...........55

3.4.1 Overview of Available Methods ....................................................55

3.4.2 The HANGUP Software ............................................................57

3.4.3 Using the HANGUP Software .....................................................58

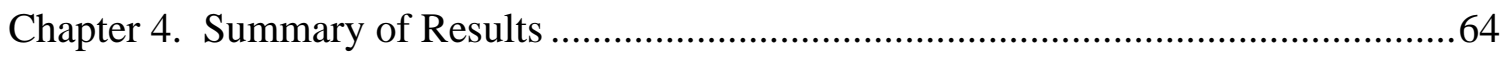

4.1 Design Vehicle Dimensions.....................................................................64

4.1.1 Single Unit Beverage Truck............................................................66

4.1.2 Articulated Beverage Truck ……………………………….......67

4.1.3 Rear-Load Garbage Truck ............................................................68

4.1.4 Aerial Fire Truck......................................................................69 
4.1.5 Pumper Fire Truck ............................................................. 70

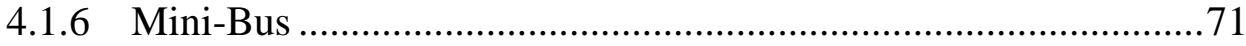

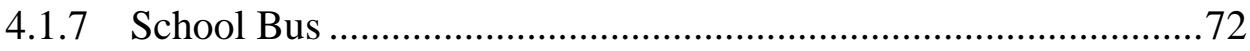

4.1.8 Single Unit Transit Bus......................................................... 73

4.1.9 Articulated Transit Bus ..................................................... 74

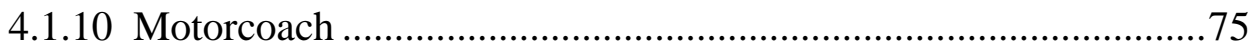

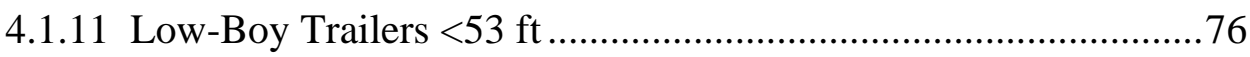

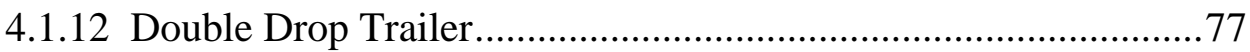

4.1.13 Car Carrier Trailer................................................................... 78

4.1.14 Belly Dump Trailer ............................................................79

4.1.15 Passenger Vehicle and Trailer - Private Use .............................80

4.1.16 Passenger Vehicle and Trailer - Commercial Use .....................81

4.1.17 Recreational Vehicle (RV) ............................................. 82

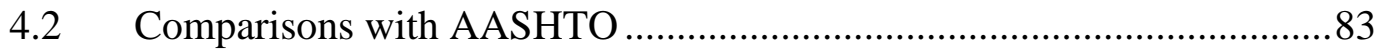

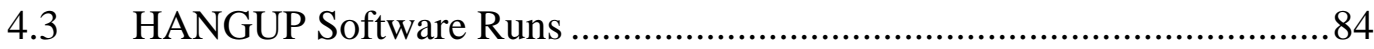

Chapter 5. Conclusions, Recommendations, Implementation ....................................86

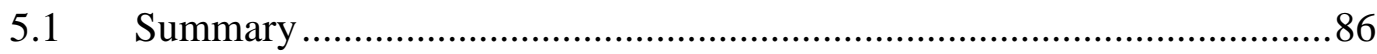

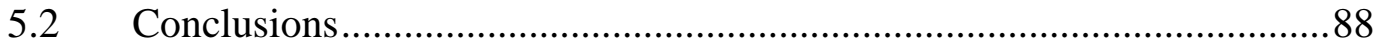

5.2.1 Conclusions Related to the Establishment of Design Vehicles .......88

5.2.2 Conclusions Specific to the Developed Design Vehicles ...............89

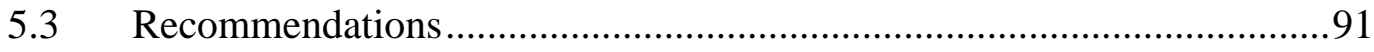

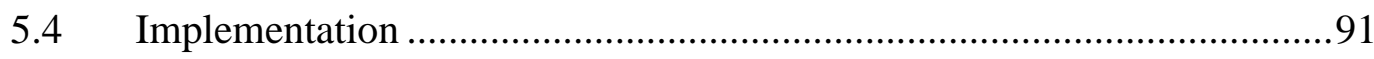

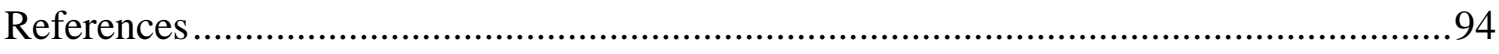

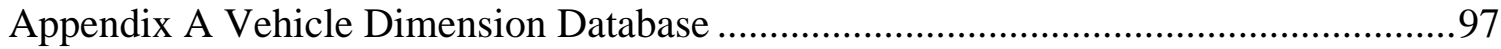

Appendix B Best, Average, and Worst Case Dimensions and Sample Sizes ............... 116

Appendix C List of Vehicle Manufacturers .............................................................. 120

Appendix D Profiles Used in HANGUP Testing and Wheelbase / Ground Clearance

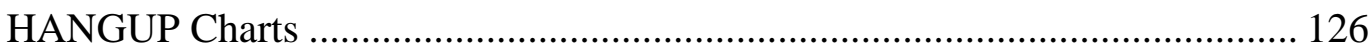

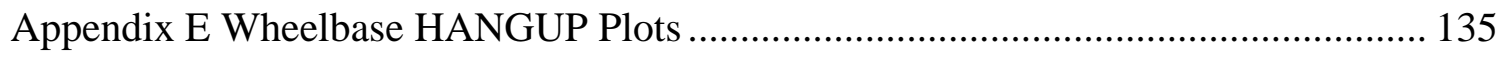

Appendix F Rear Overhang HANGUP Plots......................................................... 153

Vita. 


\section{List of Tables}

$2.1 \quad$ Federal Regulations for Length (FHWA, 1996) ............................................26

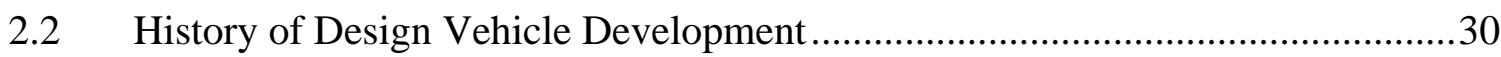

2.3 Comparison of Gattis and Howard's Dimensions (1999) and AASHTO's (2001)

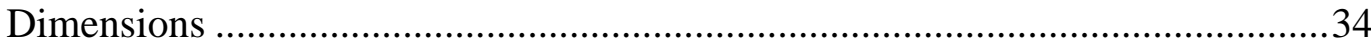

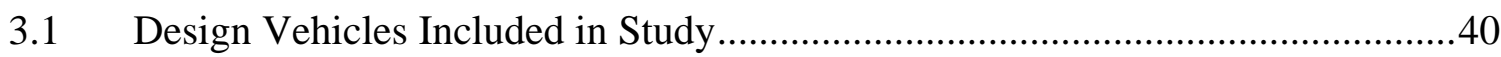

3.2 Dimensions/Characteristics to be Measured .....................................................47

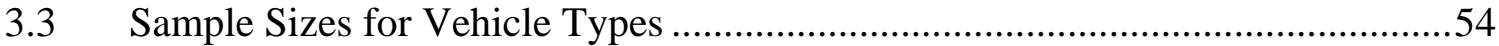

3.4 HANGUP Ground Clearance - Wheelbase Charts for Double-Track Railroad Highway Grade Crossing - Twin.prf..........................................................61

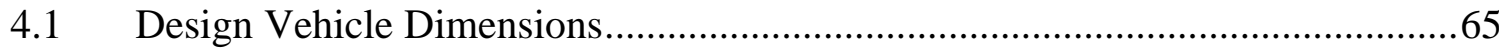

4.2 Key Comparisons of AASHTO Design Vehicles with Hang-Up Design Vehicles

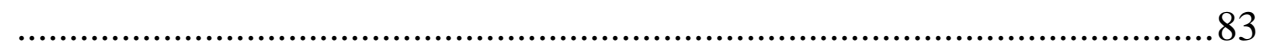

4.3 Results of HANGUP Analyses - Design Vehicles on Test Profiles ...................85

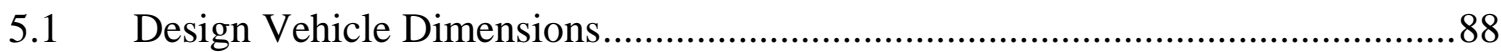




\section{List of Figures}

2.1 Vertical Curve Types as Identified by AASHTO ..............................................10

2.2 Vertical Alignment Design Criteria for Railroad-Highway Grade Crossings

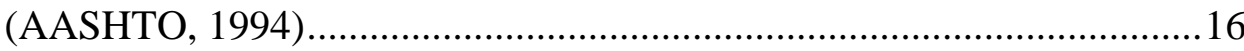

2.3 Definition of Angle of Approach and Angle of Departure .................................21

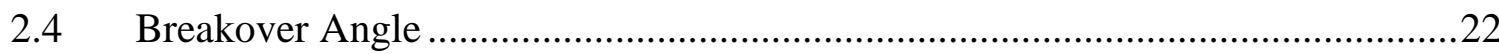

3.1 Double-Drop Trailer Silhouette ………………….........................................41

$3.2 \quad$ Wheelbase, Front and Rear Overhang ……………….....................................43

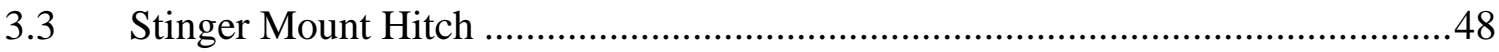

3.4 High Mount Hitch ....................................................................................48

3.5 AREMA Railroad-Highway Grade Crossing Vertical Alignment .........................58

3.6 ITE "Low Volume Driveway on Major Streets or Collector Streets" ...................59

3.7 Low Volume Driveway on a Local Street ………............................................59

3.8 Typical Double Track Mainline Railroad-Highway Grade Crossing Alignment.60

3.9 Wheelbase Hang-up Plot for Low-Boy Trailers < 53 feet ....................................62

4.1 Single Unit Beverage Truck........................................................................66

4.2 Articulated Beverage Truck ..........................................................................67

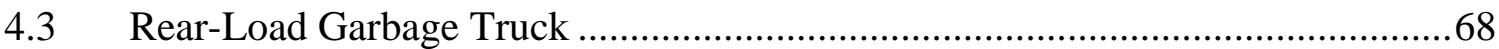

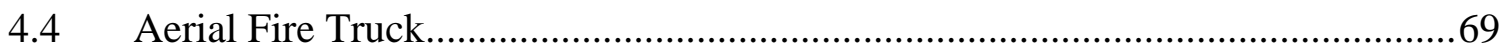

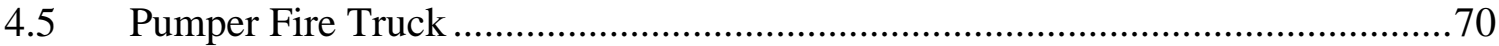

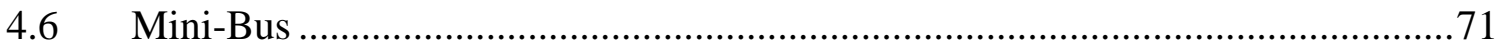

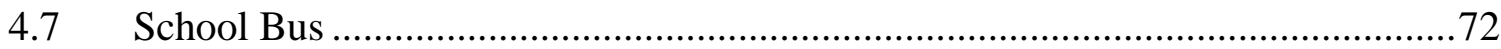

$4.8 \quad$ Single Unit Transit Bus..................................................................................73

$4.9 \quad$ Articulated Transit Bus ...............................................................................

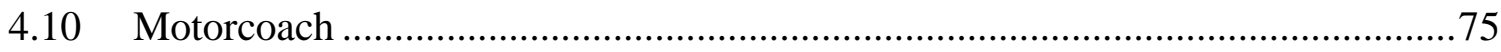

$4.1185^{\text {th }}$ Percentile Plot - Low-Boy Wheelbase Length ..............................................76

4.12 Low-Boy Trailers < 53 feet ……………………..............................................77

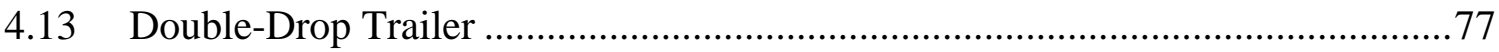

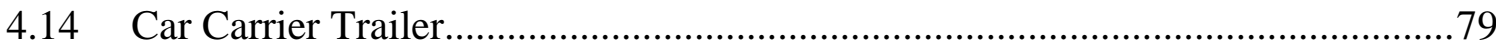

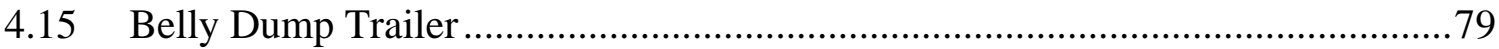

4.16 Passenger Vehicle and Trailer - Private Use ........................................................... 80 
4.17 Passenger Vehicle and Trailer - Commercial Use ........................................81

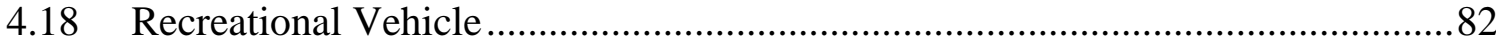




\section{List of Equations}

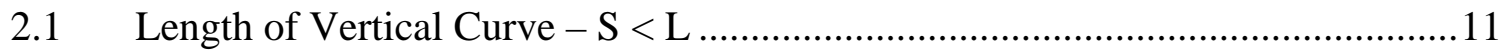

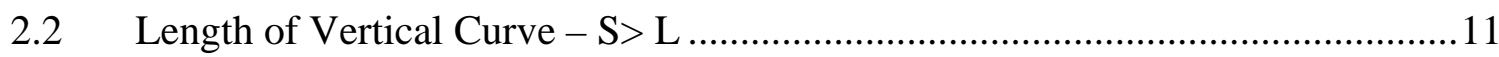

2.3 Length of Sag Vertical Curve ..........................................................................12

2.4 Minimum Length of Sag Vertical Curve (Eck and Kang) ...................................12

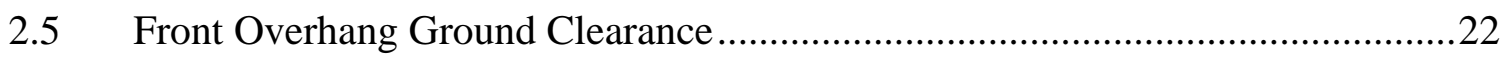

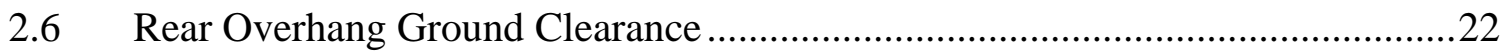

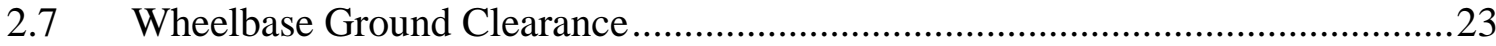




\section{Chapter 1 - Introduction}

\subsection{BACKGROUND}

A current safety issue in highway design and traffic operations involves high-profile alignments or "humps" that vehicles with a long wheelbase and low ground clearance cannot negotiate without the possibility of contacting the pavement or becoming lodged (or "hung-up") on the vertical alignment. Such problems can also occur on vertical sag curves, where long front and rear overhangs may cause the front or rear of the vehicle to drag (Eck and Kang, 1992). At best, these incidents result in some vehicular delay and minimal property damage to the vehicle and pavement surface. In the worst case, such as can occur at railroad-highway grade crossings, the vehicle may be struck by a train, resulting in loss of life and millions of dollars in property damage.

A vehicle classification count, performed in West Virginia as part of research on the hang-up problem, found that low-ground-clearance trucks made up about 5.7 percent of all trucks in the traffic stream (Eck and Kang, 1991). Eck and Kang (1991) also found that in Oregon about one crash per year was the result of a low-ground-clearance vehicle hanging up on a railroad-highway grade crossing and being struck by a train. The Mid-Atlantic region safety director of a trucking company that hauls automobiles reported 50 to 60 hang-up incidents per month involving auto transporters.

Furthermore, the National Transportation Safety Board (NTSB) has issued a warning that crossing profiles with a high, hump-like alignment are potential impediments in the operation of long-wheelbase or low-ground-clearance vehicles (Eck and Kang, 1991). In 1983, after an investigation of a hang-up related crash in North Carolina, the NTSB "warned that crossing profiles with hump-like vertical curves can impede the operation of a vehicle if the distance 
between any two axles of a vehicle spans the hump and the height of the hump exceeds the vehicle's ground clearance" (Eck and Kang, 1992). This crash, involving a tractor-lowboy semitrailer combination truck and an Amtrak Silver Meteor train, resulted in numerous injuries and property damage totaling $\$ 623,399$ (NTSB, 1984). In current dollars, the cost of this crash is equivalent to approximately $\$ 1.1$ million.

A second example illustrating the potential magnitude of crashes caused by hang-ups occurred at a railroad-highway grade crossing near Intercession City, Florida in 1993. While transporting a large 82-ton turbine, the 184-foot long trailer hauling the turbine became lodged on a railroad track owned by CSX Transportation, Inc. The load was being raised off the track when Amtrak Train Number 88 approached the crossing and struck the trailer. While no one was killed, 59 people were injured and total damages exceeded $\$ 14$ million (over $\$ 17$ million in current dollars - 2002). Several issues contributed to this accident, including (1) permitting issues for oversize vehicles, (2) discrepancies between design criteria suggested by American Railway Engineering and Maintenance-of-Way Association (AREMA) and the American Association of State Highway and Transportation Officials (AASHTO) and (3) the adherence to design guidelines for railroad-highway grade crossings (NTSB, 1995 a).

While the two examples cited here involved railroad-highway grade crossings, note that these are not the only areas prone to hang-up problems. Other hang-up prone areas include driveway connections, bridge approaches, and intersections. 


\subsubsection{Issues to Consider}

Solving the hang-up problem is difficult due to its complexity. There is a strong interrelationship between all elements (roadway, vehicle, and driver) of the highway system. Each of the elements is described below.

In the United States, some of the key elements of commercial vehicle design relative to the hang-up problem are not strongly regulated. Ground clearance, a critical hang-up related parameter, is one such example. In the economically competitive trucking industry, there is continuing pressure to haul larger and higher loads. Since maximum heights are constrained by fixed bridge, tunnel, and overhead utility clearances, the trend over time has been toward vehicles with longer wheelbases and lower ground clearances.

Relative to the roadway, it has been established that a high-profile alignment or one with sharp grade breaks can cause a long-wheelbase and/or low-ground-clearance vehicle to hang-up. However, circumstances commonly arise where a road accommodated hang-up prone vehicles, but maintenance or operational activities have changed the roadway geometry such that certain hang-up prone vehicles can no longer be accommodated. The following are a few examples of how this can occur.

Railroad-highway grade crossing design standards are available that consider lowground-clearance vehicles. However, maintenance of the railroad track often raises the elevation of the rails, including the area at the crossing. This creates a more severe geometry with increased susceptibility to hang-ups. Communications between the railroad and roadway agency are critical so that the highway agency can adjust the approaches to the crossing to maintain a suitable vertical profile across the tracks. Unfortunately, the necessary communication does not always occur. 
A similar example involves driveway-highway intersections. Conflicts may occur over coordination of roadway-related activities between these public and private owners. An owner of a driveway accessed by hang-up susceptible vehicles could find their driveway a potential area for hang-ups after the publicly owned road adjacent to it is resurfaced. Likewise, maintenance of a privately owned driveway could create problems for vehicles turning off the highway onto the driveway and encountering a severe grade change. Once again, communication between different entities is critical, but does not take place.

Finally, the human factor is another element related to hang-ups. A driver may know the wheelbase and ground clearance of the vehicle they are driving, but, in the absence of detailed information about the alignment, such knowledge is of little value in judging whether they can negotiate the alignment. A complicating matter is the visual "deception" some high-profile alignments pose to drivers. Due to their curvilinear geometry and gentle gradients, certain highprofile alignments appear, from the driver's elevated perspective, not to be a problem.

The preceding discussion has shown that the causes of hang-ups involve more than engineering issues. Human factors, jurisdictional and even legislative issues are all relevant to this problem. Thus, the overall approach to hang-up countermeasure development should be multifaceted, addressing roadway, vehicle, and driver considerations.

\subsubsection{Requirements and Approaches to Addressing the Problem}

There are two requirements for a hang-up to occur. There must be a high-profile vertical alignment or an alignment with sharp grade breaks. There also must be a low-ground-clearance and long-wheelbase or overhang vehicle. Thus, both vehicle characteristics and roadway geometry must be considered when addressing the hang-up problem. 
There are several approaches to addressing the hang-up problem, including regulations on vehicle dimensions, roadway signing, and refinement of existing highway design standards. However, as will be discussed later, there are virtually no limitations on ground clearance, and roadway signing provides little information about the geometry of high profile alignments. Additionally, while highway design standards exist for this situation, their origin and effectiveness is unknown.

Tools such as the HANGUP software program have been developed to aid in the design of vertical curves to minimize the possibility for hang-ups and analyze existing alignments for hang-up susceptibility. However, this program requires detailed information about the vehicles that will be using the alignment to maximize its effectiveness as a design tool.

The establishment of design vehicle characteristics for hang-up prone vehicles would be particularly helpful. Existing design vehicles such as those contained in the AASHTO design policy (2001) were not selected for inclusion in the policy based on hang-up susceptibility nor do they include important hang-up related dimensions. The design vehicles identified in the AASHTO design policy (2001) are described in terms of length, width, height, wheelbase and turning radii, but the ground clearance is not given for any vehicle. Furthermore, no specific information is given for highly hang-up susceptible vehicles such as the low-boy trailer. Several hang-up related dimensions are needed, including wheelbase, ground clearance, and overhangs in the front and rear. Design vehicles specifically for the hang-up problem could be used in conjunction with the HANGUP software or other analytical tools utilized when designing roadway geometry to address hang-up potential, or redesigning existing alignments to reduce the hang-up potential. 


\subsection{PROBLEM STATEMENT}

The problem of vehicles hanging-up at high-profile vertical alignments continues to be an operational problem on the roadway system. Current regulations and design standards do not adequately address the problem. To improve traffic operations and safety at hang-up prone locations, and to design or maintain roadway alignments so that little or no hang-up potential exists, there is a need to establish design vehicle characteristics for hang-up prone vehicles. These design vehicles will contribute to the alleviation of the hang-up problem because they will enable more detailed and precise analyses of hang-up prone areas, allowing safer designs to be developed. In the near term, this capability can help roadway designers and operators determine which vehicle types can and cannot negotiate particular alignments, or, conversely, allow them to modify alignments so that they can accommodate certain vehicle types. In the long term, perhaps these can be used as the foundation of a rating system for high-profile alignments or hang-up prone vehicles.

To establish these design vehicles, the necessary vehicle characteristics need to be identified and quantified. At a minimum, dimensions such as ground clearance, wheelbase, and overhang will be needed. Additionally, the specific vehicle types that are hang-up prone need to be identified. These will be vehicles with low ground clearances and long wheelbases and/or overhangs.

\subsection{PROJECT OBJECTIVES}

The goal of the project is to develop design vehicles to be used to reduce or eliminate the occurrence of hang-ups. Several objectives were identified to meet this goal: 
- To review literature pertaining to design vehicles generally and to the hang-up problem specifically

- To identify the types of vehicles that are prone to hang-ups because of low ground clearances and/or long wheelbases/overhangs.

- To gather wheelbase, overhang, and ground clearance data for the hangup prone vehicles, using information from manufacturers and field measurements.

- To perform a detailed review of the data, including statistical analysis where needed.

- To establish appropriate dimensions for the identified design vehicles.

- To present design vehicle information in a form compatible with existing design policies.

\subsection{REPORT ORGANIZATION}

Chapter 1 has identified the problem being addressed and outlined project objectives.

Chapter 2, the literature review, discusses previous research related to the hang-up problem. The chapter also reviews research relative to defining design vehicles and identifies a common approach used by researchers. The methodology of the project is presented in Chapter 3, including identification of design vehicles, data collection methods and results, ways to quantitatively define the collected data, and the methods used for data reduction. Chapter 4 introduces the established design vehicles complete with dimensions and sketches of the design vehicles. Finally, Chapter 5 presents conclusions, recommendations, and suggestions for implementation. 


\section{Chapter 2 - Literature Review}

This literature review discusses pertinent documented material in the areas of (1) the hang-up problem and (2) design vehicle development. The discussion of the hang-up problem is necessary to frame the problem and demonstrate the need for and benefits of design vehicles developed specifically for it. This discussion is divided into three areas. In Section 2.1, the magnitude of the hang-up problem is described. Sections 2.2 and 2.3 discuss the two major contributors to the hang-up problem, the roadway and the vehicle. In Section 2.2, Roadway properties and characteristics and existing design guidance are described. Section 2.3 contains a discussion of relevant vehicle properties and characteristics, and standards and regulations from groups such as truck / trailer manufacturers and the government. Design vehicle development is covered in Section 2.4, and is needed so that an effective research plan can be established to develop design vehicles for the hang-up problem.

\subsection{MAGNITUDE OF HANG-UP PROBLEM}

In their research, Eck and Kang (1991) quantified the magnitude of the hang-up problem. In order to obtain an idea about types of vehicles prone to hang-ups, and the proportion of overall traffic that was susceptible to hanging-up, vehicle classification counts were collected on I-79, a regional interstate between Charleston, West Virginia, and Erie, Pennsylvania. The results of the vehicle classification counts showed that the truck population consisted of slightly more than 13 percent of the traffic flow. About 5.7 percent of the trucks, or 0.74 percent of the overall traffic, were classified as low ground clearance (Eck and Kang, 1991). Furthermore, a mid-Atlantic region safety director (who works for a trucking company transporting automobiles) reported that the company experiences as many as 60 hang-ups a month. Finally, the National 
Transportation Safety Board (NTSB) does recognize that the hang-up problem is serious enough to justify corrective measures to be taken (Eck and Kang, 1991).

\subsection{ROADWAY GEOMETRY}

\subsubsection{Roadway Properties and Characteristics}

Several roadway properties and characteristics are areas of concern in regard to the hangup problem. These include short vertical curves, roadway crowns, sharp grade breaks such as those found at bridge approaches and driveway access points, and railroad-highway grade crossings. Standards and recommended practices will be discussed for most of these in the following sections, but first, a description of each problem area is needed.

Vertical curves can occur as crest or sag vertical curves. Figure 2.1 details the types of crest and sag vertical curves that can be used in roadway design as presented in the AASHTO Green Book (2001). The geometry of these curves includes "a parabolic curve with an equivalent vertical axis centered on the vertical point of intersection (VPI)" (AASHTO, 2001). 


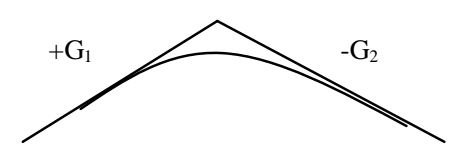

Type I

Type III

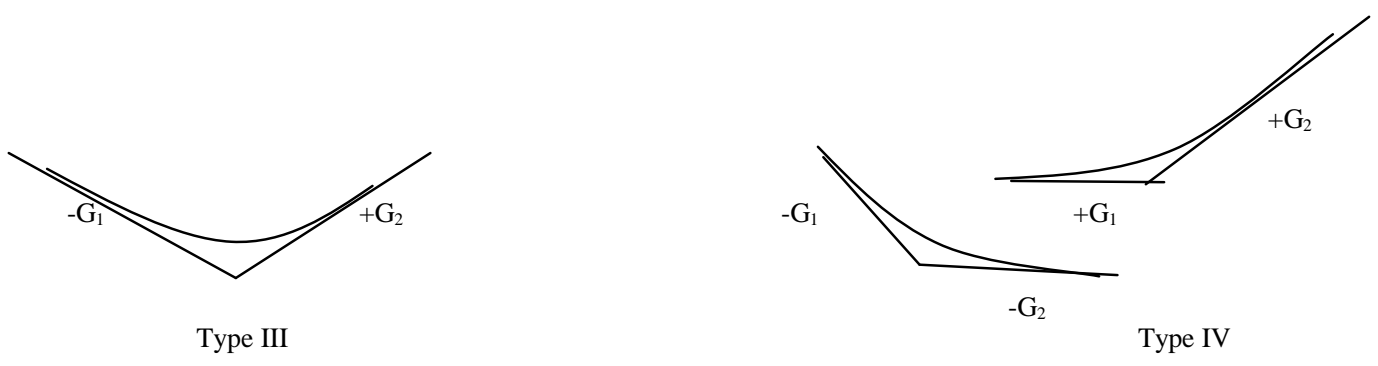

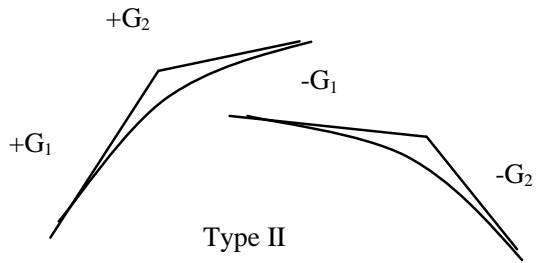

Type II

CREST VERTICAL CURVES

SAG VERTICAL CURVES

Figure 2.1: Vertical Curve Types as Identified by AASHTO

When designing vertical curves driver comfort, sight distance, drainage control, and general appearance is considered (AASHTO, 2001). No consideration is given to the potential hang-up problem created by a short curve length at the grade break resulting in a high profile alignment.

In relation to the hang-up problem, vehicles hang-up between the wheels on crest curves, and on the front and/or rear overhang on sag curves. When designing crest vertical curves, the minimum curve length is based no sight distance and driver comfort. These minimum lengths can be found with equations or graphs. The following equations calculate the length of vertical curve: 
When $\mathrm{S}$ is less than L: $\quad L=\frac{A S^{2}}{100\left(\sqrt{2 h_{1}}+\sqrt{2 h_{2}}\right)^{2}}$

When $S$ is greater than $\mathrm{L}: \quad L=2 S-\frac{200\left(\sqrt{h_{1}}+\sqrt{h_{2}}\right)^{2}}{A}$

Where:

$\mathrm{L}=$ length of vertical curve, $\mathrm{ft}$

$\mathrm{S}=$ sight distance, $\mathrm{ft}$

$\mathrm{A}=$ algebraic differences in grades, percent

$\mathrm{h}_{1}=$ height of eye above roadway surface, $\mathrm{ft}$

$\mathrm{h}_{2}=$ height of object above roadway surface, $\mathrm{ft}$

Whether or not the curves that meet these design standards are subject to hang-ups is unknown. When designing the curve, the equations consider sight distance as a leading factor for design. However, these equations do not consider the vehicle geometry (low ground clearances, long wheelbases or overhangs) of the vehicles traveling over the curves. According to Eck and Kang (1992), “To eliminate hang-up incidents at high-profile roadways, the rate of change of grade on crest vertical curves should be constant, that is, a parabolic curve."

In the AASHTO Green Book (2001), the four criteria for determining the minimum length of sag curves include headlight sight distance, passenger comfort, drainage control, and general appearance. Passenger comfort is addressed by the length of the sag curve, but only in relation to the gravitational and centripetal forces caused by the vertical displacement of the vehicle traveling through the curve, and the effects these forces have on the driver and passengers. Equation 2.3 provides additional design guidance for the design of sag curves. However, it is mainly to prevent driver discomfort caused by a vertical curve that is too short. 


$$
L=\frac{A V^{2}}{46.5}
$$

Where:

$\mathrm{L}=$ length of sag vertical curve, $\mathrm{ft}$

$\mathrm{A}=$ algebraic difference in grades, percent

$\mathrm{V}=$ design speed, $\mathrm{mph}$

Again, no consideration of vehicle dimensions relative to the hang-up problem are considered. Eck and Kang (1992) developed an equation that considered the vehicle dimensions relative to the hang-up problem. The following equation finds the minimum length of a sag vertical curve to prevent dragging at the overhang:

$$
L_{\text {min }}=\frac{144 V^{2}+h^{2}}{12 h} \cos \left[90-1 / 2 \tan ^{-1}(A)\right]
$$

Where:

$\mathrm{L}=$ length of sag vertical curve $(\mathrm{ft})$

$\mathrm{V}=$ overhang length of vehicle $(\mathrm{ft})$

$\mathrm{h}=$ ground clearance of the vehicle (in)

$\mathrm{A}=$ algebraic difference in grades (percent/100)

However, areas of even greater concern are short vertical curves at grade breaks and vertical alignments that are not designed according to any criteria. For example, a hump in the road caused by a pavement failure could cause a hang-up susceptible area.

The crown and cross slopes of a roadway are also pertinent to the hang-up problem. Crowns and cross slopes appear on "Undivided traveled ways on tangents, or on flat curves" and on divided roadways that "have a crown or high point in the middle and a cross slope downward toward both edges" (AASTHO, 2001). Crowns and cross slopes aid in the drainage of water 
from the roadway. Divided highways are designed as "one-way traveled" paths, which "may be crowned separately as on two-lane highways, or may have a unidirectional cross slope across the entire width of the traveled way, which is almost always downward to the outer edge" (AASHTO, 2001). These slopes are very desirable as they provide rapid drainage. However, steeper cross slopes and large crown heights can create areas where crossing traffic can become hung-up.

With respect to railroad-highway grade crossings, Vehicles with long wheelbases and low ground clearances traversing grade crossings with steep vertical grades may experience hang-ups on the grade break. According to the Federal Highway Administration (FHWA) in the RailroadHighway Grade Crossing Handbook (1986), "It is desirable that the intersection of highway and railroad be made as level as possible from the standpoint of sight distance, rideability, and braking and acceleration.” Part 8 of AREA's (now AREMA) Manual for Railway Engineering (1993) and AASHTO's Green Book (2001) also provide geometric design standards for railroadhighway grade crossings. The guidance provide by each are very similar and are discussed in detail in subsection 2.2.2 B of this section.

\subsubsection{Design Guidance}

\section{A. Early Research}

The first reported investigation concerning ground clearances was that by W.A.

McConnell (1958) who investigated wheelbases, minimum ground clearance, angles of approach and departure, and breakover angles for passenger vehicles as these parameters related to the problem of "rear jounce," which is the up-and-down motion experienced when the rear of the car bounces as it travels over a radical change in grade on the roadway. 
To provide roadway design guidance to correct the problem of "rear jounce" experienced when a vehicle traversed a sag curve, McConnell (1958) suggested that the maximum change of slope should be five percent between any two ten-foot chords. Additionally, the maximum ground clearance between the pavement and a ten-foot straightedge should be 1.5 inches.

Bauer (1958) followed up on the work of McConnell (1958) by examining problems that low-ground-clearance vehicles encountered when traversing suburban and residential driveways. It was proposed that a 2-inch safety margin for ground clearance be used to accommodate the downward thrust that vehicles experience when braking while traveling over a driveway profile. A manual procedure for checking the design of a driveway for hang-up potential was also introduced. This procedure involved sliding a scale model car along the profile of the curve to pinpoint trouble areas. The dimensions of the vehicle were selected based on the dimensions of vehicles likely to travel over the curve. For example, if a specific type of car traveled through the driveway, such as a single unit vehicle, the dimensions were noted and a scale model of that vehicle constructed. Once the trouble areas were detected, each could be corrected to prevent future ground clearance problems (Bauer, 1958).

\section{B. Policies of Highway and Railway Organizations}

Perhaps the first transportation organization to develop design standards aimed at addressing the hang-up problem was the American Railway Engineering Association (now the American Railway Engineering and Maintenance of Way Association, AREMA). The AREMA established geometric design guidelines (1993) for the vertical alignment of new railroadhighway grade crossings. The AREMA guideline states:

"The surface of the highway shall be in the same plane as the top rails for a distance of $2 \mathrm{ft}$. outside of the rails for either multiple or single-track crossings. 
The top of the rail plane shall be connected with the grade line of the highway each way by vertical curves of such length as is required to provide riding conditions and sight distances normally applied to the highway under consideration. It is desirable that the surface of the highway be not more than 3 in. higher nor 6 in. lower than the top of the nearest rail at a point $30 \mathrm{ft}$. from the rail, measured at right angle thereto, unless track superelevation dictates otherwise (AREA, 1993)."

The basis for these numbers in the AREMA guideline is unknown. Eck and Kang (1991) examined this guideline and found that at grade crossings where vehicle-train crashes occurred due to hang-ups, the guideline had not been followed.

AASHTO's A Policy on Geometric Design of Highways and Streets (2001) is the recognized design standard for public roadways in the United States. However, railroadhighway grade crossing vertical alignment has not always been in the AASHTO design policies. The 1984 edition of AASHTO's geometric design policy contains a short section on railroad grade crossings. However, instead of mentioning a specific vertical alignment, the manual states that "The geometric design of railroad-highway grade crossings must be made jointly with the determination of the warning devices to be used" (AASHTO, 1984). The Railroad-Highway Grade Crossing Handbook (FHWA, 1986) is referenced and the AASHTO manual advises engineers to consult this guideline when designing a grade crossing.

The 1990 AASHTO Green book contained a short section about the vertical alignment at railroad-highway grade crossings. The Green Book stated:

"Acceptable geometrics necessary to prevent drivers of low-clearance vehicles from becoming caught on the tracks would provide the crossing surface at the same plane as the top of the rails for a distance of $2 \mathrm{ft}$. outside of the rails. The surface of the highway should also not be more than 3 in. higher or 6 in. lower than the top of the nearest rail at a point $30 \mathrm{ft}$. from the rail unless track superelevation dictates otherwise as shown on Figure IX-75." (AASHTO, 1990) 
The 1994 revision of the AASHTO manual states the same paragraphs cited for the 1990 AASHTO manual. Figure 2.4 depicts the AASHTO (1994) criteria.

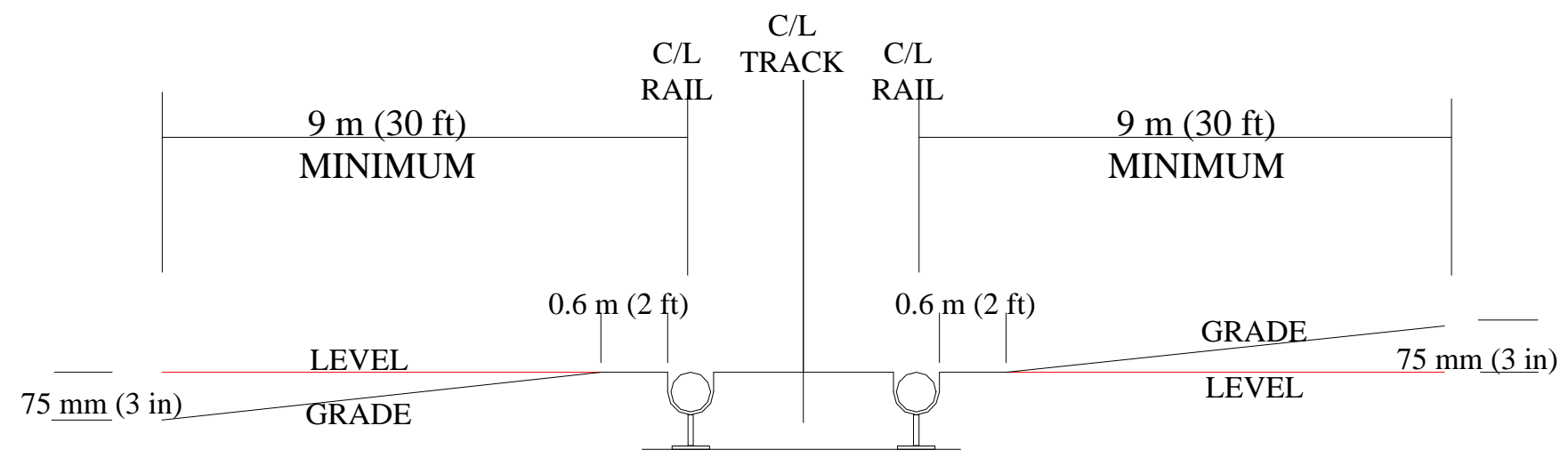

Figure 2.2 - Vertical Alignment Design Criteria for Railroad-Highway Grade Crossings (AASHTO, 1994)

Two items are noteworthy relative to this excerpt. First, it is identical to the AREMA standard (AREA, 1993). Second, there was an inconsistency between the text and the figure. The AASHTO manual states "The surface of the highway should also not be more than $75 \mathrm{~mm}$ (3 in) higher or $150 \mathrm{~mm}$ (6 in) lower than the top of nearest rail..." (1994). Figure 2.4 correctly shows the "75 mm (3 in) higher," but the distance lower than the top of the nearest rail does not match the distance given in the text.

These standards were given to prevent low-ground-clearance vehicles from hanging up on the railroad-highway grade crossing (AASHTO, 1994). Its origins are unknown, but, as noted above, the 1994 AASHTO standard is identical to the AREMA standard (AREA, 1993).

The 2001 AASHTO Green Book contains a large section devoted specifically to the horizontal and vertical alignment at railroad-highway grade crossings. The "Railroad-Highway Grade Crossings: Vertical Alignment" section states that the crossing be made "as level as practical." The surface of the crossing should be level with the rails for a $0.6 \mathrm{~m}[2 \mathrm{ft}]$ distance on 
either side of the rail. Additionally, "The surface of the highway should not be more than $75 \mathrm{~mm}$

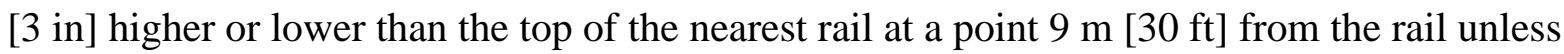
track superelevation makes a different level appropriate" (AASHTO, 2001). Note that the inconsistency found in the 1994 AASHTO Green Book was corrected in the 2001 AASHTO Green Book. The narrative also points out that "vertical curves should be used to traverse from the highway grade to the level plane of the rails."

Note that while AASHTO (2001) has consistency between the text and figure, it is now inconsistent with the AREMA standards. It is unknown which should actually be followed. Compliance with AASHTO also implies compliance with AREMA since AASHTO is more conservative.

The Federal Highway Administration (FHWA) includes maintenance guidance in their Railroad-Highway Grade Crossing Handbook (Tustin et. al, 1986). While maintenance on the roadway approach is the responsibility of the public agency owning the road, in West Virginia, the railroad's right-of-way for a single track is 66 feet. As such, the railroad agency has jurisdiction at the point where the roadway crosses the railroad tracks (Hartman, 2002).

The maintenance responsibilities at railroad-highway grade crossings present unique circumstances for both the railroad and highway agencies. The railroad company is responsible for maintaining all traffic control devices located at the crossing. Traffic control devices along the approach, however, are the public agency's responsibility. Therefore, it would be the public agency's responsibility to post any warning signs for crossings with hang-up potential to alert drivers of hang-up prone vehicles.

The crossing surface is maintained by the "maintenance of way department" of the railroad. This department inspects and repairs the track, roadbed, and drainage, which is part of 
the periodic maintenance program of the agency. Site-specific repairs are performed upon request or in emergency situations (Tustin et. al., 1986). After repairing or maintaining the roadbed, it is possible that the resulting geometry of the grade crossing will no longer meet the design standard specified in the AREMA and AASHTO manuals. A steep grade on the approach and departure of the roadway to the crossing can be created with maintenance or repair of the track (caused when the tracks are raised during the maintenance), increasing the hang-up potential. The resulting grade break at the railroad-highway grade crossing can then be significantly different and more severe after the maintenance than it was before the maintenance. This subject needs to be addressed when considering maintenance programs (Tustin et. al., 1986).

Driveways, another hang-up susceptible location, have grade breaks between the roadway (shoulder) cross slope and the grade of the driveway. An existing recommend practice for the design and construction of driveways is the Institute of Transportation Engineers (ITE) Guidelines for Driveway Location \& Design (1987). Driveway characteristics include traffic volume, right-of-way considerations, location, sight distance, use of curbs, width, radii angles, and grades are discussed in this guideline. According to the ITE guidelines, "Acceptable vertical profiles of driveways are generally governed by the operating characteristics of vehicles." The driveway profile should also be designed with respect to the potential of damage to the underside of a vehicle traveling over it. To this end, ITE proposes maximum changes in grade between the roadway and the intersecting driveway for three classes of driveways, depending on the vehicles anticipated to be traveling across those driveways. These are provided below:

- High Volume Driveway - Maximum Grade Change $= \pm 3 \%$

- Low Volume Driveway on Major or Collector Streets - Maximum Grade Change $= \pm 6 \%$ 
- Low Volume Driveway on Local Streets - Maximum Grade Change is controlled by vehicle clearance $( \pm 15 \%)$

The physical dimensions and braking capabilities of vehicles were used to establish the maximum grades for driveways. It also contains the curb and shoulder cross-section in the rightof-way, and whether a sag or crest curve is necessary to end the driveway beyond the right-ofway limits. It is recommended that the driveway's upward slope from the gutter line be a constant slope for at least ten feet for residential drives and 40 feet for industrial and commercial driveways. This allows vehicles to pull off the roadway before traveling upward through the driveway, reduces vehicle speed, and aids the driver in maintaining control of the vehicle (ITE, 1987). While the Recommended Practice mentions grades, grade breaks, and other pertinent design considerations, no mention was made of whether hang-up prone vehicle can or can not be accommodated by the three classes of driveways.

Eck and Kang analyzed the ITE driveway with a maximum grade change of 3 percent (low-volume driveway profile). They found that the standard low clearance vehicle developed in their research could not travel the driveway without experiencing problems. Because this vehicle would not pass, it was assumed that most low-ground-clearance vehicles would hang-up on the ITE low-volume driveway alignment. In their research, Eck and Kang (1992) concluded that, when "two roadways intersect, grade differences at the intersection should be less than or equal to 4.6 percent, which is the maximum slope rate for the standard low-clearance vehicle."

\subsection{VEHICLE GEOMETRY}

\subsubsection{Vehicle Properties and Characteristics}

The preceding section discussed roadway geometry. The other part of the hang-up problem involves dimensions and characteristics of vehicles negotiating the roadway. Several 
vehicle properties and characteristics affect a vehicle's hang-up potential. These properties and characteristics include:

- ground clearance

- wheelbase

- front and/or rear overhang length

- vehicle loading condition

- tire type and inflation

- angle of approach

- angle of departure

- breakover angle

The ground clearance is the defined as the distance from the bottom of the vehicle body to the ground. It should be measured at three locations: between the axles and at the front and rear overhang.

The wheelbase is the distance between the axles of the vehicle or trailer. The longer the wheelbase, the greater the potential for hang-ups. The front overhang is the distance between the very front of the vehicle or trailer and the center of the forward axle. Likewise, the rear overhang is the distance between the center of the rear-most axle on the vehicle or trailer and the end of the vehicle. Like the wheelbase, the longer the overhang lengths are, the higher the potential for dragging at those points.

The vehicle loading condition can affect the ground clearance. A vehicle with no loading might have a higher ground clearance than a vehicle with a heavy loading depending on the design and condition of the vehicle. Tire type and inflation can also affect the ground clearance. Tires with a low pressure, or significant wear (broken belts, tread separations) can cause the ground clearance to be lower than vehicles or trailers with tires in good repair.

The angle of approach, which represents a vehicle's ability to approach and scale an incline without becoming lodged on the front overhang of the vehicle, is defined as the angle between the ground and an angled line passing from the bottom of the front tire to the lowest 
point on the vehicle's bumper. The angle of approach is illustrated in Figure 2.3. Similarly, the departure angle is the angle between the ground and an angled line passing from the bottom of the rear tire to the lowest point on the bumper. This angle can be used to calculate the ground clearance at the rear overhang, which indicates if the vehicle will be prone to hanging up on the rear overhang of the vehicle, and is illustrated in Figure 2.3 (Skidplate4x4, 2001).

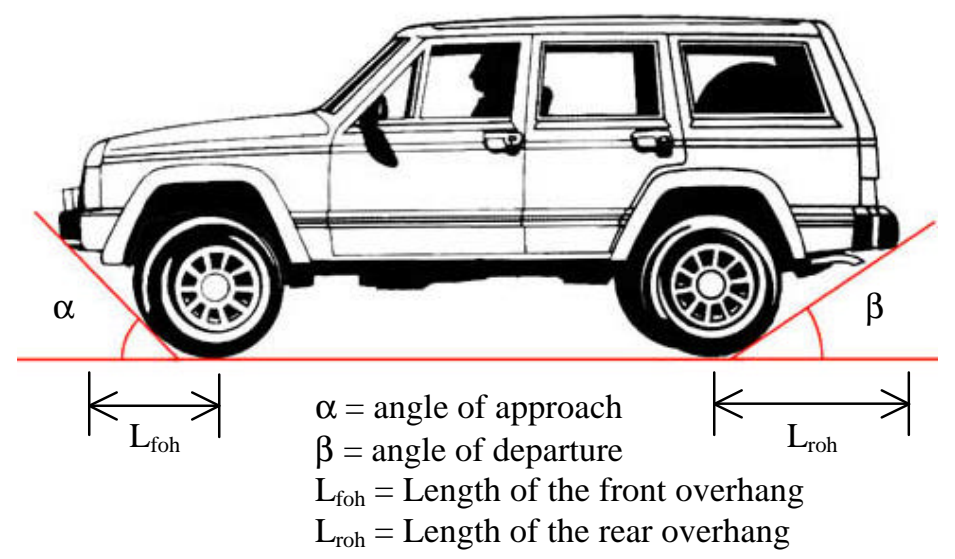

Figure 2.3: Definition of Angle of Approach and Angle of Departure

The breakover angle is another vehicle characteristic related to the hang-up problem. As shown in Figure 2.4, the breakover angle is the angle between the underside of the vehicle and an angled line tracing to the front of the rear tire. This line intersects with an angled line drawn from the back of the front tire to the center point of the underside of the vehicle. The angle described was the "excluded" angle, and can be used to calculate the ground clearance at the wheelbase (Skidplate4x4, 2001). 


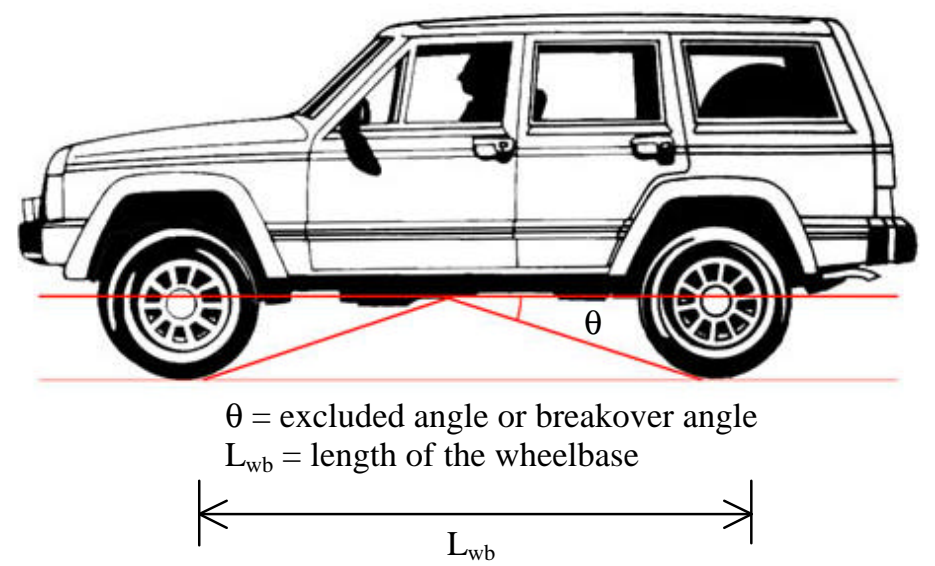

Figure 2.4: Breakover Angle

These three properties are important when ground clearances are unavailable. The angle of approach and departure and the breakover angle can aid in the determination of ground clearances for the front and rear overhang and the ground clearance between the wheels when the distances for those characteristics are not provided and the angles are known. The following equations explain the calculations for ground clearance at the front and rear overhang, and between the wheels. The lengths and angles were depicted in Figures 2.3 and 2.4. To calculate the ground clearance under the front overhang, the following equation is used:

$$
F O H_{G C}=L_{f o h} \times \tan \alpha
$$

where:

$\mathrm{FOH}_{\mathrm{GC}}=$ ground clearance under front overhang (inches) $\mathrm{L}_{\text {foh }}=$ front overhang length (inches)

$\alpha=$ angle of approach (degrees).

The equation to calculate rear overhang ground clearance is:

$$
R O H_{G C}=L_{r o h} \times \tan \beta
$$

where:

$\mathrm{ROH}_{\mathrm{GC}}=$ ground clearance under rear overhang (inches)

$\mathrm{L}_{\mathrm{roh}}=$ rear overhang length (inches) 


$$
\beta=\text { angle of departure (degrees). }
$$

Finally, the breakover angle is used to calculate the wheelbase ground clearance. The wheelbase is the distance from front axle to rear axle. This calculation is performed using the following equation:

$$
W B_{G C}=\left(L_{w b} \times 0.5\right) \times \tan \theta
$$

where:

$$
\begin{aligned}
& \mathrm{WB}_{\mathrm{gc}}=\text { ground clearance between the wheelbase of the vehicle } \\
& \text { (inches) } \\
& \mathrm{L}_{\mathrm{WB}}=\text { wheelbase (inches) } \\
& \theta=\text { breakover angle (excluded angle) (degrees) }
\end{aligned}
$$

The following section relates the use of several vehicle properties and characteristics in standards and regulations affecting the hang-up problem. It is important to note that not all of the properties discussed here are considered in the existing standards and regulations.

\subsubsection{Standards and Regulations}

In this section, vehicle-related standards, guidelines, and recommended practices applicable to the hang-up problem are critically reviewed.

\section{A. Guidelines from Truck / Trailer Manufacturer Trade Groups}

One possible approach to the hang-up problem is the establishment of design guidelines for trucks and trailers by appropriate trade groups. The Society of Automotive Engineers (SAE) has established limits for breakover angle, angle of departure, and angle of approach for 
passenger cars and light trucks (Eck and Kang, 1992). However, these are vehicles that are not prone to hang-up problems.

The United States Department of Transportation (USDOT) published a report on railroad-highway grade crossing safety in 1996 titled "Accidents that Shouldn't Happen." In this report, guidelines from the Specialized Carriers and Rigging Association (SC\&RA) and the Uniform Vehicle Code were reviewed.

The USDOT (1996) reviewed a SC\&RA guide that included a summary of any applicable state laws, definitions and regulations for trucks and trailers. In this guide, the SC\&RA mentions that some states refer to low-ground-clearance equipment as having a “...vertical body or load clearance of less than $1 / 2$ inch per foot of the distance between any two adjacent axles or in any event of less than 9 inches measured above level surface of roadway" (USDOT, 1996). However, this publication did not provide any special regulatory guidance for low-ground-clearance equipment (USDOT, 1996).

The Uniform Vehicle Code (UVC), also reviewed in USDOT's report, is a standard defining vehicles and their correct operation. In this manual, definitions of vehicles are provided. Low-ground-clearance equipment is defined as equipment with a "load clearance" of nine inches or less from the roadway surface (USDOT, 1996).

The amount of information related to vehicle (trucks and/or trailers) standards for ground clearance, wheelbase, and overhang is very limited. It should be noted, however, that this does not imply that manufacturers are not sensitive to the problem. Many manufacturers of low-boy trailers, which are one of the most hang-up prone vehicles, provide a mechanism for lowering and raising the trailer, which decreases or increases the ground clearance to assist the driver in avoiding hang-ups. 
In short, uniformity in vehicle dimensions as provided by standards could aid in the predictability of hang-up potential. This predictability would aid highway agencies when designing a roadway to reduce or prevent hang-ups. However, with the exception of a few specialized vehicles such as tank trucks or piggyback trailers, most vehicle designs are oriented towards the specific needs of the customers, creating a wide range of designs and a highly diverse fleet of vehicles (USDOT, 1996).

\section{B. Government Regulations}

Government regulations are different from the above mentioned standards, guidelines, and recommended practices (e.g. SAE, SC\&RA) in that regulations carry the force of law and are thus subject to enforcement by a policing force. Regulations can be made by any level of government, including federal, state, and local jurisdictions. Most regulations that affect the hang-up problem have been developed at the federal and state level.

State and federal regulations require commercial vehicles and trailers to be within certain height, width, weight, and length limits to operate on the Interstate System and the National Truck Network (NTN) without obtaining a permit. Relative to the hang-up problem, it is interesting to note that there are no requirements relative to minimum ground clearance or maximum wheelbase or overhang for travel on Interstate System or NTN alignments (USDOT, 1996). Table 2.1 provides the federal limits for vehicle lengths to travel on the Interstate System and the NTN without the need for a permit. The length can affect the vehicle and trailer's hangup potential. The longer the vehicle or trailer is, the larger the potential for hanging-up. The weight of a vehicle may also contribute to its hang-up susceptibility. This is particularly true if 
the condition of the vehicle is poor, such as having worn springs or shocks. The maximum weight for the Interstate System or NTN is 80,000 pounds except where FHWA's Bridge Formula dictates a lower value. However, the point at which a vehicle becomes more susceptible to hang-ups due to weight varies greatly from vehicle to vehicle.

Table 2.1 - Federal Regulations for Length (FHWA, 1996)

\begin{tabular}{|c|c|}
\hline Truck Type & $\begin{array}{c}\text { Length (FHWA, } \\
1996)\end{array}$ \\
\hline $\begin{array}{l}\text { Truck Tractor-Semitrailer } \\
\text { Combination }\end{array}$ & $\begin{array}{l}48^{\prime} \text { or grandfathered } \\
\text { limit }\end{array}$ \\
\hline $\begin{array}{l}\text { Truck Tractor-Semitrailer } \\
\text {-Trailer Combinations }\end{array}$ & 28 \\
\hline Buses & $45^{\prime}$ \\
\hline $\begin{array}{l}\text { Automobile and Boat } \\
\text { Transporter Combinations }\end{array}$ & $\begin{array}{l}\text { Conventional }-65 \\
\text { Stinger mount }-75\end{array}$ \\
\hline B-train Combinations & $28^{\prime}$ \\
\hline Beverage Semitrailers & 28 \\
\hline Maxi-cube Vehicles & $\begin{aligned} 34^{\prime}- & \text { cargo box } \\
& \text { (max) } \\
60^{\prime}- & \text { total length } \\
& (\max )\end{aligned}$ \\
\hline Saddle Mounts & 75 \\
\hline Dromedaries & $48{ }^{*} *$ \\
\hline
\end{tabular}

* Dromedaries in operation before December 1, 1982. For Dromedaries operated after this date, the state may chose to treat dromedaries as truck tractors or a straight trucks under State length limits

\section{Special Permit Vehicles}

When truck / trailer combinations need to exceed federal and state limits on weight, height, width, or length, permits can be obtained. According to Tom Klimek, a member of the Truck Size \& Weight Team at the FHWA (2002), permitted vehicles with dimensions exceeding the "statutory limits" are issued "routine permits." Additionally, "the more a vehicle and load exceed a size and/or weight limit, the more restricted the permit operation (Klimek, 2002)." Those vehicles with gross weights greater than 120,000 pounds, widths greater than 14 feet, or lengths greater than 120 feet are considered "special permit vehicles" or "superloads," requiring 
a permit more restrictive than a routine permit (USDOT, 1996). The heavier the vehicle or trailer, the more the ground clearance can be affected.

The height of special permit vehicles is limited by the state they travel through, which varies between 13.5 feet to 14 feet. However, this is not much greater than the standard for all vehicles, if at all. Therefore, unlike excessive weight, length or widths, there is little relief to be gained from the permit process for tall loads. Therefore, it is likely that under these circumstances, the only option may be to lower the ground clearance

When a vehicle is issued a permit, the route the vehicle will be traveling is outlined by planners in permit offices. However, high-profile alignments are not always a consideration in route planning. For example, the USDOT (1996) found that the maps used by permit offices to outline vehicle routes did not always notate railroad-highway grade crossings, or any high profiles at a railroad-highway grade crossing along the route. Furthermore, without a classification system for the vertical humps or some other tool such as the "HANGUP" software, the route planner would not know whether the particular vehicle could clear the grade crossing in question.

Finally, the USDOT (1996) found that enforcement of and adherence to special permit regulations is lenient. While state permit planners clearly mark out routes for the special permit vehicle to follow, those vehicles do not always follow the plotted route. This deviation is rarely detected or punished, and the resulting fines are not large enough to encourage compliance with the designated route (USDOT, 1996). 


\section{Driver and Escort Licensing}

The Commercial Driver License (CDL) and escort service training processes do little to prepare truck drivers for identifying and dealing with potential hang-ups. There is no guarantee that a driver will receive even one question related to railroad-highway grade crossing safety (of which hang-up role is small) when taking the CDL exam. This causes many drivers to be unprepared for hang-up problems that can occur on railroad-highway grade crossings. The same training problem occurs relative to training for escort vehicle services (USDOT, 1996).

An accident investigation by the National Transportation Safety Board (NTSB, 1995 b) further pointed out problems with details in the CDL process. A railroad-highway grade crossing collision near Sycamore, South Carolina between an Amtrak train and a tractor semitrailer combination (with a low trailer body - ground clearance of 12 inches) that was hung up on a "hump" instigated the investigation. The NTSB had previously (in 1983) recommended a warning to truck drivers and motor carriers of the hazards of driving over a high vertical alignment. While this recommendation made by the NTSB was later noted in the Truckdriver's Handbook, the CDL manual provides only a severely abbreviated version of this information (NTSB, 1984).

\subsection{DESIGN VEHICLES}

\subsubsection{AASHTO Design Vehicles}

As this research is focused on the establishment of design vehicles for the hang-up problem, an understanding of how design vehicles and their characteristics were established in the past is needed. 
One of the many elements of designing better, high-performance highways is establishing design vehicles that represent existing traffic (Hall and Turner, 1998). AASHTO (originally AASHO - American Association of State Highway Officials) took the first step towards creating design vehicles, resulting in the guidelines presented in today's Green Book. AASHO realized by 1920 , that motor vehicles were becoming more dominant than horse-drawn carriages on the highway system, and began to work towards consolidating information about the motorized vehicles and the required geometric design standards to accommodate them. In 1941, AASHO introduced two new elements into design practices: design speed and character of traffic. This second element served to reflect the percentages of trucks and buses traveling on the road system. AASHO went further to establish three categories of vehicles (passenger vehicles, trucks, and mixed traffic), then developed varied standards specific to those categories, such as different road widths for each category (Hall and Turner, 1998).

AASHTO (2001) defined design vehicles as,

"These selected vehicles, with representative weight, dimensions, and operating characteristics, used to establish highway design controls for accommodating vehicles of designated classes. For purposes of geometric design, each design vehicle has larger physical dimensions than most vehicles in its class."

Currently, AASHTO provides four classes of vehicles: passenger cars, trucks, buses, and recreational vehicles. Each class is broken down into a series of design vehicles, totaling 19 in all. Dimensions are provided for each vehicle, including width, front and rear overhang, wheelbase, height, and overall length. The turning radii of each design vehicle are also provided (AASHTO, 2001). Depending on the needs to be met in designing a particular roadway, the selection of a design vehicle for these characteristics is based upon the engineer's judgment of the largest vehicle that will use the facility on a frequent basis. Table 2.2 lists past and present (represented with bold-faced characters) AASHTO design vehicles and their associated 
characteristics. In addition to listing the design vehicles, the year each was established is also

noted. The wheelbase and overhang are also listed since they are related to the hang-up problem.

TABLE 2.2: History of Design Vehicle Development

\begin{tabular}{|c|c|c|c|c|}
\hline & & \multicolumn{2}{|c|}{ DIMENSIONS (FEET) } & \multirow{2}{*}{$\begin{array}{c}\text { DATE } \\
\text { ESTABLISHED }\end{array}$} \\
\hline DESIGN VEHICLE TYPE & SYMBOL & WHEELBASE & REAR OVERHANG & \\
\hline Passenger Car & $\mathbf{P}$ & 19 & 5 & 1954 \\
\hline Single Unit Truck & SU & 30 & 6 & 1954 \\
\hline \multicolumn{5}{|l|}{ BUSES } \\
\hline Single Unit Bus & $B U S$ & 25 & 8 & 1973 \\
\hline Single Unit Bus & $B U S$ & 40 & 8 & 1984 \\
\hline \multirow{2}{*}{ Inter-city Bus (Motor Coaches) } & BUS-40 & 40 & 6.3 & 2001 \\
\hline & BUS-45 & 45 & 8.5 & 2001 \\
\hline City Transit Bus & CITY-BUS & 40 & 8 & 2001 \\
\hline $\begin{array}{c}\text { Conventional School Bus (65 } \\
\text { pass.) }\end{array}$ & S-BUS 36 & 35.8 & 12 & 2001 \\
\hline Large School Bus (84 pass.) & S-BUS 40 & 40 & 13 & 2001 \\
\hline Articulated Bus & A-BUS & 60 & $\mathbf{1 0}$ & 1984 \\
\hline \multicolumn{5}{|l|}{ TRUCKS } \\
\hline $\begin{array}{c}\text { Semitrailer Combination, } \\
\text { intermediate }\end{array}$ & $C 43$ & 35 & 4 & 1954 \\
\hline Semitrailer Combination, large & C50 & 44 & 2 & 1954 \\
\hline $\begin{array}{c}\text { Semitrailer Combination, } \\
\text { intermediate }\end{array}$ & $W B-40$ & 45.5 & 2.5 & 1965 \\
\hline Intermediate semitrailer & $W B-40$ & 50 & 6 & 1984 \\
\hline Intermediate semitrailer & WB-40 & 45.5 & 2.5 & 2001 \\
\hline Semitrailer Combination, large & WB-50 & 55 & 2 & $1965^{1}$ \\
\hline Semitrailer-fulltrailer combination & $W B-60$ & 60 & 3 & 1973 \\
\hline $\begin{array}{c}\text { "Double Bottom" semitrailer-full- } \\
\text { trailer }\end{array}$ & $W B-60$ & 65 & 3 & 1984 \\
\hline Interstate Semitrailer & WB-62 & 68.5 & 2.5 & 2001 \\
\hline Interstate Semitrailer & $\begin{array}{c}\text { WB65 OR } \\
67 \\
\end{array}$ & 73.5 & $4.5-2.5$ & 2001 \\
\hline $\begin{array}{l}\text { "Double-Bottom" - } \\
\text { Semitrailer/Trailer }\end{array}$ & WD-67D & 73.3 & 3 & 2001 \\
\hline Triple-Semitrailer/Trailers & WB-100T & 104.8 & 3 & 1994 \\
\hline $\begin{array}{c}\text { Turnpike Double- } \\
\text { Semitrailer/Trailer } \\
\end{array}$ & WB-109D & 114 & 2.5 & 1994 \\
\hline \multicolumn{5}{|l|}{ RECREATIONAL VEHICLES } \\
\hline Motor Home & MH & 30 & 6 & 1984 \\
\hline Car and Camper Trailer & $\mathbf{P} / \mathbf{T}$ & 48.7 & 10 & 1984 \\
\hline Car and Boat Trailer & $\mathbf{P} / \mathbf{B}$ & 42 & 8 & 1984 \\
\hline Motor Home and Boat Trailer & MH/B & 53 & 8 & 1994 \\
\hline Farm Tractor & TR & 16 & - & 2001 \\
\hline
\end{tabular}

${ }^{1}$ In the 2001 AASHTO Green Book, the WB-50 name was changed to Intermediate Semitrailer - all dimensions remained the same.

Note that the italics denotes design vehicles that were revised/renamed/deleted and assigned different dimensions in later AASHTO documents. 
As each edition of the AASHTO Green Book was revised, several AASHTO design vehicles changed. Note that the two trucks established in 1954 were reassigned new symbols and larger dimensions in 1965 (the WB-40 and the WB-50) (AASHTO, 1965). In 1984, a new BUS replaced the previous 1973 BUS, increasing the wheelbase from 25 feet to 40 feet (AASHTO, 1984). The semitrailer-full-trailer combination from 1973 was replaced in 1984 with the "Double Bottom" semitrailer-full-trailer in 1984, which had a larger wheelbase (AASHTO, 1984). In the 2001 AASHTO Green Book, the single unit bus (BUS) is broken into 4 categories: Inter-City Bus (motorcoaches), City Transit Bus, Conventional School Bus (65 passengers), and Large School Bus (84 passengers). The "Double Bottom" semitrailer-fulltrailer from 1984 was replaced in 2001 with the "Double Bottom" Semitrailer/Trailer (AASHTO, 2001).

To determine changes or additions to the design vehicle listings, an AASHTO subcommittee on Design and its Task Force on Geometric Design gather and analyze collected data relevant to the vehicle types being considered. New manuscripts of the manual are revised and agreed upon before being sent to the Standard Committee on Highways, then to the Executive Committee for approval. With design vehicles becoming more specific, roadways can be built to better suit the increasingly varied types of vehicles traveling on them (AASHTO, 1984).

The AASHTO design vehicles, while the most widely accepted vehicle dimensions for roadway design, do not offer a complete representation of certain key dimensions, such as ground clearance, nor do they contain all of the vehicle types related to the hang-up problem. Consequently, design vehicle development and revision are ongoing processes. Several recent efforts in this regard are documented in the following sections. 


\subsubsection{The Process of Establishing Semitrailer Combination Design Vehicles and a School Bus Design Vehicle}

In the early 1980's, federal highway policy permitted the use of longer truck-semitrailer configurations and authorized the use of twin-trailer combinations nationally. Initially, the AASHTO design policy (1984) contained no design vehicles for these trucks. This was a particular concern in intersection design, as it was believed that the longer vehicles would require larger turning radii.

Fambro, Mason, and Neuman (1986) generated the underlying data that led to the development of the WB-70, WB-100, and WB-105 design vehicles for possible inclusion under the Green Book "Truck" category. These names were chosen by Fambro, Mason and Neuman (1986) to represent the overall wheelbase of the trucks. For example, the WB-70 was a twin trailer combination with an overall wheelbase (front axle of tractor to rear axle on rear of semitrailer) of 70 feet (Fambro, Mason, and Neuman, 1986). At the time, the longest tractor semitrailer combination in the Green Book was the WB-60, a two-trailer combination with a wheelbase of 65 feet (AASHTO, 1984). Fambro, Mason, and Neuman (1986) established both dimensional (length) and turning radius characteristics, consistent with AASHTO. In establishing the dimensional characteristics, the researchers referred to collected traffic flow data (queue position and acceleration rates) found by previous researchers to develop Passenger Car Equivalents, then used this data with swept path and turning radii information to determine the dimensions they needed to represent the types of trucks. They developed the wheelbases of these vehicles based on the vehicles operating on the nation's highways at that time. Overhang was not mentioned as a consideration in the size of the vehicle as it is not usually an important consideration on tractor-box trailer configurations. To establish the path made when turning, a turning radius was assigned to each vehicle and modeled on a computer program simulating the 
vehicle's movement through the curve. The resulting information was documented for each design vehicle (Fambro, Mason, and Neuman, 1986).

Gattis and Howard (1999) addressed the issue of school bus design vehicle dimensions because the AASHTO Green Book (1994) at the time listed only one category for single unit buses. The dimensions did not include typical dimensions for a school bus as the AASHTO Single Unit Bus and Articulated Bus represented intercity and transit buses, causing school buses to be inadequately represented by the Bus design vehicle. In their work, Gattis and Howard (1999) relied on several sources to establish vehicle dimensions and characteristics, including state transportation agencies, school bus operators, school bus manufacturers, and field collected data.

The researchers contacted state transportation agencies (Departments of Transportation), inquiring about existing bus dimensions used as design vehicle dimensions for school buses. Gattis and Howard (1999) found that the agencies based their design vehicles on dimensions from bus manufacturers or utilized the dimensions given in the AASHTO Green Book for the BUS design vehicle or the Single Unit (SU) design vehicle.

The school bus operators provided input on variations in types of school buses. With their guidance, it was determined that two design vehicles should be developed: a 65/66 passenger bus and an $83 / 84$ passenger bus. The researchers then contacted school bus manufacturers and requested information on the physical characteristics of those bus types, including maximum height, width, and overall length (Gattis and Howard, 1999).

Field data were collected to determine the turning radii and swept path of the bus types for the two above-mentioned design vehicles. Upon analysis of the field and manufacturer data, the worst case dimension for each characteristic was selected. These worst case results were 
combined to form one "hybrid" design vehicle for each of the two bus types. Because a single vehicle possessing all of the design vehicle characteristics did not exist, the hybrid vehicle represented the characteristics of several buses, thus allowing the facility to be designed to accommodate any bus with less restrictive characteristics. The characteristics identified included: width, length, height, front and rear overhang, wheelbase, front outer body radius, outer front wheel radius, and inner rear wheel radius (Gattis and Howard, 1999). This approach allowed for the establishment of design vehicles that in turn created a basis for AASHTO's two current school bus design vehicles. The following table shows Gattis and Howard's results and the dimensions for AASHTO’s (2001) Conventional School Bus and Large School Bus.

TABLE 2.3 - Comparison of Gattis and Howard's (1999) and AASHTO's (2001) Dimensions

\begin{tabular}{|c|c|c|c|c|}
\hline \multirow{2}{*}{ Dimensions (ft) } & \multicolumn{2}{|c|}{$\begin{array}{c}\text { Gattis and Howard (1999) } \\
\text { Vehicles }\end{array}$} & \multicolumn{2}{c|}{ AASHTO Design Vehicles } \\
\cline { 2 - 5 } & $\begin{array}{c}\text { Type C } \\
\text { School Bus }\end{array}$ & $\begin{array}{c}\text { Type D } \\
\text { School Bus }\end{array}$ & $\begin{array}{c}\text { Conventional } \\
\text { School Bus (65 } \\
\text { pass.) }\end{array}$ & $\begin{array}{c}\text { Large School } \\
\text { Bus (84 pass.) }\end{array}$ \\
\hline Width & 8.0 & 8.0 & 8.0 & 8.0 \\
\hline Length & 36.4 & 40.0 & 35.8 & 40 \\
\hline Height & 10.9 & 10.9 & 10.5 & 10.5 \\
\hline Front Overhang & 2.8 & 7.0 & 2.5 & 7 \\
\hline Wheelbase & 21.5 & 23.0 & 21.3 & 13 \\
\hline Rear Overhang & 12.1 & 10.0 & 12 & 42.8 \\
\hline Outer Front Body Radius & 40.8 & 44.1 & 39.5 & 39.4 \\
\hline Outer Front Wheel Radius & 38.9 & 40.0 & 38.9 & 25.4 \\
\hline Inner Rear Wheel Radius & 25.2 & 25.2 & 23.8 & \\
\hline
\end{tabular}

Note that AASHTO labels "Outer Front Wheel Radius" as "Minimum Design Turning Radius." Also, AASHTO does not list the "Outer Front Body Radius" in their "Minimum Turning Radii of Design Vehicles" table. This radius is depicted in Exhibit 2-8 and 2-9 in the 2001 AASHTO design policy. AASHTO lists the "Centerline Turning Radius" in their radii table, citing a radius 
of 34.9 feet for the Conventional School Bus and 35.4 feet for the Large School Bus (AASHTO, 2001).

\subsubsection{Design Vehicle Efforts Directly Related to the Hang-up Problem}

The design vehicle development efforts described in Section 2.4.2 involved vehicles that were eventually included in the AASHTO Green Book, which does not provide any heights, only lengths and widths of vehicles. Vehicle turning radius information and swept paths were the central issues. However, the underclearance issue related to the hang-up problem is different from turning path issues. The two-dimensional aspect of a vehicle in the plan view is considered when looking at the swept path of that vehicle. For underclearance issues, the two-dimensional view is with respect to elevation.

Eck and Kang (1991) presented the only documented case where the central issue was the development of design vehicle characteristics with respect to the hang-up problem. Research was performed to evaluate the magnitude of the hang-up problem, to classify vehicles with low ground clearances, to develop software to the hang-up potential of high vertical alignments, and to use the specified types of vehicles with the program to establish a single low-ground-clearance design vehicle. This process is discussed in greater detail below (Eck and Kang, 1991).

After performing vehicle classification counts to obtain an idea about types of hang-up prone vehicles, four categories of hang-up susceptible trucks were established. Eck and Kang (1991) identified:

- $\quad$ low-bed equipment trailers,

- automobile transporters,

- $\quad$ double-drop van semi trailers, and

- $\quad$ car- and truck- trailer combinations 
For identified hang-up prone vehicles, field measurements of wheelbase (center-to center distance from rear axle on the tractor to front axle on the trailer) and the ground clearance (vertical distance to the ground at the lowest point along the wheelbase) were collected at a weight station on I-79 and along I-68 in West Virginia. In addition, low-boy trailer manufacturers were contacted to request ground clearance and wheelbase information. In a few cases, drivers were interviewed to determine if they had ever experienced hang-up problems (Eck and Kang, 1991).

While conducting the field study, it became apparent that it is not feasible to design roadways to accommodate the lowest ground clearances and longest wheelbases because these were typically outliers in the sample. This could potentially lead to situations where either hangup considerations are ignored because of the unrealistic measures that would have to be taken to accommodate vehicles of these dimensions, or it could lead to grossly over-designed highways. As a comprise, the wheelbase and ground clearance data were analyzed to determine the $85^{\text {th }}$ percentile for each characteristic. These corresponded to a wheelbase of 30 feet and a ground clearance of 5 inches (Eck and Kang, 1991).

\subsection{CONCLUDING REMARKS}

The hang-up problem occurs when a low-ground-clearance and long-wheelbase or overhang vehicle encounters an alignment with sharp grade breaks. As was clearly illustrated, existing highway and vehicle design standards are not sufficient in addressing the hang-up problem. However, addressing the problem is much more complex than modifying roadway or vehicle characteristics since the problem involves human factors, enforcement, jurisdictional and legislative considerations. It seems likely that vehicle characteristics will not change in the near 
term. Thus, an engineering approach that considers actual vehicle characteristics appears to hold promise.

Only limited guidance with respect to the hang-up problem is available from current roadway design standards. Furthermore, it is not clear which specific types of vehicles are accommodated by the design criteria. However, there is no question that additional design guidance is needed in the form of specific vehicle characteristics, namely ground clearance, wheelbase, and overhang to aid in the rectification of the hang-up problem. The vehicular data available to date are not sufficient to identify design vehicles. More data need to be collected and analyzed.

Review of previous work relative to establishing design vehicles indicated that previous research has used a common methodology. The steps in the process are:

1. Establish the Design Vehicles to be Developed

2. Determine the Dimensions / Characteristics to be Defined

3. Collect Appropriate Data

4. Use Data to Quantitatively Define Dimensions / Characteristics

These same basic steps are appropriate for use in establishing design vehicles for the hang-up problem. However, due to some of the complexities described earlier, the processes within these steps will be unique to the project. The methodology used to develop design vehicles for the hang-up problem is described in Chapter 3. 


\section{Chapter 3 - Methodology}

In order to establish design vehicles for the hang-up problem, the general methodology identified in the literature review was used. This involved four steps which are identified below:

- Establish the Design Vehicles to be Developed

- Determine the Dimensions / Characteristics to be Defined

- Collect Appropriate Data

- Use Data to Quantitatively Define Dimensions / Characteristics

Each will be discussed in detail in the following sections.

\subsection{ESTABLISH THE DESIGN VEHICLES TO BE DEVELOPED}

Review of past efforts to establish design vehicles indicated that the design vehicles to be established were selected according to the following constraints:

- the specific needs for design vehicle information that is currently not available

- available resources to collect data

- reasonableness of the categories

For example, in the two cases discussed in the literature review, Fambro, Mason, and Neuman (1986) observed trucks that were longer than those for which design vehicle information was contained in the 1984 AASHTO Green Book. This constituted the need for the semi-trailer design vehicles they developed. Gattis and Howard (1999) were interested in school buses, and noted two distinct types that were not contained in the 1994 AASHTO design policy.

While there are no quantitative methodologies or exact rules to apply when establishing the number of different design vehicles that are needed to represent the population of motor vehicles, a few of the considerations were:

- the variation in the vehicle population, including types that emerge as unique

- the ramifications of using a limited number of vehicles to represent diverse sectors of the vehicle population 
- local conditions, such as the prevalence of a certain vehicle in the local geographic area.

The trade-off between precision and manageability also needs to be considered. Too few design vehicles will leave users with limited choices in selecting the vehicles that best represent the traffic stream in which they are interested. On the other hand, having too many vehicles to choose from may be confusing. For a study such as this, it was felt that approximately 20 design vehicles could provide an appropriate level of precision and minimize confusion. In addition, since this is the first effort at design vehicle development specifically for the hang-up problem, it is anticipated that future research efforts will add to or combine the design vehicles developed here, much like the process that the design vehicles in AASHTO have undergone.

Potential design vehicles were identified to represent existing vehicles based on experience and the literature review. However, after the data collection process had started, it was discovered that some of the vehicle types first proposed were not specific enough for the wide range of vehicles present in the current vehicle population. In other cases, vehicle types originally considered to be low-ground-clearance vehicles were, upon closer examination, determined not to have low ground clearances and were eliminated. These included liquid tanker trailers, dry bulk trailers, and single drop trailers. The final list of design vehicles is shown in Table 3.1. 
Table 3.1 - Design Vehicles Included in Study

\begin{tabular}{|c|}
\hline Single Unit Trucks - \\
\hline Single Unit Beverage Truck \\
\hline Articulated Beverage Truck \\
Rear-Load Garbage Truck \\
Aerial Fire Truck \\
\hline Pumper Fire Truck \\
\hline Buses \\
\hline Sini-Bus \\
\hline School Bus \\
\hline Articulated Transit Bus \\
\hline Motorcoach \\
\hline Trucks - \\
\hline Low-Boy Trailers < 53 ft \\
\hline Double-Drop Trailer \\
\hline Car Carrier Trailer \\
\hline Belly Dump Trailer \\
\hline Recreational Vehicles - \\
\hline Passenger Vehicle and Trailer - Private Use \\
\hline Passenger Vehicle and Trailer - Commercial Use \\
\hline Recreational Vehicle \\
\hline
\end{tabular}

It was realized that several of the vehicles are also contained in the AASHTO 2001 Green Book. However, as noted earlier, some of the dimensions important to the hang-up problem, such as ground clearance, are not provided in the Green Book (2001). On the other hand, wheelbase and overhang are provided. Comparisons between the AASHTO design vehicles and the design vehicles developed here will be made in Chapter 4. The hang-up susceptible vehicles contained in AASHTO were:

- School Bus

- Single Unit Transit Bus

- Articulated Transit Bus

- Motorcoach

- Passenger Vehicles and Trailers - Private Use (listed in AASHTO as Car and Camper Trailer, Car and Boat Trailer)

- Recreational Vehicle 
In addition to those vehicles contained in AASHTO (2001), several other vehicles were selected for consideration. The Single Unit Beverage Truck, Mini-Bus, and the Rear-Load Garbage Truck were chosen due to their long rear overhangs, where dragging can occur. Two types of fire trucks were included: the pumper and aerial fire truck. Pumper fire trucks are used at fires to pump water from a fire hydrant, water body (pond, river) or water tanker through a hose spraying the water over the fire. Aerial fire trucks have an aerial ladder attached to the body of the fire truck. Each of these types of fire trucks has both hang-up and dragging potential.

Low-Boy trailers with lengths greater than 53 feet were not considered because these vehicles would typically be permitted vehicles. As such they are highly variable and not suited for generalization by a design vehicle. Operators of these vehicles should analyze their individual vehicle using tools such as the HANGUP software.

The Double-Drop Trailer is a semi-trailer with a section that "drops" between the wheelbase as depicted in Figure 3.1. The drop was an area of concern, since low ground clearances increase the hang-up potential.

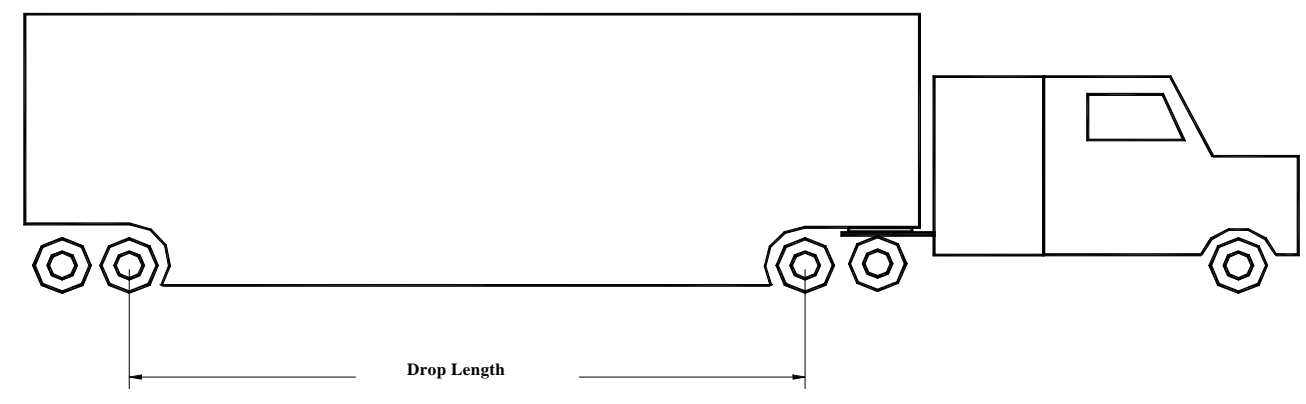

Figure 3.1 - Double Drop Trailer Silhouette 
Passenger vehicles and trailers were broken into two categories: private use and commercial use. Private use passenger vehicles and trailers included the Car and Camper Trailer and Car and Boat Trailer listed in the 2001 AASHTO Green Book, as well as many other hangup susceptible trailers, including utility and car trailers. The trailers in this category are generally intended for personal use, such as for recreational purposes. The Commercial Use Passenger Vehicles and Trailers include vehicles intended to haul commercial products, such as car carrier trailers and flat beds. Modern pick-up trucks are powerful enough to haul substantial loads, and are being used to haul goods previously hauled by tractor-trailers. The primary incentive to haul these larger loads on a for-mileage basis with a pick-up is that a CDL is not required.

\subsection{DETERMINE THE DIMENSIONS / CHARACTERISTICS TO BE DEFINED}

\subsubsection{Dimensions / Characteristics Important to the Hang-up Problem}

As noted in the literature review, a large number of vehicle characteristics could be defined in establishing a design vehicle. The vehicle characteristics specific to the hang-up problem that were of interest are as follows:

- ground clearance

- wheelbase

- front and / or rear overhang

- loading

- tire size, inflation, pressure and wear

- angle of approach

- angle of departure

- breakover angle

- hitch location 
Each of these characteristics is defined below along with a discussion of the advantages and disadvantages of using them in this study. The decision of whether or not to use the characteristics is also noted.

\section{A. Ground Clearance, Wheelbase, Front / Rear Overhang}

A vehicle's ability to traverse a high-profile alignment depends in part on the ground clearance. As used here, ground clearance is defined as the distance from the bottom of the vehicle body (for example, the underside of a trailer) to the ground. Low ground clearances cause hang-up problems when the vehicle has either a long wheelbase, front or rear overhang. The wheelbase is the distance between the centerline of the first forward axle on the vehicle (for vehicles with one front axle) to the centerline of the first rear axle at the rear of the vehicle. For vehicles such as truck semi-trailers, the wheelbase is the distance from the centerline of the last forward axle on the truck to the centerline of the first rear axle on the trailer. The rear overhang is the distance from the centerline of the rear-most axle to the rear of the vehicle. The front overhang is the distance from the centerline of the forward axle to the front of the vehicle.

Figure 3.2 illustrates these parameters.

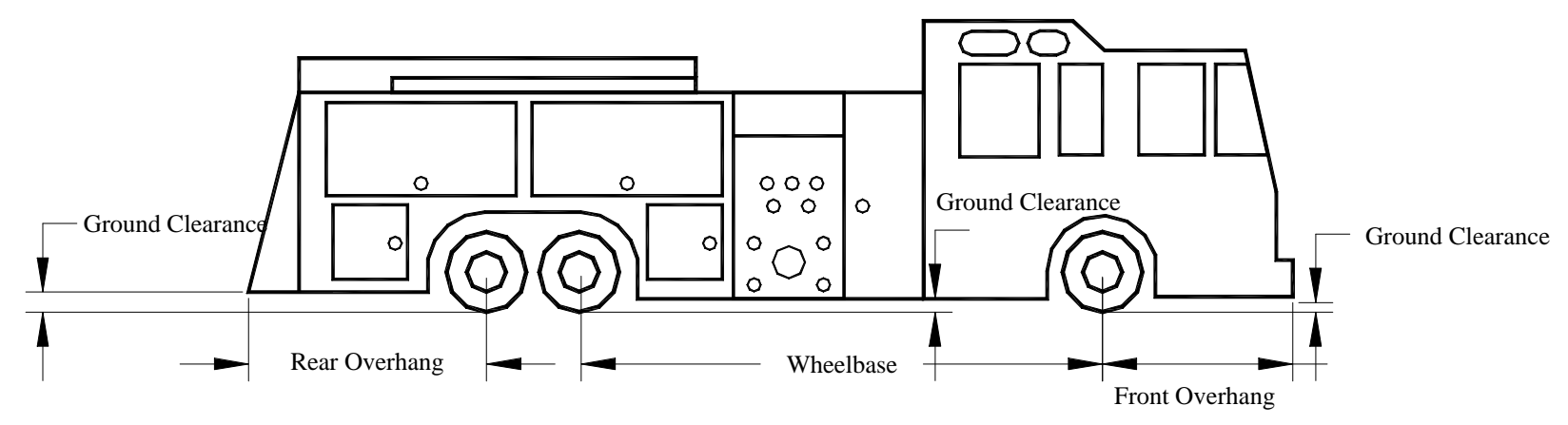

Figure 3.2 - Wheelbase, Front and Rear Overhang

Three locations were of interest for ground clearance: between the axles and at the front and rear overhang. The wheelbase of a vehicle has hang-up potential if it is long and the ground 
clearance is low. From the literature review, it was evident that long overhang lengths in the front or rear of the vehicle were other locations on the vehicle to be considered for hang-up or dragging potential.

\section{B. Loading}

The weight of the load on a vehicle could have an effect on ground clearance. Tractortrailer combinations are rated by federal and state regulations for weight. When the weight is under the rated maximum for the trailer, it was expected by the researchers that the ground clearance between the wheelbases and at the front and rear overhangs should remain near the "designed" ground clearance (the ground clearance noted on manufacturers' specifications). However, as the loading increases beyond the rating for the trailer, the ground clearance could decrease. Many of the vehicles measured during the data collection were loaded. While it is important to consider the effects of weight on ground clearance, the weight was not recorded by the researchers in the field since scales were not usually available. However, in many cases, whether a vehicle was loaded could be determined visually, and was noted when appropriate. This data could only be used to compare ground clearances to see if there was an affect on the clearance from the loading, but the rating of the trailer or vehicle was not always known.

\section{Tire Size, Inflation, and Wear}

Some other important considerations in field data collection that could reduce the ground clearance of a vehicle are the tire size, inflation pressure and wear. Each vehicle measured was quickly inspected for abnormalities at the tires, such as broken belts or tread separation (indicating wear) and bulging sidewalls or low pressure (indicating the pressure of the tire). 
These characteristics could be related to the ground clearance of a vehicle or trailer (for example, a trailer with low pressure in the tires could have a lower ground clearance than a trailer with the proper air pressure). However, without appropriate equipment, exact measurements could not be taken. The quick glances at the tires during the measurement of the vehicle did not allow the researchers to pinpoint deviances in the tire that could greatly influence the ground clearance.

\section{Angles of Approach and Departure, Breakover Angle}

Other data that are useful when ground clearance isn't known include the angle of approach, angle of departure, and the breakover angle. These angles can be used to calculate ground clearance in instances where ground clearance measurements are not available. Unfortunately, these angles do not result in actual clearances like those measured in the field, only theoretical clearances if taken from manufacturer specifications. These clearances can be higher than field measured ground clearances and are generally undesired. However, where field data could not be collected or were not available, the angles were used. For instance, when collecting manufacturer information about transit buses, many of the manufacturers had blueprints of their vehicles online with the dimensions specified. Instead of listing ground clearance, though, the angle of approach and departure and the breakover angle were listed. The ground clearances were found with these values.

\section{E. Hitch Location}

For vehicle-trailer combinations with hitches, such as car carrier trailers and passenger vehicles towing trailers, the hitch was located as well. Hitches are an important consideration in hang-up susceptibility since vehicles are likely to hang-up at hitch points. When a hitch is 
between two wheels, the hang-up dynamics are less like a "hang-up between the wheels" and more like a "dragging overhang" problem, with the distance to the hitch being the length of overhang.

\subsubsection{Dimensions / Characteristics to be Measured}

The necessary dimensions and characteristics measured for each vehicle type varied depending on where the vehicle was susceptible to hang-ups. Table 3.2 details the required dimensions and characteristics for each vehicle type. Note that certain non-hang-up specific characteristics, such as vehicle make and model, were collected. These were collected in case questions arose regarding the vehicle after the data collection was complete. Each is described below. 
Table 3.2 Dimensions/Characteristics to be Measured

\begin{tabular}{|c|c|c|c|c|c|c|c|c|c|c|c|c|c|c|c|c|c|c|}
\hline \multirow[b]{3}{*}{ Vehicles } & \multicolumn{6}{|c|}{ Required Dimensions } & \multicolumn{12}{|c|}{ Required Characteristics } \\
\hline & \multirow{2}{*}{ 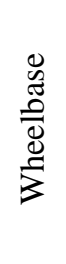 } & \multicolumn{2}{|c|}{ Overhang } & \multicolumn{3}{|c|}{$\begin{array}{c}\text { Ground } \\
\text { Clearance } \\
\end{array}$} & \multicolumn{3}{|c|}{ Trailer } & \multicolumn{2}{|c|}{ Tractor } & & \multirow{2}{*}{ 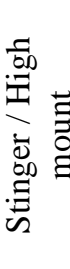 } & & \multirow{2}{*}{ 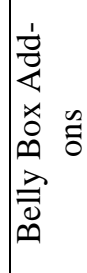 } & & \multirow{2}{*}{\multicolumn{2}{|c|}{ 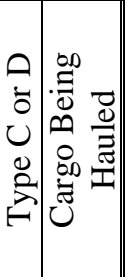 }} \\
\hline & & 壱 & ๕ & 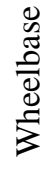 & 蒙 & $\approx$ & 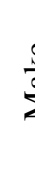 & & & 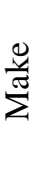 & $\begin{array}{l}\overline{\bar{d}} \\
\bar{\Sigma}\end{array}$ & & & & & & & \\
\hline \multicolumn{19}{|l|}{ Single Unit Trucks - } \\
\hline Single Unit Beverage Truck & $\mathrm{X}$ & & $\mathrm{X}$ & $\mathrm{X}$ & & $\mathrm{X}$ & & & & $\mathrm{X}$ & $\mathrm{X}$ & & & & & $\mathrm{X}$ & & \\
\hline Articulated Beverage Truck & $\mathrm{X}$ & & & $\mathrm{X}$ & & & $y$ & & & $X$ & $\mathrm{X}$ & & & & & $X$ & & \\
\hline Rear-Load Garbage Truck & $\mathrm{X}$ & & $\mathrm{X}$ & $\mathrm{X}$ & & $\mathrm{X}$ & $\bar{x}$ & & & $\mathrm{X}$ & $\mathrm{X}$ & $\mathrm{X}$ & & & & & & \\
\hline Aerial Fire Truck & $\mathrm{X}$ & $\mathrm{X}$ & $\mathrm{X}$ & $\mathrm{X}$ & $\mathrm{X}$ & $\mathrm{X}$ & & & & $\mathrm{X}$ & $\mathrm{X}$ & & & & & & & \\
\hline Pumper Fire Truck & $\mathrm{X}$ & $\mathrm{X}$ & $\mathrm{X}$ & $\mathrm{X}$ & $\mathrm{X}$ & $\mathrm{X}$ & & & & $\mathrm{X}$ & $\mathrm{X}$ & & & & & & & \\
\hline \multicolumn{19}{|l|}{ Buses - } \\
\hline Mini- & $\mathrm{X}$ & & $\mathrm{X}$ & $\mathrm{X}$ & & $\mathrm{X}$ & & & & $\mathrm{X}$ & $\mathrm{X}$ & & & & & & & \\
\hline School Bus & $\mathrm{X}$ & & X & $\mathrm{X}$ & & $\mathrm{X}$ & & & & & & & & & & & $\mathrm{X}$ & \\
\hline Single Unit Transit Bus & $\mathrm{X}$ & $\mathrm{X}$ & $\mathrm{X}$ & $\mathrm{X}$ & $\mathrm{X}$ & $\mathrm{X}$ & & & & $\mathrm{X}$ & $\mathrm{X}$ & & & $\mathrm{X}$ & & & & \\
\hline Articulated Transit Bus & $\mathrm{X}$ & $\mathrm{X}$ & $\mathrm{X}$ & $\mathrm{X}$ & $\mathrm{X}$ & $\mathrm{X}$ & & & & $\mathrm{X}$ & $\mathrm{X}$ & & & $\mathrm{X}$ & & & & \\
\hline Motorcoach & $\mathrm{X}$ & $\mathrm{X}$ & $\mathrm{X}$ & $\mathrm{X}$ & $\mathrm{X}$ & $\mathrm{X}$ & & & & $\mathrm{X}$ & $\mathrm{X}$ & & & & & & & \\
\hline \multicolumn{19}{|l|}{ Truck - } \\
\hline Low-Boy Trailers $<53 \mathrm{ft}$ & $\mathrm{X}$ & & $\mathrm{X}$ & $\mathrm{X}$ & & $\mathrm{X}$ & $\mathrm{I}$ & & & $\mathrm{X}$ & $\mathrm{X}$ & & & & $\mathrm{X}$ & & & $\mathrm{X}$ \\
\hline Double-Drop Trailer & $\mathrm{X}$ & & $\mathrm{X}$ & $\mathrm{X}$ & & $\mathrm{X}$ & $\bar{Y}$ & & & $\mathrm{X}$ & $\mathrm{X}$ & & & & $\mathrm{X}$ & & & $\mathrm{X}$ \\
\hline Car Carrier Trailer & $\mathrm{X}$ & & $\mathrm{X}$ & $\mathrm{X}$ & & $\mathrm{X}$ & 2 & & & $\mathrm{X}$ & $\mathrm{X}$ & $\mathrm{X}$ & $\mathrm{X}$ & & & & & $\mathrm{X}$ \\
\hline Belly Dump Trailer & $\mathrm{X}$ & & $\mathrm{X}$ & $\mathrm{X}$ & & $\mathrm{X}$ & 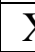 & & & $\mathrm{X}$ & $\mathrm{X}$ & & & & $\mathrm{X}$ & & & \\
\hline \multicolumn{19}{|l|}{ Recreational Vehicles - } \\
\hline $\begin{array}{c}\text { Passenger Vehicle and Trailer } \\
\text { - Private Use }\end{array}$ & $\mathrm{X}$ & & $\mathrm{X}$ & $\mathrm{X}$ & & $\mathrm{X}$ & 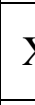 & & & $\mathrm{X}$ & $\mathrm{X}$ & & & & & & & $\mathrm{X}$ \\
\hline $\begin{array}{c}\text { Passenger Vehicle and Trailer } \\
\text { - Commercial Use }\end{array}$ & $\mathrm{X}$ & & $\mathrm{X}$ & $\mathrm{X}$ & & $\mathrm{X}$ & $\mathrm{r}$ & & & $\mathrm{X}$ & $\mathrm{X}$ & & & & & & & $\mathrm{X}$ \\
\hline Recreation Vehicle & $\mathrm{X}$ & $\mathrm{X}$ & $\mathrm{X}$ & $\mathrm{X}$ & $\mathrm{X}$ & $X$ & & & & $\mathrm{X}$ & $\mathrm{X}$ & & & & & & & \\
\hline
\end{tabular}

The capacity of a vehicle or trailer is the maximum weight or volume that it can accommodate. For example, the hopper (the bin holding garbage) on rear-load garbage trucks can range in capacity from under 20 cubic yards (CY) to $32 \mathrm{CY}$. The capacity of a car carrier trailer is the number of cars that can be hauled.

Car carriers were the only vehicles studied that could have either a stinger or high mount hitch. The hitch location for stinger and high mount trailers is depicted in Figure 3.3 and 
3.4, respectively. With stinger trailers, the hitch location was between the first set of double axles on the trailer and the last set of double axles. The ground clearance at this hitch location was much lower than that at the high mount, which was located above the rear axles of the truck, similar to a semitrailer hitch. As noted previously, hitch location can affect the hang-up susceptibility of the vehicle.

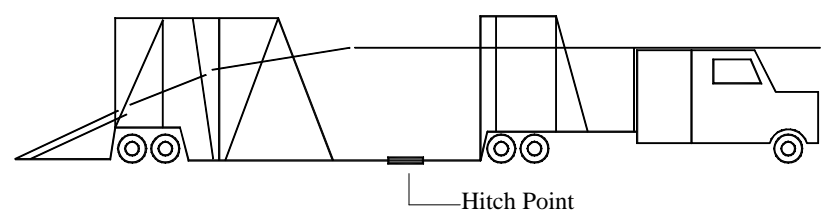

Figure 3.3 - Stinger Mount Hitch

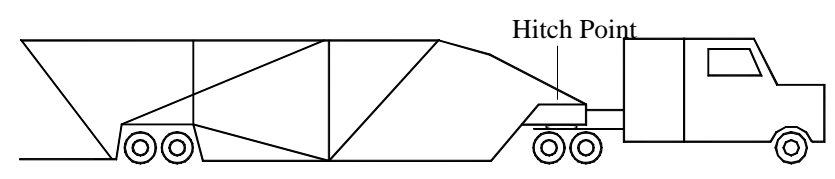

Figure 3.4 - High Mount Hitch

Transit vehicles can have either high or low floors. If the floor is classified as "high," riders must ascend steps to reach the seating level in the bus. Low-floor transit vehicles allow passengers to simply enter the bus doors and take a seat without ascending steps, as the entrance and aisle way are at curb level. The difference in floor levels may affect the ground clearance of the transit vehicle.

Belly box add-ons can be found on commercial trailers. These boxes vary in size and are used to store maintenance tools, straps for tying down cargo, and other items that may be needed by the truck driver. If a trailer has a long wheelbase, the reduced ground clearance under the box could increase the hang-up susceptibility of the trailer. 
The storage areas on beverage trucks are divided into bays. Single Unit Beverage Trucks have fewer bays ( 4 - 12 bays) than Articulated Beverage Trucks (14 - 16 bays), simply because of the difference in length of the units.

School buses have two classifications: type C or type D. The engine of a type $\mathrm{C}$ vehicle is located at the front of the vehicle. These buses have a long front to accommodate the engine. Type D vehicles have rear-mounted engines, creating a flat front on the vehicle, i.e., there is little or no front overhang.

The dimensions and characteristics indicated in Table 3.2 were recorded on a data collection form along with information about the date and location of measurement (if field measured) and descriptions of anything unusual (e.g. small or flat tires). The source of the information was gathered from were noted with an I (internet), F (field measurement), or P (phone conversation) on the data collection form. Additional notations for data sources were Fax (information received via a faxed document) and $\mathrm{E}$ (e-mail message with data). The completed data collection forms can be found in Appendix A.

\subsection{DATA COLLECTION}

\subsubsection{Data Collection Techniques Overview}

There were several techniques that could be used to collect data:

- field measurements at storage facilities for specific vehicle types

- general field measurements (vehicles as encountered)

- information from manufacturers

- photogrammetric techniques.

Because there were a wide range of vehicles to be measured, one method of data collection was to measure specific vehicle types at maintenance locations or storage areas for those vehicles. For example, to facilitate this method of measurement, specific sites - garbage 
truck maintenance yards - were visited to gather measurements of garbage trucks. This method was extremely efficient in providing the desired data for garbage trucks, school buses, fire trucks, beverage vehicles and transit buses. However, for some vehicles, such as passenger vehicles and trailers, recreational vehicles, and low-boys, many different variations of those vehicles exist in the population, so other data collection strategies were used.

Field measurements were also taken at locations where the vehicle population was highly variable. For example, the full range of commercial vehicles, including car carriers, belly dumps, low-boys, and double-drop trailers could be found at truck inspection stations. Commercial vehicles such as those found at inspection stations, as well as RV's and passenger vehicles towing trailers were found at rest areas. Because the range of vehicles encountered at these locations was broad, this provided good coverage of these vehicle types. However, in most cases, outliers in the data set were collected under these circumstances.

In addition to measuring vehicles in the field, the manufacturers of most of the vehicles measured during field data collection were also contacted to obtain dimensions for any additional low-clearance vehicles. The contact with manufacturers added to the database of dimensions and characteristics being collected and helped to identify worst-case scenarios relative to hang-up susceptibility.

As an alternative to manual field data collection, an automated procedure using photogrammetry was considered. This technique involves capturing a stereoscopic image of the vehicle from the shoulder of the highway and extracting the appropriate measurements from the photos. To take these images, two 35-mm cameras are mounted near the roadway, and a trigger is pushed to take two different pictures of the point of interest on the passing vehicle. This method of data collection requires one researcher to operate the camera and can be performed 
rapidly. However, several concerns, such as the ability to capture the images of a fast moving vehicle, shadows under the truck, and the analysis method to extract information from the pictures, caused this method to be dismissed. Each of these concerns is addressed in detail below.

The high speed of the vehicle passing the observation point makes it difficult to clearly capture the point of interest in both images. Shadows can also create a problem when taking a picture of the point of interest. The ground clearance of a vehicle is measured from the lowest point of the vehicle to the ground. However, this point may be a structural member or other feature which is located near the centerline of the vehicle, hidden by shadows. A strobe lighting system of some type could be devised to illuminate the area; however significant effort was not devoted to the development of this process due to its other drawbacks.

When analyzing the photographs, accuracy is a major issue. The photogrammetric process would have provided accuracies to a few feet. For this project, an accuracy of one or two inches was desired. Obviously, the measurements from the photographs would not have been accurate enough for this project.

A software package is available to analyze the collected photos. However, it still involves significant manual input, requiring an amount of time that is equal to or greater than the time involved to manually measure the vehicles. Additionally, the software package had not been updated for several years, thus requiring modifications to make it compatible with current PC's before it can be used.

Because of the complexities involved in using this technique, this method was not used by the researchers. Instead, field data were collected manually. 


\subsubsection{Field Data Collection}

Field data were collected at the following rest areas and weigh stations at least once.

These were:

- I-79 Southbound weight station near Fairmont, West Virginia (Milepost 141)

- I-81 Northbound weight station near Marion, Pennsylvania (Milepost 7)

- I-79 Southbound rest area, Monongalia County, West Virginia (Milepost 158)

- I-79 Northbound weigh station / rest area near Bridgeville, Pennsylvania (Milepost 50)

- I-64 Westbound near Winfield, West Virginia (Milepost 42)

Field data were also collected at vehicle maintenance yards and garages. These included:

- Port Authority Transit maintenance facility near Pittsburgh, Pennsylvania (transit buses)

- Mountain Line Transit Authority, Morgantown, West Virginia (transit buses)

- Suburban Sanitation, Fairmont, West Virginia (garbage trucks)

- Waste Management Inc., Charleston, West Virginia (garbage trucks)

- City garage, Pittsburgh, Pennsylvania (garbage trucks)

- Stonewall Jackson Lake State Park, boat ramp, West Virginia (boat trailers)

- Keystone RV Center, Marion, Pennsylvania (RV's)

- University High School, Morgantown, West Virginia (loaded school buses)

- Cameron Coca-Cola Bottling Company, Houston, Pennsylvania (beverage vehicles)

- Various fire stations in Pittsburgh, Pennsylvania

- Morgantown Fire Department, Morgantown, West Virginia

- Blacksville Volunteer Fire Department, Blacksville, West Virginia

- Bridgeport Fire Department, Bridgeport, West Virginia

- Black Lick Volunteer Fire Department, Black Lick, Pennsylvania

\subsubsection{Manufacturer Data Collection}

The manufacturer data were collected either through a phone conversation or from the manufacturers' web pages for the following vehicles: beverage trucks, transit buses, school 
buses, fire trucks (aerial and pumper), rear-load garbage trucks, passenger vehicles and trailers commercial use (mainly fifth-wheel car carriers and livestock trailers), and recreational vehicles.

As discussed previously, field-measured ground clearances were preferred to those provided by the manufacturer. However, the manufacturers were an excellent source for wheelbase, overhang, and hitch location information. For some design vehicles - such as belly dump trailers - which are not commonly found in the geographic area where the study was conducted, the manufacturer data was extremely valuable and constituted a significant portion of the overall database. The manufacturers contacted can be found in Appendix C. While not every manufacturer producing a vehicle or trailer was contacted, those that were provided important information that aided in the data collection process. For those manufacturers that did not provide ground clearance dimensions, the angle of approach and departure, and the breakover angle were used.

\subsubsection{Concluding Remarks}

Approximately 75 percent of the vehicle dimensions were collected in the field. Vehicle types more heavily reliant on manufacturer data were: mini-buses, single unit transit buses, articulated transit buses, motorcoaches, belly dump trailers, and aerial fire trucks. The data for each vehicle type were compiled on datasheets and are in Appendix B. Table 3.3 shows the sample sizes collected for each vehicle type. 
Table 3.3 - Sample Sizes for Vehicle Types

\begin{tabular}{|c|c|}
\hline Vehicle Type & Sample Size \\
\hline Single Unit Trucks - & \\
\hline Single Unit Beverage Truck & 12 \\
\hline Articulated Beverage Truck & 9 \\
\hline Rear-Load Garbage Truck & 44 \\
\hline Aerial Fire Truck & 9 \\
\hline Pumper Fire Truck & 16 \\
\hline Muses - & 6 \\
\hline School Bus & 30 \\
\hline Single Unit Transit Bus & 47 \\
\hline Articulated Transit Bus & 7 \\
\hline Motorcoach & 18 \\
\hline Trucks - & 93 \\
\hline Low-Boy Trailers < 53 ft & 31 \\
\hline Double-Drop Trailer & 29 \\
\hline Car Carrier Trailer & 20 \\
\hline Belly Dump Trailer & \\
\hline Recreational Vehicles - & 49 \\
\hline Passenger Vehicle and Trailer - Private Use & 45 \\
\hline Passenger Vehicle and Trailer - Commercial Use & 42 \\
\hline Recreational Vehicle & \\
\hline
\end{tabular}

The sample sizes were selected with consideration to the number of manufacturers and the number of vehicles in the population field in the region of the study. In cases such as the low-boy trailer, where a large variation existed, a large sample size was collected. With the larger number of low-boys, a larger chance for variances exists, and a larger sample size was needed to obtain the most-likely dimensions for a worst-case design vehicle. This was also true for passenger vehicles and trailers (private and commercial use), single unit transit buses, recreational vehicles, garbage trucks, belly dump trailers, and car carrier trailers.

In other cases, where variability was limited and the researchers sought the worst-case dimensions, a virtually almost exhaustive survey of manufacturers was performed. For example, consider the belly dump. These trailers are more common to other areas other than the mid- 
Atlantic area, so few were field measured. Additionally, only six manufacturers make belly dump trailers. A small sample size was reasonable because of the smaller chance for variances (due to the small number of manufacturers and small vehicle population).

\subsection{USING DATA TO QUANTITATIVELY DEFINE DIMENSIONS / CHARACTERISTICS}

\subsubsection{Overview of Available Methods}

Once the data collection was completed, the data were reduced to develop dimensions and characteristics for a design vehicle for each vehicle type. In their work, Gattis and Howard (1999) used the method of selecting the worst-case dimension for each characteristic. The final design vehicles (two school buses) were "hybrid" vehicles. The dimensions of a hybrid vehicle are from more than one vehicle (e.g., the wheelbase is from one vehicle, the overhang length is from another). This results in a vehicle that represents a larger portion of the vehicle population, as the dimensions of more than one vehicle were considered when establishing the hybrid vehicle. However, outliers can negatively affect the establishment of a hybrid vehicle, as dimensions which are grossly severe represent a very small portion of the vehicle population. For some vehicle types, this method was not appropriate (low-boys, passenger vehicles and trailers) due to the variability of dimensions within those types. This was the case with low-boy trailers and trailers being towed by passenger vehicles.

Several statistical measures could be used to establish dimensions for design vehicles:

- mean,

- median, or some other percentage value such as $15^{\text {th }}$ or $85^{\text {th }}$ percentile,

- mean and some multiple of the standard deviation

The mean value is an average of the collected data and offers a quick description of the data. It accounts for all of the data and is easy to perform. For large observations, the mean is 
skewed in the direction of the larger number of measurements (Mendenhall, Beaver, and Beaver, 1999). It is easy to measure. However, because the mean is an average of the values, resulting in design vehicle dimensions that are not too moderate, many vehicles in the field will be more susceptible to hang-ups than the design vehicle.

The positive square root of the variance (a value that measures the dispersion of a data set) is defined as the standard deviation. This value indicates how close the mean is to the observations made during the data collection process. As the standard deviation increases, so does the variation in the data set. However, the standard deviation is sensitive to outliers (Mendenhall, Beaver, and Beaver, 1999). Both the mean value and the standard deviation can be calculated and used as checks on the selected dimensions when looking for outliers and checking the database, even if the direct output is not used as a design vehicle dimension.

The median value is defined as the middle point of the data (50\% of the data points are above the median, and $50 \%$ are below). This parameter is used when the data set is asymmetric or when many outliers exist. The median is less likely to be influenced by significantly large data (Mendenhall, Beaver, and Beaver, 1999). Like the mean, the median provides moderate dimensions that are less susceptible to hang-ups than $50 \%$ of the vehicles in the population measured. This measure is also too moderate for use in defining design vehicle dimensions. A parameter used by Eck and Kang (1991) in characterizing low-clearance vehicles was the $85^{\text {th }}$ percentile. If it were used to establish design vehicle dimensions, 85 percent of the vehicles studied would have shorter wheelbases and higher ground clearances than the design vehicle. While 15 percent of the vehicles would still be more hang-up susceptible, the $85^{\text {th }}$ percentile is understood by traffic engineers, as it is often used in other applications, such as 
speed studies. This method is beneficial as it provides a balance between worst case and more moderate measures. To apply this method, however, a large database is required.

Another method for use in establishing design vehicle dimensions is vehicle simulation. In the case of hang-ups, the vehicle traveling on the vertical alignment is simulated and the resulting hang-up potential analyzed. A single vehicle with the worst or near-worst hang-up potential can be selected, and its dimensions used to represent all of the vehicles of that type. This method is ideal for roadways carrying vehicles with similar characteristics and for roadways with vertical alignment prone to hang-ups. The full ramifications of the design vehicle dimensions are understood. The disadvantage of this method is that the technique is not a "stand alone" technique. Dimensions must be established from some other method before they can be tested. This method is better for fine-tuning selections or checking them for reasonableness.

The method used in most cases in this research was the worst-case method, with testing using simulation. The $85^{\text {th }}$ percentile was used in the case of low-boys due to their variability and large database.

\subsubsection{The HANGUP Software}

The HANGUP software was used for simulation. This simulation program was developed to analyze the movement of low-ground-clearance vehicles over vertical alignments and pinpoint areas where hang-ups could occur. The program requires two general inputs:

- roadway profile information

- vehicle information (ground clearance, wheelbase and overhang)

The roadway geometry information is supplied by the user for a specific alignment either from the field or from a design. Included in this information are breakpoints and grades. These are needed to establish a profile of the grade break or high-profile alignment. 
Vehicle wheelbase, overhang, and ground clearance information are needed to perform a simulation run in the program. This is accomplished simply by entering these dimensions into the appropriate data fields. The program also permits all combinations of ground clearance and wheelbase/overhang over specified ranges to be listed.

\subsubsection{Using the HANGUP Software}

The HANGUP software program was used with four different test alignments. Each design vehicle was entered into the program and its movement simulated over each of the alignments. The curve data used included designs from ITE, AREMA, and an existing curve available in the HANGUP program. Each are described in detail below. A table of vertical and horizontal alignment data for each alignment was prepared and is in Appendix D.

The AREMA railroad-highway grade crossing design standard calls for a grade equivalent to six inches in 30 feet followed by a two-foot flat area leading to the rails. The equivalent vertical was calculated and entered into the HANGUP software (HANGUP file name - railroad.prf).

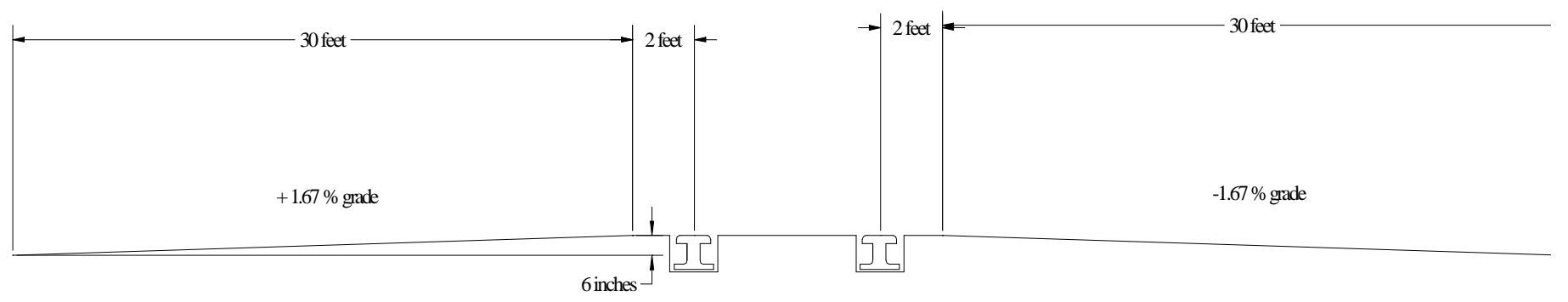

Figure 3.5 - AREMA Railroad-Highway Grade Crossing Vertical Alignment

Using the ITE Guidelines for Driveway Location \& Design (1987), the "Low Volume Driveway on Major or Collector Streets" was input into the HANGUP program. This driveway utilizes a $+3 \%$ grade followed by a $-3 \%$ grade (HANGUP file name - vertical.prf). Alignments 
with this curvature can be found along the driveway itself, at a roadway-driveway intersection where a superelevated curve with a 3 percent grade leads to a -3 driveway, or at crossing roadways where the crown is higher than average.

Figure 3.6 - ITE “Low Volume Driveway on Major Streets or Collector Streets”

A second curve was constructed using information also in the ITE guideline (1987). This sag curve allowed researchers to evaluate the effects of vehicles dragging on severe sag curves by employing a $15 \%(-2 \%,+13 \%)$ grade break. The $-2 \%$ corresponds to the cross slope of the roadway, and the $+13 \%$ is the grade of the driveway (HANGUP file name - sag.prf). Driveway curves similar to this are found in rural areas with steep grades.

\section{$-2 \%$}

Figure 3.7 - Low Volume Driveway on a Local Street

Finally, a humped double track mainline railroad-highway grade crossing available with the program was utilized. The profile of this curve had a variable approaching grade between +4 - 5\%, a level track bed of 5 feet, and a departure grade of $-6 \%$ (HANGUP file name - twin.prf). 


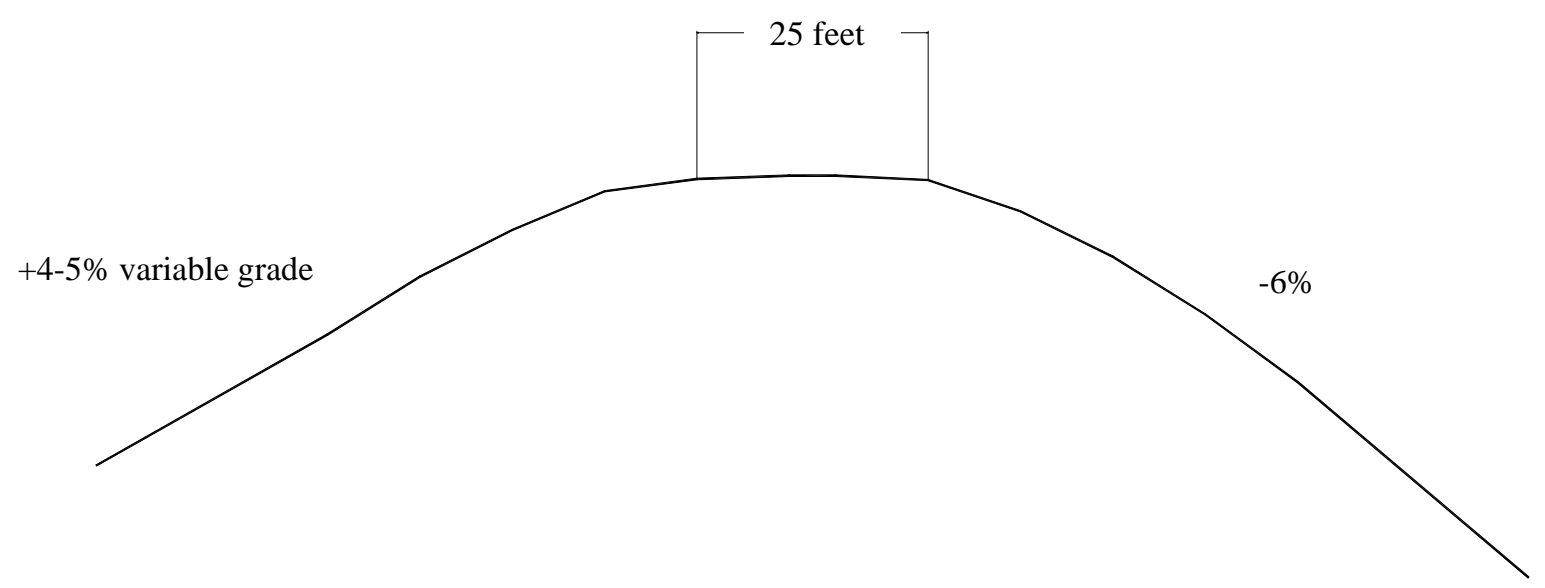

Figure 3.8 - Typical Double Track Mainline Railroad-Highway Grade Crossing Alignment

These profiles were entered into the program and the alignments analyzed with the software option where all combinations of wheelbases, overhangs and ground clearances are used for the analysis, which produced a chart like that shown in Table 3.4. This chart shows which vehicles of a certain wheelbase and ground clearance hang-up as they travel over a selected alignment. The results are presented in a matrix that shows all combinations of wheelbases and ground clearances. A "1" signifies a hang-up, a " 0 " signifies the vehicle can safely cross the alignment without hanging-up, and a "*" signifies that a "more detailed study" is warranted. The hang-up charts for the four files used herein can be found in Appendix D.

Table 3.4 is an example showing the hang-up results for the double track railroadhighway grade crossing. In this particular case, the wheelbase-ground clearance combination of 10 feet and 3 inches will not hang-up on the double track mainline railroad-highway grade crossing alignment, as indicated by a " 0 ." However, a vehicle with a 40 -foot wheelbase and 3 inches of ground clearance will hang-up, as indicated by a "1." A vehicle with a wheelbase of 19 feet and ground clearance of 2 inches may or may not hang-up on the double track curve. A more detailed study is necessary to discover what will happen with this combination. 
Table 3.4 - HANGUP Ground Clearance - Wheelbase Chart for Double-Track Railroad Highway Grade Crossing- Twin.prf

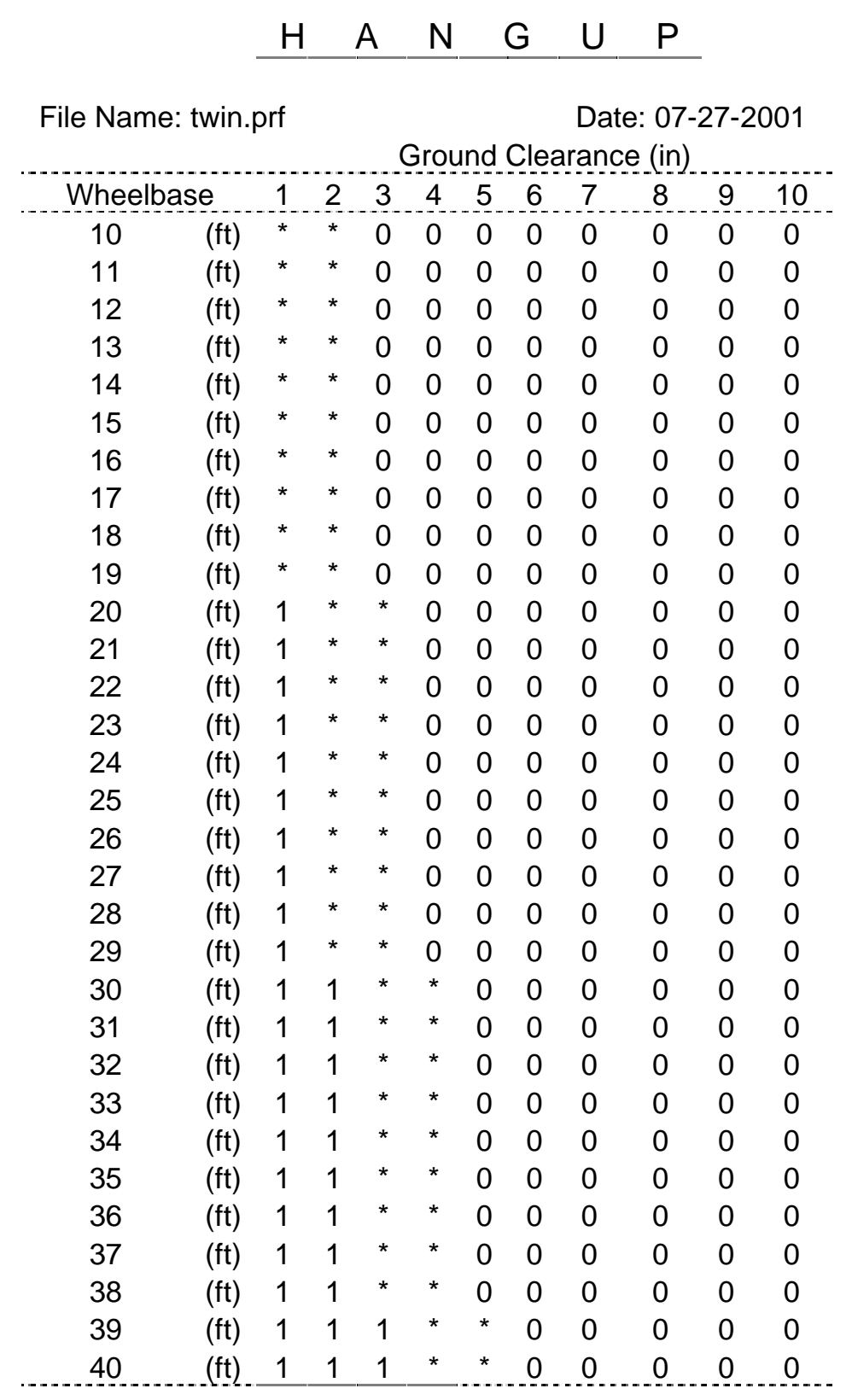

From this simulation, the boundary line between hang-ups and safe crossings for each profile was drawn on a graph using the wheelbase and ground clearance values where hang-ups occur as determined from the Ground Clearance - Wheelbase charts. Additionally, for each 
vehicle type, the database was plotted on this graph, with the best, average, and worst case dimensions highlighted.

Two sets of plots were made: (1) wheelbase and (2) rear overhang, depending on where the vehicle was susceptible to hang-ups. These plots can be found in Appendix E and F. Figure 3.5 depicts the Low-Boy Trailer < 53 feet Wheelbase Hang-up Plot. Note that, for the wheelbase plots, the sag curve data was not plotted, because the vehicles do not hang-up between the wheels on sag curves.

The data points were shown with respect to the plotted lines where hang-ups could occur (based on the four curves and whether vehicles could travel over the curves without hanging-up), and denoted whether or not the vehicle's dimensions would hang-up on the entered curves. If a vehicle did hang-up, the point was located to the left of the lines representing the alignments. Data points to the right of the lines were vehicle dimensions that did not hang-up.

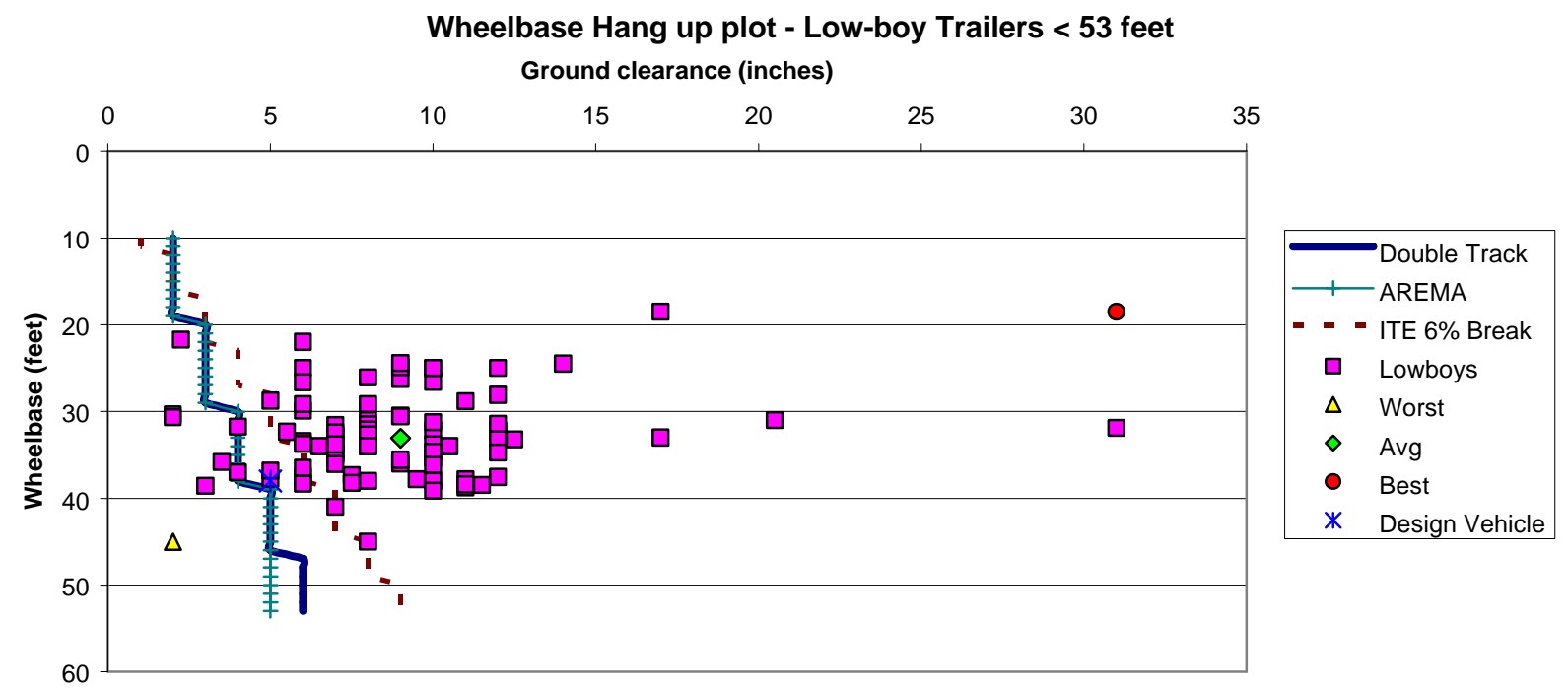

Figure 3.9 - Wheelbase Hang-up Plot for Low-Boy Trailers $<53$ feet

Figure 3.9 shows how the low-boy data related to the hang-up potential on the three crest vertical curves. The square points represent the vehicle dimensions collected during the data 
collection procedure. The best, average, and worst case dimensions are shown as a circle, a diamond, and a triangle, respectively. Finally, the AREMA design standard is shown by a line with hash marks perpendicularly through it, the ITE Low Volume Driveway is shown as the dashed line, and the double track shown as a solid line. As can be seen, a majority of the vehicles were not susceptible to hang-ups on those alignments. Fifteen of the sample vehicles' dimensions were susceptible to a hang-up with six hanging-up on everything and an additional nine that only hung-up on the ITE driveway alignment. Both the worst-case and best-case dimensions are outliers. The data have a large spread, although most of the dimensions are within a 5-inch to 14 -inch ground clearance range and a 20 -foot to a 40-foot range.

These plots were used in selecting the final design vehicle dimensions for each vehicle type. Design vehicle dimensions were chosen to reasonably represent the types of vehicles with consideration to the hang-up potential. Outliers were easily detected and, if necessary, discarded. The design vehicle dimensions were selected using the $85^{\text {th }}$ percentile method or engineering judgment. These dimensions reasonably represented the vehicle population. 


\section{Chapter 4-Summary of Results}

\subsection{DESIGN VEHICLE DIMENSIONS}

In this chapter, the design vehicles resulting from the methodology described in Chapter 3 are presented. A drawing of each vehicle is provided depicting the relevant dimensions, including front/rear overhang, wheelbase, ground clearance, and, for appropriate vehicle-trailer combinations, the hitch location.

Design vehicle dimension selection was largely based on judgment after careful consideration of parameters such as worst-case measurements, statistical measures such as $85^{\text {th }}$ percentiles and averages, and hang-up susceptibility on the test profiles discussed in Chapter 3. As discussed, for the four vertical alignments, all combinations of wheelbase or overhang and ground clearance were tested on the profile. Wheelbase - Hang-up plots showing the results of these analyses can be found in Appendix E. Likewise, Rear Overhang - Hang-up plots can be found in Appendix F.

For each design vehicle, a drawing similar to that presented in the AASHTO Green Book (2001) is included. In addition, a synopsis of the dimension selection process is provided. In the majority of cases, the worst-case dimensions were used as the basis for the design vehicle dimensions. The following were exceptions relative to selection of wheelbase dimensions:

- Car Carrier Trailer

- Double-Drop Trailer

- Passenger Vehicles and Trailers - Commercial Use

- Passenger Vehicles and Trailers - Private Use

- Single Unit Transit Bus

In addition, the following were exceptions relative to selection of rear overhang dimensions:

- Motorcoaches

- Passenger Vehicles and Trailers - Commercial Use

- Recreation Vehicles

- Aerial Fire Truck 
Table 4.1 lists the design vehicles and their corresponding dimensions. Each design vehicle is discussed in detail below.

Table 4.1 - Design Vehicle Dimensions

\begin{tabular}{|c|c|c|c|c|c|c|}
\hline \multirow{2}{*}{ Design Vehicles } & \multirow{2}{*}{ Wheelbase (ft) } & \multicolumn{2}{|c|}{ Overhang (ft) } & \multicolumn{3}{|c|}{ Ground clearance (in) } \\
\cline { 3 - 7 } & & Front & Rear & Wheelbase & Front & Rear \\
\hline Single Unit Trucks - & & & & & & \\
\hline Single Unit Beverage Truck & 24 & -- & 10 & 6 & -- & 8 \\
\hline Articulated Beverage Truck & 30 & -- & -- & 10 & -- & -- \\
\hline Rear-Load Garbage Truck & 20 & -- & 12.5 & 12 & -- & 14 \\
\hline Aerial Fire Truck & 20 & 7 & 12 & 9 & 11 & 10 \\
\hline Pumper Fire Truck & 22 & 8 & 10 & 7 & 8 & 10 \\
\hline Buses - & & & & & & \\
\hline Mini-Bus & 15 & -- & 16 & 10 & -- & 8 \\
\hline School Bus & 23 & -- & 13 & 7 & -- & 11 \\
\hline Single Unit Transit Bus & 25 & 18 & -- & 8 & 6 & -- \\
\hline Articulated Transit Bus & $22 / 26$ & -- & 10 & $10 / 10$ & -- & 9 \\
\hline Motorcoach & 27 & 7.6 & 10 & 7 & 10 & 8 \\
\hline Trucks - & & & & & & \\
\hline Low-Boy Trailers < 53 ft & 38 & -- & -- & 5 & -- & -- \\
\hline Double-Drop Trailer & 40 & -- & -- & 6 & -- & -- \\
\hline Car Carrier Trailer & 40 & -- & 14 & 4 & -- & 6 \\
\hline Belly Dump Trailer & 40 & -- & -- & 11 & -- & -- \\
\hline Recreational Vehicles - & & & & & & \\
\hline $\begin{array}{c}\text { Passenger Vehicle and Trailer - } \\
\text { Private Use }\end{array}$ & 20 & -- & 13 & 5 & -- & 5 \\
\hline $\begin{array}{c}\text { Passenger Vehicle and Trailer - } \\
\text { Commercial Use }\end{array}$ & 27 (24 to hitch) & -- & 13 & 7 & -- & 7 \\
\hline Recreation Vehicle & 27 & 7.8 & 16 & 7 & 6 & 8 \\
\hline
\end{tabular}

-- These vehicle characteristics were not susceptible to the hang-up problem, thus not reported. 


\subsubsection{Single Unit Beverage Truck}

Dimensions for the single unit beverage truck design vehicle were based on the worst case dimensions. The worst-case dimensions were 6 inches of ground clearance and a 24.5 -foot wheelbase. The selected design vehicle dimensions were 6 inches of ground clearance and a wheelbase of 24 feet (rounded down from 24.5 feet). The rear overhang dimensions selected for this vehicle were also based on the worst-case dimensions: 10-foot rear overhang, and an 8-inch ground clearance. The overhang lengths for the individual vehicles in the database for this vehicle were fairly uniform, so the 10 -foot overhang length represents these vehicles well. Since the ground clearance varied greatly but had no outliers, the lowest was selected.

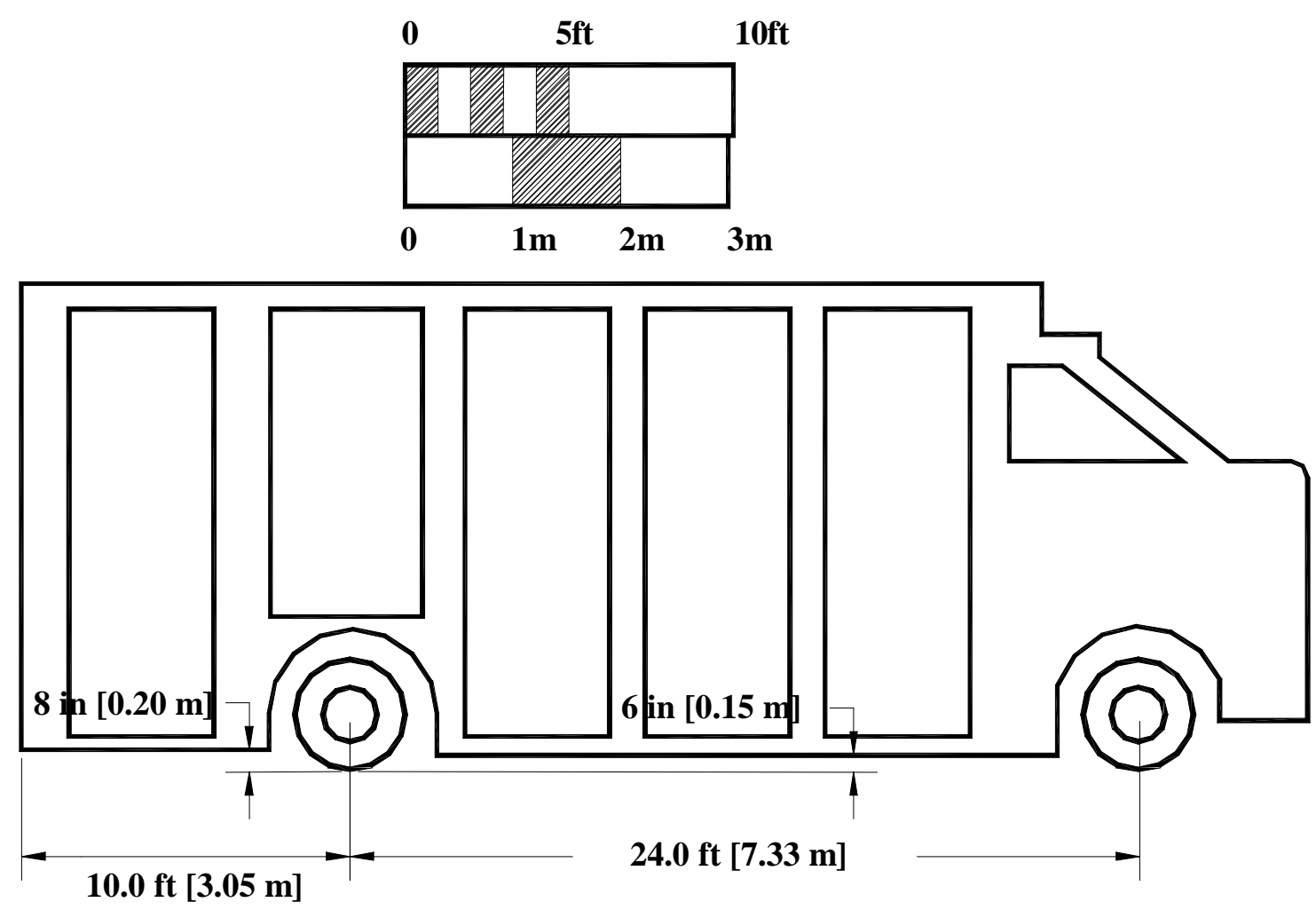

Figure 4.1 - Single Unit Beverage Truck 


\subsubsection{Articulated Beverage Truck}

The wheelbase of the articulated beverage design vehicle was 30 feet, with a ground clearance of 10 inches. The worst-case vehicles from the database had values of 31 feet, 10 inches, with a second vehicle very similar to it at 28.5 feet and 10 inches. As the two points were close to 30 feet, the 30 -foot wheelbase was chosen to represent the vehicle. The two worstcase vehicles in the database each had a ground clearance of 10-inches, which was selected.
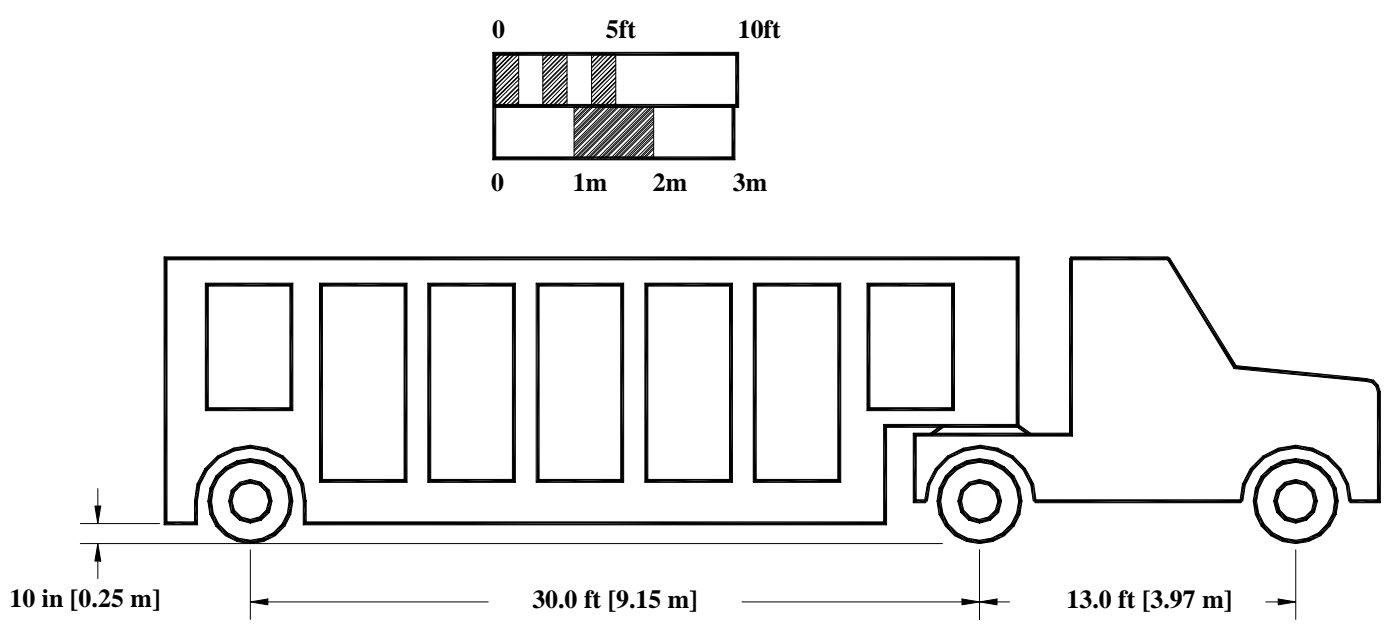

Figure 4.2 - Articulated Beverage Truck 


\subsubsection{Rear-Load Garbage Truck}

While the main dimension of interest for garbage trucks was rear overhang, a wheelbase was established to further characterize the vehicle. The selected wheelbase dimensions were not influenced by the worst-case vehicle, but by the cluster of vehicles having wheelbases ranging from 17.92 feet to 21.17 feet and ground clearances ranging from 11 inches to 13 inches. A rounded average of the wheelbase lengths yielded the final design dimension of 20 feet and an average of the ground clearances provided the final design vehicle dimension of 12 inches. The garbage truck rear overhang hang-up plot (Appendix F) showed that there were several vehicles with dimensions similar to the worst-case vehicle. Because of this, the worst case was selected for the design vehicle dimensions. This garbage truck had 14 inches of ground clearance and a rear overhang of 10.5 feet.

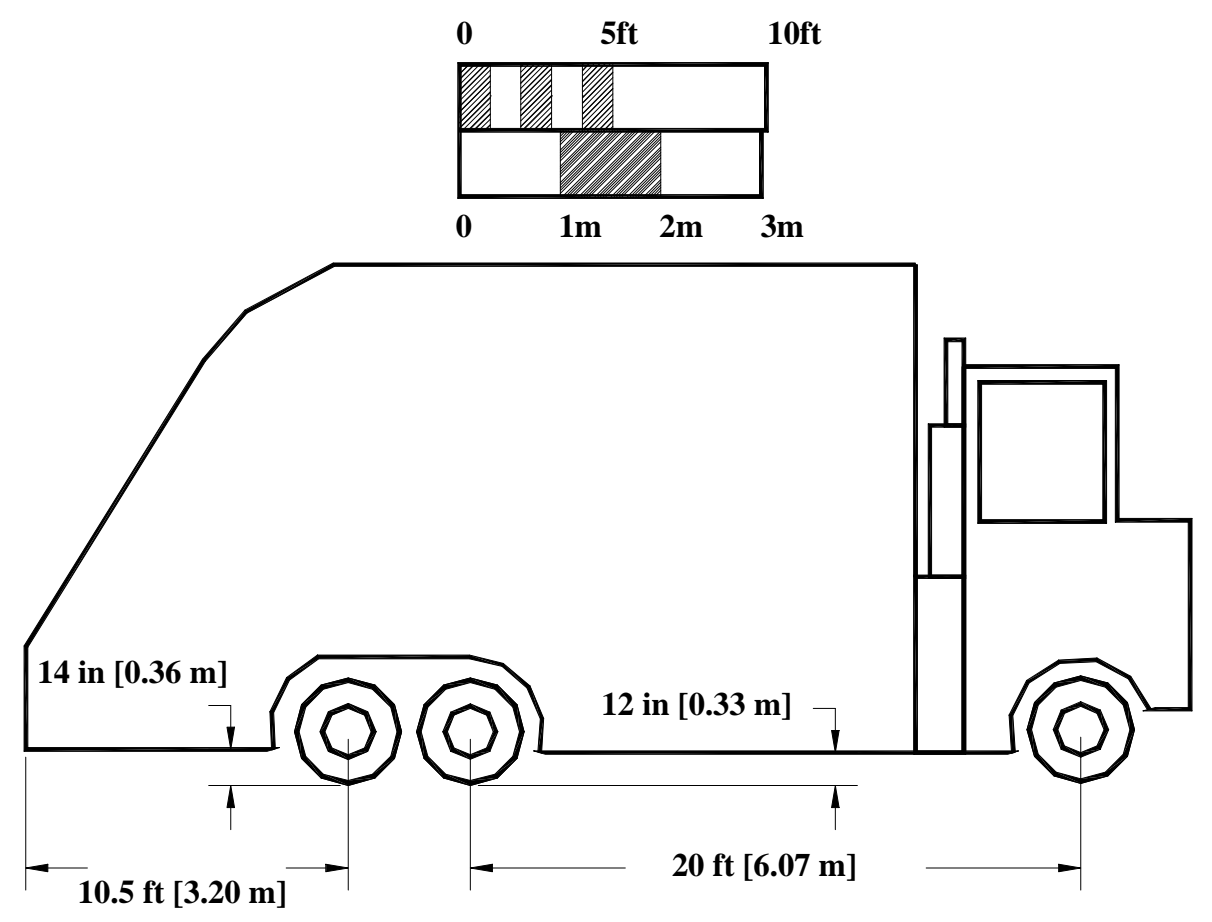

Figure 4.3 - Rear-Load Garbage Truck 


\subsubsection{Aerial Fire Truck}

The worst-case vehicle dimensions were used to establish this design vehicle's dimensions. The worst-case dimensions were 9 inches of ground clearance and a wheelbase of 21.58 feet. The 21.58 feet was rounded down to 20 feet to provide a better fit with the other vehicles in the database, as there were 3 vehicles with wheelbases of approximately 20 feet. The worst-case dimension of 9 inches was considered reasonable and accepted as the design vehicle's ground clearance dimension. The rear overhang dimensions were not selected from the worstcase dimensions, as they were considered outliers. Instead, the next longest and lowest vehicle was selected. It was felt that these dimensions, since they both occurred on the same vehicle, better represented this vehicle type. Hence, the dimensions were 10 inches of ground clearance at the rear and a rear overhang length of 12 feet.
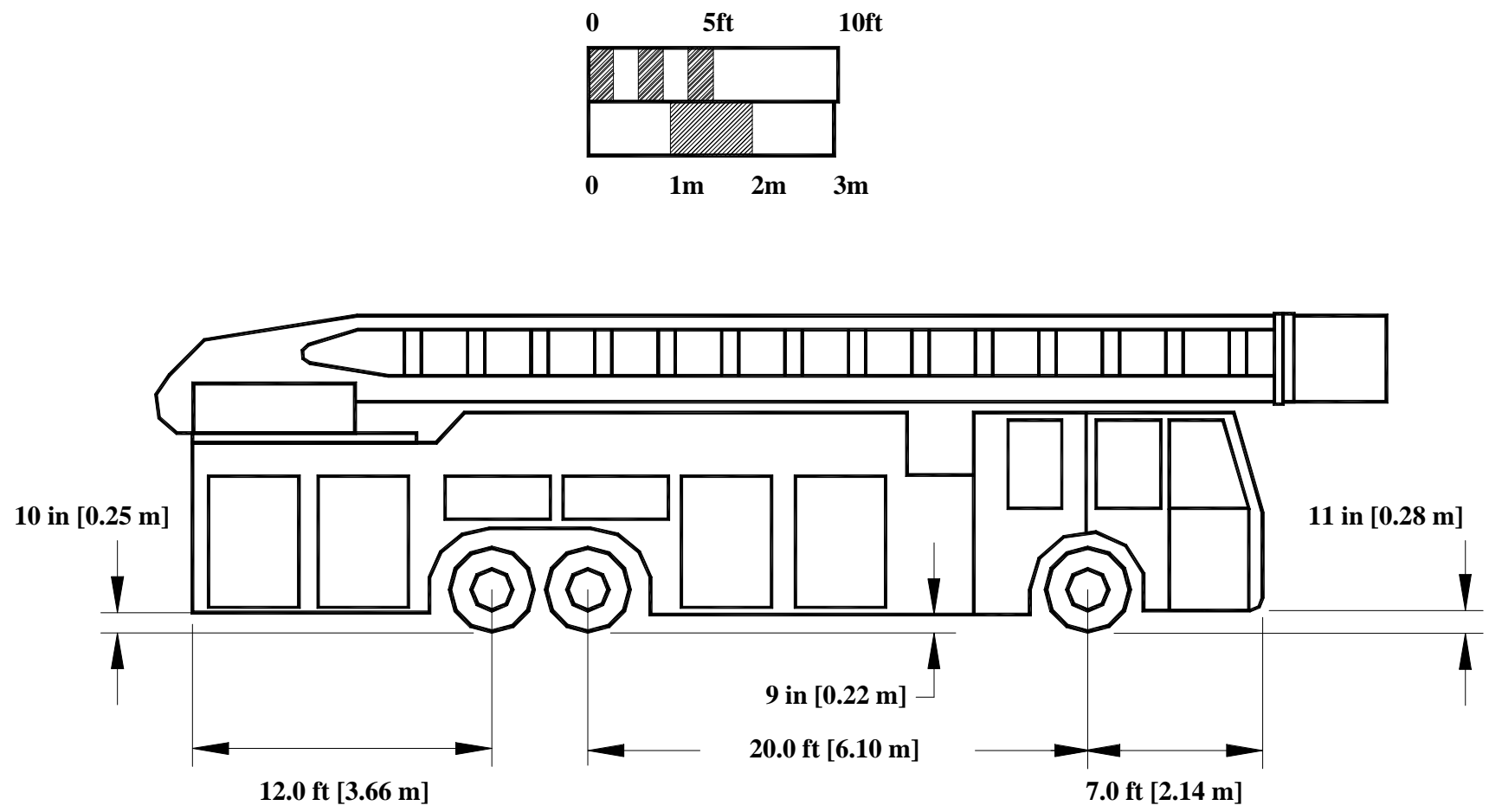

Figure 4.4 - Aerial Fire Truck 


\subsubsection{Pumper Fire Truck}

The worst-case dimensions for the pumper fire truck was a wheelbase of 21.5 feet and a ground clearance of 7 inches. For the design vehicle, the 7 inches of ground clearance was selected to represent the ground clearance between the axles. The selected wheelbase was 22 feet (21.5 feet rounded up). The rear overhang for this design vehicle was also fixed using the worst-case vehicle dimensions: a 10-foot rear overhang, and a ground clearance of 10 inches.
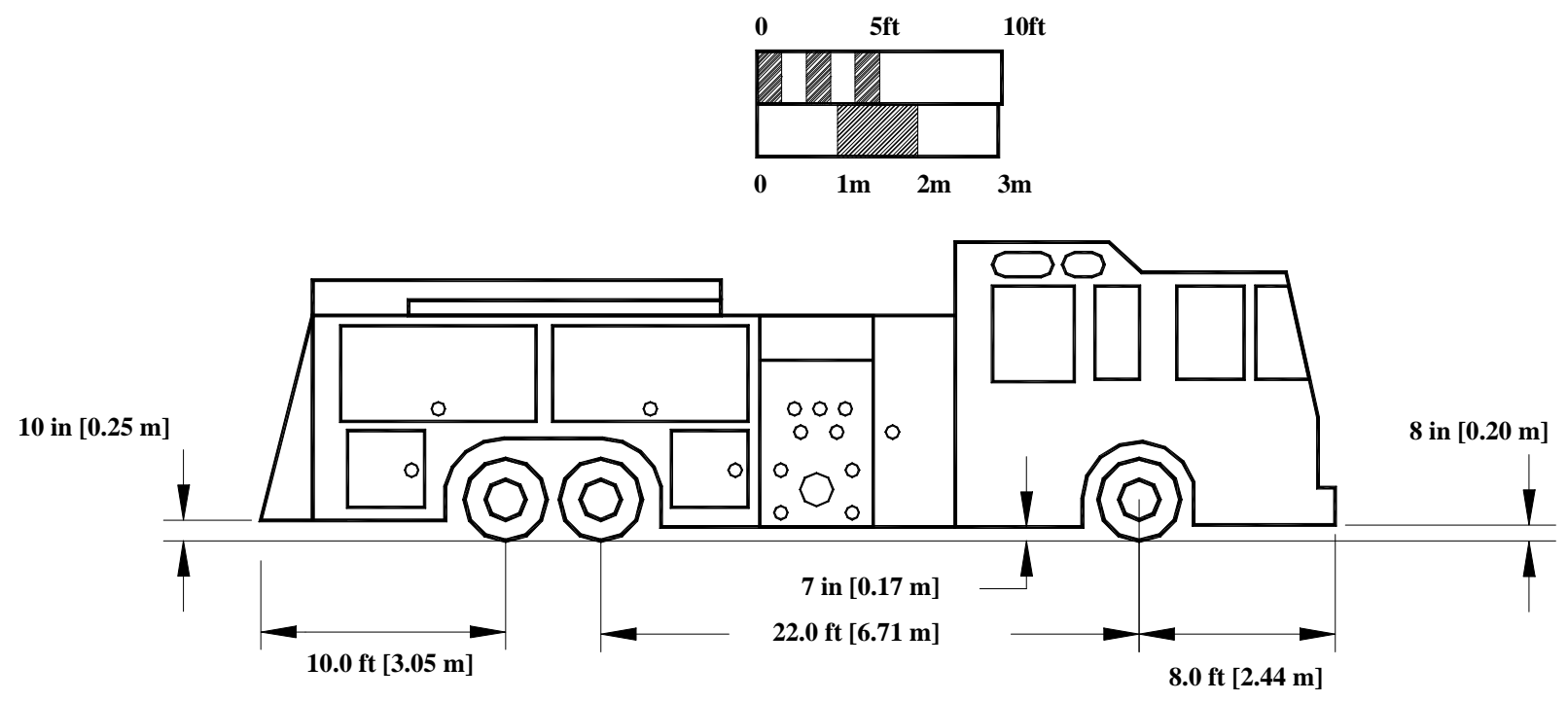

Figure 4.5 - Pumper Fire Truck 


\subsubsection{Mini-Bus}

Due to the short wheelbase of this vehicle type, it was not an issue in the hang-up problem. Instead, rear overhang was the major issue due to its susceptibility to dragging on vertical alignments. The rear overhang was chosen using the worst-case vehicle as a basis for the dimensions. The dimensions for the design vehicle's rear overhang were 8 inches of ground clearance and a 16-foot rear overhang. While the wheelbase was not the dimension of concern, the average wheelbase (rounded to 15 feet) and average ground clearance (rounded down to 10 inches) were selected.

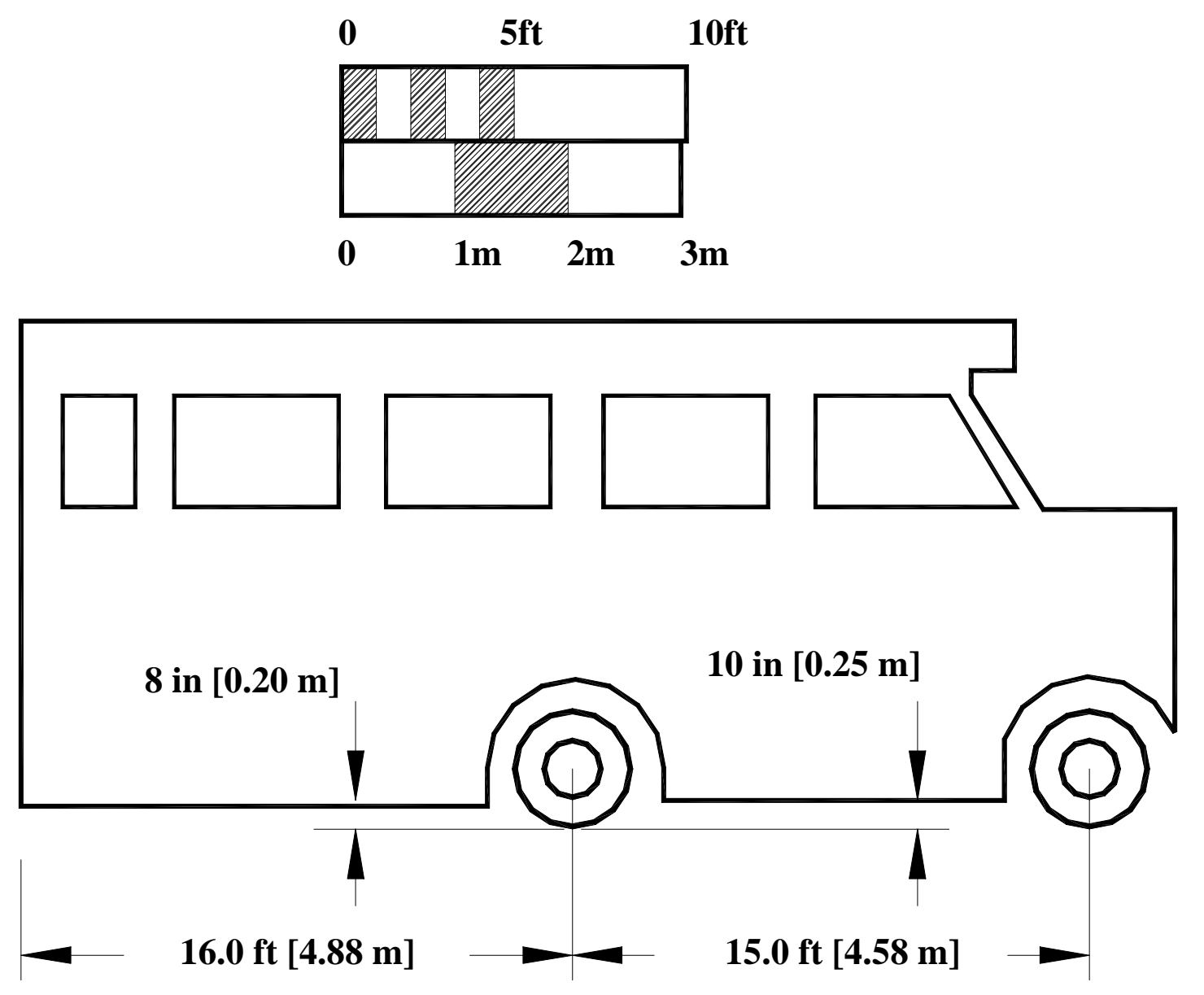

Figure 4.6- Mini-Bus 


\subsubsection{School Bus}

The design vehicle for school buses was chosen using the worst-case vehicle dimensions. A ground clearance of 7 inches with a wheelbase of 23 feet were selected. The rear overhang dimensions for the design vehicle also utilized the worst-case dimensions. These dimensions were an 11-inch ground clearance and a 13-foot rear overhang.
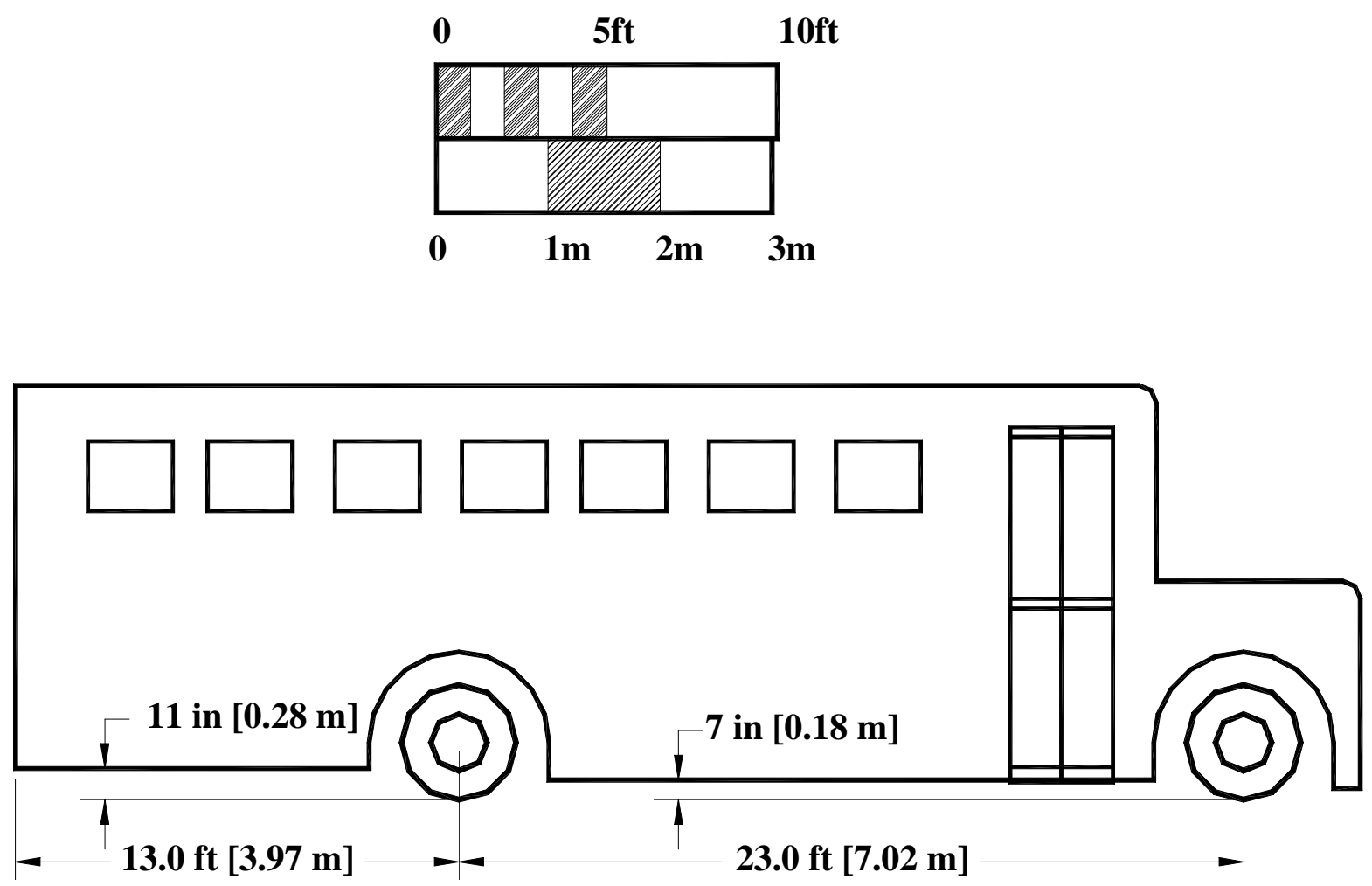

Figure 4.7 - School Bus 


\subsubsection{Single Unit Transit Bus}

The worst-case wheelbase dimensions for the single unit transit bus (a 27-foot wheelbase/ 4-inch ground clearance) were considered outliers. Consequently, to determine the design vehicle dimensions, the six data points closest to the worst case were averaged. An average of the ground clearances between the wheels was 8.25 inches, which was rounded to 8 inches. While the average of the wheelbases was 21.2 feet, a longer value was chosen to better represent the vehicles. This value was 25 feet. The front overhang on the single unit transit bus was also significant to the hang-up problem, causing the bus to be susceptible to dragging at the front overhang. The worst-case front overhang dimension was 17.83 feet, with a ground clearance of 6 inches. During the simulations, it was found that both the worst-case and the best-case dimensions hung-up on the alignments. Therefore, the 17.83-foot front overhang was rounded up the 18 feet and, along with the 6-inch ground clearance, were chosen to represent the transit bus.
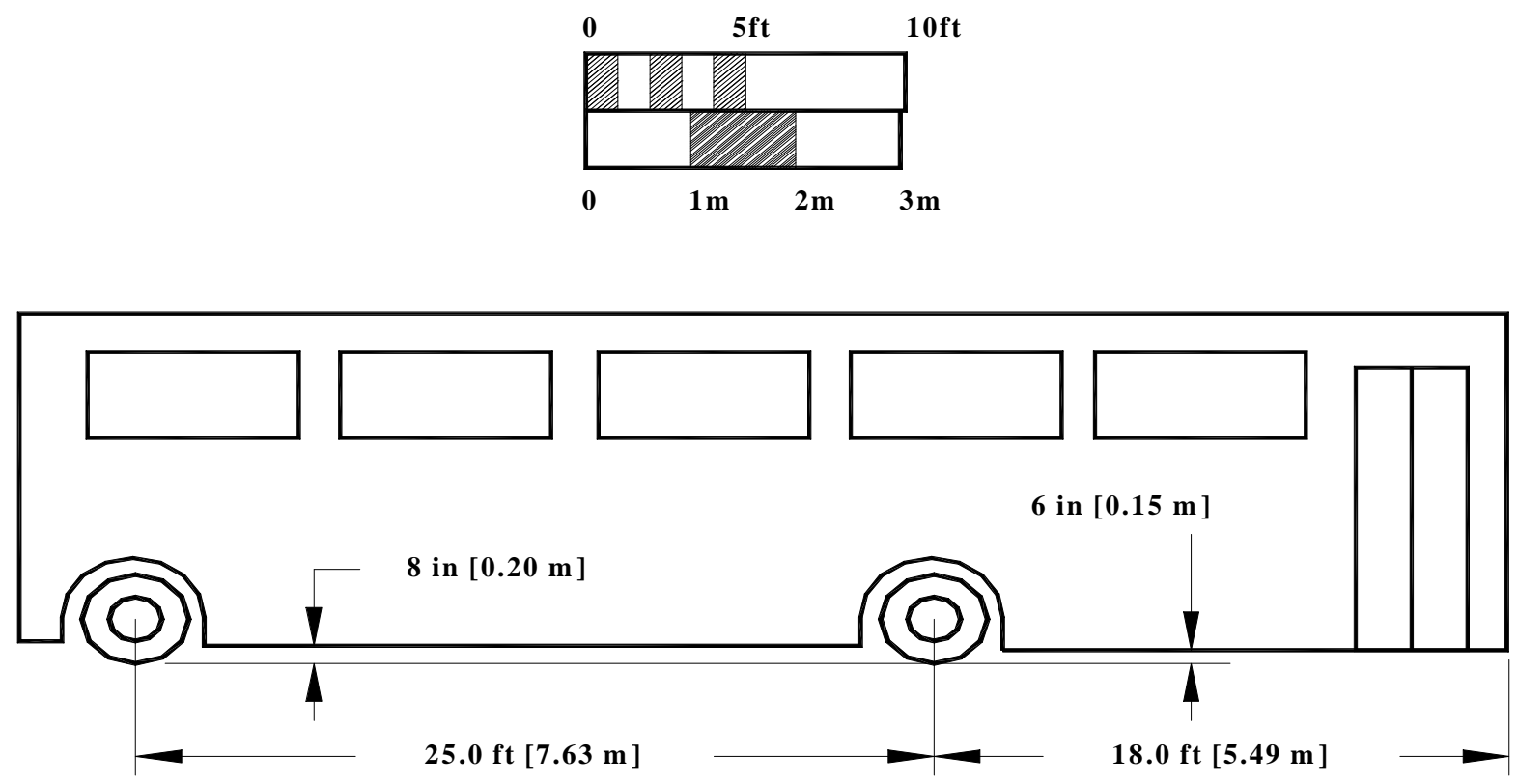

Figure 4.8 - Single Unit Transit Bus 


\subsubsection{Articulated Transit Bus}

Since the worst-case vehicle was not an outlier compared to the other vehicles sampled, the design vehicle dimensions selected for the articulated transit bus were worst case, at a wheelbase of 26 and a ground clearance of 10 inches. The rear overhang of 10 feet was chosen using the worst-case vehicle's dimensions. Since two measured vehicles had both a 10-foot overhang and nearly 9 inches of ground clearance, a 10-foot overhang and 9-inch ground clearance were selected for design vehicle dimensions.
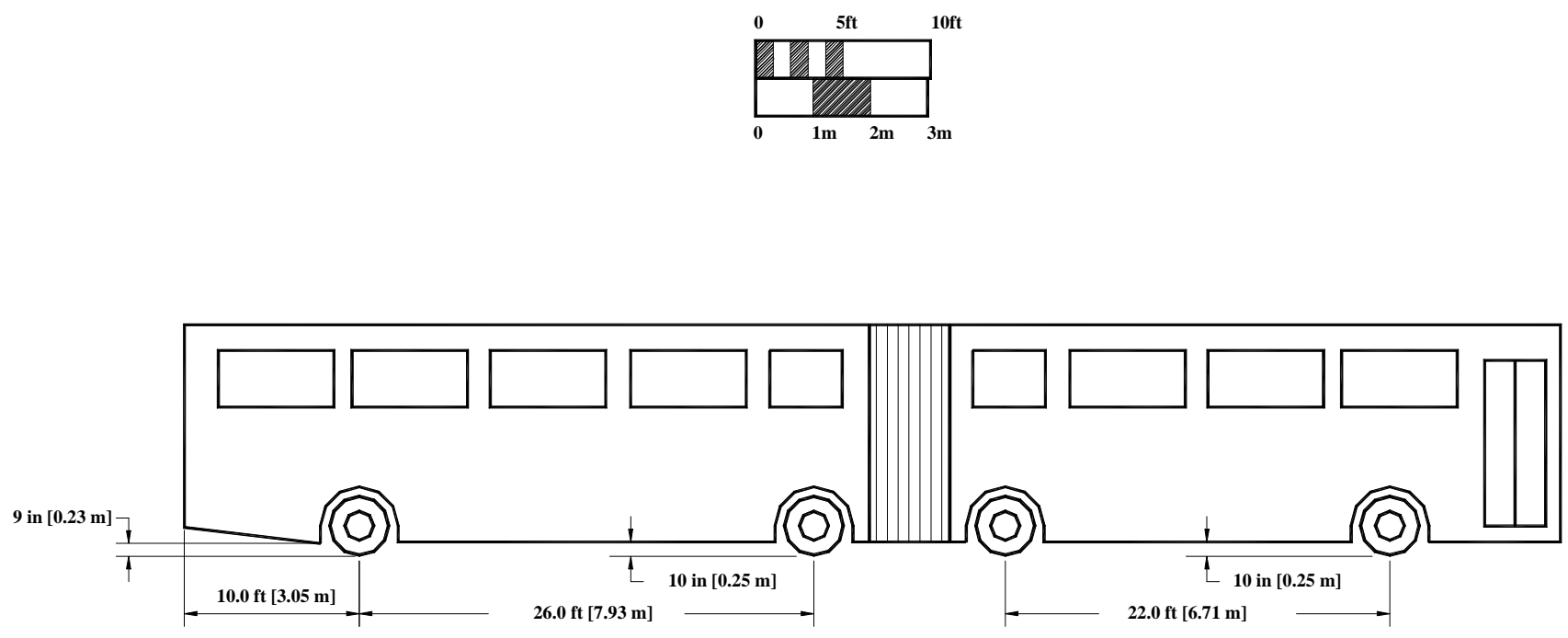

Figure 4.9 - Articulated Transit Bus 


\subsubsection{Motorcoach}

It was decided that the wheelbase of the design vehicle for the Motorcoach would have the same dimensions as the worst-case dimensions, as there was no potential for hang-up on any of the test profiles. The selected wheelbase was 27 feet (rounded up from 26.5 feet) and the ground clearance was 7 inches.

The plot of the rear overhang contained in Appendix F was greatly exaggerated, causing the vehicles in the database to appear much more susceptible to hang-ups than they actually were. This was considered when examining the plotted data with respect to the hang-up lines for the vertical alignments. Because of this exaggeration and the distance between the closest points to the worst-case dimensions, the worst-case vehicle's dimensions were not considered, as these data points were outliers. A ground clearance of 8 inches was established by considering the two lowest vehicles, and a rear overhang of 10 feet chosen by looking at the second largest rear overhang (10.5 feet). This value was rounded down to the 10 -foot rear overhang.
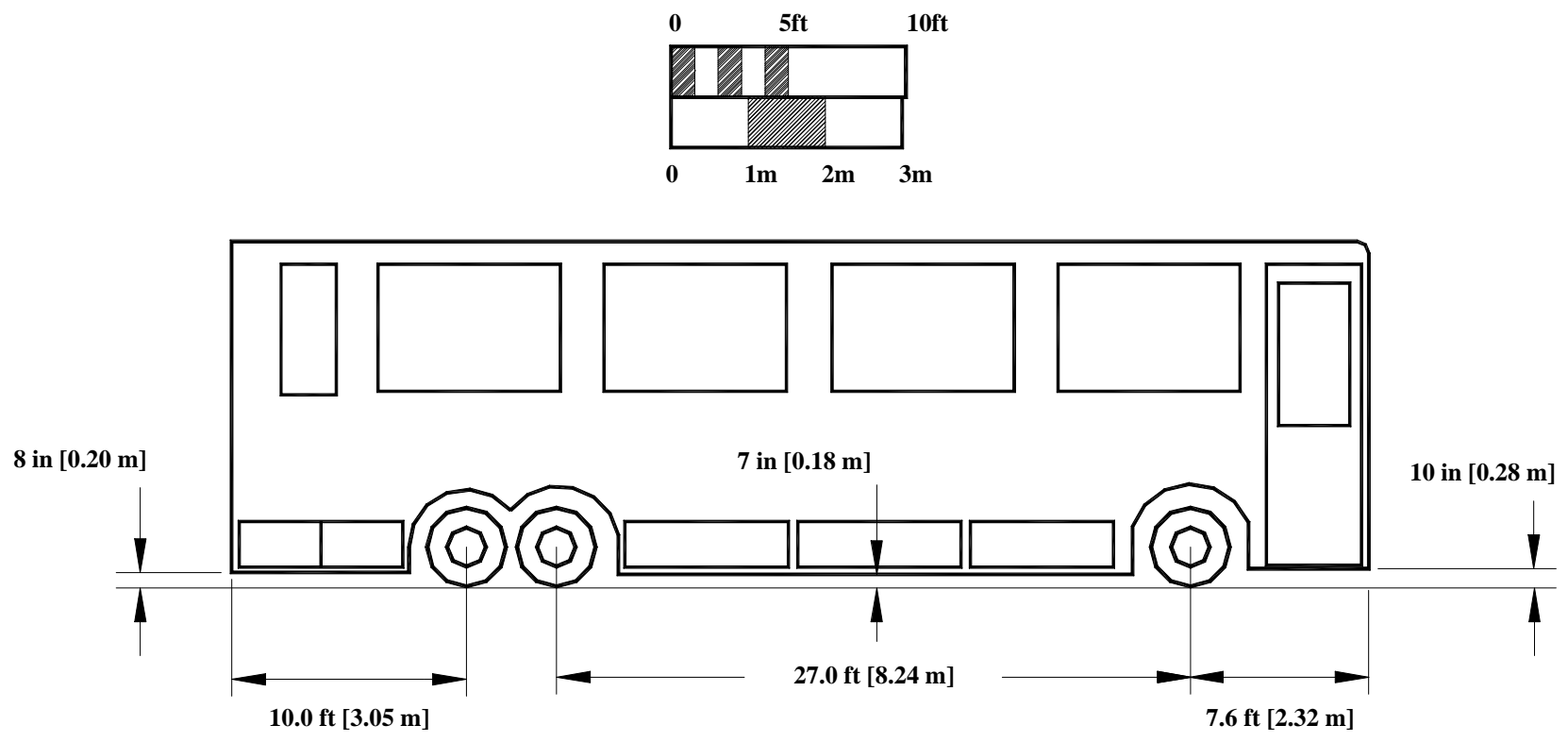

Figure 4.10 - Motorcoach 


\subsubsection{Low-Boy Trailers < $53 \mathrm{ft}$}

The low-boy design vehicle dimensions were more difficult to determine than by just examining the wheelbase corresponding plot (see Appendix C). The wheelbase was found using the $85^{\text {th }}$ percentile plot, which is shown as Figure 4.11.

\section{5th Percentile Plot for Low-Boys}

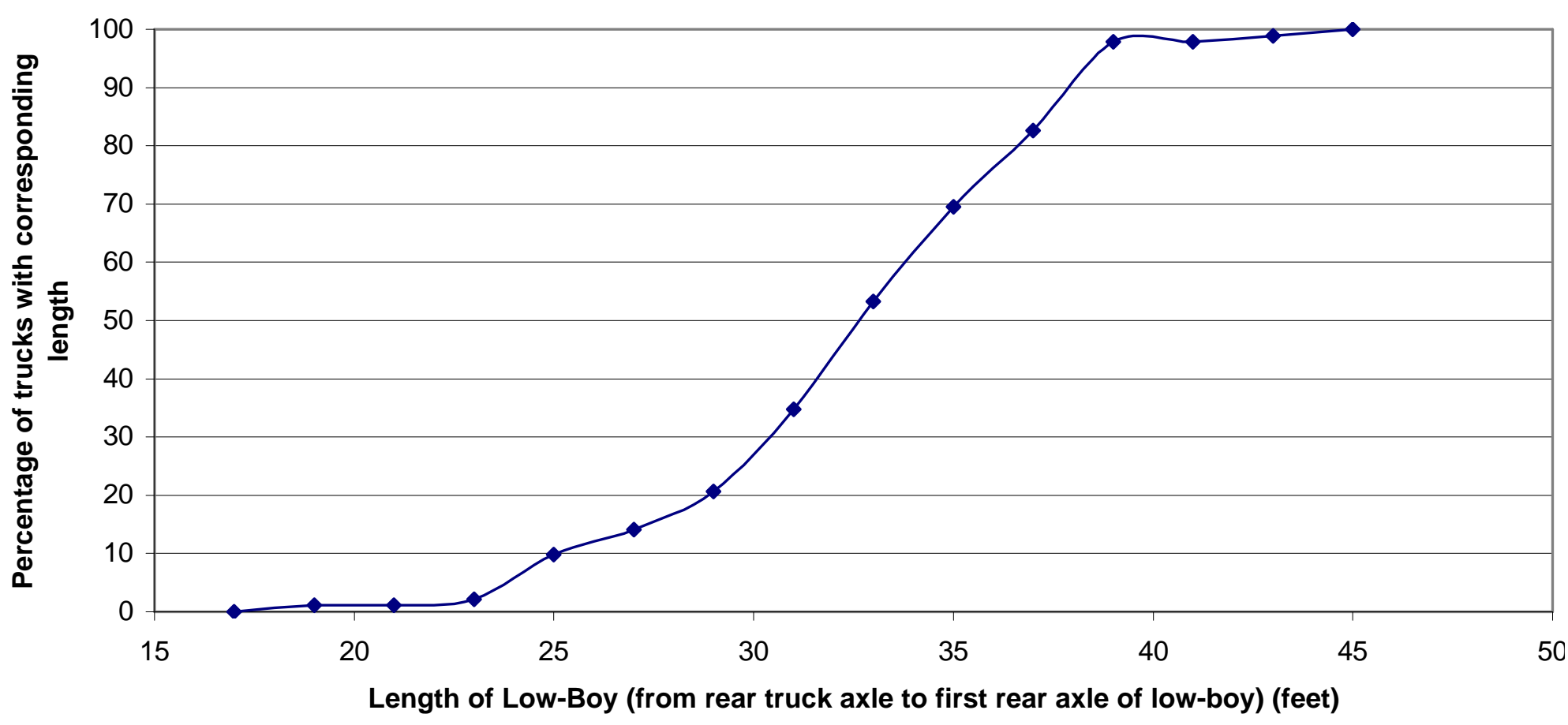

Figure $4.11-85^{\text {th }}$ Percentile Plot - Low-Boy Wheelbase Length

The $85^{\text {th }}$ percentile wheelbase was 38 feet. Looking at the plot for wheelbase hang-up (see Appendix E) there appeared to be several points around this length; the 38-foot wheelbase fit the data well. The ground clearances for the sampled low-boy trailer were highly variable, which was expected. The worst-case ground clearance was near 0 inches. In contrast, it was noted that many of these trailers could be raised when traveling over hang-up prone alignments. As a compromise that provided a reasonable value, 5 inches was selected. This was based in part on 
Eck and Kang's (1991) generic low-clearance design vehicles that also had a ground clearance of 5 inches.
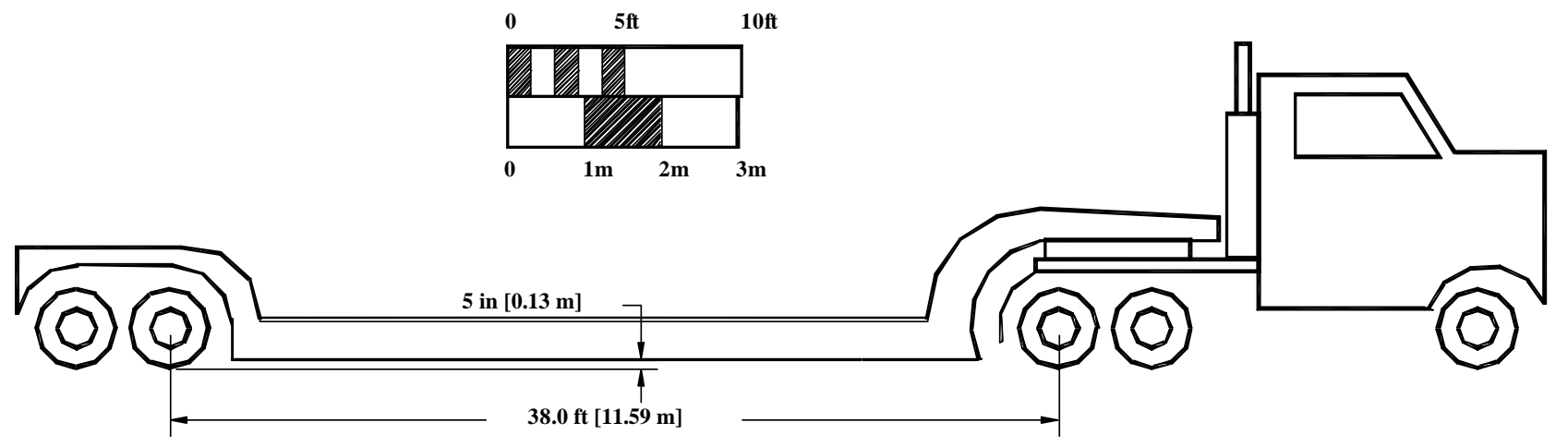

Figure 4.12 - Low-Boy Trailers $<53$ feet

\subsubsection{Double-Drop Trailer}

The double-drop trailer data had one major outlier that affected the worst-case dimensions. This outlier was discarded, and the resulting final design vehicle dimensions were selected based on the next longest and lowest dimensions. This resulted in a design vehicle with a 40-foot wheelbase and a 6-inch ground clearance.
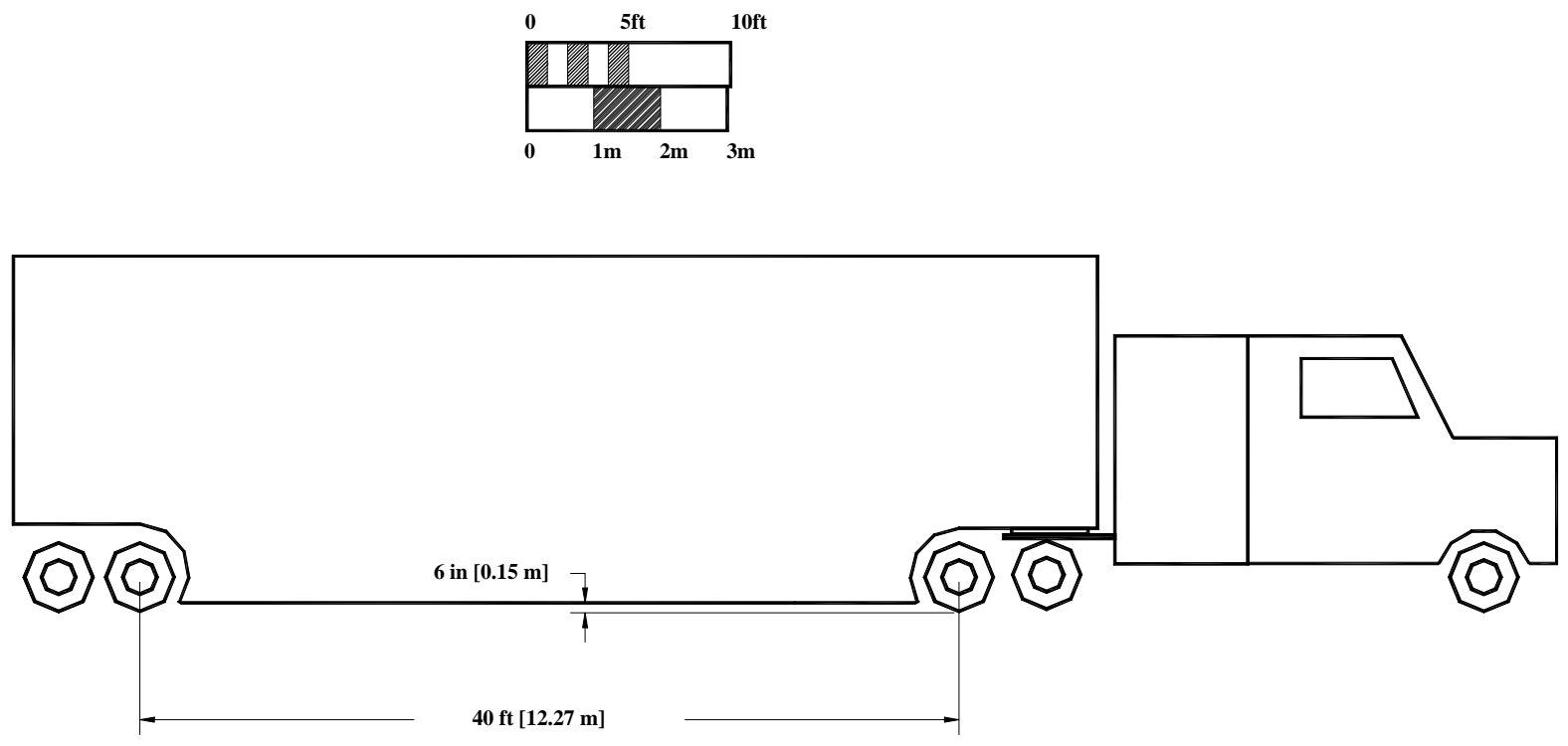

Figure 4.13 - Double-Drop Trailer 


\subsubsection{Car Carrier Trailer}

Because the worst-case vehicle's dimensions (48' wheelbase, 3" ground clearance) were much larger than the other data points, they were considered outliers. The worst-case wheelbase was actually the result of two different vehicles. When car carriers were field measured, the distances from the hitch to the two adjacent axles were separate measurements. The "worstcase" wheelbase was then formulated by adding together the worst-case scenarios for each of these two "wheelbase" measurements individually.

The worst-case wheelbase (from the Car Carrier raw data in Appendix A - r2 to hitch plus hitch to r3) came from two separate car carriers. One, a stinger hitch trailer manufactured by Cottrell, had a "hitch to forward axle" length of 10 feet. The second, a Take 3 high-mount car carrier, had a "hitch to rear axle" length of 38 feet. The resulting overall wheelbase was 48 feet $(10$ feet +38 feet $)$. However, because these were different types of trailers (stinger vs. highmount) it was inappropriate to add them together. This worst-case trailer cannot exist, as there are no high-mount-stinger hitch combinations existing in the car carrier trailer population. Therefore, a design vehicle was selected using smaller dimensions for a stinger hitch trailer (as these were the majority of the population measured). These dimensions were 4 inches of ground clearance and a 40-foot wheelbase, which represented the database well. It was decided that due to the problematic nature of the vehicle in dragging on the rear overhang, the worst-case vehicle dimensions should be used for it. These were 6 inches of ground clearance and a 14-foot long rear overhang. 

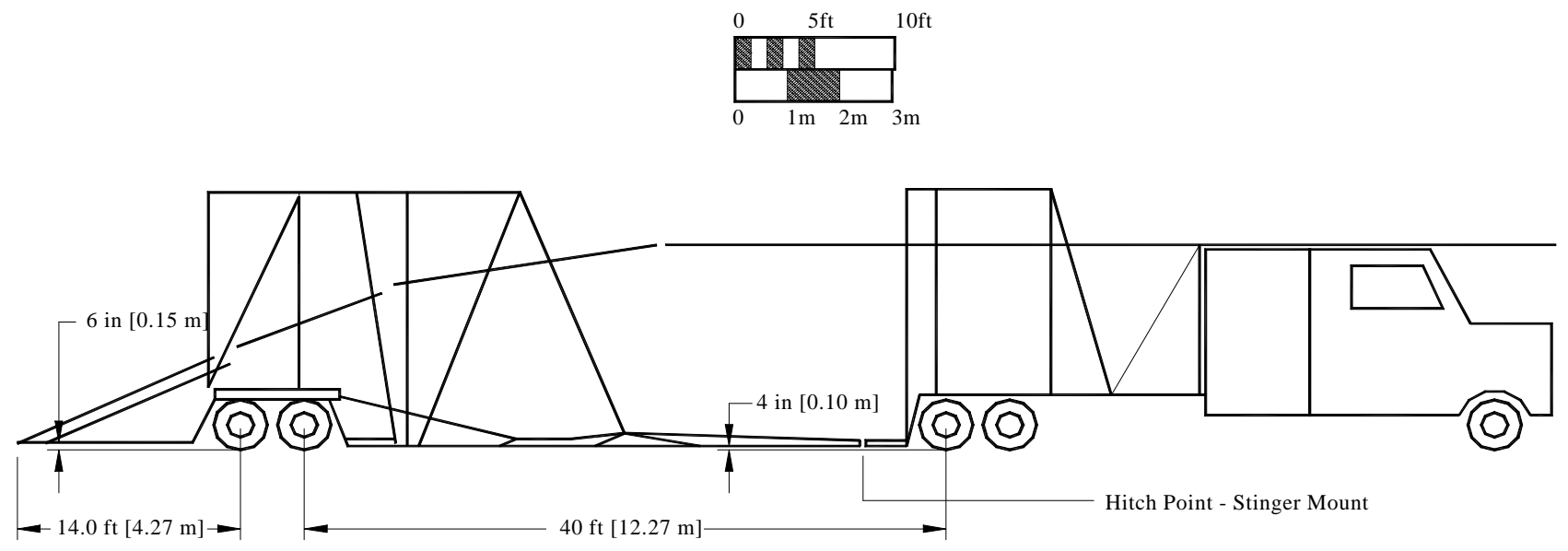

Figure 4.14 - Car Carrier Trailer

\subsubsection{Belly Dump Trailer}

The worst-case data point (see the Wheelbase Hang-up Plot for this vehicle in Appendix E) had no potential for hang-up on any of the test profiles. Therefore, the selected dimensions for this design vehicle matched the worst-case dimensions with a wheelbase of 40 feet and a ground clearance of 11 inches.
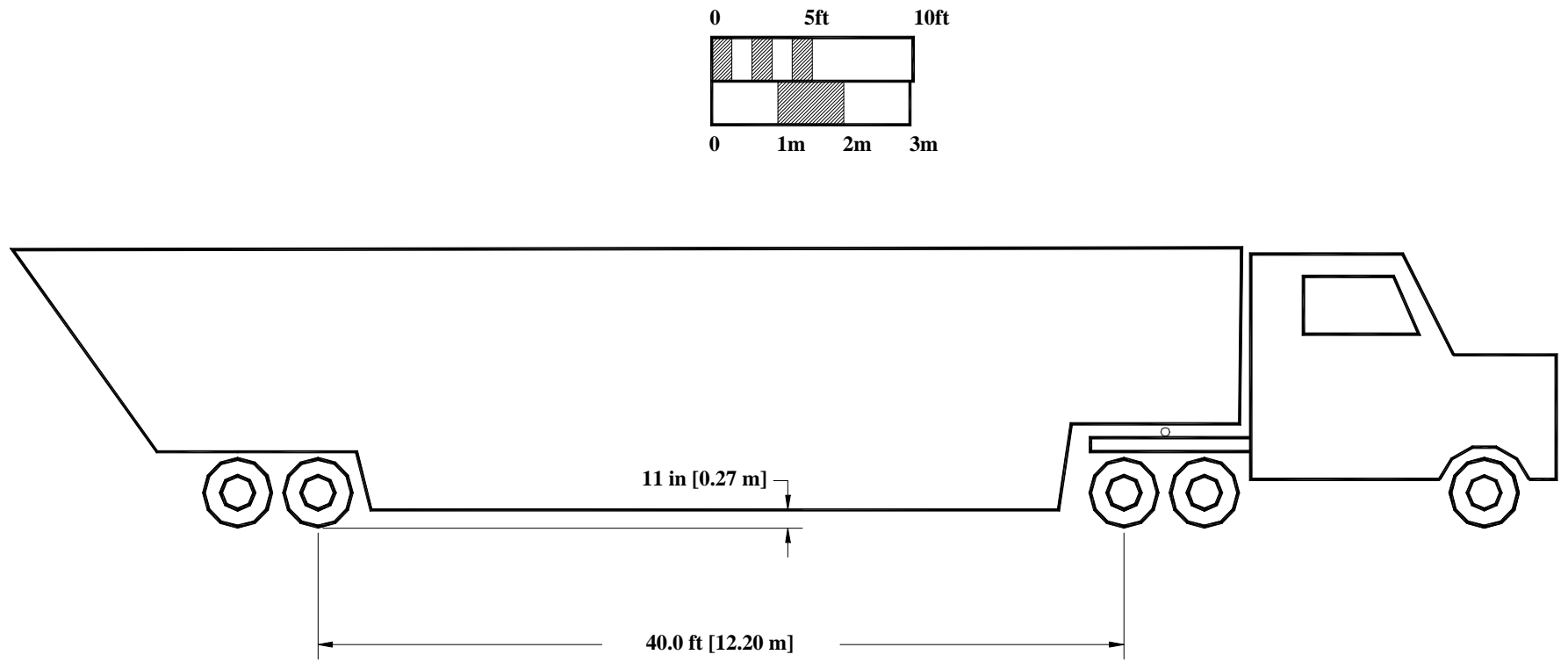

Figure 4.15 - Belly Dump Vehicle 


\subsubsection{Passenger Vehicle and Trailer - Private Use}

To determine the wheelbase for this design vehicle, the worst-case dimensions (4.5-inch ground clearance, 25-foot wheelbase) were considered. However, the vehicle containing each of these dimensions was an outlier compared to the other vehicles in the database. The next worstcase vehicles had a wheelbase ranging from 19.75 to 14.92 feet and a ground clearance ranging from 8 to 4.5 inches. Therefore, most of the low-ground clearance vehicles were shorter than 20 feet (only 10 of 59 vehicles measured were longer than 20 feet). Furthermore, this length seemed to be a cutoff point for drastic changes in ground clearance. Because of this, the wheelbase was selected to be 20 feet. The ground clearance was the worst-case dimension ( 4.5 inches) rounded up. There were several vehicles with a similar ground clearance supporting this selection.
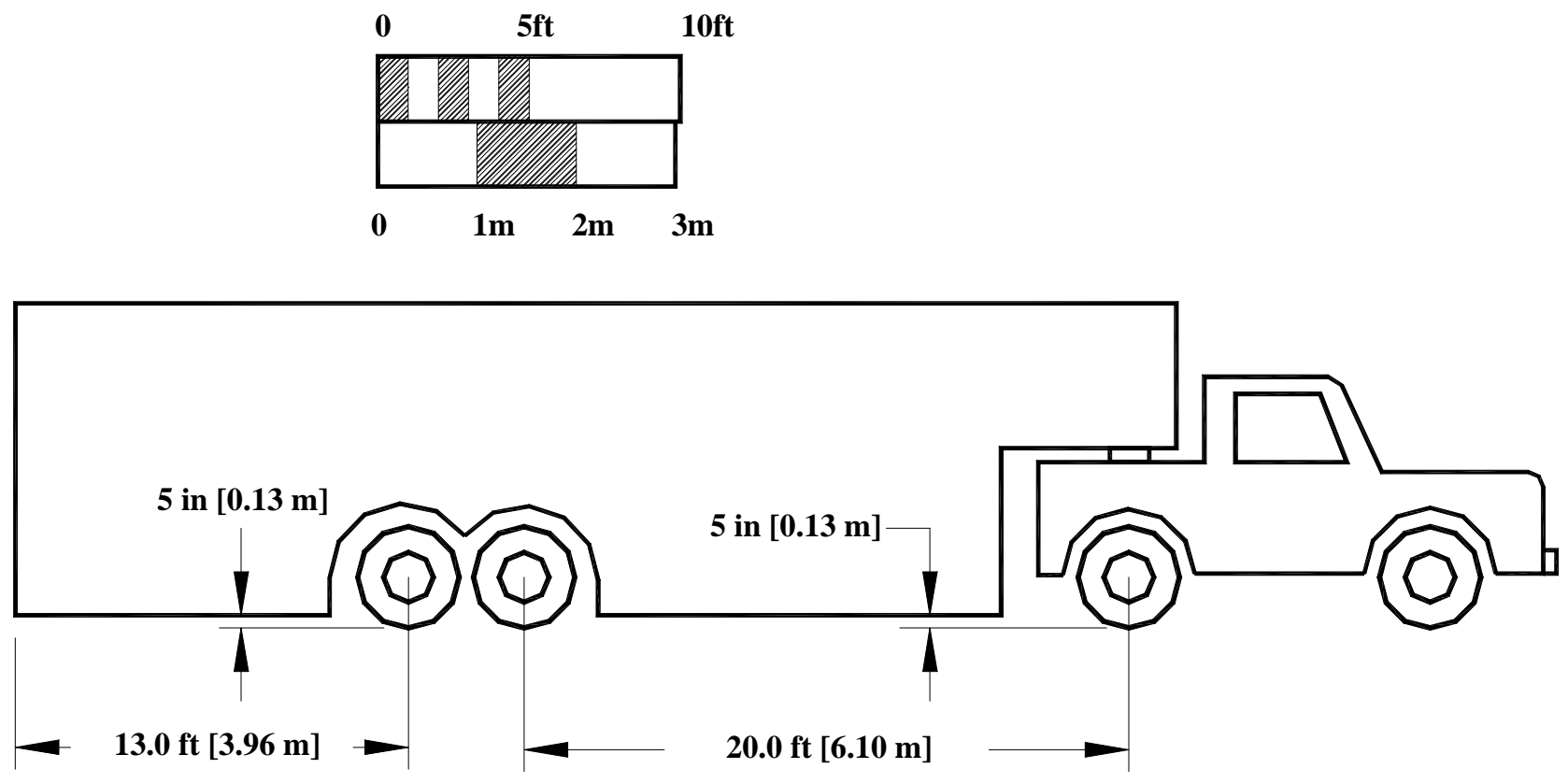

Figure 4.16 - Passenger Vehicle and Trailer - Private Use 


\subsubsection{Passenger Vehicle and Trailer - Commercial Use}

The worst-case dimensions for this design vehicle were considered outliers (4-inch ground clearance, 40 -foot wheelbase). The 40-foot wheelbase came from a fifth wheel Trailer Tech car carrier. These car carriers are designed for commercially hauling cars like car carrier tractor-trailers do, and are longer than many other commercial trailers that can be pulled by passenger vehicles.

Referring to the Wheelbase Hang-up Plots in Appendix E, the next two closest values had wheelbases of 40 feet to 18 feet, and ground clearances of 10 inches to 5 inches. Therefore, an average was taken of the two next-closest points to represent the design vehicle. The resulting final design vehicle dimensions were 30 feet (rounded up from 29 feet) and 7 inches (rounded down from 7.5).

The rear overhang for the design vehicle was chosen not using the worst-case dimensions, but by using the ground clearance of the lowest trailer, which was a race car transporter with a ground clearance of 7 inches and a wheelbase of the next longest trailer, which was a car carrier, with a rear overhang of 13 feet. Both are common trailer types, and as such are believed to represent this vehicle type well.
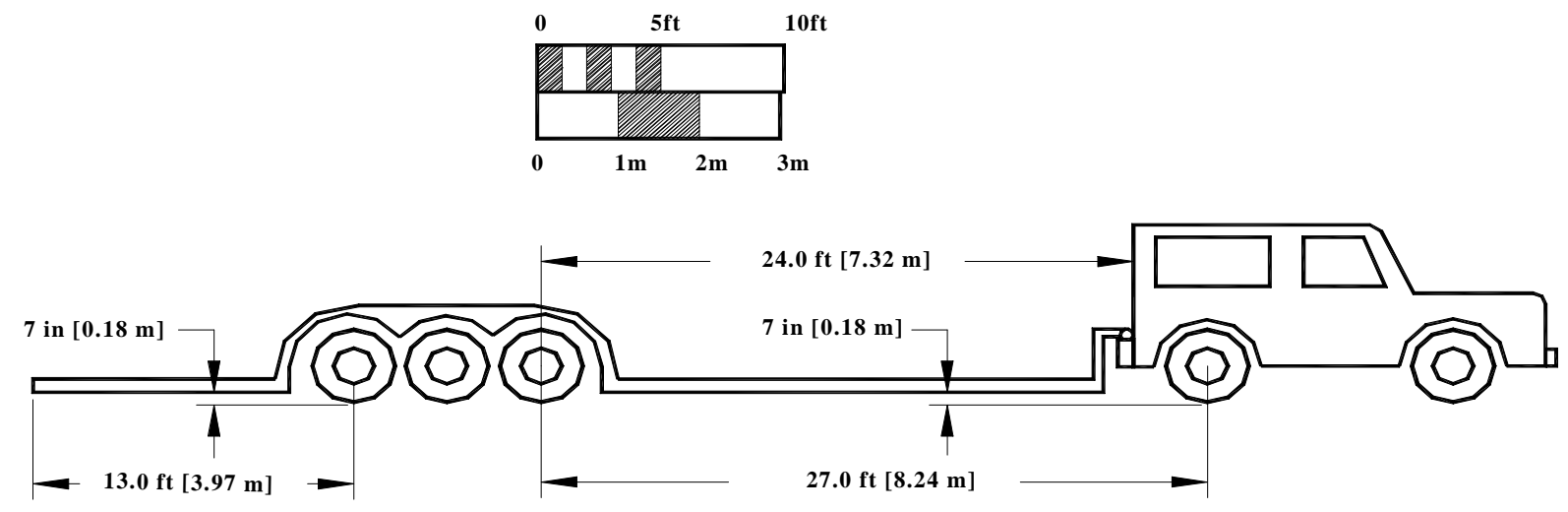

Figure 4.17 - Passenger Vehicle and Trailer - Commercial Use 


\subsubsection{Recreational Vehicle (RV)}

The design vehicle for RVs was based on the worst-case vehicle dimensions. The worstcase ground clearance of 7.5 inches was rounded down to 7 inches, and the worst-case wheelbase of 26 feet 4 inches was rounded up to 27 inches. The rear overhang was not established using the worst-case dimensions (19.58-foot rear overhang, 6-inch ground clearance), as those dimensions were considered outliers. The next closest ranged from 19.42 feet to 12 feet for the wheelbase, with ground clearances ranging from 12 inches to 6 inches. As a compromise between these ranges, a ground clearance of 8 inches and rear overhang of 16 feet chosen as design vehicle dimensions.

Note that there are two general classes of RV's. The AASHTO (2001) motor home design vehicle has a wheelbase of 20 feet, a front overhang of 4 feet, and a rear overhang of 6 feet. The design vehicle established in this research is significantly larger than AASHTO's, and is closer in size to a Motorcoach. In the adoption process, consideration should be given to establishing a second, smaller RV design vehicle to represent more typical versions of this vehicle.
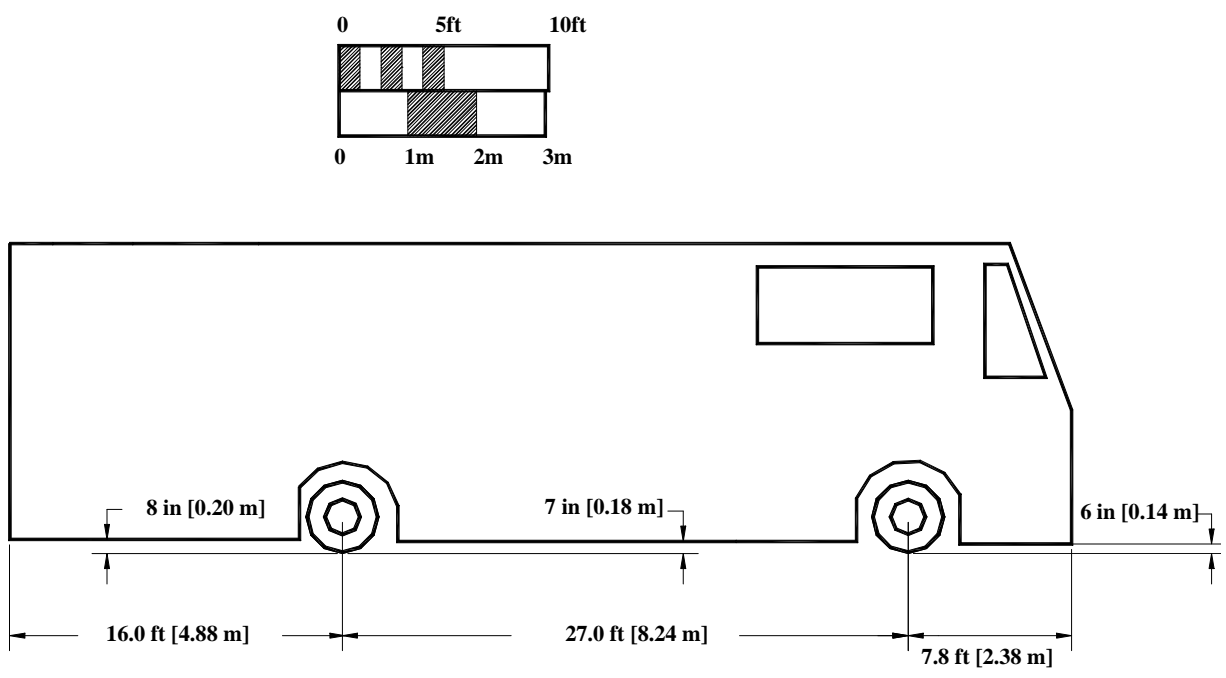

Figure 4.18 - Recreation Vehicle 


\subsection{COMPARISONS WITH AASHTO}

A few comparisons can be made to those design vehicles listed in the AASHTO Green

Book (2001). Table 4-2 lists key parameters for comparison with the hang-up design vehicles.

Table 4.2 - Key Comparisons of AASHTO Design Vehicles with Hang-up Design Vehicles

\begin{tabular}{|c|c|c|c|c|}
\hline $\begin{array}{c}\text { AASHTO } \\
\text { Design Vehicle }\end{array}$ & $\begin{array}{l}\text { Compared } \\
\text { Parameter }\end{array}$ & $\begin{array}{c}\text { AASHTO } \\
\text { Dimension }(\mathrm{ft})\end{array}$ & Hang-up Design Vehicle & $\begin{array}{c}\text { Dimension } \\
(\mathrm{ft})\end{array}$ \\
\hline \multirow[t]{5}{*}{ Single Unit } & \multirow[t]{5}{*}{ Wheelbase } & \multirow[t]{5}{*}{20} & Mini-bus & 15 \\
\hline & & & Rear-Load Garbage Truck & 20 \\
\hline & & & Aerial Fire Truck & 20 \\
\hline & & & Pumper Fire Truck & 22 \\
\hline & & & Single Unit Beverage Truck & 24 \\
\hline \multirow[t]{3}{*}{ City Transit Bus } & Wheelbase & 25 & \multirow[t]{3}{*}{ Single Unit Transit Bus } & 25 \\
\hline & Front Overhang & -- & & 18 \\
\hline & Rear Overhang & 8 & & -- \\
\hline \multirow[t]{2}{*}{ Intercity Bus } & Wheelbase & 26.5 & \multirow[t]{2}{*}{ Motorcoach } & 27 \\
\hline & Rear Overhang & 8.5 & & 10 \\
\hline \multirow[t]{2}{*}{ Motor Home } & Wheelbase & 20 & \multirow[t]{2}{*}{ Recreational Vehicle } & 27 \\
\hline & Rear Overhang & 6 & & 16 \\
\hline 36-ft School Bus & \multirow[t]{2}{*}{ Rear Overhang } & 12 & \multirow[t]{2}{*}{ School Bus } & \multirow[t]{2}{*}{13} \\
\hline 40-ft School Bus & & 13 & & \\
\hline \multirow{4}{*}{$\begin{array}{l}\text { Passenger Car } \\
\text { and Camper } \\
\text { Trailer }\end{array}$} & Rear Overhang & 10.9 & $\begin{array}{l}\text { Passenger Vehicle and Trailer - } \\
\text { Commercial }\end{array}$ & \multirow[t]{2}{*}{27} \\
\hline & & & Passenger Vehicle and Trailer - Private & \\
\hline & \multirow[t]{2}{*}{ Wheelbase } & \multirow[t]{2}{*}{17.7} & $\begin{array}{l}\text { Passenger Vehicle and Trailer - } \\
\text { Commercial }\end{array}$ & \multirow[t]{2}{*}{20} \\
\hline & & & Passenger Vehicle and Trailer - Private & \\
\hline
\end{tabular}

The value of establishing design vehicles for the hang-up problem is demonstrated in the comparison of AASHTO design vehicles with the newly established vehicles. The effect that these dimensions can have when designing a roadway is significant.

The Single Unit Vehicle (SU) in AASHTO (2001) has a wheelbase of 20 feet. In the absence of this research the Single Unit Beverage Truck would all be represented by AASHTO's SU. However, the Single Unit Beverage Truck has a wheelbase of 24 feet. A driveway designed to accommodate these vehicles could be deficient if AASHTO's SU is used since single unit beverage trucks can have wheelbases up to $20 \%$ longer. 
The Single Unit Transit Bus has the same wheelbase length as the AASHTO (2001) City Transit Bus, but has a significant front overhang (18 feet) and no rear overhang while the AASHTO bus has no front overhang and a large rear overhang ( 8 feet). The Motorcoach design vehicle established from this research has a 0.5-foot longer wheelbase than AASHTO's Intercity Bus, and a 1.5-foot longer rear overhang than the AASHTO bus.

The AASHTO Motor Home had a wheelbase and rear overhang much shorter than the Recreational Vehicle dimensions, with a 7-foot longer wheelbase and 10-foot longer rear overhang. The research showed that there are actually two different vehicle types: a short RV (represented by AASHTO), and a long RV (represented by this research).

The school bus from the hang-up research had a longer rear overhang than AASHTO's (2001) 36-foot School Bus, but that rear overhang was the same as the 40-foot School Bus. The wheelbase of the bus, however, is 1.7 feet longer than either of AASHTO's school buses.

The AASHTO (2001) Passenger Car and Camper Trailer had both a smaller rear overhang and wheelbase than the Passenger Vehicle and Trailer-Private and Commercial. Relative to trailers, the longest wheelbase of 40 feet, belonging to the Belly Dump, Car Carrier, and Double-Drop Trailers. The Low-Boy Trailer had a length of 38 feet, and the Articulated Beverage Truck had a length of 30 feet. The AASHTO Green Book's longest wheelbase is 39.4 feet (belonging to the WB-65 semitrailer). The shortest wheelbase is the 23foot trailer used in double and triple trailer combinations.

\subsection{HANGUP SOFTWARE RUNS}

The results of the HANGUP analyses run using the design vehicles on the four test profiles are provided in Table 4.3. These results show how the design vehicles performed on 
high-profile alignments. The car carrier trailer hung-up on all of the alignments, and the low-boy and double-drop trailers hung-up on the ITE Driveway (6\% grade break) curve. The mini-bus, car carrier trailer, both passenger vehicles and trailers, and RV all hung-up on the Double Track Crossing alignment. Finally, the ITE sag driveway curve caused all of the vehicles to drag except the single unit transit bus, articulated beverage truck, double-drop trailer, and the belly dump trailer.

Table 4.3 - Results of HANGUP Analyses - Design Vehicles on Test Profiles

\begin{tabular}{|l|c|c|c|c|}
\hline \multicolumn{1}{|c|}{ Design Vehicle } & \multicolumn{4}{|c|}{ Hang-up on ... (Y/N) } \\
\cline { 2 - 5 } & $\begin{array}{c}\text { ITE } \\
\text { Driveway } \\
6 \% \text { grade } \\
\text { break })\end{array}$ & $\begin{array}{c}\text { AREMA } \\
\text { Rail } \\
\text { Crossing }\end{array}$ & $\begin{array}{c}2 \text { Track } \\
\text { Crossing }\end{array}$ & $\begin{array}{c}\text { ITE Sag } \\
\text { Driveway } \\
(15 \% \text { grade } \\
\text { break })\end{array}$ \\
\hline Rear-load Garbage Truck & N & N & N & Y \\
\hline Aerial Fire Truck & N & N & N & Y \\
\hline Pumper Fire Truck & N & N & N & Y \\
\hline Single Unit Beverage Truck & N & N & N & Y \\
\hline Mini-bus & N & N & Y & Y \\
\hline School Bus & N & N & N & Y \\
\hline Single Unit Transit Bus & N & N & N & N \\
\hline Motorcoach & N & N & N & Y \\
\hline Articulated Transit Bus & N & N & N & Y \\
\hline Articulated Beverage Truck & N & N & N & N \\
\hline Low-Boy Trailers <53 feet & Y & N & N & Y \\
\hline Double-Drop Trailer & Y & N & N & N \\
\hline Car Carrier Trailer & Y & Y & Y & Y \\
\hline Belly Dump Trailer & N & N & N & N \\
\hline Passenger Vehicles and Trailers - Private Use & N & N & Y & Y \\
\hline Passenger Vehicles and Trailers - Commercial Use & N & N & Y & Y \\
\hline Recreational Vehicles (RV) & N & N & Y & Y \\
\hline
\end{tabular}




\section{Chapter 5-Conclusions, Recommendations, Implementation}

\subsection{SUMMARY}

The problem with hang-ups on high profile alignments continues to afflict operators of long-wheelbase / overhang or low-ground-clearance vehicles. Property damage and loss of life due to crashes caused by the hang-up problem can be great, particularly at railroad-highway grade crossings. A review of existing roadway and vehicle standards revealed that those standards were not sufficient in addressing the hang-up problem. This study focused on the vehicle characteristics related to the hang-up problem. Additional guidance is needed by roadway designers and maintainers so they can provide roadways which reduce the susceptibility to hang-ups. This guidance comes in the form of specific vehicle characteristics, namely ground clearance, wheelbase and overhang, leading to the establishment of design vehicles specifically for the hang-up problem. The following vehicle properties and characteristics related to the hang-up problem were identified:

- ground clearance

- wheelbase length

- front and/or rear overhang length

- loading

- tire type and inflation

- angle of approach

- angle of departure

- breakover angle

Ground clearance and wheelbase and front or rear overhang lengths were identified as the defining characteristics of the design vehicle to be developed. To establish these characteristics for each design vehicle, data needed to be collected and analyzed. Once the data were collected, a methodology for establishing design vehicles was needed. A general methodology used by past researchers was identified from reviewed literature. 
This methodology was used to establish design vehicle dimensions for the following types of hang-up susceptible vehicles:

- Single Unit Truck

- Single Unit Beverage Truck

- Articulated Beverage Truck

- Rear-Load Garbage Truck

- Aerial Fire Truck

- Pumper Fire Truck

- Buses

- Mini-Bus

- School Bus

- Single Unit Transit Bus

- Articulated Transit Bus

- Motorcoach

- Trucks

- Low-Boy Trailer < 53 feet

- Double-Drop Trailer

- Car Carrier Trailer

- Belly Dump Trailer

- Recreational Vehicles

- Passenger Vehicle and Trailer - Private Use

- Passenger Vehicle and Trailer - Commercial Use

- Recreational Vehicle

For each vehicle, field collected and manufacturer data were used to establish dimensions for ground clearance, wheelbase, and front/rear overhang as appropriate, depending on where the vehicle experiences hang-up problems. The HANGUP software was used to assess the performance of the design vehicles on several recognized high-profile alignments. The results of this analysis were a key input in the establishment of the design vehicles.

The design vehicle dimensions for each vehicle type are provided in Table 5.1. 
Table 5.1 - Design Vehicle Dimensions

\begin{tabular}{|c|c|c|c|c|c|c|}
\hline \multirow{2}{*}{ Design Vehicles } & Wheelbase & \multicolumn{2}{|c|}{ Overhang (ft) } & \multicolumn{3}{|c|}{ Ground clearance (in) } \\
\cline { 4 - 7 } & $(\mathbf{f t})$ & Front & Rear & Wheelbase & Front & Rear \\
\hline Single Unit Trucks - & & & & & & \\
\hline Single Unit Beverage Truck & 24 & -- & 10 & 6 & -- & 8 \\
\hline Articulated Beverage Truck & 30 & -- & -- & 10 & -- & -- \\
\hline Rear-Load Garbage Truck & 20 & -- & 12.5 & 12 & -- & 14 \\
\hline Aerial Fire Truck & 20 & 7 & 12 & 9 & 11 & 10 \\
\hline Pumper Fire Truck & 22 & 8 & 10 & 7 & 8 & 10 \\
\hline Buses - & & & & & & \\
\hline Mini-Bus & 15 & -- & 16 & 10 & -- & 8 \\
\hline School Bus & 23 & -- & 13 & 7 & -- & 11 \\
\hline Single Unit Transit Bus & 25 & 18 & -- & 8 & 6 & -- \\
\hline Articulated Transit Bus & $22 / 26$ & -- & 10 & $10 / 10$ & -- & 9 \\
\hline Motorcoach & 27 & 7.6 & 10 & 7 & 10 & 8 \\
\hline Trucks - & & & & & & \\
\hline Low-Boy Trailers < 53 ft & 38 & -- & -- & 5 & -- & -- \\
\hline Double-Drop Trailer & 40 & -- & -- & 6 & -- & -- \\
\hline Car Carrier Trailer & 40 & -- & 14 & 4 & -- & 6 \\
\hline Belly Dump Trailer & 40 & -- & -- & 11 & -- & -- \\
\hline Recreational Vehicles - & & & & & & \\
\hline $\begin{array}{c}\text { Passenger Vehicle and Trailer - } \\
\text { Private Use }\end{array}$ & 20 & -- & 13 & 5 & -- & 5 \\
\hline $\begin{array}{c}\text { Passenger Vehicle and Trailer - } \\
\text { Commercial Use }\end{array}$ & $27(24$ to & -- & 13 & 7 & -- & 7 \\
\hline $\begin{array}{c}\text { Recreation Vehicle } \\
\text { hitch) }\end{array}$ & 27 & 7.8 & 16 & 7 & 6 & 8 \\
\hline
\end{tabular}

-- These vehicle characteristics were not susceptible to the hang-up problem, thus not reported.

\subsection{CONCLUSIONS}

\subsubsection{Conclusions Related to the Establishment of Design Vehicles}

Several conclusions related to the establishment of design vehicles were drawn from the research. First, a rational methodology for establishing design vehicles was identified. In general, the procedure is:

- Define Vehicle Categories from which design vehicles can be established.

- Define Relevant Dimensions / Characteristics

- Develop Data Collection Strategy

- Quantitatively Define 
Second, several constraints and considerations in implementing the general methodology were identified. From review of past efforts to establish design vehicles, the following constraints were observed:

- the specific needs for design vehicle information that is currently not available

- available resources to collect data

- reasonableness of the categories

Third, several considerations for establishing the number of design vehicles to be investigated were:

- the variation in the vehicle population, including types that emerge as unique

- the ramifications of using a limited number of vehicles to represent diverse sectors of the vehicle population

- local conditions, such as the prevalence of a certain vehicle in the local geographic area.

\subsubsection{Conclusions Specific to the Developed Design Vehicles}

First, it was noted that several design vehicles had dimensions larger than the comparable AASHTO design vehicles listed in the 2001 Green Book:

- Single Unit Beverage Truck

- Pumper Fire Truck

- Single Unit Bus

- Motorcoach

- School Bus

- Belly Dump Trailer

- Car Carrier Trailer

- Passenger Vehicle and Trailer - Private Use

- Passenger Vehicle and Trailer-Commercial Use

- Recreational Vehicle

This is significant when considering the implications on design or maintenance. A designer will consult the AASHTO Green Book for design vehicle dimensions to represent the vehicle population. In cases where the vehicles listed above are present in the population, the selected design vehicle from the AASHTO Green Book will not represent the above vehicles 
adequately, increasing the chances for hang-ups. Therefore, to reduce hang-up potential, the design vehicle established from this research should be included in the design and maintenance of a roadway.

Lastly, while the established dimensions for the design vehicles have not been qualified statistically, these design vehicles were established using a sound procedure, and sample sizes that were judged to be adequate. In cases such as the low-boy trailer, where a large variation existed and statistical parameters were used to establish design vehicle dimensions, a large sample size was collected. In other cases, where variability was limited and the researchers sought the worst-case dimensions, a virtually exhaustive survey of manufacturers almost certainly collected these data. While it is recognized that these design vehicles are not adopted by any appropriate agency and are used at the risk of the users, they are recommended for use with confidence.

Several limitations were noted during the research process. The geographic area where the vehicle data were collected is a limitation since field measurements were confined to West Virginia and Pennsylvania. Some vehicles, such as low-boys, are common to most areas in the nation. However, other vehicles with a similar hang-up potential may not be as common in one area as it is in another. For example, the belly dump trailer is widely used in other parts of the country but used infrequently in West Virginia. Other vehicles with hang-up susceptibility that are prevalent in specific parts of the country should be identified.

In addition, due to the nature of the vehicles involved, there are infinite combinations that cannot be accounted for by a limited number of design vehicles. For example, a recreational vehicle can be pulling an automobile and a boat trailer. An "over-sized" low-boy can be extended or lowered to accommodate special loads. These arrangements can affect the hang-up 
susceptibility of the units and are difficult to predict when designing a roadway for a specific design vehicle. Furthermore, trailers and vehicles can be modified by the owner or operator, thereby changing the hang-up susceptibility of the vehicle. Users of the design vehicles should be aware of this situation.

\subsection{RECOMMENDATIONS}

These design vehicle dimensions can be used in designing new vertical roadway profiles or adjusting existing ones to reduce the hang-up potential for the vehicles traveling over the profile. While these design vehicles have not been adopted by AASHTO, ITE, or any other authoritative body, it is recommended that these design vehicle dimensions be reviewed by these agencies so that they can be officially adopted.

Since the scope of the project was confined to the Mid-Atlantic region, there are likely vehicle types and configurations that were not included in the analysis. It is recommended that data be collected for low-ground-clearance vehicles in other parts of the United States.

\subsection{IMPLEMENTATION}

Users of these design vehicles must recognize that they have not been officially adopted by any authoritative body, and that they are to be used at their own risk. However, since they resulted from a quality research plan and effort, they are recommended for use immediately. It is also recommended that they be considered for official adoption by AASHTO, ITE, or other pertinent organizations. Once these design vehicles have been officially adopted, they can be used in several ways. 
The design vehicles established in this research should be disseminated to transportation agencies. This will allow designers to use the design vehicles and assist in the process of identifying vehicles and configurations not included in this analysis.

Minimum roadway geometric design standards can be developed for each design vehicle. For example, the minimum curve length or grade that the low-boy design vehicle can safely travel over without hanging-up can be documented in the AREMA standards for railroadhighway grade crossings, ITE recommendations for driveway design, and AASHTO standards for roadways. These standards can aid civil engineers in designing roadways and railroadhighway grade crossings with minimal hang-up potential.

In the interim, the design vehicles can be used in conjunction with analytical tools dealing with the hang-up problem. For example, the HANGUP software permits the user to input specific vehicular dimensions and roadway geometry. It was possible to enter specific vehicular dimensions into the software prior to the establishment of these design vehicles. However, the vehicles established in this research will provide designers with dimensions that represent the vehicle population, allowing the designers to simulate closely how a vehicle will travel over an alignment.

Finally, these vehicles can be used as the basis for a vertical alignment rating system. This system would use the design vehicles established here to determine which types of vehicles could or could not cross a particular geometry without becoming hung-up. The classification system can be used to measure the geometry at railroad-highway grade crossings and other vertical alignments where hang-ups can occur, which would be cross-referenced to the established design vehicles and their hang-up potential. In addition, this system could be used to rate a vehicle's hang-up potential. 
The benefits of such a rating system can be realized on several levels:

- Operation - This rating gives information to the truck driver that can be used to avoid hang-ups. By understanding the rating of an alignment, and the corresponding rating of the truck being driven, the driver will know if his or her truck can pass over the alignment without becoming hung-up.

- Highway Design - The crossing can be designed to a certain rating depending on prevailing truck traffic. Also, if a project modifies an existing crossing, the rating system can be used to determine if it has been improved or degraded.

- Trip Planning - A specific vehicle can plan routes that avoid crossings with ratings indicating that it can not be accommodated. Using a roadway mapping system similar to that used when routing permitted vehicles, routes can be developed for a vehicle.

- Highway Planning - The rating information can be used in most infrastructure management system to determine which crossings are in need of improvement. 


\section{REFERENCES}

American Association of State Highway and Transportation Officials. A Policy on Geometric Design of Highways and Streets. Washington, D.C.: AASHTO, 2001: 15-17, 26-27, 270279, 312, 313, 735-737.

American Association of State Highway and Transportation Officials. A Policy on Geometric Design of Highways and Streets. Washington, D.C.: AASHTO, 1994: 15-19.

American Association of State Highway and Transportation Officials. A Policy on Geometric Design of Highways and Streets. Washington, D.C.: AASHTO, 1990: 842-843.

American Association of State Highway and Transportation Officials. A Policy on Geometric Design of Highways and Streets. Washington, D.C.: AASHTO, 1984: iv, 21, 888-896.

American Association of State Highway Officials. A Policy on Geometric Design of Rural Highways. Washington, D.C.: AASHO, 1965: 86.

American Association of State Highway Officials. A Policy on Geometric Design of Rural Highways. Washington, D.C.: AASHO, 1954: 71-78.

American Association of State Highway and Transportation Officials. A Policy on Geometric Design of Urban Highways and Arterial Streets. Washington, D.C.: AASHTO, 1973: 269.

American Railway Engineering Administration. "Part 8: Highway-Railway Crossings." AREA Manual for Highway Engineering. Washington, D.C..: AREA, 1993.

Bauer, L. A. "Passenger Car Overhang and Underclearance as Related to Driveway Profile Design, Part II - Street and Highway Design." Bulletin 195. Washinton D.C.: National Research Council, 1958. 23-29.

Eck, Ronald W. and S.K. Kang. "Low-Clearance Vehicles at Rail-Highway Grade Crossings: An Overview of the Problem and Potential Solutions." Transportation Research Record 1327 (1991): 27-35.

Eck, Ronald W. and S.K. Kang. "Roadway Design Standards to Accommodate Low-Clearance Vehicles." Transportation Research Record 1356 (1992): 80-89.

Fambro, Daniel B., John M. Mason, Jr., Timothy R. Neuman. "Accommodating Larger Trucks at At-Grade Intersections." Guide for Monitoring and Enhancing Safety on the National Truck Network Federal Highway Administration: Office of Highway Safety (Oct. 1986).

Federal Highway Administration. Federal_Size Regulations for Commercial Motor Vehicles. Washington, D.C., 1996. 22 Jan. 2002 <http://www.ops.fhwa.dot.gov/ freight/ regulate/ sw/federall.pdf>. 
Tustin, B. H., H. Richards, H. McGee, and R. Patterson. Federal Highway Administration. Railroad-Highway Grade Crossing Handbook. Sept. 1986. 7 Sept. 2001 <http://www.fhwa.dot.gov/tfhrc/safety/pubs/86215/86215.pdf>.

Finkelstein, Robert. Federal Railroad Administration. "Re: information." E-mail to Amy Clawson. 8 Feb. 2002.

Gattis, J. L. and M.D. Howard. "School Bus Design Vehicle Dimensions.” FHWA/AR-98-008 Federal Highway Administration, Washington, D.C. (1999).

Hall, Jerome W. and Daniel S. Turner. "Development and Adoption of Early AASHO Design Criteria." Transportation Research Record 1612 (1998): 26-33.

Hartman, Bill. State Rail Authority, West Virginia Department of Transportation. "Re: Thesis Questions." E-mail to Amy Clawson. 25 Jan. 2002.

Institute of Transportation Engineers. Guidelines for Driveway Location \& Design. Washington D.C.: ITE Publications, 1987: 15-16.

Isaacson, Randy. "Standardized Testing - Chapter 14." P250 Education Psychology (Fall 2000) (5 June 2001) <http://www.iusb.edu/ edp250/P250CH14/P250\%20OH\%20Chapter \%2014\%20PDF\%20F2000.PDF>.

Klimek, Thomas. Truck Size \& Weight Team, Federal Highway Administration Truck Regulations. "Re: Information for Thesis." E-mail to Amy Clawson. 22 Jan. 2002.

McConnell, W.A. "Passenger Car Overhang and Underclearance as Related to Driveway Profile Design, Part 1 - Vehicle Data." Bulletin 195. Washington, D.C.: National Research Council, 1958. 14-23.

Mendenhall, William, Robert J. Beaver, Barbara M. Beaver. Introduction to Probability \& Statistics. 10th ed. New York: Brooks/Cole Publishing Company, 1999. 5, 48-50, 58.

National Transportation Safety Board. Collision of Amtrak Train No. 88 with Tractor Lowboy Semitrailer Combination. NTSB/RHR-84/01, 1984. 24 May 2001 <http://www.ntsb.gov/ Publictn/1984/RHR8401.htm>.

National Transportation Safety Board. Collision of Amtrak Train No. 88 with Rountree Transport and Rigging, Inc., Vehicle on CSX Transportation, Inc., Railroad Near Intercession City, Florida, November 30, 1993. Washington, D.C.: NTSB, 1995 a.

National Transportation Safety Board. "Highway/rail grade crossing collision near Sycamore, South Carolina." Highway Accident Report NSTB/HAR-96/01 (May 2, 1995 b): 31-32. 17 Sept. $2001<$ http://www.ntsb.gov/publictn/1996/har9601.pdf>. 
NCS Pearson, Inc. "Research Notes Part 2: Descriptive Statistics.” NCS Pearson Inc. 1996-2000 (6 June 2001) <http://www.ncspearson.com/ncscorp/research/95-12.htm>.

Skidplate4x4. Approach_and Departure Angles. 2001. 6 June 2001 <http://skidplate4x4.tripod.com/The_Breakover_Angle_explanation>.

U.S. Department of Transportation Grade Crossing Safety Task Force. "Accidents that Shouldn't Happen.” A Report of the Grade Crossing Safety Task Force to Secretary Federico Pena (1 March 1996) 30 May $2001<$ http://safety.fhwa.dot.gov/ fourthlevel/pdg/TaskForceReport.pdf $>$. 
APPENDIX A - Vehicle Dimension Database 
SINGLE UNIT BEVERAGE TRUCK

\begin{tabular}{|c|c|c|c|c|c|c|c|c|c|c|c|}
\hline $\begin{array}{l}\text { Rear } \\
\text { Overhang } \\
\text { (in) } \\
\end{array}$ & $\begin{array}{l}\text { Wheel } \\
\mathrm{f} \text { to } \mathrm{r} 1\end{array}$ & $\begin{array}{r}\text { ase (in) } \\
\text { r1 to r2 } \\
\end{array}$ & $\begin{array}{c}\text { Ground Cl } \\
\text { Between } \\
\text { Tires } \\
\end{array}$ & $\begin{array}{l}\text { arance (in) } \\
\text { Rear } \\
\text { Overhang } \\
\end{array}$ & $\begin{array}{l}\text { Drop } \\
\text { Length } \\
\text { (in) } \\
\end{array}$ & $\begin{array}{c}\text { Make/Model/ } \\
\text { Year } \\
\text { Body Manu. } \\
\end{array}$ & $\begin{array}{c}\text { No. } \\
\text { of } \\
\text { Bays }\end{array}$ & Picture? & $\begin{array}{l}\text { Anything Unusual? } \\
\text { [Small Tires, Flat Tires } \\
\text { Overloaded] }\end{array}$ & $\begin{array}{l}\text { Source } \\
(\mathrm{I}, \mathrm{P}, \text { or } \mathrm{F})\end{array}$ & $\begin{array}{l}\text { (Internet, Phone, Fie } \\
\text { Other } \\
\end{array}$ \\
\hline 90 & 252 & & 6 & 19 & & International & 6 & No & & $F(5 / 7 / 01)$ & \\
\hline 98 & 272 & & 6 & 18 & & Mickey & 5 & No & Load Bear Series-Grizzly & $F(5 / 10 / 01)$ & \\
\hline 84 & 254 & & 11 & 15 & & International & 6 & No & fully loaded & $\mathrm{F}(5 / 10 / 01)$ & I-79N Pitt \\
\hline 82 & 196 & & 14 & 12 & 99 & International & 4 & No & hauling $6045 \mathrm{lb}$ bottles & $\mathrm{F}(5 / 10 / 01)$ & I-79N Pitt \\
\hline 82 & 253 & & 16 & 18 & 156 & International & 6 & No & empty & $F(5 / 10 / 01)$ & I-79N Pitt \\
\hline 90 & 276 & & 10 & 10 & 180 & Chevy Diesel & 6 & No & & $\mathrm{F}(5 / 10 / 01)$ & I-79N Pitt \\
\hline 81 & 258 & & 10 & 17 & 160 & International & 6 & No & & $F(5 / 10 / 01)$ & Coke plant @ Houston \\
\hline 85 & 254 & & 10 & 21 & 157 & International & 6 & No & & $F(5 / 10 / 01)$ & ]Coke plant @ Houston \\
\hline 85 & 257 & & 10 & 20 & 156 & International & 6 & No & & $F(5 / 10 / 01)$ & Coke plant @ Houston \\
\hline & 295 & & 20 & & & Mickey & 7 & No & Manufacturer - worst case & $P(6 / 14 / 01)$ & \\
\hline 100 & 281 & & 16 & 21 & & Hackney & 5 & No & Columbia Propane - 12klbs & $F(7 / 10 / 01)$ & Star City \\
\hline
\end{tabular}

Based on the sample we have, the design vehicle dimensions would be as follows:

\begin{tabular}{cccccccc}
\hline $\begin{array}{c}\text { Rear } \\
\begin{array}{c}\text { Overhang } \\
\text { (in) }\end{array}\end{array}$ & $\begin{array}{c}\text { Wheel Base (in) } \\
\text { f to r1 }\end{array}$ & r1 to r2 & $\begin{array}{c}\text { Getween } \\
\text { Tires }\end{array}$ & $\begin{array}{c}\text { Rear } \\
\text { Overhang }\end{array}$ & $\begin{array}{c}\text { Drop } \\
\text { Length } \\
\text { (in) }\end{array}$ & $\begin{array}{c}\text { Max. \# } \\
\text { of bays } \\
\text { per side }\end{array}$ & worst case \\
\hline \hline 100 & 295 & 0 & 6 & 10 & 180 & 7 & average \\
88 & 259 & 0 & 12 & 17 & 151 & 6 & best case \\
81 & 196 & 0 & 20 & 21 & 99 & 4 &
\end{tabular}

sample size $=12$ 
ARTICULATED BEVERAGE TRUCK

\begin{tabular}{|c|c|c|c|c|c|c|c|c|c|c|c|c|c|}
\hline No. & $\begin{array}{l}\text { Wheel B } \\
\text { f to } 11\end{array}$ & $\begin{array}{l}\text { ase (in) } \\
r 1 \text { to } r 2\end{array}$ & r2 to $\mathrm{r} 3$ & $r 3$ to $r 4$ & $\begin{array}{c}\text { Ground Clearance } \\
\text { Between } \\
\text { Tires (in) }\end{array}$ & $\begin{array}{l}\text { Length of } \\
\text { Drops } \\
\text { (in) }\end{array}$ & $\begin{array}{l}\text { Make/ Model } \\
\text { Year } \\
\text { Body Manu. }\end{array}$ & $\begin{array}{l}\text { No. } \\
\text { of } \\
\text { Bays }\end{array}$ & $\begin{array}{l}\text { Tractor Type/ } \\
\text { characteristics }\end{array}$ & Picture? & $\begin{array}{l}\text { Anything Unusual? } \\
\text { [Small Tires, Flat Tires } \\
\text { Overloaded] }\end{array}$ & $\begin{array}{l}\text { Source } \\
(\mathrm{I}, \mathrm{P}, \text { or } \mathrm{F})\end{array}$ & $\begin{array}{l}\text { (Internet, Phone, Field) } \\
\text { Other }\end{array}$ \\
\hline $\begin{array}{ll}1 \\
1\end{array}$ & 10144 & 292 & $\begin{array}{r}32 \\
\end{array}$ & & 12 & & Mickey & 7 & Freightliner & No & & $F(5 / 7 / 01)$ & \\
\hline 2 & 149 & 342 & & & 10 & 271 & Mickey load bear 2000 & 8 & International & No & & $F(5 / 10 / 01)$ & I-79 N Pitt \\
\hline 3 & & 372 & & & 13 & 291 & Mickey load bear 2000 & 9 & Sterling & No & $1 / 3$ load & $F(5 / 10 / 01)$ & I-79 N Pitt \\
\hline 4 & & 326 & & & 12.5 & 290 & Mickey load bear 2000 & 9 & Mack & No & $3 / 4$ load & $F(5 / 10 / 01)$ & I-79 N Pitt \\
\hline 5 & & 327 & 46 & & 11 & 246 & Mickey load bear 2000 & 10 & Mack & No & full load & $F(5 / 10 / 01)$ & I-79 N Pitt \\
\hline 6 & 156 & 327 & & & 11.5 & 245 & Mickey load bear 2000 & 8 & Mack & No & & \begin{tabular}{|l|}
$F(5 / 10 / 01)$ \\
\end{tabular} & Coke plant @ Houston \\
\hline 7 & & 340 & & & 14 & 343 & Mickey load bear 2000 & 8 & International & No & & $F(5 / 10 / 01)$ & Coke plant @ Houston \\
\hline 8 & & 358 & & & 14 & & Mickey & 13 & & No & worst case & $\mathrm{P}(6 / 14 / 01)$ & $\overline{\text { manufacturer }}$ \\
\hline 9 & & 310 & & & 14 & 231 & Mickey & 8 & International & No & $3 / 4$ Full & $F(7 / 9 / 01)$ & $1-64$ \\
\hline
\end{tabular}

Based on the sample we have, the design vehicle dimensions would be as follows:

\begin{tabular}{|c|c|c|c|c|c|c|c|}
\hline $\begin{array}{l}\text { Wheel } \\
\text { f to } 11\end{array}$ & $\begin{array}{l}\text { ase (in) } \\
\mathrm{r} 1 \text { to } 2\end{array}$ & $\mathrm{r} 2$ to $\mathrm{r} 3$ & r3 to $r 4$ & $\begin{array}{c}\text { Ground Clearance } \\
\text { Between } \\
\text { Tires (in) } \\
\end{array}$ & $\begin{array}{l}\text { Length of } \\
\text { Drops } \\
\text { (in) }\end{array}$ & $\begin{array}{l}\text { Max. \# } \\
\text { of bays } \\
\text { per side }\end{array}$ & \\
\hline 156 & 372 & 46 & 0 & 10 & 343 & 13 & worst case \\
\hline 150 & 333 & 39 & 0 & 12 & 274 & 8 & average \\
\hline 144 & 292 & 32 & 0 & 14 & 231 & 7 & best case \\
\hline
\end{tabular}


REAR LOAD GARBAGE TRUCK

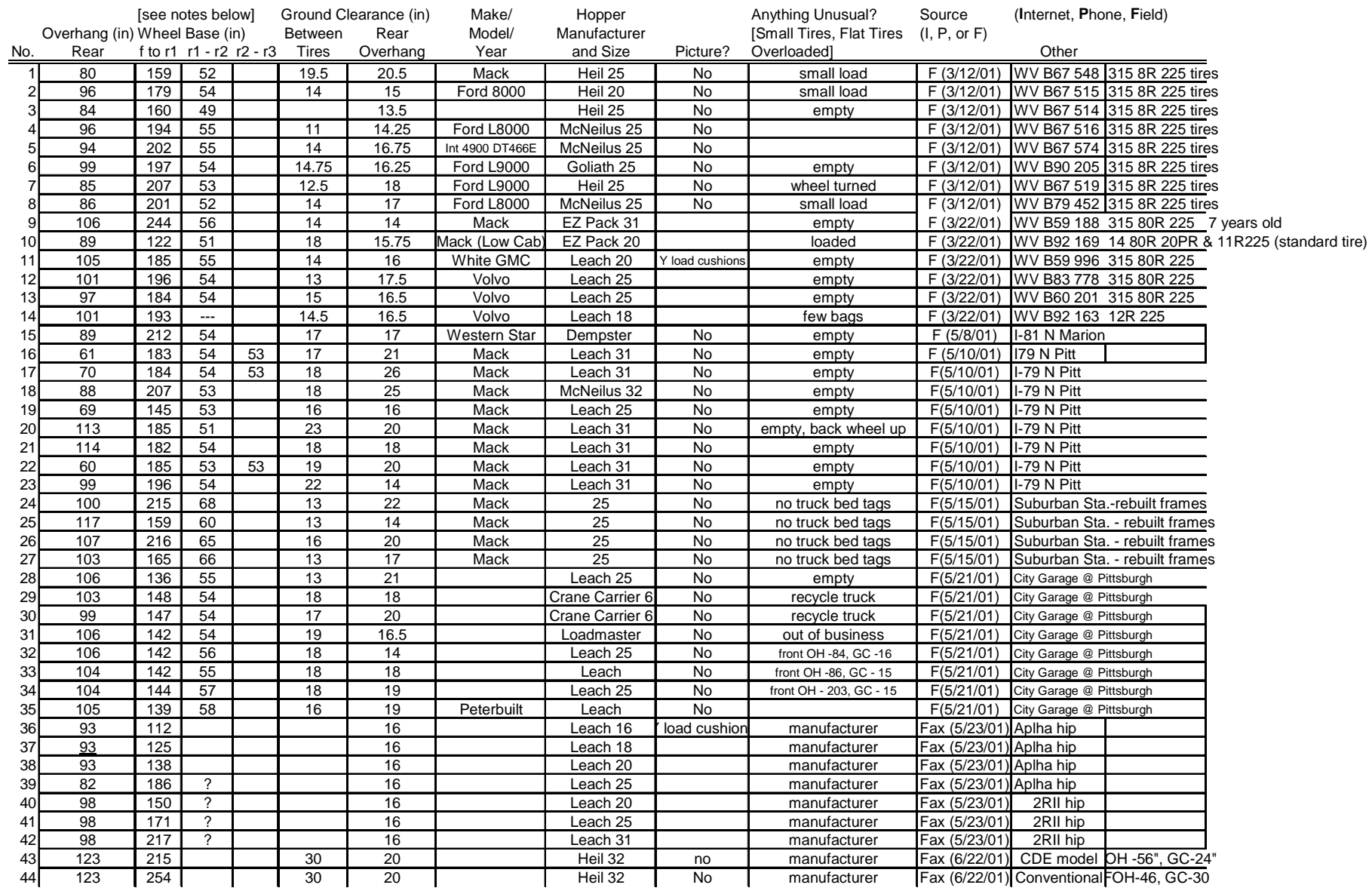

Based on the sample we have, the design vehicle dimensions would be as follows:

\begin{tabular}{|c|c|c|c|c|c|c|}
\hline $\begin{array}{l}\text { Overhang (in) } \\
\text { Rear }\end{array}$ & $\begin{array}{l}\text { Wheel } \\
\text { f to } r 1\end{array}$ & $\begin{array}{l}\text { Base } \\
\mathrm{r} 1-\mathrm{r} 2\end{array}$ & $\begin{array}{l}\text { in) } \\
\text { r2 }-r 3\end{array}$ & $\begin{array}{c}\text { Between } \\
\text { Tires } \\
\end{array}$ & $\begin{array}{c}\text { Rear } \\
\text { Overhang }\end{array}$ & \\
\hline 123 & 254 & 68 & 53 & 11 & 13.5 & \\
\hline 96 & 176 & 55 & 53 & 17 & 18 & average \\
\hline 60 & 112 & 49 & 53 & 30 & 26 & best case \\
\hline
\end{tabular}




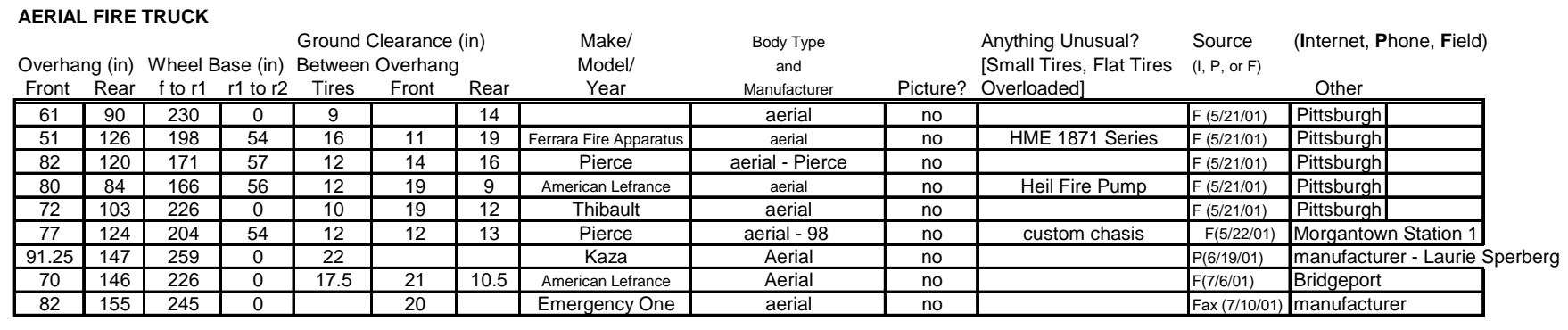

Based on the sample we have, the design vehicle dimensions would be as follows:

Overhang (in) Wheel Base (in) Between Overhang

Front Rear $\mathrm{fto} r$ 1 $\mathrm{r} 1$ to $\mathrm{r} 2$ Tires Front Rear

\begin{tabular}{cccccccc}
\hline \hline 91.25 & 155 & 259 & 57 & 9 & 11 & 9 & worst case \\
74 & 122 & 214 & 25 & 14 & 17 & 13 & average \\
70 & 122 & 213.89 & 55 & 14 & 17 & 13 & average without zeros \\
51 & 84 & 166 & 0 & 23 & 21 & 19 & best case
\end{tabular}

sample size $=$

13 average without zeros

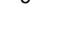




\section{PUMPER FIRE TRUCK}

\begin{tabular}{|c|c|c|c|c|c|c|c|c|c|c|c|c|c|}
\hline \multicolumn{3}{|c|}{ Overhang (in) } & \multicolumn{2}{|c|}{$\begin{array}{l}\text { [see notes below] } \\
\text { Wheel Base (in) }\end{array}$} & \multicolumn{3}{|c|}{$\begin{array}{l}\text { Ground Clearance (in) } \\
\text { Between Overhang }\end{array}$} & $\begin{array}{l}\text { Make/ } \\
\text { Model/ }\end{array}$ & \multicolumn{2}{|l|}{$\begin{array}{l}\text { Body Type (see below) } \\
\text { and }\end{array}$} & \multirow{2}{*}{$\begin{array}{l}\text { Anything Unusual? } \\
\text { [Small Tires, Flat Tires } \\
\text { Overloaded] }\end{array}$} & \multirow[t]{2}{*}{$\begin{array}{l}\text { Source } \\
(\mathrm{I}, \mathrm{P}, \text { or } \mathrm{F})\end{array}$} & (Internet, Phone, Field \\
\hline No. & Front & Rear & $f$ to $r 1$ & $r 1$ to $r 2$ & Tires & Front & Rear & Year & Manufacturer & Picture? & & & Other \\
\hline 1 & 0 & 120 & 254 & 56 & 20 & & 20 & American Lefrance & worst case design & no & & P-Chief engin & רeer (Randy) 5/16/01 \\
\hline 2 & 87 & 81 & 184 & 0 & 13 & 14 & 11 & 3D Manufacturer & Pumper & no & & $\mathrm{F}(5 / 21 / 01)$ & Pittsburgh \\
\hline 3 & 0 & 101 & 200 & 0 & 14 & & 13 & \begin{tabular}{|l|} 
Chevy 70 diesel \\
\end{tabular} & MAC & no & & $F(5 / 21 / 01)$ & Pittsburgh \\
\hline 4 & 72 & 87 & 157 & 0 & 10 & & 16 & \begin{tabular}{|l|} 
Pierce \\
\end{tabular} & Pumper & no & & $F(5 / 21 / 01)$ & Pittsburgh \\
\hline 5 & 82 & 78 & 180 & 0 & 7 & 8 & 10 & American Lefrance & Pumper & no & & $\mathrm{F}(5 / 21 / 01)$ & Pittsburgh \\
\hline 6 & 88 & 86 & 171 & 0 & 11 & 18 & 14 & Pierce & Pumper & no & & $F(5 / 21 / 01)$ & Pittsburgh \\
\hline 7 & 0 & 87 & 235 & 0 & 11 & & 10 & Pierce & Pumper & no & 2 wheel drive & $F(5 / 22 / 01)$ & Morgantown Station 1 \\
\hline 8 & 87 & 86 & 229 & 0 & 10.5 & 17.5 & 17 & Pierce & Pumper & no & & $F(5 / 27 / 01)$ & Black Lick, PA \\
\hline 9 & 0 & 30 & 220 & 0 & 16 & & & Emergency One & two worst case & no & & $P(6 / 19 / 01)$ & manufacturer \\
\hline 10 & 87 & 92 & 175 & 0 & 22 & & & Kaza & Pumper & no & & $\mathrm{P}(6 / 19 / 01)$ & manufacturer - Laurie \\
\hline 11 & 95 & 84 & 191 & 0 & 12 & 9.5 & 23 & Pierce & pumper & no & & $\mathrm{F}(7 / 6 / 01)$ & Bridgeport \\
\hline 12 & 75 & 87 & 192 & 0 & 12 & 19 & 10.5 & Pierce & pumper & no & & $\mathrm{F}(7 / 6 / 01)$ & Bridgeport \\
\hline 13 & 56 & 98 & 258 & 54 & 19 & & 18 & Freightliner & pumper & no & & $F(7 / 10 / 01)$ & Blacksville \\
\hline 14 & 56 & 84 & 194 & 0 & 14 & 21 & 10 & Ford 8000 Gruman & pumper & no & & $F(7 / 10 / 01)$ & Blacksville \\
\hline
\end{tabular}

Based on the sample we have, the design vehicle dimensions would be as follows:

Overhang (in) Wheel Base (in) Between Overhang

\begin{tabular}{|c|c|c|c|c|c|c|c|}
\hline 列 & & & & \multicolumn{3}{|c|}{ 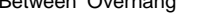 } & \\
\hline Front & Rear & $\mathrm{f}$ to $\mathrm{r} 1$ & $\mathrm{r} 1$ to $\mathrm{r} 2$ & Tires & Front & Rear & \\
\hline 95 & 120 & 258 & 56 & 7 & 8 & 10 & worst case \\
\hline 56 & 86 & 203 & 8 & 14 & 15 & 14 & average \\
\hline 65 & 86 & 215 & 55 & 14 & 15 & 14 & average without zeros \\
\hline 0 & 30 & 157 & 0 & 22 & 21 & 23 & best case \\
\hline san & e size $=$ & 16 & & & & & \\
\hline
\end{tabular}


MINI BUS

\begin{tabular}{|c|c|c|c|c|c|c|c|c|c|c|c|c|c|}
\hline \multicolumn{3}{|c|}{ Overhang (in) } & \multirow{2}{*}{$\begin{array}{l}\text { Wheel } \\
\text { Base (in) } \\
\text { f to } r 1\end{array}$} & \multicolumn{2}{|c|}{ Ground Clearance (in) } & \multicolumn{2}{|r|}{ Make/ } & Low & \multirow[b]{2}{*}{ City } & \multirow[b]{2}{*}{ Picture? } & \multirow{2}{*}{$\begin{array}{l}\text { Anything Unusual? } \\
\text { [Small Tires, Flat Tires } \\
\text { Overloaded] }\end{array}$} & \multirow[t]{2}{*}{$\begin{array}{l}\text { Source } \\
(\mathrm{I}, \mathrm{P}, \text { or F) }\end{array}$} & \multirow{2}{*}{$\begin{array}{l}\text { (Internet, Phone, Field) } \\
\text { Other }\end{array}$} \\
\hline No. & Front & Rear & & Tires & Front & Rear & Year & Floor? & & & & & \\
\hline 1 & 0 & 1117 & 204 & 10 & & 18 & International 3400 T444E & No & Pittsburgh & No & Airport Shuttle (3rd kind) & $\overline{F(5 / 21 / 01)}$ & \\
\hline 2 & 0 & 60 & 176 & 8 & & & Girardin & No & Manufacturer & No & Airport Shuttle (3rd kind) & $\mathrm{P}(6 / 19 / 01)$ & \\
\hline 3 & 30 & 70 & 187 & 12 & & & Thor (El Dorado Nat.) & No & \begin{tabular}{|l|} 
Manufacturer \\
\end{tabular} & No & Airport Shuttle (3rd kind) & \begin{tabular}{|l}
$\mathrm{P}(6 / 19 / 01)$ \\
\end{tabular} & \\
\hline 4 & 0 & 85 & 158 & 11.5 & & & Glaval & No & Manufacturer & Yes & Airport Shuttle (3rd kind) & $\mathrm{P}(6 / 21 / 01)$ & Universal Model \\
\hline 5 & 0 & 95 & 176 & 11.5 & & & Glaval & No & \begin{tabular}{|l|} 
Manufacturer \\
\end{tabular} & & Airport Shuttle (3rd kind) & \begin{tabular}{|l|}
$\mathrm{P}(6 / 21 / 01)$ \\
\end{tabular} & Universal Model \\
\hline 6 & 0 & 85 & 186 & 11.5 & & & Glaval & No & Manufacturer & & Airport Shuttle (3rd kind) & $\begin{array}{l}\mathrm{P}(6 / 21 / 01) \\
\end{array}$ & Universal Model \\
\hline
\end{tabular}

Based on the sample we have, the design vehicle dimensions would be as follows:

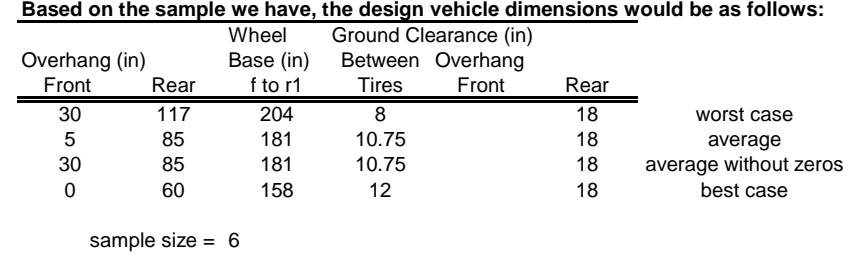




\section{SCHOOL BUS}

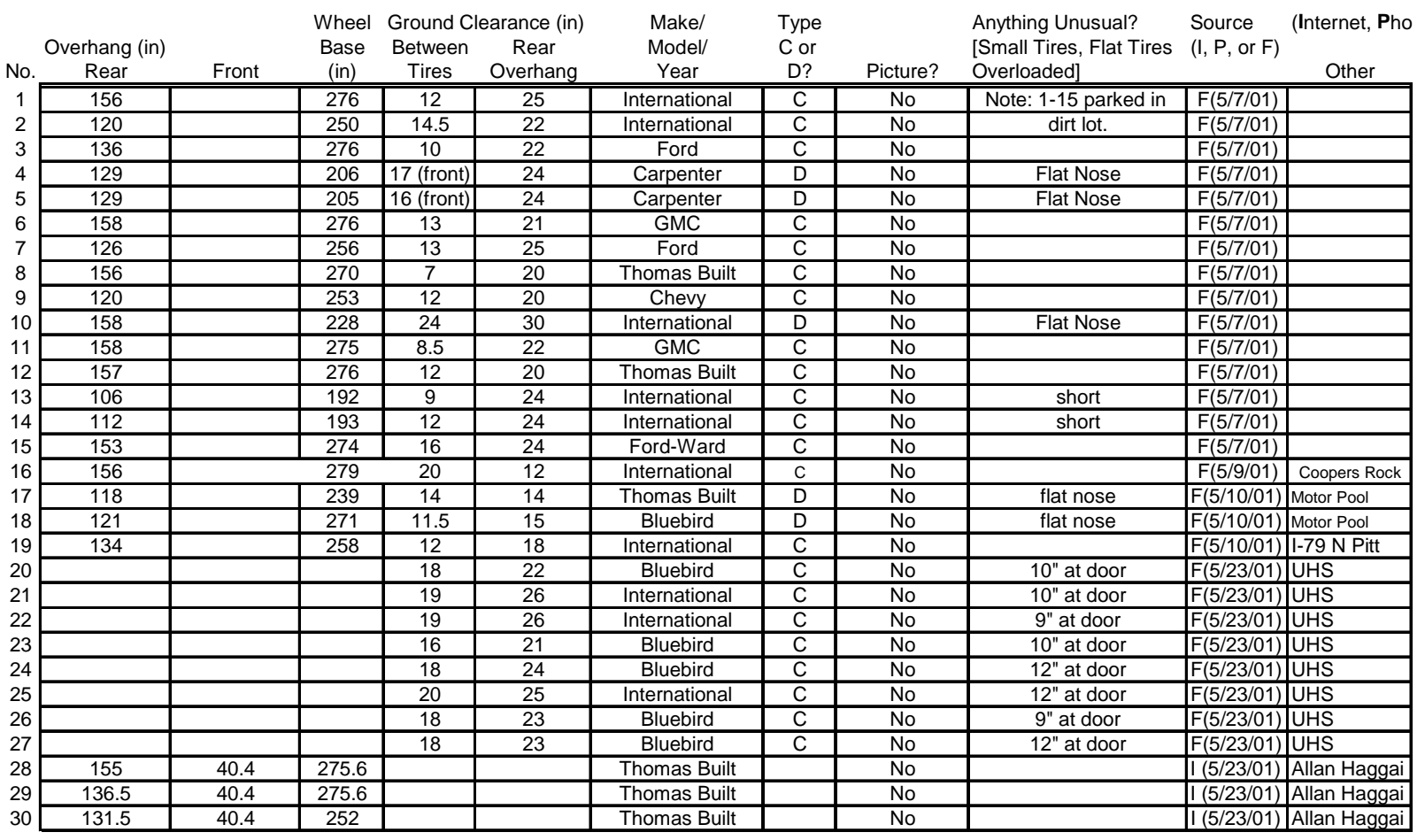

Based on the sample we have, the design vehicle dimensions would be as follows:

\begin{tabular}{cccccc}
\hline \multirow{2}{*}{$\begin{array}{c}\text { Overhang (in) } \\
\text { Rear }\end{array}$} & Front & Base & \multicolumn{2}{c}{ Wheel } & \multicolumn{2}{c}{ Ground Clearance (in) } \\
Between & $\begin{array}{c}\text { Rear } \\
\text { Tires }\end{array}$ & \\
Overhang & \\
\hline \hline 158 & 40.4 & 279 & 7 & 12 & worst case \\
138 & 40 & 253 & 15 & 22 & average \\
106 & 40.4 & 192 & 24 & 30 & best case
\end{tabular}

sample size $=30$ 
SINGLE UNIT TRANSIT BUS

\begin{tabular}{|c|c|c|c|c|c|c|c|c|c|c|c|c|c|c|}
\hline & Overhan & (in) & $\begin{array}{l}\text { Wheel } \\
\text { Base (in }\end{array}$ & & $\begin{array}{l}\text { Ground } \\
\text { Betwee }\end{array}$ & $\begin{array}{l}\text { learanc } \\
\text { Overha }\end{array}$ & $\begin{array}{l}\text { (in) } \\
\text { gg }\end{array}$ & $\begin{array}{l}\text { Make/ } \\
\text { Model/ }\end{array}$ & Low & & & $\begin{array}{l}\text { Anything Unusual? } \\
\text { [Small Tires, Flat Tires }\end{array}$ & $\begin{array}{l}\text { Source } \\
(I, P, \text { or } F)\end{array}$ & (Internet, P \\
\hline No. & Front & Rear & $\mathrm{f}$ to $\mathrm{r} 1$ & $\mathrm{r} 1$ to $\mathrm{r} 2$ & Tires & Front & Rear & Year & Floor? & City & Picture? & Overloaded] & & Other \\
\hline 1 & 0 & 84 & 156 & & 11 & & 12 & Ford-E & No & Mo'town & No & \begin{tabular}{|l} 
(small bus) \\
\end{tabular} & $\mathrm{F}(5 / 7 / 01)$ & \\
\hline 2 & 0 & 84 & 158 & & 11 & & 12 & Ford-E & No & Mo'town & No & (small bus) & $\mathrm{F}(5 / 7 / 01)$ & \\
\hline 3 & 214 & 100 & 180 & & 4 & 9 & 12 & Flxible & No & Mo'town & No & & $\mathrm{F}(5 / 7 / 01)$ & \\
\hline 4 & 98 & 102 & 180 & & 9 & 15 & 8 & Flxible & No & Mo'town & No & & $\mathrm{F}(5 / 7 / 01)$ & \\
\hline 5 & 0 & 100 & 189 & & & 16 & 12 & Wheeled Coach & No & Mo'town & No & & $\mathrm{F}(5 / 7 / 01)$ & \\
\hline 6 & 0 & 102 & 192 & & 16 & & 12 & Wheeled Coach & No & Mo'town & No & & $\mathrm{F}(5 / 7 / 01)$ & \\
\hline 7 & 53 & 112 & 178 & & 10 & 17 & 12 & Goshen Coach & No & Mo'town & No & & $\mathrm{F}(5 / 7 / 01)$ & \\
\hline 8 & 52 & 72 & 180 & & 8.5 & 12 & 12 & Goshen Coach & No & Mo'town & No & & $\mathrm{F}(5 / 7 / 01)$ & \\
\hline 9 & 54 & 99 & 210 & & 6 & 10 & 14 & Holland Bus & No & Mo'town & No & & $\mathrm{F}(5 / 7 / 01)$ & \\
\hline 10 & 60 & 96 & 211 & & 6 & 11 & 19 & Holland Bus & No & Mo'town & No & & $\mathrm{F}(5 / 7 / 01)$ & \\
\hline 11 & 88 & 114 & 285 & & 10 & 11 & 11 & Nova Classic & No & Pittsburgh & No & Classic model & $\mathrm{F}(5 / 21 / 01)$ & \\
\hline 12 & 100 & 118 & 276 & & 11 & 10 & 10 & 99 Neoplan lowfloor & Yes & Pittsburgh & No & & $F(5 / 21 / 01)$ & \\
\hline 13 & 84 & 102 & 300 & & 12 & 6 & 10 & Flxible & No & Pittsburgh & No & & $F(5 / 21 / 01)$ & \\
\hline 14 & 90 & 116 & 282 & & 9 & 7 & 7 & 91 Orion & No & Pittsburgh & No & & $\mathrm{F}(5 / 21 / 01)$ & \\
\hline 15 & 90 & 120 & 270 & & 8.5 & 8 & 6 & 87 Neoplan & No & Pittsburgh & No & & $\mathrm{F}(5 / 21 / 01)$ & \\
\hline 16 & 84 & 126 & 270 & 52 & 11 & 13 & 9 & 01 Neoplan Metroliner & No & Pittsburgh & No & & $\mathrm{F}(5 / 21 / 01)$ & \\
\hline 17 & 86 & 118 & 264 & & 23 & 13 & 18 & Nabi & No & Manufacturer & Yes & Model 416 & $\mathrm{I}(5 / 22 / 01)$ & \\
\hline 18 & 86 & 118 & 276 & & 24 & 13 & 18 & Nabi & Yes & Manufacturer & Yes & Model 40LFLW & $\mathrm{I}(5 / 22 / 01)$ & \\
\hline 19 & 91 & 123 & 275 & & 20 & 14 & 19 & Nabi & No & Manufacturer & Yes & Model 40C-LFW Compobus & $\mathrm{I}(5 / 22 / 01)$ & \\
\hline 20 & 26 & 101 & 245 & & 21 & 15 & 16 & Nabi & No & Manufacturer & Yes & Model 30-LFN & $\mathrm{I}(5 / 22 / 01)$ & \\
\hline 21 & 93.5 & 103.5 & 231.5 & 52 & 20 & 13 & 18 & Neoplan & No & Manufacturer & Yes & AN340/3 40' & $\mathrm{I}(5 / 22 / 01)$ & \\
\hline 22 & 93.5 & 118 & 274.5 & 54 & 24 & 13 & 20 & Neoplan & No & Manufacturer & Yes & AN340/3 45' & $\mathrm{I}(5 / 22 / 01)$ & \\
\hline 23 & 95.5 & 102 & 231.5 & 52.5 & 18 & 16 & 17 & Neoplan & No & Manufacturer & Yes & AN 116/3 40' & $\mathrm{I}(5 / 22 / 01)$ & \\
\hline 24 & 95.5 & 116 & 274.5 & 54 & 21 & 16 & 20 & Neoplan & No & Manufacturer & Yes & AN 116/3 45' & $\mathrm{I}(5 / 22 / 01)$ & \\
\hline 25 & 93.25 & 120.75 & 205.75 & & 18 & 13 & 19 & Neoplan & No & Manufacturer & Yes & $\mathrm{AN} 435$ & $\mathrm{I}(5 / 22 / 01)$ & \\
\hline 26 & 93.25 & 120.75 & 266 & & 23 & 13 & 19 & Neoplan & No & Manufacturer & Yes & AN440 & $\mathrm{I}(5 / 22 / 01)$ & \\
\hline 27 & 93 & 113 & 214 & & 18 & 13 & 17 & Neoplan & Yes & Manufacturer & Yes & AN435LF & $\mathrm{I}(5 / 22 / 01)$ & \\
\hline 28 & 93 & 113 & 274 & & 24 & 13 & 17 & Neoplan & Yes & Manufacturer & Yes & AN440LF & $\mathrm{I}(5 / 22 / 01)$ & \\
\hline 29 & 93 & 113 & 274 & & 24 & 13 & 17 & Neoplan & Yes & Manufacturer & No & AN440TLF & $\mathrm{I}(5 / 22 / 01)$ & \\
\hline 30 & 93 & 113 & 334 & & 29 & 13 & 17 & Neoplan & Yes & Manufacturer & No & AN445TLF & $\mathrm{I}(5 / 22 / 01)$ & \\
\hline 31 & 60 & 107 & 168 & & & & & Holland Bus & No & Manufacturer & Yes & Classic American Series 26' & $\operatorname{Fax}(5 / 16 / 01)$ & \\
\hline 32 & 60 & 112 & 208 & & & & & Holland Bus & No & Manufacturer & Yes & Classic American Series 31' & $\operatorname{Fax}(5 / 16 / 01)$ & \\
\hline 33 & 95 & 128 & 267 & & & & & Holland Bus & No & Manufacturer & Yes & Classic American Series 40' & $\operatorname{Fax}(5 / 16 / 01)$ & \\
\hline 34 & 104 & 126 & 190 & & 29 & 18 & 22 & Holland Bus & No & Manufacturer & Yes & Rear engine trolley & $\operatorname{Fax}(5 / 16 / 01)$ & \\
\hline 35 & 101 & 124 & 268 & & & & & Nova RTS Express & No & Manufacturer & No & & $I(6 / 14 / 01)$ & \\
\hline 36 & 91 & 90 & 298.7 & & 26 & 12 & 15 & Nova RTS & No & Manufacturer & No & & $\mathrm{I}(6 / 14 / 01)$ & \\
\hline 37 & 112.3 & 123.5 & 244 & & 20 & 17 & 19 & Nova LFS & Yes & Manufacturer & No & & I (6/14/01) & \\
\hline 38 & 51 & 118 & 176 & & 15 & 10 & 20 & Chance Coach, Inc & No & Manufacturer & Yes & american heritage streetcar & $I(6 / 15 / 01)$ & \\
\hline 39 & 90 & 106 & 163.5 & & 12 & 13 & 19 & Chance Coach, Inc & Yes & Manufacturer & Yes & Opus low floor bus & $\mathrm{I}(6 / 15 / 01)$ & \\
\hline 40 & 81.5 & 118.5 & 151 & & 22 & 11 & 16 & Bluebird & No & Manufacturer & Yes & 29' Q-bus & $I(6 / 15 / 01)$ & \\
\hline 41 & 81.5 & 118.5 & 221 & & 19 & 12 & 15 & Bluebird & No & Manufacturer & Yes & 35' Q-bus & $\mathrm{I}(6 / 15 / 01)$ & \\
\hline 42 & 51 & 118 & 176 & & 21 & 10 & 20 & Chance Coach, Inc & No & Manufacturer & No & american heritage streetcar & $\mathrm{P}(6 / 19 / 01)$ & \\
\hline 43 & 90 & 106 & 163 & & 14 & 13 & 16 & Chance Coach, Inc & No & Manufacturer & No & opus & $\mathrm{P}(6 / 19 / 01)$ & \\
\hline 44 & 42.75 & 107.25 & 178 & & & & & Goshen Coach & No & Manufacturer & No & & $\mathrm{P}(6 / 19 / 01)$ & \\
\hline 45 & 0 & 128 & 208 & & 11.5 & & & Glaval & No & Manufacturer & Yes & Apollo - longest & $\mathrm{P}(6 / 21 / 01)$ & \\
\hline 46 & 0 & 128 & 218 & & 11.5 & & & Glaval & No & Manufacturer & & & $\mathrm{P}(6 / 21 / 01)$ & \\
\hline 47 & 0 & 128 & 234 & & 11.5 & & & Glaval & No & Manufacturer & & & $\mathrm{P}(6 / 21 / 01)$ & \\
\hline
\end{tabular}

Based on the sample we have, the design vehicle dimensions would be as follows:

\begin{tabular}{|c|c|c|c|c|c|c|c|}
\hline \multirow{2}{*}{\multicolumn{2}{|c|}{ Overhang (in) }} & \multirow{2}{*}{\multicolumn{2}{|c|}{$\begin{array}{l}\text { Wheel } \\
\text { Base (in) }\end{array}$}} & \multicolumn{4}{|c|}{ Ground Clearance (in) } \\
\hline & & & & Betwee & Overha & & \\
\hline Front & Rear & $\mathrm{f}$ to $\mathrm{r} 1$ & $r 1$ to $r 2$ & Tires & Front & Rear & \\
\hline 214 & 128 & 334 & 54 & 4 & 6 & 6 & worst case \\
\hline 72 & 111 & 227 & 53 & 16 & 13 & 15 & average \\
\hline 85 & 111 & 227 & 53 & 16 & 13 & 15 & average without zeros \\
\hline 0 & 72 & 151 & 52 & 29 & 18 & 22 & best case \\
\hline
\end{tabular}


ARTICULATED TRANSIT BUS

\begin{tabular}{|c|c|c|c|c|c|c|c|c|c|c|c|c|c|c|}
\hline \multicolumn{3}{|c|}{ Overhang (in) } & \multicolumn{2}{|c|}{ Wheel Base (in) } & \multicolumn{3}{|c|}{$\begin{array}{l}\text { Ground Clearance (in) } \\
\text { Between Overhang }\end{array}$} & \multirow{2}{*}{$\begin{array}{l}\text { Make/ } \\
\text { Model/ } \\
\text { Year }\end{array}$} & Low & \multirow[b]{2}{*}{ City } & \multirow[b]{2}{*}{ Picture? } & \multirow{2}{*}{$\begin{array}{l}\text { Anything Unusual? } \\
\text { [Small Tires, Flat Tires } \\
\text { Overloaded] }\end{array}$} & \multirow{2}{*}{$\begin{array}{l}\text { Source } \\
(\mathrm{I}, \mathrm{P} \text {, or } \mathrm{F})\end{array}$} & \multirow{2}{*}{$\begin{array}{l}\text { (Internet, Phone, Field) } \\
\text { Other }\end{array}$} \\
\hline No. & Front & Rear & $\mathrm{f}$ to $\mathrm{r} 1$ & r2 to $\mathrm{r} 3$ & Tires & Front & Rear & & Floor? & & & & & \\
\hline 1 & 99 & 117 & 264 & 236 & 10 & 9 & 9 & 92 IKARUS & No & Pittsburgh & No & aka Naby & $F(5 / 21 / 01)$ & to hinge - $159 "$ ", GC - 12" \\
\hline 2 & 96 & 120 & 207 & 300 & 14 & 9 & 9 & 99 Neoplan & No & Pittsburgh & No & & $F(5 / 21 / 01)$ & to hinge - 220", GC - 11" \\
\hline 3 & 100 & 116 & 264 & 232 & 20 & 15 & 19 & Nabi & No & Manufacturer & Yes & Model 436 & I (5/22/01) & \\
\hline 4 & 93.25 & 120.75 & 209.19 & 297.19 & 18 & 13 & 19 & Neoplan & No & Manufacturer & Yes & AN 460 & I (5/22/01) & \\
\hline 5 & 47.5 & 49 & 170 & 212 & & & & Chance Coach Inc & No & Manufacturer & Yes & AMTV & I (6/15/01) & $\mathrm{ROH} 1=93.5, \mathrm{FOH} 2=50$ \\
\hline 6 & 0 & 0 & 228.2 & 306.4 & 21 & $9 \mathrm{D}$ & $9 \mathrm{~d}$ & New Flyer & yes & Manufacturer & Yes & D 60 LF & $I(6 / 25 / 01)$ & need info \\
\hline 7 & 0 & 0 & 208 & 309 & & & & New Flyer & No & Manufacturer & Yes & \begin{tabular}{|l} 
D $60 \mathrm{HF}$ \\
\end{tabular} & $I(6 / 25 / 01)$ & need info \\
\hline
\end{tabular}

Based on the sample we have, the design vehicle dimensions would be as follows:

Overhang (in) Wheel Base (in) Between Overhang

Overhang (in) Wheel Base (in) Between Overhang

\begin{tabular}{cccccccc} 
Front & Rear & $\mathrm{f}$ to $\mathrm{r} 1$ & $\mathrm{r} 2$ to $\mathrm{r} 3$ & Tires & Front & Rear & \\
\hline \hline 100 & 120.75 & 264 & 309 & 10 & 9 & 9 & worst case \\
62 & 75 & 221 & 270 & 17 & 12 & 14 & average \\
87 & 105 & 221 & 270 & 16 & 12 & 14 & average without zeros \\
0 & 0 & 170 & 212 & 21 & 15 & 19 & best case \\
\multicolumn{2}{l}{ sample size $=7$} & & & & & \\
\end{tabular}




\begin{tabular}{|c|c|c|c|c|c|c|c|c|c|c|c|c|c|}
\hline \multicolumn{14}{|c|}{ MOTORCOACH } \\
\hline \multirow{2}{*}{\multicolumn{3}{|c|}{ Overhang (in) }} & \multirow{2}{*}{\multicolumn{2}{|c|}{$\begin{array}{l}\text { Wheel } \\
\text { Base (in) }\end{array}$}} & \multirow{2}{*}{\multicolumn{3}{|c|}{$\begin{array}{l}\text { Ground Clearance (in) } \\
\text { Between Overhang }\end{array}$}} & \multirow{2}{*}{\multicolumn{2}{|c|}{$\begin{array}{l}\text { Make/ } \\
\text { Model/ }\end{array}$}} & & \multirow{3}{*}{$\begin{array}{l}\text { Anything Unusual? } \\
\text { [Small Tires, Flat Tires } \\
\text { Overloaded] }\end{array}$} & \multirow{3}{*}{$\begin{array}{l}\text { Source } \\
(\mathrm{I}, \mathrm{P} \text {, or } \mathrm{F})\end{array}$} & \multirow{3}{*}{$\begin{array}{c}\text { (Internet, } \mathbf{P h} \\
\text { Other }\end{array}$} \\
\hline & & & & & & & & & & & & & \\
\hline No. & Front & Rear & f to $r 1$ & $r 1$ to $r 2$ & Tires & Front & Rear & Year & Carrier & Picture? & & & \\
\hline 1 & - & $254 / 81$ & 280 & 49 & 13.5 & 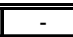 & 15 & $\mathrm{MCl}$ & & No & no passengers & $\mathrm{F}(4 / 30 / 01)$ & \\
\hline 2 & 65 & 92 & 260 & & 8 & 15 & 8 & $\mathrm{MCl}$ & & No & no passengers & $\mathrm{F}(5 / 10 / 01)$ & \\
\hline 3 & 71 & 77 & 283 & 46 & 10 & 15 & 11 & $\mathrm{MCl}$ & & No & no passengers & $F(5 / 10 / 01)$ & \\
\hline 4 & 82 & 84 & 288 & 60 & 12 & 13 & 8 & Prevost & & No & no passengers & $F(5 / 14 / 01)$ & \\
\hline 5 & 82 & 84 & 288 & 60 & 12 & 13 & & Prevost & & No & no passengers & $F(5 / 14 / 01)$ & \\
\hline 6 & 78.25 & 150.25 & 315 & & & & & $\mathrm{MCl} \mathrm{E} 4500$ & & No & Manufacturer & $\mathrm{I}(6 / 12 / 01)$ & \\
\hline 7 & 78.25 & 150.25 & 315 & & & & & $\mathrm{MCl} \mathrm{J} 4500$ & & No & Manufacturer & $\mathrm{I}(6 / 12 / 01)$ & \\
\hline 8 & 75.9 & 131.5 & 318 & & & & & $\mathrm{MCl} \mathrm{D} 4000$ & & No & Manufacturer & $I(6 / 12 / 01)$ & \\
\hline 9 & 75.9 & 153.1 & 318 & & & & & MCI D4500 & & No & Manufacturer & $\mathrm{I}(6 / 12 / 01)$ & \\
\hline 10 & 92.2 & 118.9 & 214 & & & & & $\mathrm{MCI} F 3500$ & & No & Manufacturer & $I(6 / 12 / 01)$ & \\
\hline 11 & 84.1 & 83.5 & 315 & & & & & $\mathrm{MCl} \mathrm{G} 4500$ & & No & Manufacturer & $\mathrm{I}(6 / 12 / 01)$ & \\
\hline 12 & 70.7 & 107 & \begin{tabular}{|l|}
317 \\
\end{tabular} & & 11 & & & Prevost & & No & Manufacturer & $\mathrm{P}(6 / 19 / 01)$ & XLII-45 model \\
\hline 13 & 69.25 & 103.5 & 316.1 & & 11 & & & Prevost & & No & Manufacturer & $\mathrm{P}(6 / 19 / 01)$ & H3-45 model \\
\hline 14 & 71.5 & 103.5 & 268 & & 11 & & & Prevost & Jerry & No & Manufacturer & $\operatorname{Fax}(6 / 20 / 01)$ & H3-41 model \\
\hline 15 & 70.75 & 82.5 & 279 & & 11 & & & Prevost & Jerry & No & Manufacturer & $\operatorname{Fax}(6 / 20 / 01)$ & XLII-40 model \\
\hline 18 & 73 & 100 & 312 & 48 & 11 & 11 & 11.5 & Prevost & & No & shell bus - private coach & $\mathrm{F}(7 / 2 / 01)$ & H3-45 model \\
\hline
\end{tabular}

\begin{tabular}{|c|c|c|c|c|c|c|c|}
\hline \multirow{3}{*}{\multicolumn{2}{|c|}{$\begin{array}{l}\text { Based on the sa } \\
\text { Overhang (in) } \\
\text { Front Rear }\end{array}$}} & \multirow{2}{*}{\multicolumn{2}{|c|}{$\begin{array}{l}\text { Wheel } \\
\text { Base (in) }\end{array}$}} & \multirow{2}{*}{\multicolumn{3}{|c|}{$\begin{array}{l}\text { Ground Clearance (in) } \\
\text { Between Overhang }\end{array}$}} & \multirow{6}{*}{$\begin{array}{c}\text { worst case } \\
\text { average } \\
\text { best case }\end{array}$} \\
\hline & & & & & & & \\
\hline & & $\mathrm{f}$ to $\mathrm{r} 1$ & $\mathrm{r} 1$ to $\mathrm{r} 2$ & Tires & Front & Rear & \\
\hline 92.2 & 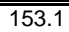 & 318 & 60 & 7 & 10 & 8 & \\
\hline 76 & 109 & 294 & 53 & 11 & 13 & 10 & \\
\hline \multirow[t]{2}{*}{65} & 77 & 214 & 46 & 13.5 & 15 & 15 & \\
\hline & Sar & $z e=$ & 18 & & & & \\
\hline
\end{tabular}




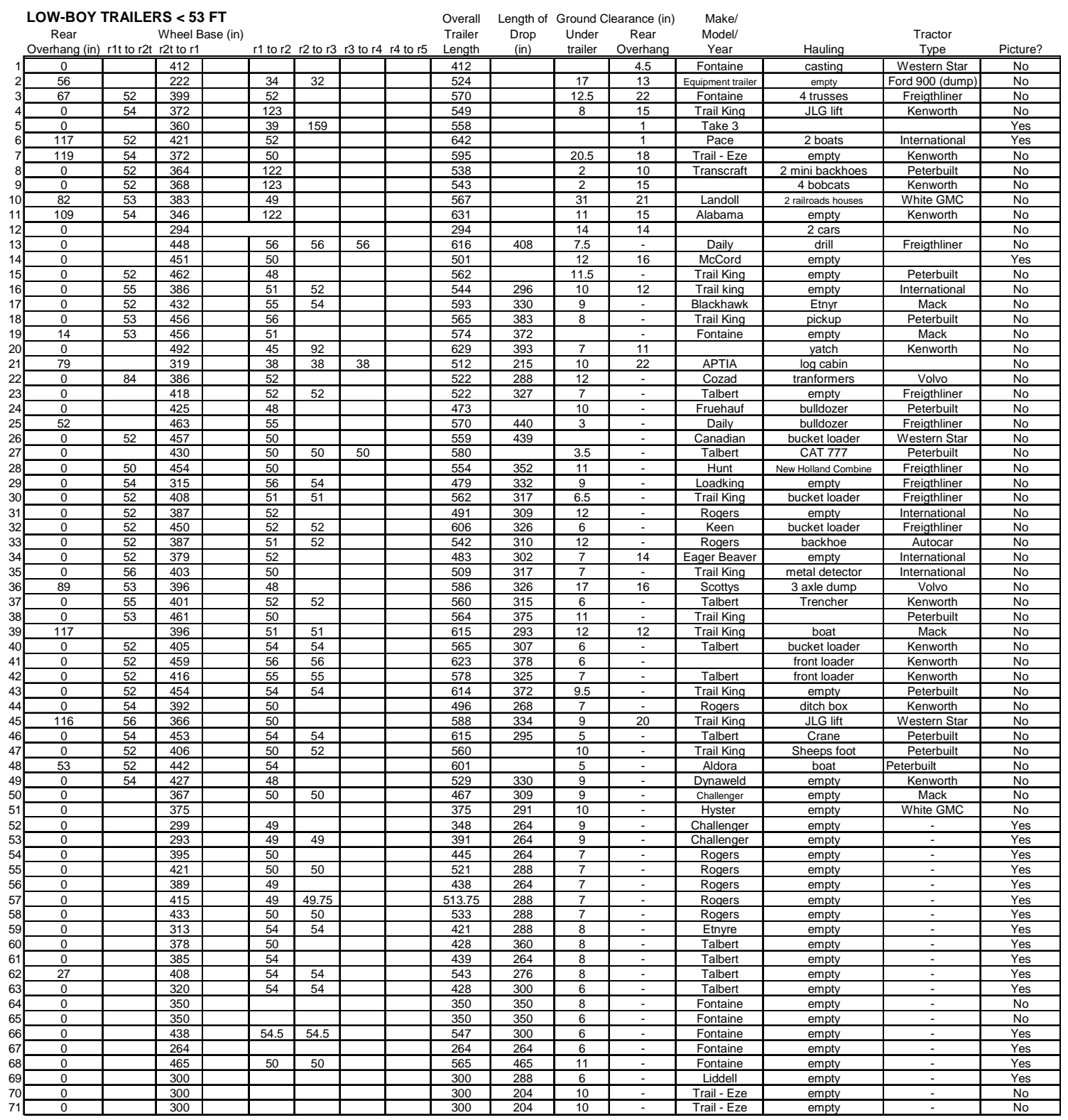




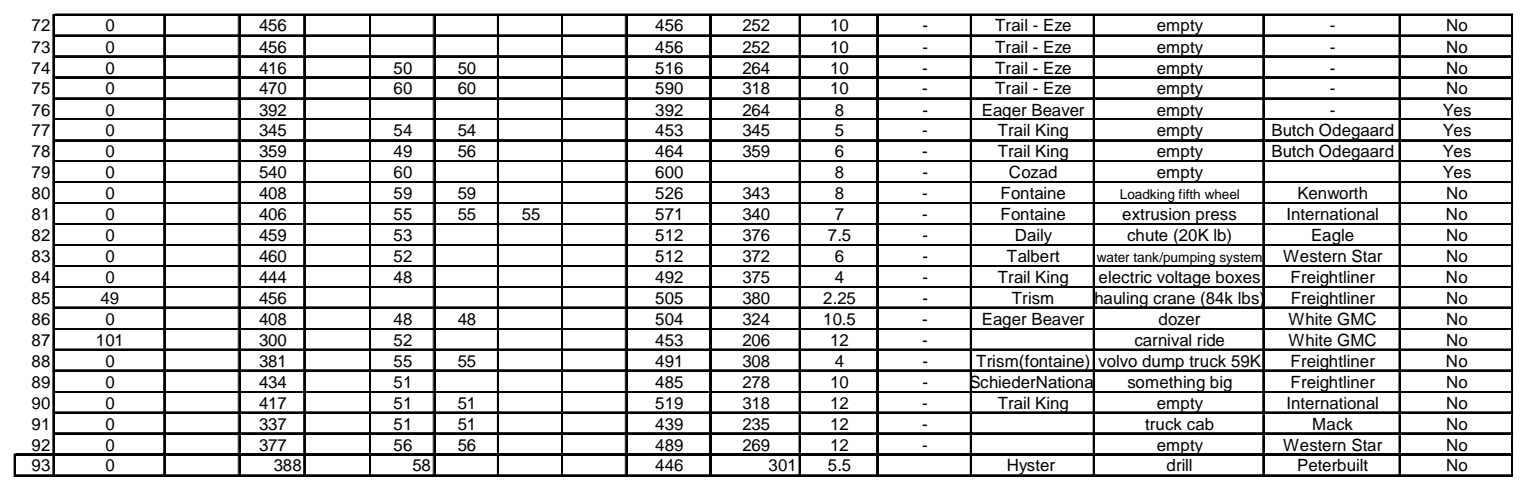

Based on the sample we have, the design vehicle dimensions would be as follows:

\begin{tabular}{|c|c|c|c|c|c|c|c|c|c|c|c|}
\hline $\begin{array}{c}\text { Rear } \\
\text { Overhang (in) }\end{array}$ & r1t to $r 2 t$ & $\begin{array}{l}\text { Wheel Base (in) } \\
\mathrm{t} \text { r2t to } r 1\end{array}$ & $\mathrm{r} 1$ to $\mathrm{r} 2$ & $2 \mathrm{r} 2$ to $\mathrm{r} 3$ & $r 3$ to $r 4$ & $\mathrm{r} 4$ to $\mathrm{r} 5$ & $\begin{array}{l}\text { Overall } \\
\text { Trailer } \\
\text { Length }\end{array}$ & $\begin{array}{l}\text { Length of } \\
\text { Drop } \\
\text { (in) }\end{array}$ & $\begin{array}{l}\text { Ground C } \\
\text { Under } \\
\text { trailer }\end{array}$ & $\begin{array}{c}\text { Clearance (in) } \\
\text { Rear } \\
\text { Overhang }\end{array}$ & \\
\hline 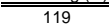 & $\begin{array}{l}84 \\
\end{array}$ & $\begin{array}{l}540 \\
\end{array}$ & "123 & 159 & $\begin{array}{l}56 \\
\end{array}$ & $\begin{array}{ll}0 \\
0\end{array}$ & 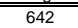 & 4665 & 2 & 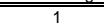 & worst case \\
\hline 13 & 54 & 397 & 55 & 56 & 50 & 0 & 508 & 315 & 9 & 14 & average \\
\hline 0 & 50 & 222 & 34 & 32 & 38 & 0 & 264 & 204 & 31 & 22 & best case \\
\hline
\end{tabular}

sample size $=\quad 93$ 


\section{DOUBLE-DROP TRAILER}

Wheel Base (in)

Ground Clearance Length of

Between Over hang Drop

Make/

Specia

No. Belly Anything Unusual?

of Box [Small Tires, Flat Tires

Source (Internet, Phone, Fie No. $r 1$ to $r 2 r 2$ to $r 3 r 3$ to $r 4 r 4$ to r5 Overhang

(in)

Year (livestock, moving, etc) Drops Add-on? Overloaded]

(I, P, or F)

Other Picture?

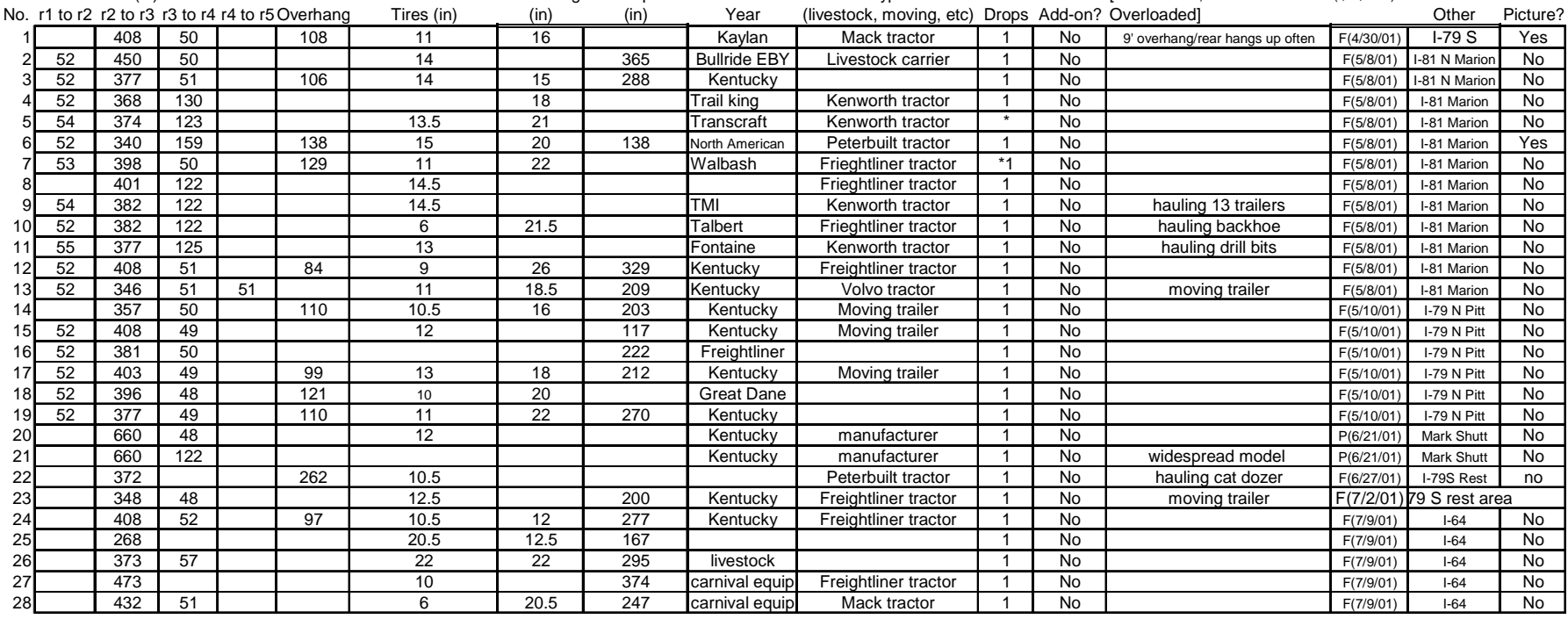

Based on the sample we have, the design vehicle dimensions would be as follows:

\begin{tabular}{|c|c|c|c|c|c|c|c|c|}
\hline \multirow{2}{*}{\multicolumn{2}{|c|}{ Wheel Base (in) }} & \multirow{3}{*}{$r 3$ to $r 4$} & \multirow{3}{*}{\multicolumn{2}{|c|}{$\begin{array}{c}\text { Rear } \\
4 \text { to r5 Overhang }\end{array}$}} & \multicolumn{2}{|c|}{ Ground Clearance } & \multirow{3}{*}{$\begin{array}{l}\text { Length of } \\
\text { Drop } \\
\text { (in) }\end{array}$} & \multirow[b]{4}{*}{ worst case } \\
\hline & & & & & Between & Over hang & & \\
\hline$r 1$ to $r 2$ & r2 to r3 & & & & Tires (in) & & & \\
\hline 255 & (2660 & 159 & 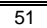 & 20262 & 6 & 12 & 374 & \\
\hline 53 & 405 & 75 & 51 & 124 & 12 & 19 & 245 & average \\
\hline 52 & 268 & 48 & 51 & 84 & 22 & 26 & 117 & best case \\
\hline \multicolumn{2}{|r|}{ size $=$} & 31 & & & & & & \\
\hline
\end{tabular}




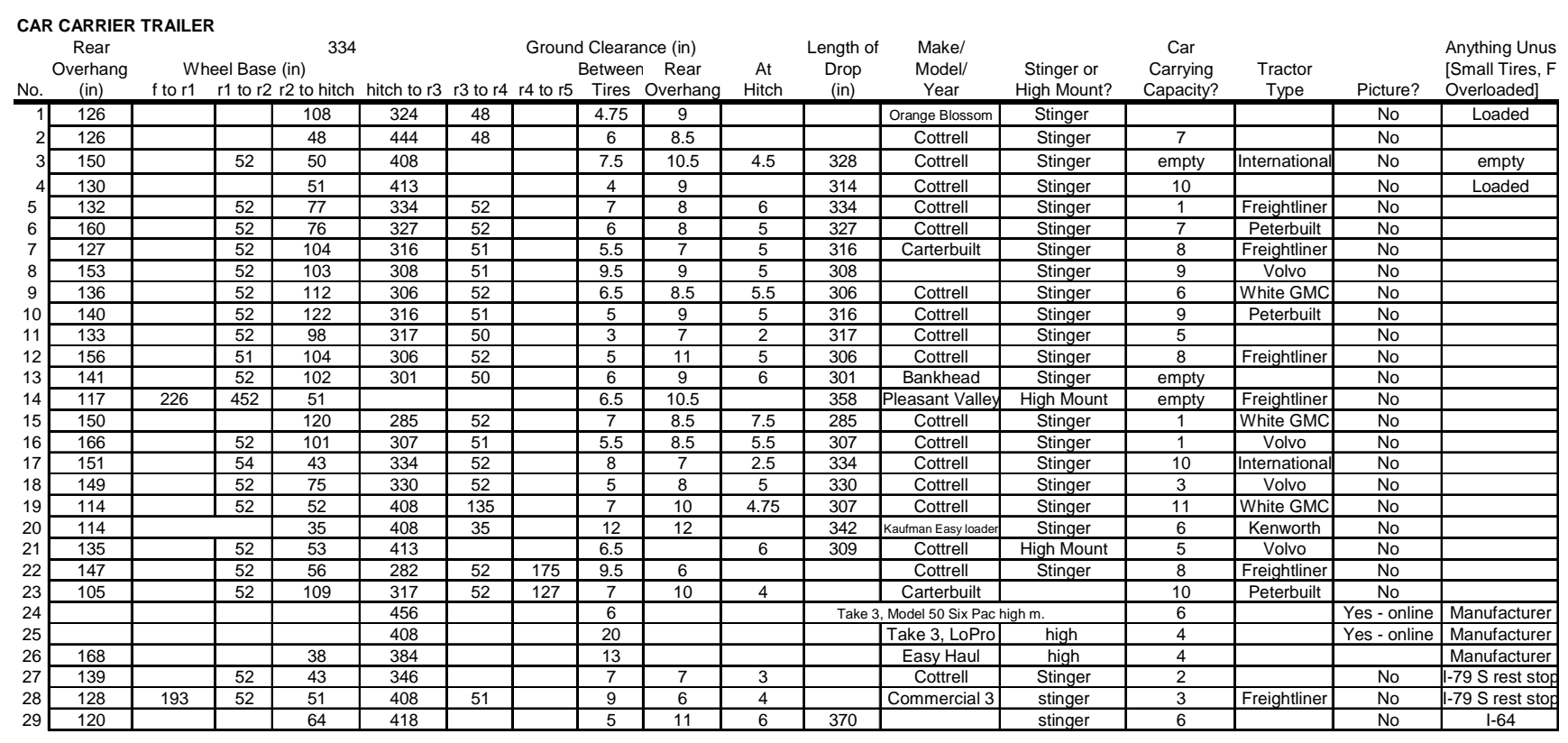

Based on the sample we have, the design vehicle dimensions would be as follows:

\begin{tabular}{|c|c|c|c|c|c|c|c|c|c|c|c|}
\hline \multirow{3}{*}{$\begin{array}{c}\text { Rear } \\
\text { Overhang } \\
\text { (in) } \\
\end{array}$} & \multirow[b]{3}{*}{$\mathrm{f}$ to $\mathrm{r} 1$} & \multirow{2}{*}{\multicolumn{2}{|c|}{ Wheel Base (in) }} & \multirow{3}{*}{ hitch to $\mathrm{r} 3$} & \multicolumn{4}{|c|}{ Ground Clearance (in) } & \multirow{3}{*}{$\begin{array}{c}\text { At } \\
\text { Hitch }\end{array}$} & \multirow{3}{*}{$\begin{array}{l}\text { Length of } \\
\text { Drop } \\
\text { (in) } \\
\end{array}$} & \multirow[b]{4}{*}{ worst case } \\
\hline & & & & & & & Betweer & en Rear & & & \\
\hline & & $\mathrm{r} 1$ to $\mathrm{r} 2$ & r2 to hitch & & $\mathrm{r} 3$ to $\mathrm{r} 4$ & $\mathrm{r} 4$ to $\mathrm{r} 5$ & Tires & Overhang & & & \\
\hline 168 & 226 & 54 & 122 & 456 & 135 & 175 & 3 & 6 & 2 & 370 & \\
\hline 138 & 210 & 72 & 76 & 354 & 54 & 151 & 7 & 9 & 5 & 321 & average \\
\hline \multirow{2}{*}{105} & 193 & 51 & 35 & 282 & 35 & 127 & 20 & 12 & 7.5 & 285 & best case \\
\hline & samp & size $=$ & 29 & & & & & & & & \\
\hline
\end{tabular}


BELLY DUMP TRAILER

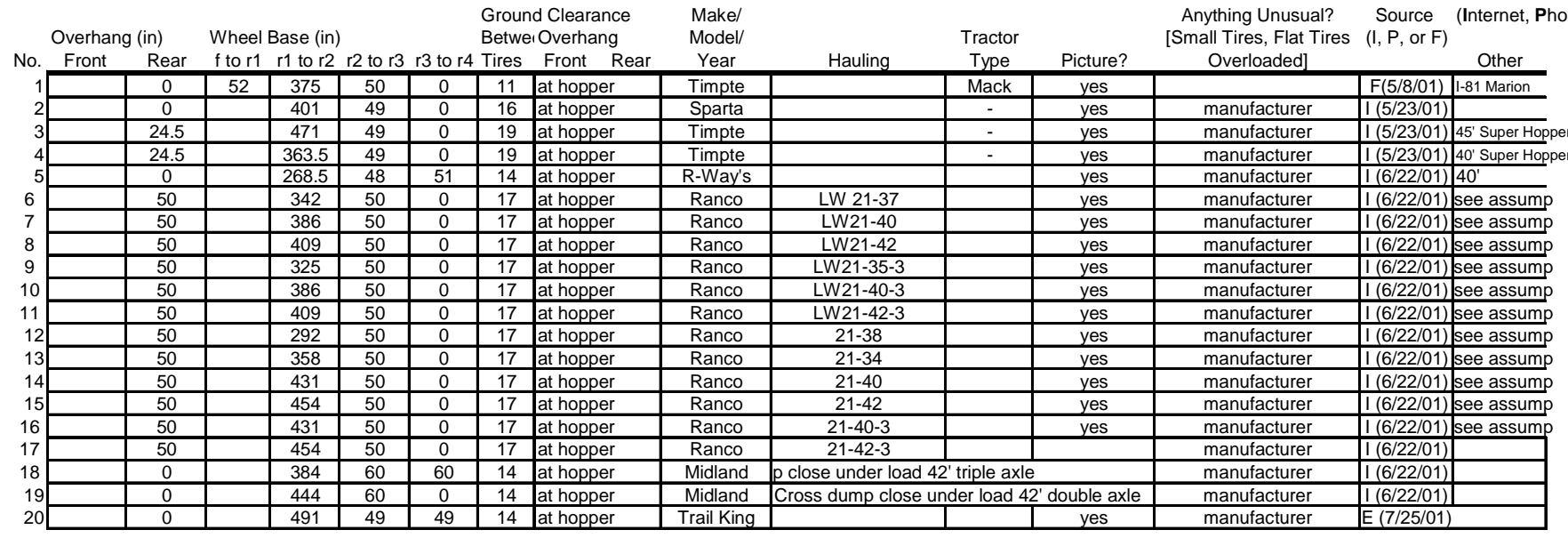

Based on the sample we have, the design vehicle dimensions would be as follows:

\begin{tabular}{|c|c|c|c|c|c|c|c|}
\hline \multicolumn{2}{|c|}{ Overhang (in) } & \multicolumn{2}{|c|}{ Wheel Base (in) } & \multirow{2}{*}{ r2 to r3 } & \multirow{2}{*}{ r3 to $r 4$} & \multirow{2}{*}{\multicolumn{2}{|c|}{ Ground Clearanc }} \\
\hline Front & Rear & $f$ to $r 1$ & $r 1$ to $r 2$ & & & & d Clearance \\
\hline 0 & 50 & 252 & $4 \quad 491$ & 6 & 60 & 11 & worst case \\
\hline 0 & 32 & 52 & 394 & 51 & 8 & 16 & average \\
\hline 0 & 46 & 52 & 394 & 51 & 53 & 16 & average without zeros \\
\hline 0 & 0 & 52 & 268.5 & 48 & 0 & 19 & best case \\
\hline
\end{tabular}

sample size $=20$ 


\section{PASSENGER VEHICLE \& TRAILER - PRIVATE USE}

\begin{tabular}{|c|c|c|c|c|c|c|c|c|c|c|c|c|c|c|}
\hline No. & $\begin{array}{l}\text { Rear } \\
\text { Overhang (in) }\end{array}$ & $\begin{array}{l}r t=r e a r \\
\text { Wheel } \\
r \text { to rt1 }\end{array}$ & $\begin{array}{l}\text { trailer wheels } \\
\text { Base (in) } \\
\text { rt1 to rt2 }\end{array}$ & $\begin{array}{l}\text { Length } \\
\text { to } \\
\text { hitch (in) }\end{array}$ & $\begin{array}{l}\text { Ground } \\
\text { Between } \\
\text { Tires }\end{array}$ & $\begin{array}{l}\text { Clearance(in) } \\
\text { Rear } \\
\text { Overhang }\end{array}$ & $\begin{array}{l}\text { Make/ } \\
\text { Model/ } \\
\text { Year }\end{array}$ & $\begin{array}{l}\text { Car } \\
\text { Type }\end{array}$ & Hauling & Picture? & $\begin{array}{l}\text { Location } \\
\text { (if field } \\
\text { measured) }\end{array}$ & $\begin{array}{l}\text { Anything Unusual? } \\
\text { [Small Tires, Flat Tires } \\
\text { Overloaded] }\end{array}$ & $\begin{array}{l}\text { Source } \\
(\mathrm{I}, \mathrm{P}, \text { or } \mathrm{F})\end{array}$ & $\begin{array}{l}\text { (Internet, } \\
\text { Phone, Field) } \\
\text { Other }\end{array}$ \\
\hline 1 & \begin{tabular}{|l|}
161 \\
\end{tabular} & 300 & 35 & 246 & 17 & 15 & Hornet by Keystone & Ford & camper & No & I-81 Marion & & 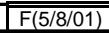 & \\
\hline 2 & 114 & 261 & 36 & 207 & 12 & 12 & Roulottes -camper & Ford & camper & No & I-81 Marion & & $F(5 / 8 / 01)$ & \\
\hline 3 & 52 & 160 & & 104 & 12 & 13 & U-Haul & Ford F-150 & & No & I-79 Rest Area & man. By Paramount Mig. Co. & $F(5 / 9 / 01)$ & \\
\hline 4 & 128 & 276 & 34 & - & 16 & 14 & Terry by Fleetwood & Dodge Ram 2500 & camper & No & I-79 Rest Area & fifth wheel & $F(5 / 9 / 01)$ & \\
\hline 5 & 122 & 216 & 30 & - & 18 & 13 & Alum-lite & Ford F-250XLT & camper & No & I-79 N Pitt & fifth wheel & $F(5 / 10 / 01)$ & \\
\hline 6 & 56 & 176 & 35 & 52 & 9 & 9.5 & U-Haul & U-Haul & car & No & I-79 N Pitt & & $F(5 / 10 / 01)$ & \\
\hline 7 & 96 & 33 & & 24 & 11 & 9 & Magic Tilt & Ford & boat & No & I-79 N Pitt & & $F(5 / 10 / 01)$ & \\
\hline 8 & 123 & 247 & 34 & - & 10 & 18 & Carri-lite & & camper & No & I-79 N Pitt & 5th wheel, by Carriage & $F(5 / 10 / 01)$ & \\
\hline 9 & 53 & 173 & 34 & 128 & 10 & 12 & U-Haul & Ford Bronco XLT & & No & I-79 N Pitt & & $F(5 / 10 / 01)$ & \\
\hline 10 & 38 & 150 & & 106 & 9 & 4.5 & Featherlite & Chrysler Grand voyager & shopvac, wheelbarrow & No & I-79 N Pitt & & $F(5 / 10 / 01)$ & \\
\hline 11 & 0 & 178 & & - & 11 & & Penske & Moving van & empty & No & I-79 N Pitt & & $F(5 / 10 / 01)$ & \\
\hline 12 & 59 & 234 & 34 & 168 & 8 & 14 & Foster & Ford & bobcat & No & I-79 N Pitt & & $F(5 / 10 / 01)$ & \\
\hline 13 & 139 & 179 & 42 & 99 & 4.5 & 5.5 & U-Haul & U-Haul & car & No & I-79 N Pitt & & $F(5 / 10 / 01)$ & \\
\hline 14 & 52 & 48 & & 199 & 5 & 8 & & Ford F150 & boat & No & I-79 N Pitt & & $F(5 / 10 / 01)$ & \\
\hline 15 & & & & 90 & 8 & 4.5 & Ryder car trailer & Ryder truck & towing car & No & \begin{tabular}{|l|} 
I-79 N Pitt \\
\end{tabular} & & $F(5 / 10 / 01)$ & \\
\hline 16 & 45 & 142 & & 91 & 6.5 & 13.5 & U-Haul & Uhaul & Pontiac Bonneville & No & I-79 S Rest area & & $F(6 / 26 / 01)$ & \\
\hline 17 & 91 & 196 & 31 & 140 & 12 & 13 & & Chevy 2500 & Buick Century & No & 1-79 S Rest area & open car trailer & $\mathrm{F}(6 / 26 / 01)$ & \\
\hline 18 & 90 & 201 & & 138 & 9 & 16 & Sun Ridge by Fleetwood & GMC Suburban & camper & No & \begin{tabular}{|l|l} 
1-79 S Rest area \\
\end{tabular} & & $F(6 / 26 / 01)$ & \\
\hline 19 & 40 & 227 & & 177 & 10 & 12 & Wesco boat trailer & Ford F150 & fishing boat & No & 1-79 S Rest area & & $F(6 / 26 / 01)$ & \\
\hline 20 & 66 & 220 & & 140 & 13 & 11.5 & United Transporters & Uhaul - Ford & & No & I-79 S Rest area & & $F(6 / 26 / 01)$ & \\
\hline 21 & 108 & 238 & 35 & 189 & 10 & 11.5 & 87 Hi Lo Camper & Ford F150 & camper & No & I-79 S Rest area & & $F(6 / 26 / 01)$ & $\begin{array}{l}\text { man. Calls } \\
\text { onners tor } \\
\text { suggestions }\end{array}$ \\
\hline 22 & 84 & 187 & & 141 & 14 & 12 & & Chevy 1500 & camping supplies & No & 1-79 S Rest area & small trailer & $F(6 / 26 / 01)$ & \\
\hline 23 & 44 & 180 & 35 & & 6 & 12.5 & U-Haul & $\operatorname{Ram} 1500$ & & No & 1-79 S Rest area & & $F(6 / 28 / 01)$ & \\
\hline 24 & 128 & 264 & 36 & & 18 & 17 & Carriage & Ford F350 & 5thwheel camper & No & I-79 S Rest area & Cameo LXI & $F(6 / 28 / 01)$ & \\
\hline 25 & 70 & 178 & & 125 & 13 & 12 & Rockwood Freedom & GMC 1500 Sub & camper & No & 1-79 S Rest area & & $F(6 / 28 / 01)$ & \\
\hline 26 & 48 & 152 & & 107 & 6.5 & 13 & U-Haul & Ford Caravan & & No & 1-79 S Rest area & tirepcold $=50$ & $F(6 / 28 / 01)$ & \\
\hline 27 & 54 & 221 & & 179 & 11 & 15 & Tracker trailstar & Chevy 1500 & boat & No & \begin{tabular}{|l|l} 
1-79 S Rest area \\
\end{tabular} & & $F(7 / 2 / 01)$ & \\
\hline 28 & 41 & 199 & & 160 & 8.5 & 12 & & Ford Explorer & fishing boat & No & 1-79 S Rest area & boat trailer & $\mathrm{F}(7 / 2 / 01)$ & \\
\hline 29 & 42 & 144 & & 103 & 12 & 10.5 & Cedar by Fleetwood & Dodge Caravan & camper & No & 1-79 S Rest area & & $\mathrm{F}(7 / 2 / 01)$ & \\
\hline 30 & 75 & 205 & 34 & 159 & 10 & 12 & & Chevy 1500 & car/sofa & No & 1-79 S Rest area & car trailer & $F(7 / 2 / 01)$ & \\
\hline 31 & 60 & 197 & 26 & 148 & 11.5 & 9.5 & Cub & GMC Safari & camper & No & 1-79 S Rest area & & $\begin{array}{l}\mathrm{F}(7 / 2 / 01) \\
\end{array}$ & \\
\hline 32 & 124 & 146 & 31 & 194 & 17 & 13 & Sunline Solaris & Ford F150 & camper & No & 1-79 S Rest area & & \begin{tabular}{|l}
$F(7 / 3 / 01)$ \\
\end{tabular} & \\
\hline 33 & 84 & 196 & 26 & 144 & 8.5 & 6 & Hi Lo & Chevy Astro & & No & 1-79 S Rest area & Funlite camper & $F(7 / 3 / 01)$ & \\
\hline 34 & 104 & 265 & 33 & 149 & 12.5 & 21 & Hornet by Keystone & Ram 250 Van & camper & No & 1-79 S Rest area & & $\mathrm{F}(7 / 3 / 01)$ & \\
\hline 35 & 84 & 215 & 33 & 155 & 12 & 13 & Sunline & Chevy Silverado & camper & No & I-79 S Rest area & & $F(7 / 3 / 01)$ & \\
\hline 36 & 96 & 231 & 35 & 184 & 11 & 9.5 & Coachman & Dodge van & Coachman trailer & No & 1-79 S Rest area & Catalina lite & $F(7 / 3 / 01)$ & \\
\hline 37 & 48 & 221 & & 174 & 10 & 13 & Stratos trail & F 150 Econoline & empty & No & Stonewall Jackson Lake & boat trailers & $\mathrm{F}(7 / 5 / 01)$ & \\
\hline 38 & 53 & 222 & & 174 & 16.5 & 11.5 & Ranger trail & Chevy Truck & empty & No & Stonewall Jackson Lake & boat trailers & $F(7 / 5 / 01)$ & \\
\hline 39 & 42 & 223 & & 175 & 17 & 18.5 & Trail Star & Chevy Truck & empty & No & Stonewall Jackson Lake & boat trailers & $F(7 / 5 / 01)$ & \\
\hline 40 & 46 & 223 & & 178 & 16.5 & 17 & Trail Star & Buick car & empty & No & Stonewall Jackson Lake & boat trailers & $F(7 / 5 / 01)$ & \\
\hline 41 & 46 & 223 & & 175 & 13.5 & 20 & Trail Star & Dodge Caravan & empty & No & Stonewall Jackson Lake & boat trailers & $F(7 / 5 / 01)$ & \\
\hline 42 & 51 & 230 & & 179 & 16 & 16.5 & Stratus Trail & Chevy Truck & empty & No & Stonewall Jackson Lake & boat trailers & $F(7 / 5 / 01)$ & \\
\hline 43 & 49 & 227 & & 168 & 15 & 12.5 & Trail Star & \begin{tabular}{|l|} 
Chevy Silverado \\
\end{tabular} & empty & No & Stonewall Jackson Lake & boat trailers & $F(7 / 5 / 01)$ & \\
\hline 44 & 50 & 239 & & 186 & 12 & 12 & Custom Frame & \begin{tabular}{|l|} 
Ford Truck \\
\end{tabular} & empty & No & Stonewall Jackson Lake & boat trailers & \begin{tabular}{|l}
$F(7 / 5 / 01)$ \\
\end{tabular} & \\
\hline 45 & 49 & 238 & & 186 & 12 & 13.5 & Trail Star & Chevy Caprice & empty & No & Stonewall Jackson Lake & boat trailers & $F(7 / 5 / 01)$ & \\
\hline 46 & 48 & 233 & & 167 & 11 & 11 & Javelin & Ford Truck & empty & No & Stonewall Jackson Lake & boat trailers & $F(7 / 5 / 01)$ & \\
\hline 47 & 39 & 237 & 33 & 182 & 7 & 10 & Custom Haul & \begin{tabular}{|l|} 
Chevy Silverado \\
\end{tabular} & empty & No & Stonewall Jackson Lake & boat trailers & $F(7 / 5 / 01)$ & \\
\hline 48 & 58 & 240 & & 191 & 11 & 12 & Stratus Trail & Chevy Silverado & empty & No & Stonewall Jackson Lake & boat trailers & $F(7 / 5 / 01)$ & \\
\hline 49 & 91 & 248 & & 197 & 16 & 16 & & \begin{tabular}{|l|} 
Ford F250 \\
\end{tabular} & Bayliner & No & Stonewall Jackson Lake & boat trailers & $F(7 / 5 / 01)$ & \\
\hline 50 & 45 & 216 & & 164 & 15 & 15 & Tee Nee & Ford F350 & empty & No & Stonewall Jackson Lake & boat trailers & $F(7 / 5 / 01)$ & \\
\hline 51 & 55 & 252 & & 207 & 12 & 10.5 & Triton Boats & Yukon & empty & No & \begin{tabular}{|l|} 
Stonewall Jackson Lake \\
\end{tabular} & boat trailers & $F(7 / 5 / 01)$ & \\
\hline 52 & 54 & 222 & 34 & 178 & 10 & 12 & Road runner & Yukon & Celebrity boat & No & I-79 S Rest area & boat trailers & $F(7 / 6 / 01)$ & \\
\hline 53 & 49 & 243 & & 193 & 14 & 12 & Maxum & Ram 1500 & Maxum boat & No & 1-79 S Rest area & boat trailers & $F(7 / 6 / 01)$ & \\
\hline 54 & 39 & 184 & & 128 & 13 & 12 & Shoreland & Ford F250 & wave runners & No & 1-79 S Rest area & boat trailers & $F(7 / 6 / 01)$ & \\
\hline 55 & 58 & 188 & & 128 & 12 & 15 & Enterprise Inc & Ford F150 & 3 4-wheelers & No & I-79 S Rest area & utility trailer & $F(7 / 6 / 01)$ & \\
\hline 56 & 54 & 223 & 39 & 91 & 5 & 12 & Ryder car trailer & $\begin{array}{l}\text { Ford E350 } \\
\end{array}$ & towing car & No & \begin{tabular}{|l|l} 
1-79 S Rest area \\
\end{tabular} & & \begin{tabular}{|l}
$F(7 / 6 / 01)$ \\
\end{tabular} & \\
\hline 57 & 124 & 246 & 36 & & 21 & 24 & Montana by Keystone & GMC 3500 & & No & 1-79 S Rest area & fifth wheel & $F(7 / 6 / 01)$ & \\
\hline 58 & 88 & 182 & 39 & 182 & 18 & 20 & Wildwood & Ford F250 & & No & I-79 S Rest area & camper - fifth wheel & \begin{tabular}{|l}
$F(7 / 6 / 01)$ \\
\end{tabular} & \\
\hline 59 & 67 & & & 146 & 16.5 & 16.5 & Chalet camper & & & No & manufacturer & & $\mathrm{E}(7 / 4 / 01)$ & \\
\hline
\end{tabular}

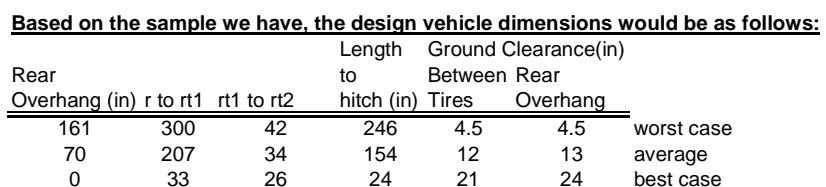


PASSENGER VEHICLE \& TRAILER - COMMERCIAL USE

rt=rear trailer wheels Length Ground Clearance(in) Make/ Lnything Unusual? Source Rear Wheel Base (in) $\quad$ to Between Rear Model/ Car (if field

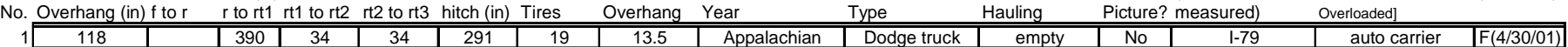

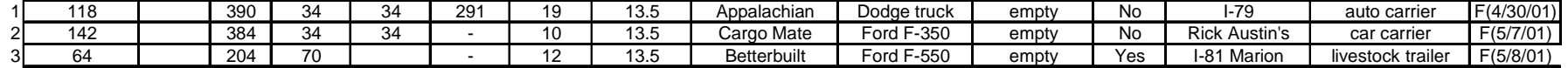

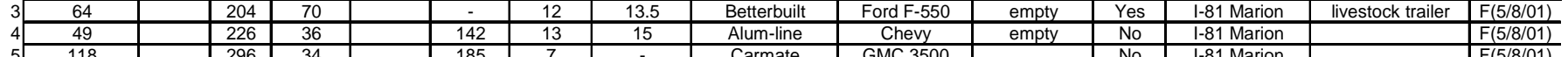

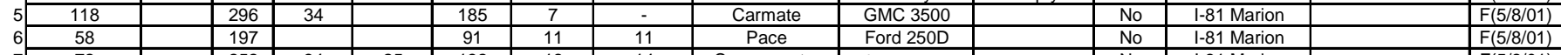

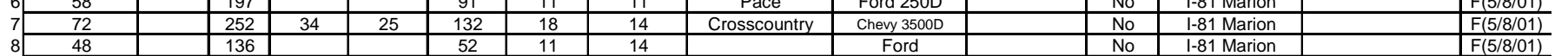

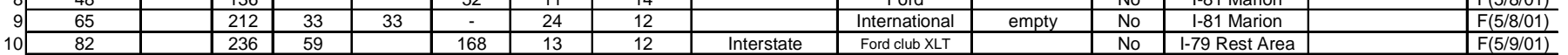

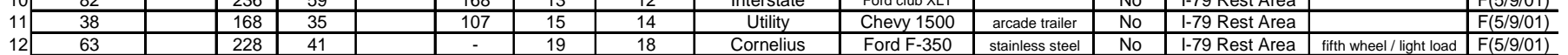

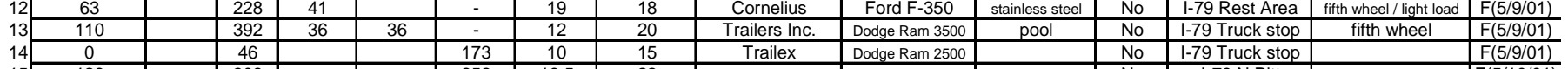

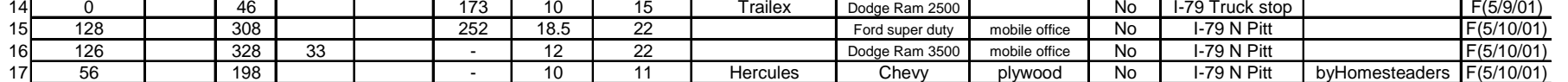

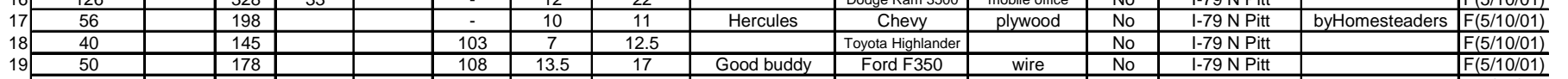

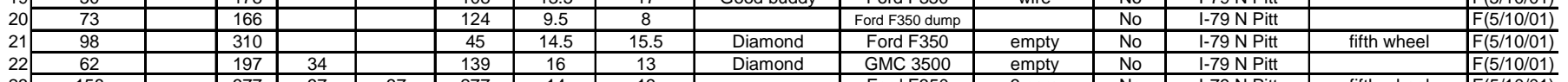

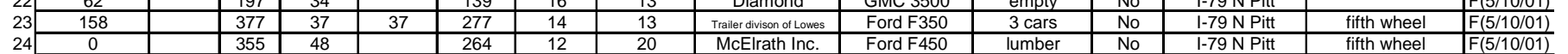

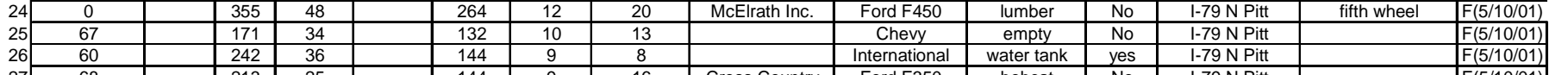

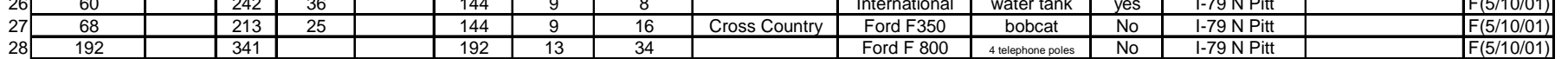

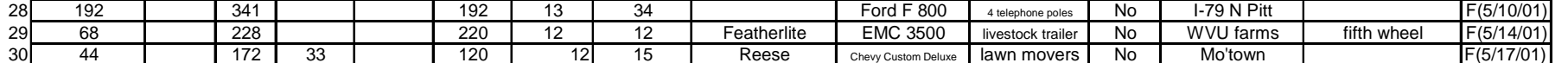

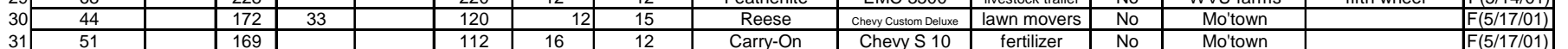

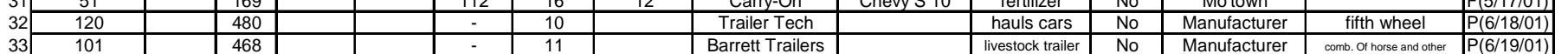

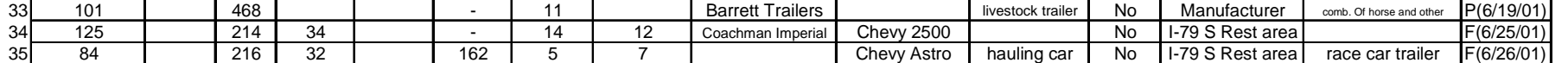

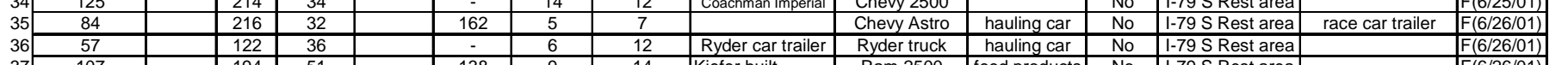

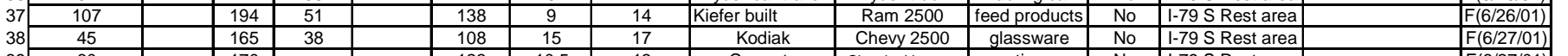

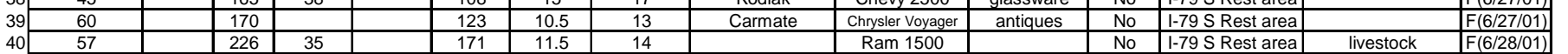

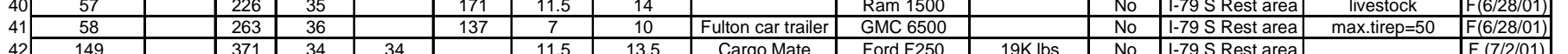

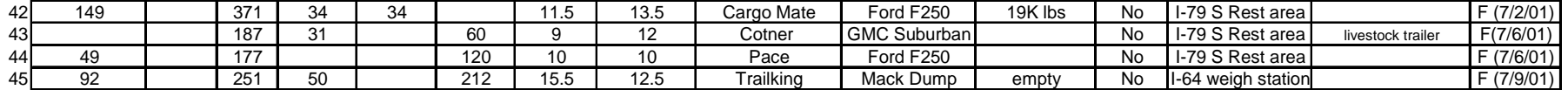
Based on the sample we have, the design vehicle dimensions would be as follows:

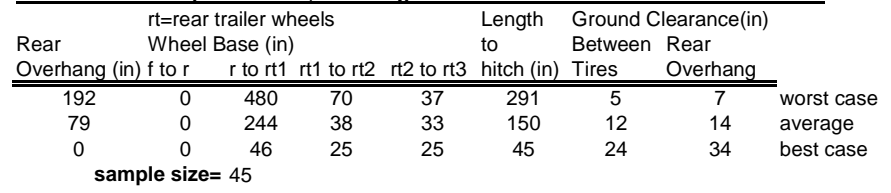




\section{RECREATION VEHICLES}

\begin{tabular}{|c|c|c|c|c|c|c|c|c|c|c|c|c|c|}
\hline \multicolumn{5}{|c|}{$\begin{array}{c}\text { Wheel } \\
\text { Overhang (in' Base (in) }\end{array}$} & \multicolumn{4}{|c|}{$\begin{array}{l}\text { Ground Clearance (in) } \\
\text { Betweer Overhang }\end{array}$} & \multirow[t]{2}{*}{$\begin{array}{c}\text { Make/ } \\
\text { Model/ } \\
\text { Year }\end{array}$} & \multirow{2}{*}{\multicolumn{2}{|c|}{$\begin{array}{l}\text { Anything Unusual? } \\
\text { [Small Tires, Flat Tires } \\
\text { Picture? Overloaded] }\end{array}$}} & \multirow[t]{2}{*}{$\begin{array}{l}\text { Source } \\
(\mathrm{I}, \mathrm{P}, \\
\quad \text { or F) }\end{array}$} & \multirow[t]{2}{*}{$\begin{array}{l}\text { (Internet, } \\
\text { Phone, Field) } \\
\text { Other }\end{array}$} \\
\hline No. & Front & Rear & $\mathrm{f}$ to $\mathrm{r} 1$ & $r 1$ to $r 2$ & r2 to $r 3$ & Tires & Front & Rear & & & & & \\
\hline 1 & 60.0 & 142 & 206 & & & 10 & 8 & 14 & Gulf Stream & No & & $F(5 / 7 / 01)$ & \begin{tabular}{|l} 
Rick Austin's Trailer Sales \\
\end{tabular} \\
\hline 2 & 52.0 & 149 & 177 & & & 12 & 15 & 14 & Classic & No & & $F(5 / 7 / 01)$ & \begin{tabular}{|l} 
Rick Austin's Trailer Sales \\
\end{tabular} \\
\hline 3 & 0 & 126 & 222 & & & 14 & 15 & & Crown Royal by Monaco & No & towing car & $F(5 / 8 / 01)$ & I-81N \\
\hline 4 & 0.0 & 118 & 231 & & & 13 & 17 & 16 & Dolphin by National RV & No & & $\mathrm{F}(5 / 8 / 01)$ & Keystone RV Center \\
\hline 5 & 0.0 & 141 & 231 & & & 12 & & 16 & Dolphin by National RV & No & & $F(5 / 8 / 01)$ & Keystone RV Center \\
\hline 6 & 0.0 & 137 & 192 & & & 11 & & 17 & Hurricane by Thor & No & & $F(5 / 8 / 01)$ & Keystone RV Center \\
\hline 7 & 0.0 & 119 & 226 & & & 14 & & 17 & Sea Breeze by National RV & No & & $F(5 / 8 / 01)$ & Keystone RV Center \\
\hline 8 & 0.0 & 130 & 227 & & & 12 & & 13 & Tradewinds by National RV & No & & $F(5 / 8 / 01)$ & Keystone RV Center \\
\hline 9 & 70.0 & 130 & 207 & & & 13 & 14 & 12 & Tradewinds by National RV & No & & $F(5 / 8 / 01)$ & Keystone RV Center \\
\hline 10 & 0.0 & 235 & 189 & & & 9.5 & & 17 & Euroroller & No & & $F(5 / 8 / 01)$ & Keystone RV Center \\
\hline 11 & 0.0 & 148 & 218 & & & 11 & & 17 & Dolphin by National RV & No & & $F(5 / 8 / 01)$ & Keystone RV Center \\
\hline 12 & 0.0 & 130 & 192 & & & 13 & & 18 & Hurricane by Thor & No & & $F(5 / 8 / 01)$ & Keystone RV Center \\
\hline 13 & 0.0 & 132 & 190 & & & 9 & & 16 & Fourwinds by Thor & No & & $F(5 / 8 / 01)$ & Keystone RV Center \\
\hline 14 & 0.0 & 142 & 264 & 33 & 33 & & & & Tenton Homes & Yes & & $F(5 / 8 / 01)$ & Keystone RV Center \\
\hline 15 & 0.0 & 170 & 258 & 34 & & & & & Fourwinds by Thor & No & & $F(5 / 8 / 01)$ & Keystone RV Center \\
\hline 16 & 0.0 & 153 & 260 & 33 & & & & & Prowler by Fleetwood & Yes & & $F(5 / 8 / 01)$ & \begin{tabular}{|l} 
Keystone RV Center \\
\end{tabular} \\
\hline 17 & 0.0 & 108 & 180 & & & 9 & & 8 & Gulf Stream Conquest & No & & $F(5 / 9 / 01)$ & $\mathrm{I}-79 \mathrm{~S}$ rest area \\
\hline 18 & 0.0 & 117 & 187 & & & 12 & & 13 & Gulfstream conquest & No & & $F(5 / 9 / 01)$ & I-79 S rest area \\
\hline 19 & 0.0 & 148 & 226 & & & 14 & 6 & 16 & Southwind by Fleetwood & No & & $F(5 / 10 / 01)$ & I-79 N Pitt \\
\hline 20 & 94.0 & 127 & 252 & & & 14 & 6 & 16 & Endevor by Holiday Rambler & No & & $F(5 / 10 / 01)$ & I-79 N Pitt \\
\hline 21 & 48.0 & 233 & 209 & & & 11 & & 12 & Southwind by Fleetwood & No & $82 "$ to wheel-hitch towing car & $\mathrm{F}(5 / 10 / 01)$ & I-79 N Pitt \\
\hline 22 & 69.0 & 226 & 226 & & & 11 & 16.5 & 11 & Renegade & No & $226 "$ wheel towheel towing car & $F(5 / 10 / 01)$ & I-79 N Pitt \\
\hline 23 & 0.0 & 107 & 180 & & & 10 & & 16 & Argosy & No & $84 "$ to hitch towing car & $F(5 / 10 / 01)$ & I-79 N Pitt \\
\hline 24 & 55.0 & 161 & 211 & & & 12 & 13 & 16 & Cruise Air III & No & & $F(5 / 12 / 01)$ & Bridgeport \\
\hline 25 & 69.0 & 107 & 316 & & & 11 & 11 & 11 & Featherlite & Yes & Model H3 - 45' & $\mathrm{P}(6 / 14 / 01)$ & Man.Tom Breznik \\
\hline 26 & 83 & 121 & 274 & & & 17 & & 11 & London Cruise by Newman & No & $66 "$ to hitch towing car & $F(6 / 25 / 01)$ & I-79 S rest area \\
\hline 27 & 45 & 144 & 228 & & & 7.5 & & 6 & Southwind by Fleetwood & No & 198.5" to hitch towing traile* ${ }^{\star *}$ & $F(6 / 25 / 01)$ & I-79 S rest area \\
\hline & e: $\operatorname{tr}$ & & 114 & ROH o & $75 \mathrm{G}$ & of 8 & is $a$ & ulme & trailer, and is loaded & vith a c & car. Gets hung up on dri & veway en & trances \\
\hline 28 & & 95 & 274 & & & 12 & & 10 & Coachman & No & $83 "$ to hitch towing car & $F(6 / 25 / 01)$ & I-79S rest area \\
\hline 29 & & 189 & & & & 11 & & 10 & Hurricane by Thor & No & towing car & $F(6 / 26 / 01)$ & I-79S rest area \\
\hline 30 & 72.0 & 127 & 227 & & & 13 & 15 & 14 & Tradewinds by National RV & No & towing car & $F(6 / 26 / 01)$ & I-79 S rest area \\
\hline 31 & & 132 & 197 & & & 10 & 8.5 & & Conquest by Gulfstream & No & & $F(6 / 27 / 01)$ & I-79 S rest area \\
\hline 32 & 48 & 88 & 141 & & & 10 & & 10 & Georgetown by Forest River & No & & $F(6 / 27 / 01)$ & I-79 S rest area \\
\hline 33 & & 151 & 176 & & & 10 & & 11 & Tioga by Fleetwood & No & & $F(6 / 27 / 01)$ & I-79 S rest area \\
\hline 34 & 73.0 & 133 & 240 & & & 15.5 & 15 & 16.5 & Discovery by Fleetwood & No & towing car & $F(6 / 28 / 01)$ & I-79 S rest area \\
\hline 35 & & 144 & 175 & & & 10 & & 10 & Tioga by Fleetwood & No & & $F(6 / 28 / 01)$ & I-79 S rest area \\
\hline 36 & 81 & 120 & 252 & & & 13 & 16.5 & 12 & Dutch Star by Newman & No & & $F(6 / 28 / 01)$ & I-79 S rest area \\
\hline 37 & 49 & 146 & 205 & 43 & & 14 & 13 & 14 & Bounder by Fleetwood & No & & $F(7 / 6 / 01)$ & 1-79 S rest area \\
\hline 38 & 38 & 131 & 230 & & & 11.5 & & 12 & Pace Arrow by Fleetwood & No & towing car & $F(7 / 2 / 01)$ & I-79 S rest area \\
\hline 39 & 78 & 126 & 204 & & & 13 & 11 & 9 & Ambassador by Holiday Rambler & No & & $F(7 / 3 / 01)$ & I-79 S rest area \\
\hline 40 & 45 & 140 & 172 & 50 & & & & 10 & Imperial by Holiday Rambler & No & towing car & $F(7 / 3 / 01)$ & I-79 S rest area \\
\hline 41 & 39 & 154 & 228 & & & 11.5 & & 11 & Endeavor by Holiday Rambler & No & towing car & $\mathrm{F}(7 / 3 / 01)$ & I-79 S rest area \\
\hline 42 & 44 & 137 & 227 & & & 14 & & 12 & Hurricane by Thor & No & drags in rear & $\mathrm{F}(7 / 3 / 01)$ & I-79 S rest area \\
\hline
\end{tabular}

Based on the sample we have, the design vehicle dimensions would be as follows:

\begin{tabular}{|c|c|c|c|c|c|c|c|c|}
\hline \multirow{2}{*}{\multicolumn{2}{|c|}{ Overhang (in }} & \multicolumn{3}{|l|}{ Wheel } & \multicolumn{3}{|c|}{ Ground Clearance (in) } & \\
\hline & & Base (ir & & & \multirow{2}{*}{$\begin{array}{l}\text { Betweer } \\
\text { Tires }\end{array}$} & \multirow{2}{*}{$\begin{array}{l}\text { Overh } \\
\text { Front }\end{array}$} & \multirow{2}{*}{$\begin{array}{l}\text { רg } \\
\text { Rear } \\
\end{array}$} & \\
\hline Front & Rear & $\mathrm{f}$ to $\mathrm{r} 1$ & $\mathrm{r} 1$ to $\mathrm{r} 2$ & r2 to $r 3$ & & & & \\
\hline 94.0 & $\overline{235.0}$ & 316.0 & 50.0 & 33.0 & 7.5 & 6 & 6 & worst case \\
\hline 32.8 & 140.8 & 217.7 & 38.6 & 33.0 & 11.9 & 12.5 & 13.1 & average \\
\hline 60.6 & 140.8 & 217.7 & 38.6 & 33.0 & 11.9 & 12.5 & 13.1 & average without zeros \\
\hline 0.0 & 88.0 & 141.0 & 33.0 & 33.0 & 17 & 17 & 18 & best case \\
\hline sample & size $=$ & 42 & & & & & & \\
\hline
\end{tabular}


APPENDIX B - Best, Average, and Worst Case Dimensions and Sample Sizes 


\section{Single Unit Trucks -}

Single Unit Beverage Truck

Rear Ground Clearance (in)

Drop Max. \# Overhang Wheel Base (in) Between Rear Length of bays

\begin{tabular}{|c|c|c|c|c|c|c|c|}
\multicolumn{1}{c}{ (in) } & f to 1 r1 to $r 2$ & Tires & \multicolumn{2}{c}{ Overhang } & (in) & per side \\
\hline \hline 100 & 295 & 0 & 6 & 10 & 180 & 7 \\
\hline 88 & 259 & 0 & 12 & 17 & 151 & 6 & Worst \\
\hline 81 & 196 & 0 & 20 & 21 & 99 & 4 & Berage \\
\hline
\end{tabular}

Sample Size $=12$

\section{Articulated Beverage Truck}

\begin{tabular}{|c|c|c|c|c|c|c|}
\hline $\begin{array}{l}\text { Nheel Base (in } \\
\mathrm{f} \text { to } \mathrm{r} 1\end{array}$ & $\mathrm{r} 1$ to $\mathrm{r} 2$ & r2 to r3 & $\begin{array}{c}\text { Ground Cle } \\
\text { Between } \\
\text { Tires (in) }\end{array}$ & $\begin{array}{l}\text { Length of } \\
\text { Drops } \\
\text { (in) }\end{array}$ & $\begin{array}{l}\text { Max. \# } \\
\text { of bays } \\
\text { per side }\end{array}$ & \\
\hline 156 & 372 & 46 & 10 & 343 & 13 & Worst \\
\hline 150 & 333 & 39 & 12 & 274 & 8 & \\
\hline 144 & 292 & 32 & 14 & 231 & 7 & Best \\
\hline
\end{tabular}

Sample Size $=9$

\section{Rear Load Garbage Truck}

\begin{tabular}{|c|c|c|c|c|c|c|}
\hline & \multicolumn{3}{|c|}{ Ground Clearance } & \\
\hline \multicolumn{3}{|c|}{ Overhang (in) eel Base (in) } & & Between & Rear & \\
\hline Rear & $f$ to $r 1$ & $r 1-r 2$ & $r 2-r 3$ & Tires & Overhang & \multirow{4}{*}{$\begin{array}{l}\text { worst case } \\
\text { average } \\
\text { best case }\end{array}$} \\
\hline 123 & 254 & 68 & 53 & 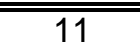 & 13.5 & \\
\hline 96 & 176 & 65 & 53 & 17 & 18 & \\
\hline 60 & 112 & 49 & 53 & 30 & 26 & \\
\hline
\end{tabular}

Sample Size $=44$

\section{Aerial Fire Truck}

\begin{tabular}{|c|c|c|c|c|c|c|}
\hline \multirow{3}{*}{$\begin{array}{l}\text { Overhang (in } \\
\text { Front }\end{array}$} & \multirow[b]{3}{*}{ Rear } & \multicolumn{5}{|c|}{ Ground Clearance } \\
\hline & & \multicolumn{2}{|c|}{ Wheel Base (in) } & \multirow{2}{*}{$\begin{array}{c}\text { Between } \\
\text { Tires } \\
\end{array}$} & \multirow{2}{*}{$\begin{array}{c}\text { Overhang } \\
\text { Front }\end{array}$} & \multirow[b]{2}{*}{ Rear } \\
\hline & & $f$ to $r 1$ & $r 1$ to $r 2$ & & & \\
\hline 91.25 & 15 & 2259 & 57 & 9 & 11 & 9 \\
\hline 70 & 122 & 213.89 & 55 & 14 & 17 & 13 \\
\hline 51 & 84 & 166 & 0 & 23 & 21 & 19 \\
\hline
\end{tabular}

worst case verage

Sample Size $=9$

\section{Pumper Fire Truck}

\begin{tabular}{|c|c|c|c|c|c|c|}
\hline \multirow{3}{*}{$\begin{array}{c}\text { Overhang (in) } \\
\text { Front }\end{array}$} & \multicolumn{6}{|c|}{ Ground Clearance } \\
\hline & \multicolumn{3}{|c|}{ Wheel Base (in) } & \multirow{2}{*}{$\begin{array}{c}\text { Between } \\
\text { Tires }\end{array}$} & \multirow{2}{*}{$\begin{array}{c}\text { Overhang } \\
\text { Front }\end{array}$} & \multirow[b]{2}{*}{ Rear } \\
\hline & Rear & $f$ to $r 1$ & $r 1$ to $r 2$ & & & \\
\hline 95 & 120 & 258 & 56 & 7 & 8 & 10 \\
\hline 65 & 86 & 215 & 55 & 14 & 15 & 14 \\
\hline 0 & 30 & 157 & 0 & 22 & 21 & 23 \\
\hline
\end{tabular}




\section{Buses}

\section{Mini Bus}

\begin{tabular}{|c|c|c|c|c|c|}
\hline \multirow{3}{*}{$\begin{array}{l}\text { Overhang (in) } \\
\text { Front }\end{array}$} & \multirow[b]{3}{*}{ Rear } & \multirow{2}{*}{$\begin{array}{l}\text { Wheel } \\
\text { Base (in }\end{array}$} & & (in) & \\
\hline & & & Between & Overhang & \\
\hline & & $f$ to $r 1$ & Tires & Rear & \\
\hline 30 & 117 & 204 & 8 & 18 & Vorst \\
\hline 30 & 85 & 181 & 10.75 & 18 & Average \\
\hline 0 & 60 & 158 & 12 & 18 & Best \\
\hline
\end{tabular}

Sample Size $=6$

\section{School Bus}

\begin{tabular}{|c|c|c|c|c|c|}
\hline \multirow[b]{2}{*}{$\begin{array}{l}\text { Overhang (in) } \\
\text { Rear }\end{array}$} & \multirow{2}{*}{\multicolumn{2}{|c|}{$\begin{array}{c}\text { Wheel } \\
\text { Base } \\
\text { (in) }\end{array}$}} & \multicolumn{2}{|c|}{ nd Clearance (in) } & \\
\hline & & & $\begin{array}{c}\text { Between } \\
\text { Tires }\end{array}$ & $\begin{array}{c}\text { Rear } \\
\text { Overhang }\end{array}$ & \\
\hline 158 & 40.4 & 279 & 7 & 12 & Worst \\
\hline 138 & 40 & 253 & 15 & 22 & Average \\
\hline 106 & 40.4 & 192 & 24 & 30 & Best \\
\hline
\end{tabular}

Sample Size $=30$

Single Unit Transit Bus

\begin{tabular}{|c|c|c|c|c|c|c|c|}
\hline \multirow{3}{*}{$\begin{array}{c}\text { Overhang (in) } \\
\text { Front }\end{array}$} & \multirow[b]{3}{*}{ Rear } & \multirow{2}{*}{$\begin{array}{l}\text { Wheel } \\
\text { Base (in) }\end{array}$} & \multicolumn{3}{|c|}{ Ground Clearance (in) } & \multirow[b]{3}{*}{ Rear } & \\
\hline & & & & Betwee & Overhang & & \\
\hline & & $f$ to $r 1$ & $r 1$ to $r 2$ & Tires & Front & & \\
\hline 214 & 128 & 334 & 54 & 4 & 6 & 6 & orst \\
\hline 85 & 111 & 227 & 53 & 16 & 13 & 15 & erag \\
\hline 0 & 72 & 151 & 52 & 29 & 18 & 22 & Best \\
\hline
\end{tabular}

Sample Size $=47$

\section{Articulated Transit Bus}

\begin{tabular}{|c|c|c|c|c|c|c|c|}
\hline \multirow{3}{*}{$\begin{array}{c}\text { Overhang (in) } \\
\text { Front }\end{array}$} & \multicolumn{7}{|c|}{ Ground Clearance (in) } \\
\hline & & Wheel E & (in) & Betweer & Overhang & & \\
\hline & Rear & $\mathrm{f}$ to $\mathrm{r} 1$ & r2 to $r 3$ & Tires & Front & Rear & \\
\hline 10 & 120.75 & 264 & 309 & 1010 & 99 & 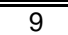 & worst case \\
\hline 87 & 105 & 221 & 270 & 16 & 12 & 14 & average \\
\hline 0 & 0 & 170 & 212 & 21 & 15 & 19 & best case \\
\hline
\end{tabular}

$$
\text { Sample Size }=7
$$

\begin{tabular}{|c|c|c|c|c|c|c|c|}
\hline \\
\hline \multicolumn{2}{|l|}{ Motorcoach } & Wheel & \multicolumn{3}{|c|}{ Ground Clearance (in) } & \multirow[b]{3}{*}{ Rear } & \\
\hline Overhang (in) & & Base (in) & & Betweer & Overhang & & \multirow{5}{*}{$\begin{array}{c}\text { worst case } \\
\text { average } \\
\text { best case }\end{array}$} \\
\hline Front & Rear & $f$ to $r 1$ & $r 1$ to $r 2$ & Tires & Front & & \\
\hline 992.2 & 153.1 & 318 & 60 & 7 & 10 & 8 & \\
\hline 76 & 109 & 294 & 53 & 11 & 13 & 10 & \\
\hline 65 & 77 & 214 & 46 & 13.5 & 15 & 15 & \\
\hline
\end{tabular}

Sample Size $=18$

\section{Trucks -}

\section{Low-boy Trailers $<53 \mathrm{ft}$}

Rear eel Base (in) Overhang (in) r1t to r2t r2t to

\begin{tabular}{|c|c|c|c|c|c|c|c|c|c|c|}
\hline Overhang (in & $\mathrm{r} 1 \mathrm{t}$ to $\mathrm{r} 2 \mathrm{t}$ & ret to $r 1$ & $\mathrm{r} 1$ to $\mathrm{r} 2$ & r2 to $\mathrm{r} 3$ & r3 to $r 4$ & Length & (in) & trailer & Overhang & \\
\hline 119 & 84 & 540 & 123 & 159 & 56 & 642 & 465 & 2 & 1 & worst case \\
\hline 13 & 54 & 397 & 55 & 56 & 50 & 508 & 315 & 9 & 14 & average \\
\hline 0 & 50 & 222 & 34 & 32 & 38 & 264 & 204 & 31 & 22 & est case \\
\hline
\end{tabular}

Sample Size $=93$ 


\section{Double Drop Trailer}

\begin{tabular}{|c|c|c|c|c|c|c|c|c|}
\hline \multirow{2}{*}{\multicolumn{3}{|c|}{ Nheel Base (in) }} & \multicolumn{3}{|c|}{ Ground Clearance } & \multicolumn{3}{|c|}{ Length of } \\
\hline & & & & Rear & Between & Overhang & Drop & \\
\hline$r 1$ to $r 2$ & r2 to $r 3$ & $r 3$ to $r 4$ & r4 to r5 & Overhang & Tires (in) & (in) & (in) & \\
\hline 55 & 660 & 159 & 51 & 262 & 6 & 12 & 374 & worst case \\
\hline 53 & 405 & 75 & 51 & 124 & 12 & 19 & 245 & average \\
\hline 52 & 268 & 45 & 51 & 84 & 22 & 26 & 117 & best case \\
\hline
\end{tabular}

Sample Size $=31$

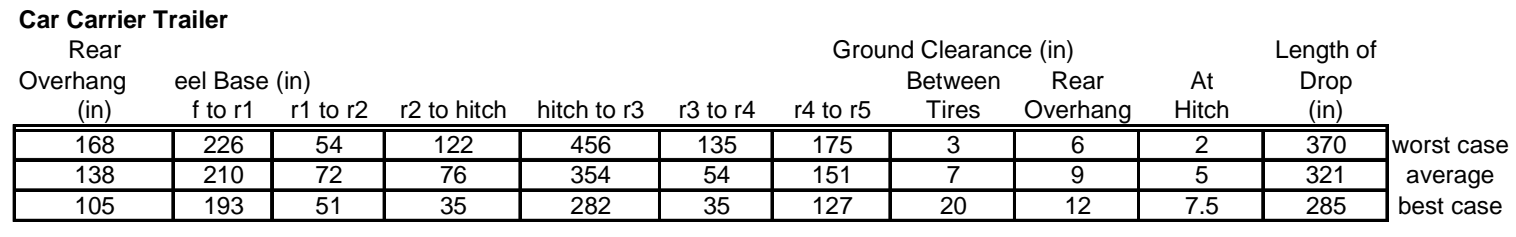

Sample Size $=29$

Belly Dump Trailer

Overhang (in) eel Base (in)

\begin{tabular}{|c|c|c|c|c|c|l|}
\multicolumn{1}{c|}{ Rear } & f to r1 & r1 to r2 & r2 to r3 & r3 to r4 & Ground Clearance \\
\hline \hline 50 & 52 & 491 & 60 & 60 & 11 & worst case \\
\hline 46 & 52 & 394 & 51 & 53 & 16 & average \\
\hline 0 & 52 & 268.5 & 48 & 0 & 19 & best case \\
\hline
\end{tabular}

Sample Size $=20$

Recreational Vehicles -

Passenger Vehicle and Trailer - Private Use

$\begin{array}{ccc} & \text { Length Ground Clearance(in) } \\ \text { Rear Vheelbase to Between Rear }\end{array}$

Overhang (in) $r$ to rt1 rt1 to rt2 hitch (in) $\quad$ Tires Overhang

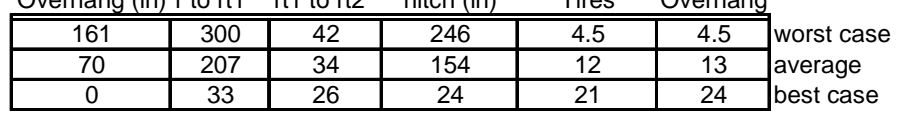

Sample Size $=59$

Passenger Vehicle and Trailer - Commercial Use

$\mathrm{rt}=$ rear trailer wheels Length Ground Clearance(in)

Rear eel Base (in) to Between Rear

Overhang (in) $r$ to rt1 rt1 to rt2 rt2 to rt3 hitch (in) $\quad$ Tires Overhang

\begin{tabular}{|c|c|c|c|c|c|c|c|}
\hline 192 & 480 & 70 & 37 & 291 & 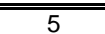 & 7 & worst case \\
\hline 79 & 244 & 38 & 33 & 150 & 12 & 14 & average \\
\hline 0 & 46 & 25 & 25 & 45 & 24 & 34 & best case \\
\hline
\end{tabular}

Sample Size $=45$

Recreation Vehicle

\begin{tabular}{|c|c|c|c|c|c|c|c|c|}
\hline \multirow{3}{*}{$\begin{array}{l}\text { Overhang (in) } \\
\text { Front }\end{array}$} & \multicolumn{8}{|c|}{ Ground Clearance (in) } \\
\hline & \multicolumn{3}{|c|}{ Wheelbase (in) } & \multicolumn{4}{|c|}{ Between Overhang } & \\
\hline & Rear & $f$ to $r 1$ & $r 1$ to $r 2$ & r2 to r3 & Tires & Front & Rear & \multirow{4}{*}{$\begin{array}{l}\text { worst case } \\
\text { average without zeros } \\
\text { best case }\end{array}$} \\
\hline 94.0 & 235.0 & 316.0 & 50.0 & 33.0 & 7.5 & 6 & 6 & \\
\hline 60.6 & 140.8 & 217.7 & 38.6 & 33.0 & 11.9 & 12.5 & 13.1 & \\
\hline 0.0 & 88.0 & 141.0 & 33.0 & 33.0 & 17 & 17 & 18 & \\
\hline
\end{tabular}

Sample Size $=42$ 
APPENDIX C - List of Vehicle Manufacturers 


\begin{tabular}{|c|c|c|}
\hline \multicolumn{3}{|c|}{ List of Manufacturers } \\
\hline Vehicle Type & Manufacturer & Source \\
\hline Single Unit Beverage Truck & Hackney & Field \\
\hline & Mickey & $\begin{array}{l}\text { Field, } \\
\text { Phone }\end{array}$ \\
\hline Articulated Beverage Truck & Mickey & $\begin{array}{l}\text { Field, } \\
\text { Phone }\end{array}$ \\
\hline \multirow[t]{4}{*}{ Mini-Bus } & Girardin & Phone \\
\hline & Glaval & Phone \\
\hline & International & Field \\
\hline & Thor & Phone \\
\hline \multirow[t]{7}{*}{ Bus } & Bluebird & Field \\
\hline & Carpenter & Field \\
\hline & Chevy & Field \\
\hline & Ford & Field \\
\hline & GMC & Field \\
\hline & International & Field \\
\hline & Thomas Built & $\begin{array}{c}\text { Field, } \\
\text { Internet }\end{array}$ \\
\hline \multirow[t]{11}{*}{ Single Unit Transit Bus } & Bluebird & Internet \\
\hline & Chance Coach & Internet \\
\hline & Flxible & Field \\
\hline & Glaval & Phone \\
\hline & Goshen Coach & Field \\
\hline & Holland Bus & $\begin{array}{l}\text { Field, } \\
\text { Phone }\end{array}$ \\
\hline & Nabi & Internet \\
\hline & Neoplan & $\begin{array}{c}\text { Field, } \\
\text { Internet }\end{array}$ \\
\hline & Nova & $\begin{array}{c}\text { Field, } \\
\text { Internet }\end{array}$ \\
\hline & Orion & Field \\
\hline & Wheeled Coach & Field \\
\hline \multirow[t]{5}{*}{ Articulated Transit Bus } & Chance Coach & Internet \\
\hline & Ikarus (aka Naby) & Field \\
\hline & Nabi & Internet \\
\hline & Neoplan & Internet \\
\hline & New Flyer & Internet \\
\hline \multirow[t]{3}{*}{ Motorcoach } & $\mathrm{MCl}$ & $\begin{array}{c}\text { Field, } \\
\text { Internet }\end{array}$ \\
\hline & Prevost & $\begin{array}{l}\text { Field, } \\
\text { Phone }\end{array}$ \\
\hline & Van Hool & Field \\
\hline \multirow[t]{3}{*}{ Rear Load Garbage Truck } & Crane Carrier & Field \\
\hline & Dempster & Field \\
\hline & EZ Pack & Field \\
\hline
\end{tabular}




\begin{tabular}{|c|c|c|}
\hline & Goliath & Field \\
\hline & Heil & Field Phone \\
\hline & Leach & $\begin{array}{l}\text { Field, } \\
\text { Phone }\end{array}$ \\
\hline & Loadmaster & Field \\
\hline & McNeilus & Field \\
\hline \multirow[t]{6}{*}{ Aerial Fire Truck } & American LaFrance & Field \\
\hline & Emergency One & Phone \\
\hline & Ferrara & Field \\
\hline & Kaza & Phone \\
\hline & Pierce & Field \\
\hline & Thibault & Field \\
\hline \multirow[t]{8}{*}{ Pumper Fire Truck } & 3D Manufacturer & Field \\
\hline & American LaFrance & $\begin{array}{l}\text { Field, } \\
\text { Phone }\end{array}$ \\
\hline & Emergency One & Phone \\
\hline & Ford Gruman & Field \\
\hline & Freightliner & Field \\
\hline & Kaza & Phone \\
\hline & Kodiak & Field \\
\hline & Pierce & Field \\
\hline \multirow{23}{*}{ Low-Boy Trailers $<53 \mathrm{ft}$} & Alabama & Field \\
\hline & Aldora & Field \\
\hline & APTIA & Field \\
\hline & Blackhawk & Field \\
\hline & Canadian & Field \\
\hline & Challenger & $\begin{array}{c}\text { Field, } \\
\text { Internet }\end{array}$ \\
\hline & Chieder Nation & Field \\
\hline & Cozad & $\begin{array}{l}\text { Field, } \\
\text { Phone }\end{array}$ \\
\hline & Daily & Field \\
\hline & Dynaweld & Field \\
\hline & Eager Beaver & $\begin{array}{l}\text { Field, } \\
\text { Phone }\end{array}$ \\
\hline & Etnyre & Internet \\
\hline & Fontaine & $\begin{array}{c}\text { Field, } \\
\text { Internet }\end{array}$ \\
\hline & Fruehauf & Field \\
\hline & Hunt & field \\
\hline & Hyster & Field \\
\hline & Keen & Field \\
\hline & Landoll & Field \\
\hline & Liddell & Internet \\
\hline & Loadking & Field \\
\hline & McCord & Field \\
\hline & Pace & Field \\
\hline & Rogers & $\begin{array}{c}\text { Field, } \\
\text { Internet }\end{array}$ \\
\hline
\end{tabular}




\begin{tabular}{|c|c|c|}
\hline & Scottys & Field \\
\hline & Take 3 & Field \\
\hline & Trail King & $\begin{array}{l}\text { Field, } \\
\text { Phone }\end{array}$ \\
\hline & Trail-Eze & $\begin{array}{c}\text { Field, } \\
\text { Internet }\end{array}$ \\
\hline & Tralbert & $\begin{array}{c}\text { Field, } \\
\text { Internet }\end{array}$ \\
\hline & Transcraft & Field \\
\hline & Trism & Field \\
\hline \multirow{10}{*}{ Double Drop Trailer } & Bullride EBY & Field \\
\hline & Fontaine & Field \\
\hline & Great Dane & Field \\
\hline & Kaylan & Field \\
\hline & Kentucky & $\begin{array}{l}\text { Field, } \\
\text { Phone }\end{array}$ \\
\hline & Talbert & Field \\
\hline & TMI & Field \\
\hline & Trail King & Field \\
\hline & Transcraft & Field \\
\hline & Walbash & Field \\
\hline \multirow[t]{9}{*}{ Car Carrier Trailer } & Bankhead & Field \\
\hline & Carterbuilt & Field \\
\hline & Commercial 3 & Field \\
\hline & Cottrell & Field \\
\hline & Easy Haul & Phone \\
\hline & $\begin{array}{c}\text { Kaufman Easy } \\
\text { Loader }\end{array}$ & Field \\
\hline & Orange Blossom & Field \\
\hline & Pleasant Valley & Field \\
\hline & Take 3 & Phone \\
\hline \multirow[t]{6}{*}{ Belly Dump Trailer } & Midland & Internet \\
\hline & Ranco & Internet \\
\hline & R-Way & Internet \\
\hline & Sparta & Internet \\
\hline & Timpte & Field \\
\hline & Trail King & Internet \\
\hline \multirow[t]{12}{*}{ Passenger Vehicle and Trailer - Private Use } & Alum-lite & Field \\
\hline & Carriage & Field \\
\hline & Chalet & Internet \\
\hline & Coachman & Field \\
\hline & Cub & Field \\
\hline & Custom Frame & Field \\
\hline & Custom Haul & Field \\
\hline & Enterprise Inc. & Field \\
\hline & Featherlite & Field \\
\hline & Fleetwood & Field \\
\hline & Foste & Field \\
\hline & Hi Lo & Field \\
\hline
\end{tabular}




\begin{tabular}{|c|c|c|}
\hline & Javelin & Field \\
\hline & Keystone & Field \\
\hline & Magic Tilt & Field \\
\hline & Maxum & Field \\
\hline & Penske & Field \\
\hline & Ranger Trail & Field \\
\hline & Road Runner & Field \\
\hline & Rockwood Freedom & Field \\
\hline & Roulottes & Field \\
\hline & Ryder & Field \\
\hline & Shoreland & Field \\
\hline & Stratos Trail & Field \\
\hline & Stratus Trail & Field \\
\hline & Sunline & Field \\
\hline & Sunline Solaris & Field \\
\hline & Tee Nee & Field \\
\hline & Tracker Trailstar & Field \\
\hline & Trail Star & Field \\
\hline & Trinton Boats & Field \\
\hline & U-Haul & Field \\
\hline & United Transporters & Field \\
\hline & Wesco & Field \\
\hline & Wildwood & Field \\
\hline $\begin{array}{l}\text { Passenger Vehicle and Trailer - Commercial } \\
\text { Use }\end{array}$ & Alum-line & Field \\
\hline & Appalachian & Field \\
\hline & Barrett Trailers & Phone \\
\hline & Better Built & Field \\
\hline & Cargo Mate & Field \\
\hline & Carmate & Field \\
\hline & Carry-on & Field \\
\hline & Coachman & Field \\
\hline & Cornelius & Field \\
\hline & Cotner & Field \\
\hline & Crosscountry & Field \\
\hline & Diamond & Field \\
\hline & Featherlite & Field \\
\hline & Fulton & Field \\
\hline & Good Buddy & Field \\
\hline & Hercules & Field \\
\hline & Interstate & Field \\
\hline & Kiefer Built & Field \\
\hline & Kodiak & Field \\
\hline & Lowes & Field \\
\hline & McEIrath Inc. & Field \\
\hline & Pace & Field \\
\hline & Reese & Field \\
\hline & Ryder & Field \\
\hline
\end{tabular}




\begin{tabular}{|c|c|c|}
\hline & Trailer Tech & Phone \\
\hline & Trailers Inc. & Field \\
\hline & Trailex & Field \\
\hline & Trailking & Field \\
\hline \multirow[t]{16}{*}{ Recreational Vehicle } & Argosy & Field \\
\hline & Classic & Field \\
\hline & Coachman & Field \\
\hline & Cruise Air III & Field \\
\hline & Euroroller & Field \\
\hline & Featherlite & Field \\
\hline & Fleetwood & Field \\
\hline & Forest River & Field \\
\hline & Gulf Stream & Field \\
\hline & Holiday Rambler & Field \\
\hline & Monaco & Field \\
\hline & National RV & Field \\
\hline & Newman & Field \\
\hline & Renegade & Field \\
\hline & Tenton Homes & Field \\
\hline & Thor & Field \\
\hline
\end{tabular}


APPENDIX D - Profiles Used in HANGUP Testing and Wheelbase / Ground Clearance HANGUP Charts 
AREMA Manual for Railway Engineering (AREMA, 1993)

Railroad-Highway Grade Crossing Vertical Alignment Data

\begin{tabular}{||c|c|}
\hline Distance (feet) & Elevation (inches) \\
\hline-35 & -6.0 \\
\hline-22 & -4.5 \\
\hline-15 & -3.0 \\
\hline-8 & -1.5 \\
\hline-5 & 0.0 \\
\hline 0 & 0.0 \\
\hline 5 & 0.0 \\
\hline 8 & -1.5 \\
\hline 15 & -3.0 \\
\hline 22 & -4.5 \\
\hline 35 & -6.0 \\
\hline
\end{tabular}

Note: Point $(0,0)$ is the center of the rails 
File Name : railroad.prf Date : 04-04-2002

Ground Clearance (in)

\begin{tabular}{|c|c|c|c|c|c|c|c|c|c|c|}
\hline leel Ba & & & & & & & & & & \\
\hline $10(\mathrm{ft})$ & * & $*$ & 0 & 0 & 0 & & 0 & & & \\
\hline $11(\mathrm{ft})$ & * & * & 0 & 0 & 0 & 0 & 0 & & 0 & \\
\hline $12(\mathrm{ft})$ & 1 & $*$ & 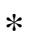 & 0 & 0 & 0 & 0 & & 0 & \\
\hline $13(\mathrm{ft})$ & 1 & $*$ & * & 0 & 0 & 0 & 0 & & 0 & 0 \\
\hline $14(\mathrm{ft})$ & 1 & $*$ & * & 0 & 0 & 0 & 0 & & 0 & 0 \\
\hline $15(\mathrm{ft})$ & 1 & * & * & 0 & 0 & 0 & 0 & ) & 0 & 0 \\
\hline $16(\mathrm{ft})$ & 1 & $*$ & * & 0 & 0 & 0 & 0 & & 0 & 0 \\
\hline $17(\mathrm{ft})$ & 1 & 1 & * & * & 0 & 0 & 0 & & 0 & \\
\hline $18(\mathrm{ft})$ & 1 & 1 & * & * & 0 & 0 & 0 & & 0 & 0 \\
\hline $19(\mathrm{ft})$ & 1 & 1 & * & * & 0 & 0 & 0 & & 0 & \\
\hline $20(\mathrm{ft})$ & 1 & 1 & * & * & 0 & 0 & 0 & & 0 & \\
\hline $21(\mathrm{ft})$ & 1 & 1 & * & * & 0 & 0 & 0 & & 0 & 0 \\
\hline $22(\mathrm{ft})$ & 1 & 1 & * & * & 0 & 0 & 0 & & 0 & \\
\hline $23(\mathrm{ft})$ & 1 & 1 & 1 & * & * & 0 & 0 & & 0 & \\
\hline $24(\mathrm{ft})$ & 1 & 1 & 1 & * & * & 0 & 0 & ) & 0 & \\
\hline $25(\mathrm{ft})$ & 1 & 1 & 1 & * & * & 0 & 0 & & 0 & \\
\hline $26(\mathrm{ft})$ & 1 & 1 & 1 & * & * & 0 & 0 & & 0 & 0 \\
\hline $27(\mathrm{ft})$ & 1 & 1 & 1 & * & * & 0 & 0 & & 0 & \\
\hline $28(\mathrm{ft})$ & 1 & 1 & 1 & 1 & * & * & 0 & ) & 0 & \\
\hline $29(\mathrm{ft})$ & 1 & 1 & 1 & 1 & * & * & 0 & ) & 0 & \\
\hline $30(\mathrm{ft})$ & 1 & 1 & 1 & 1 & * & $*$ & 0 & & 0 & \\
\hline $31(\mathrm{ft})$ & 1 & 1 & 1 & 1 & * & * & 0 & & 0 & \\
\hline $32(\mathrm{ft})$ & 1 & 1 & 1 & 1 & * & * & 0 & & 0 & \\
\hline $33(\mathrm{ft})$ & 1 & 1 & 1 & 1 & * & * & 0 & ) & 0 & \\
\hline $34(\mathrm{ft})$ & 1 & 1 & 1 & 1 & 1 & * & * & & 0 & 0 \\
\hline $35(\mathrm{ft})$ & 1 & 1 & 1 & 1 & 1 & * & * & ) & 0 & \\
\hline $36(\mathrm{ft})$ & 1 & 1 & 1 & 1 & 1 & * & * & & 0 & \\
\hline $37(\mathrm{ft})$ & 1 & 1 & 1 & 1 & 1 & * & $*$ & ) & 0 & \\
\hline $38(\mathrm{ft})$ & 1 & 1 & 1 & 1 & 1 & * & $*$ & & 0 & \\
\hline $39(\mathrm{ft})$ & 1 & 1 & 1 & 1 & 1 & 1 & * & & 0 & 0 \\
\hline $40(\mathrm{ft})$ & 1 & 1 & & & 1 & 1 & * & & & 0 \\
\hline
\end{tabular}


ITE Guidelines for Driveway Location \& Design (ITE, 1987) "Low Volume Driveway on Major Streets or Collector Streets"

\begin{tabular}{|c|c|}
\hline Distance (feet) & Elevation (inches) \\
\hline-100 & -36.00 \\
\hline-90 & -32.40 \\
\hline-80 & -28.80 \\
\hline-75 & -27.00 \\
\hline-70 & -25.20 \\
\hline-60 & -21.60 \\
\hline-50 & -18.00 \\
\hline-40 & -14.40 \\
\hline-30 & -10.80 \\
\hline-25 & -9.00 \\
\hline-20 & -7.20 \\
\hline-10 & -3.60 \\
\hline 0 & 0 \\
\hline 10 & -3.60 \\
\hline 20 & -7.20 \\
\hline 25 & -9.00 \\
\hline 30 & -10.80 \\
\hline 40 & -14.40 \\
\hline 50 & -18.00 \\
\hline 60 & -21.60 \\
\hline 70 & -25.20 \\
\hline 75 & -27.00 \\
\hline 80 & -28.80 \\
\hline 90 & -32.40 \\
\hline 100 & -36.00 \\
\hline
\end{tabular}

Note: Point $(0,0)$ is the center of the grade break. 


\section{$\begin{array}{llllll}H & A & N & G & \text { U } & \text { P }\end{array}$}

File Name : vertical.prf Date : 04-04-2002

Ground Clearance (in)

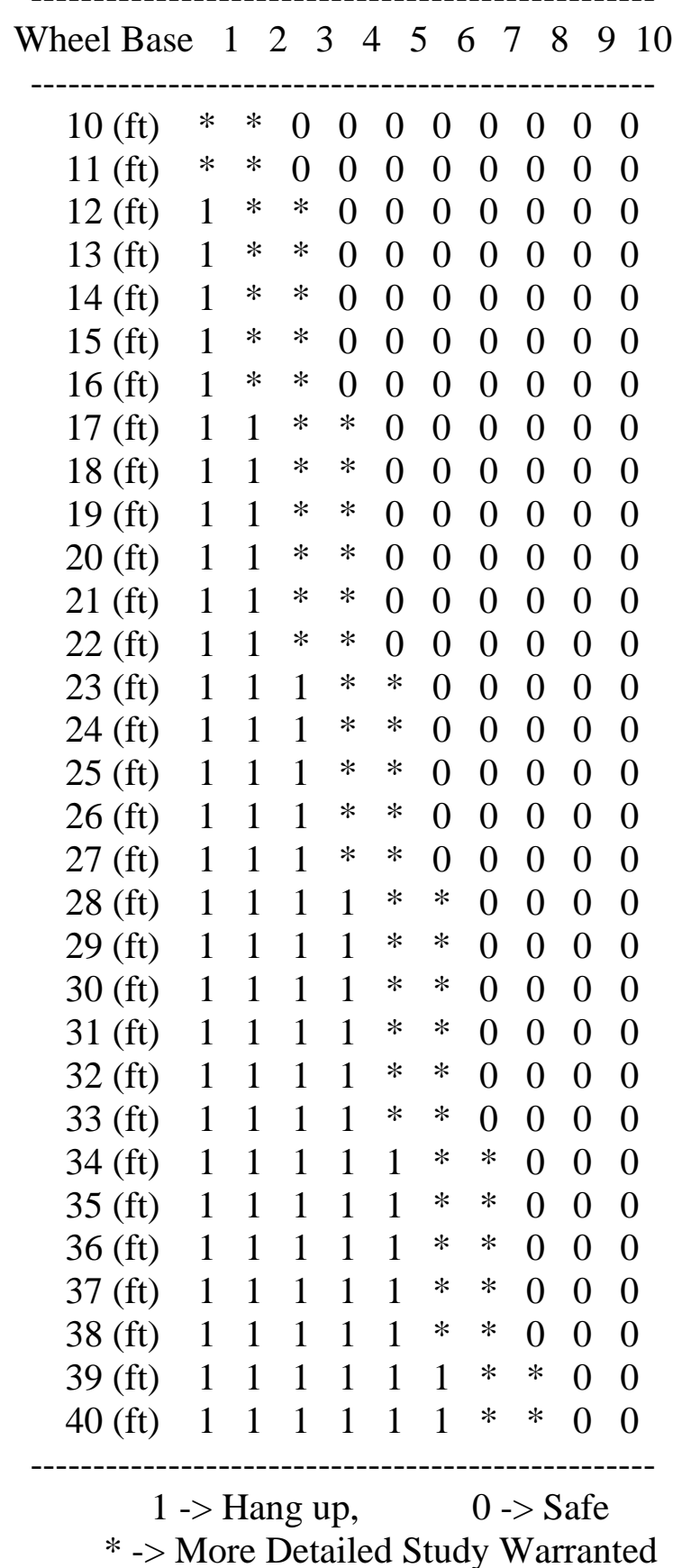


ITE Guidelines for Driveway Location \& Design (ITE, 1987) "Low Volume Driveway on a Local Street"

\begin{tabular}{|c|c|}
\hline Distance (feet) & Elevation (inches) \\
\hline-100 & 24.0 \\
\hline-90 & 21.6 \\
\hline-80 & 19.2 \\
\hline-70 & 16.8 \\
\hline-60 & 14.4 \\
\hline-50 & 12.0 \\
\hline-40 & 9.6 \\
\hline-30 & 7.2 \\
\hline-20 & 4.8 \\
\hline-10 & 2.4 \\
\hline-5 & 1.2 \\
\hline 0 & 0 \\
\hline 5 & 7.8 \\
\hline 10 & 15.6 \\
\hline 20 & 31.2 \\
\hline 30 & 46.8 \\
\hline 40 & 62.4 \\
\hline 50 & 78.9 \\
\hline 60 & 93.6 \\
\hline 70 & 109.2 \\
\hline 80 & 124.8 \\
\hline 90 & 140.4 \\
\hline 100 & 156.0 \\
\hline
\end{tabular}

Note: Point $(0,0)$ is the center of the grade break 


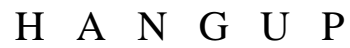

File Name : sag.prf

Date : 10-01-2001

Ground Clearance (in)

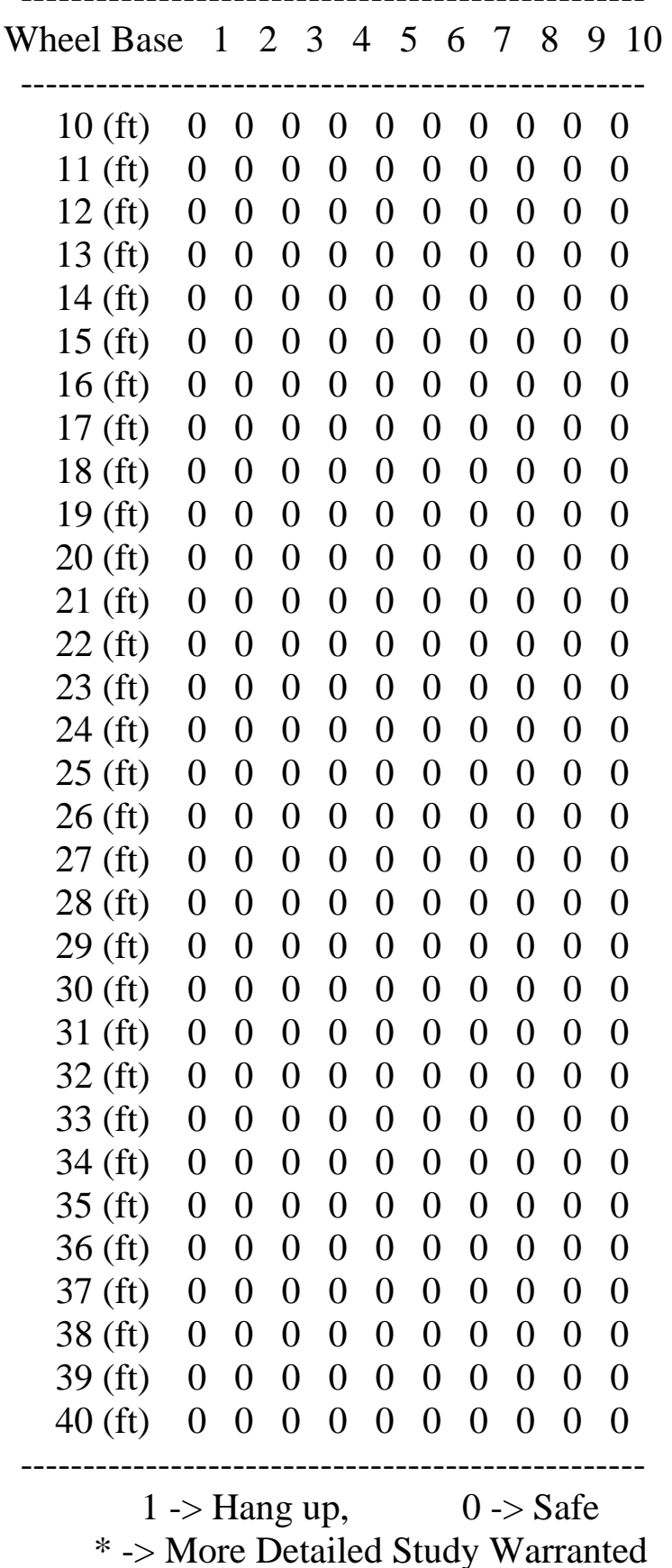




\section{Typical Double Track Mainline Railroad Crossing}

\begin{tabular}{|c|c|}
\hline Distance (feet) & Elevation (inches) \\
\hline-80 & -31.32 \\
\hline-55 & -17.16 \\
\hline-45 & -10.92 \\
\hline-35 & -5.88 \\
\hline-25 & -1.68 \\
\hline-15 & -0.36 \\
\hline-5 & 0.0 \\
\hline 0 & 0.0 \\
\hline 10 & -0.48 \\
\hline 20 & -3.84 \\
\hline 30 & -8.76 \\
\hline 40 & -15.0 \\
\hline 50 & -22.32 \\
\hline 75 & -43.44 \\
\hline
\end{tabular}


Ground Clearance (in)

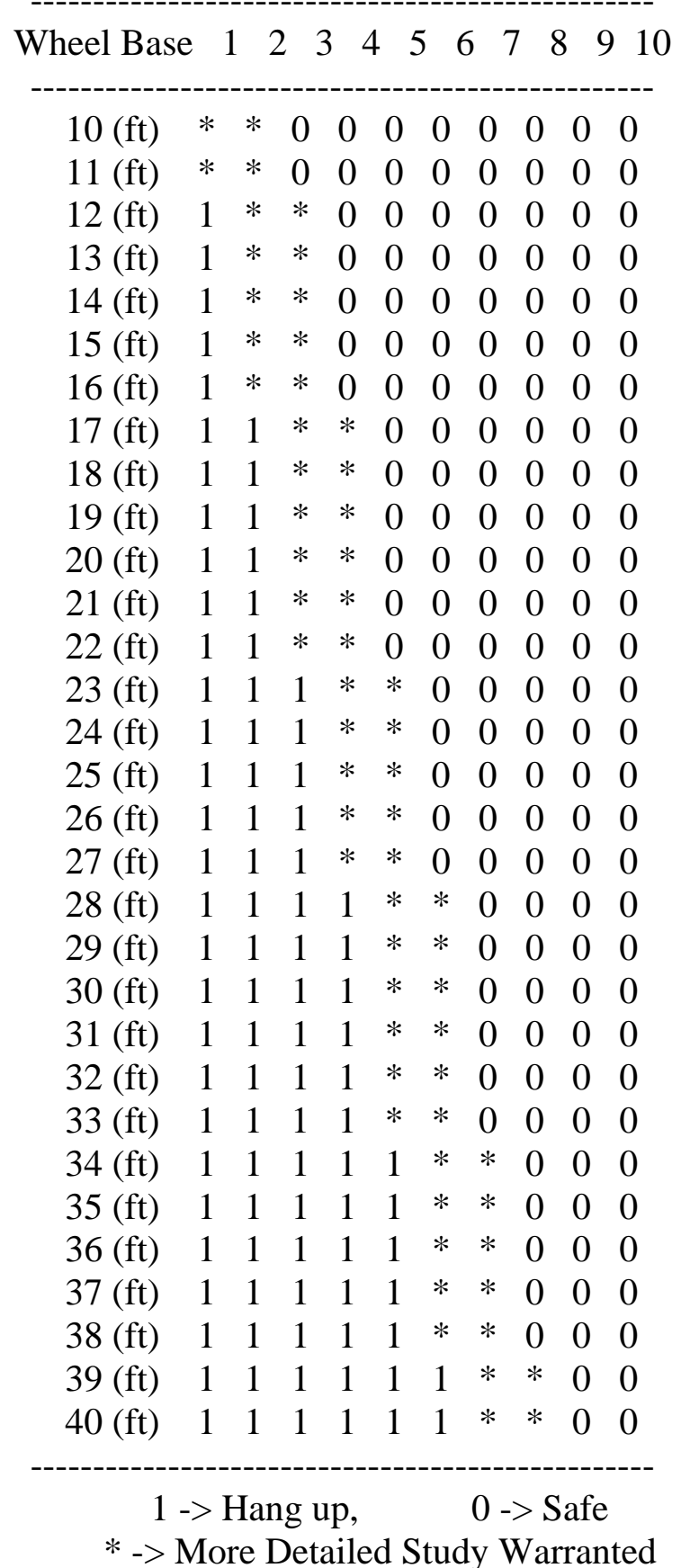


APPENDIX E - Wheelbase HANGUP Plots 


\section{Wheelbase Hang up plot - Single Unit Beverage Truck}

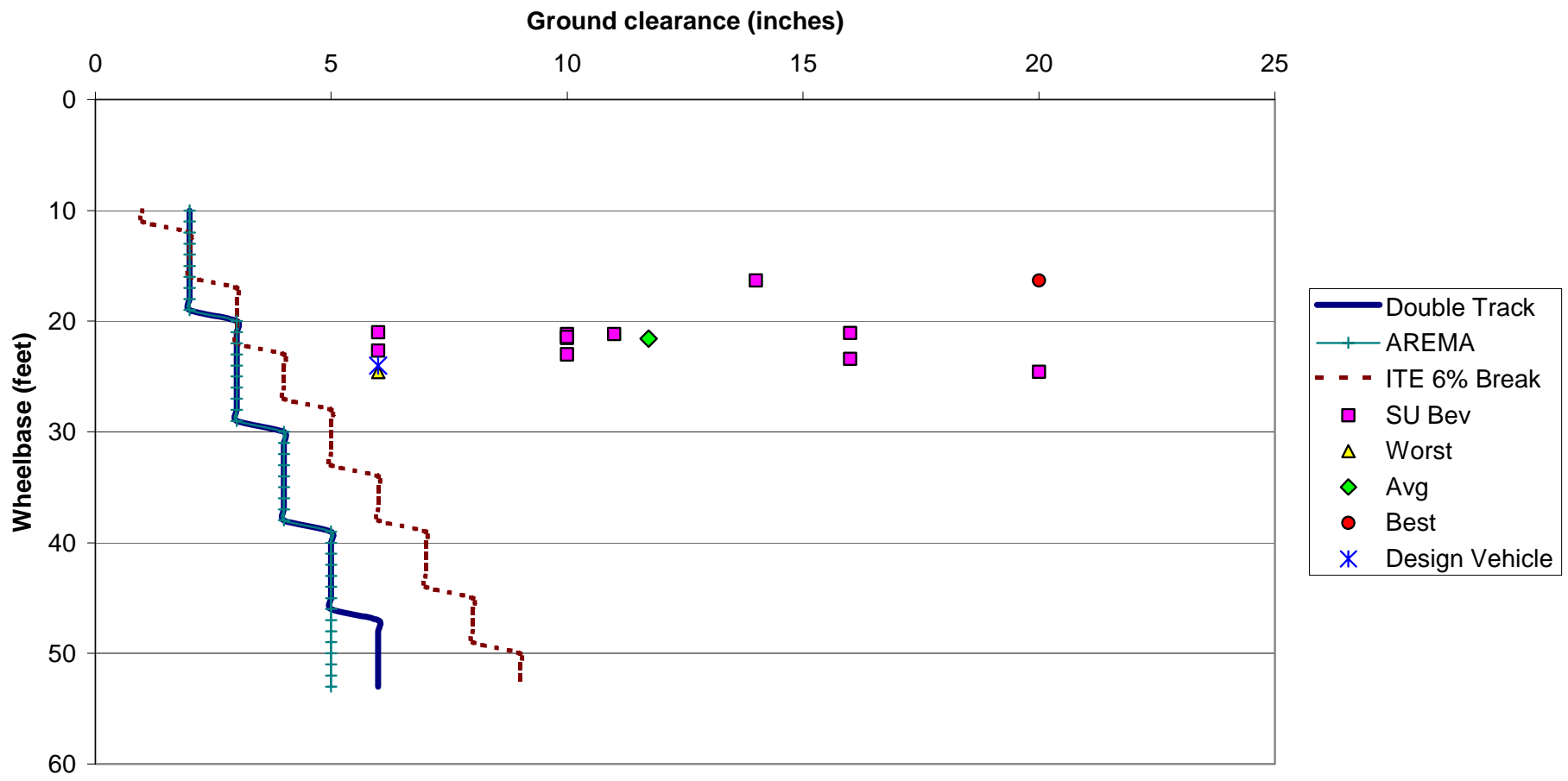


Wheelbase Hang up plot - Articulated Beverage Truck

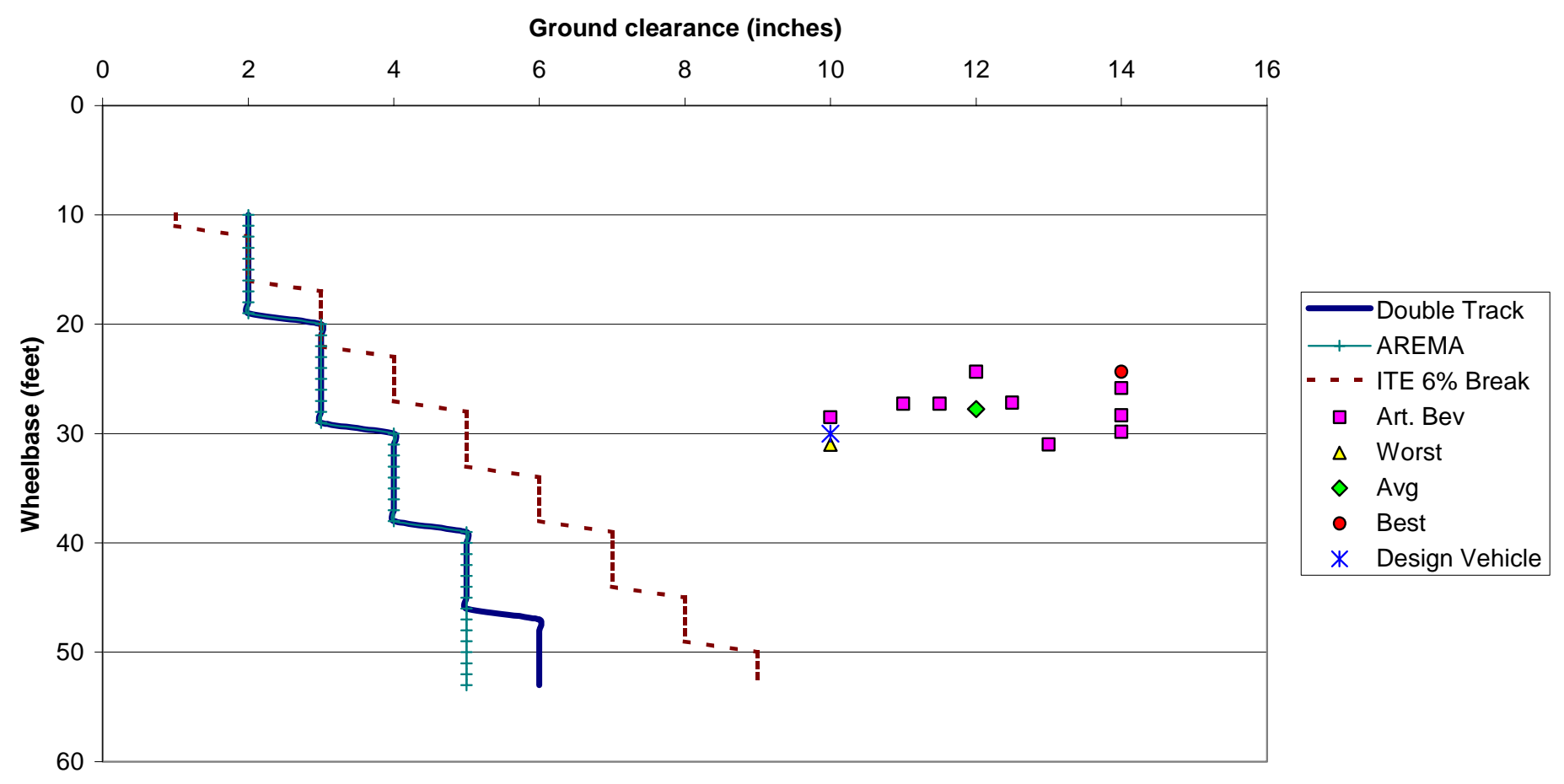




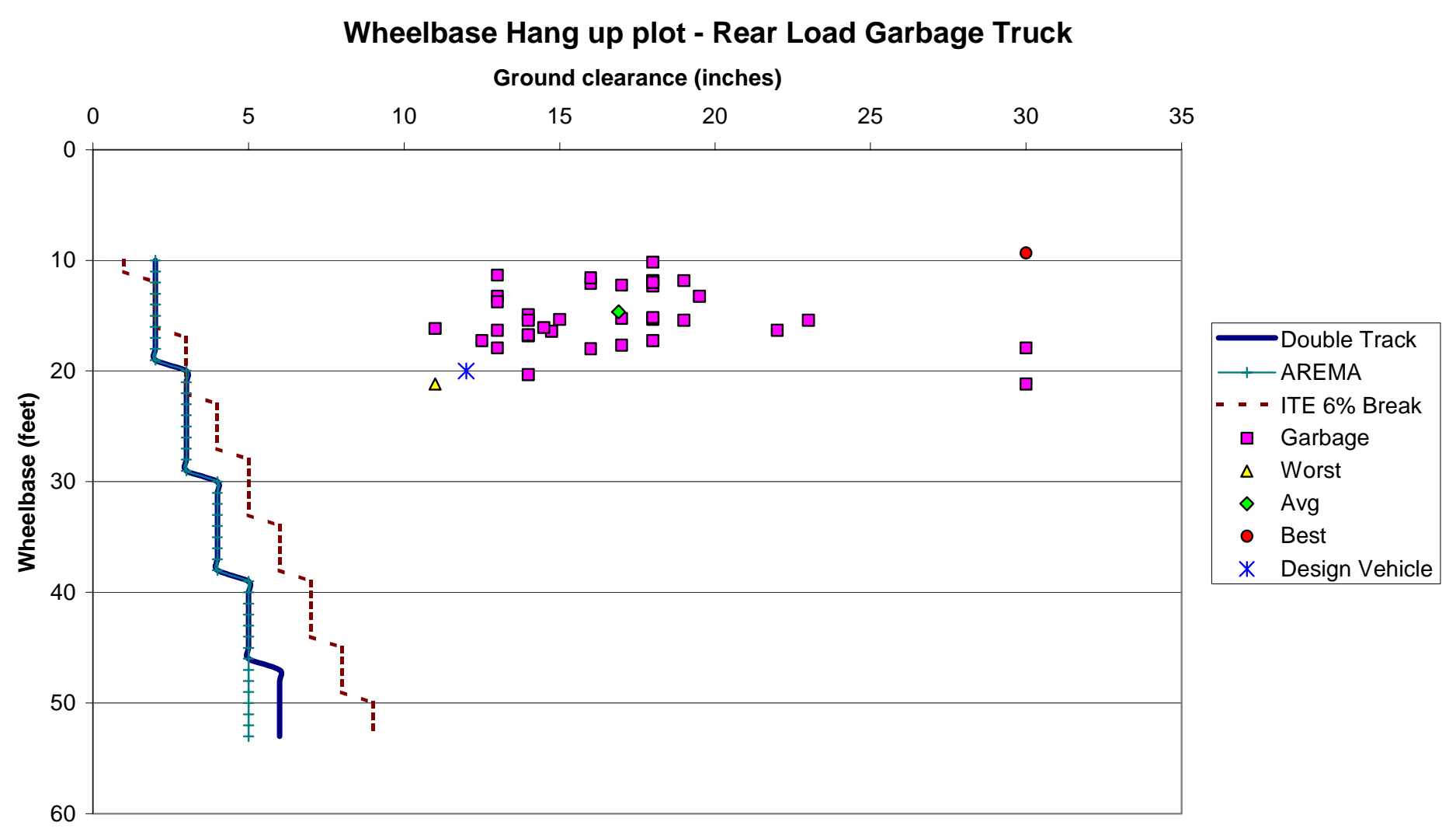


Wheelbase Hang up plot - Aerial Fire Truck

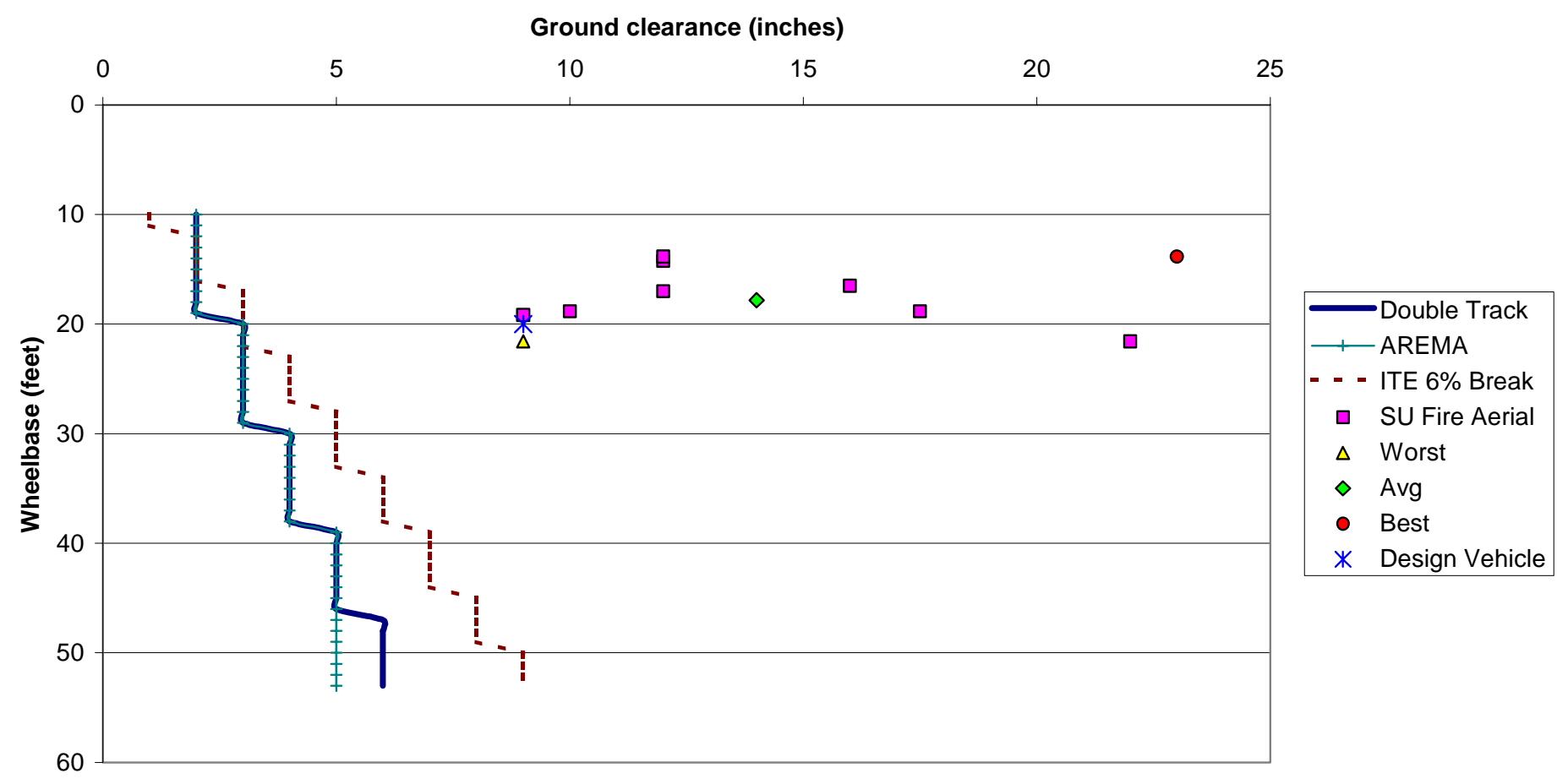


Wheelbase Hang up plot - Pumper Fire Truck

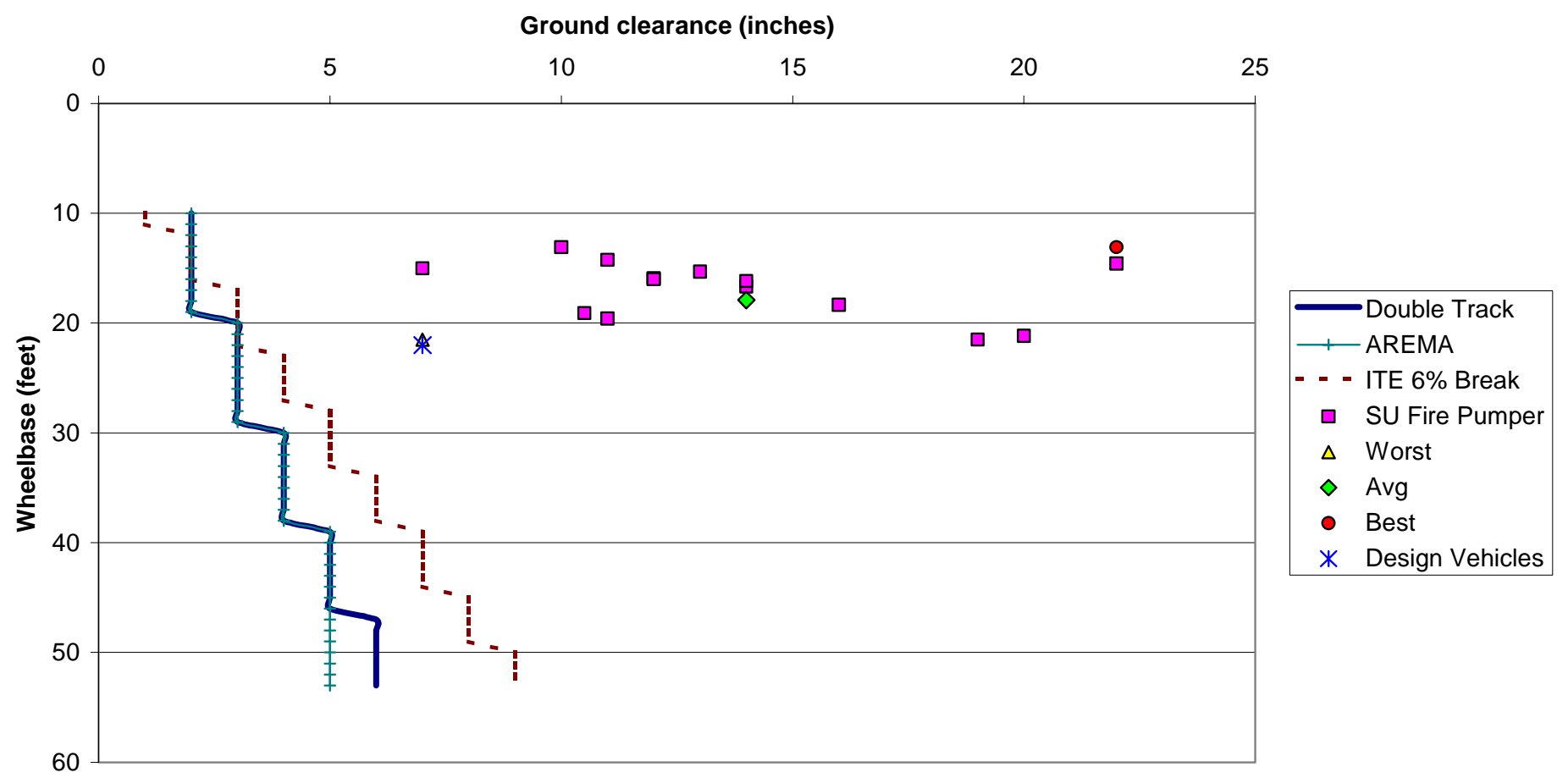


Wheelbase Hang up plot - Minibus (transit)

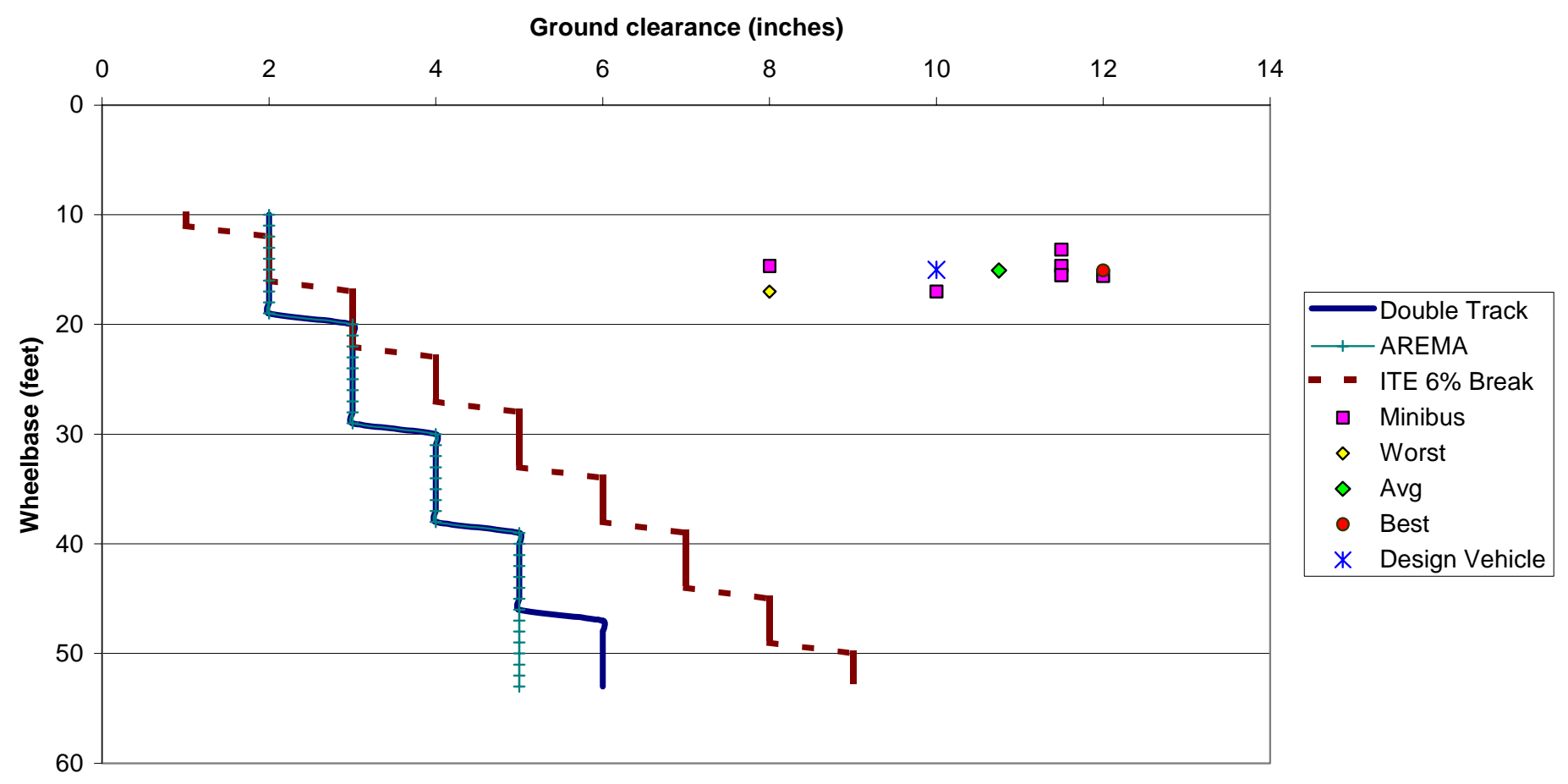




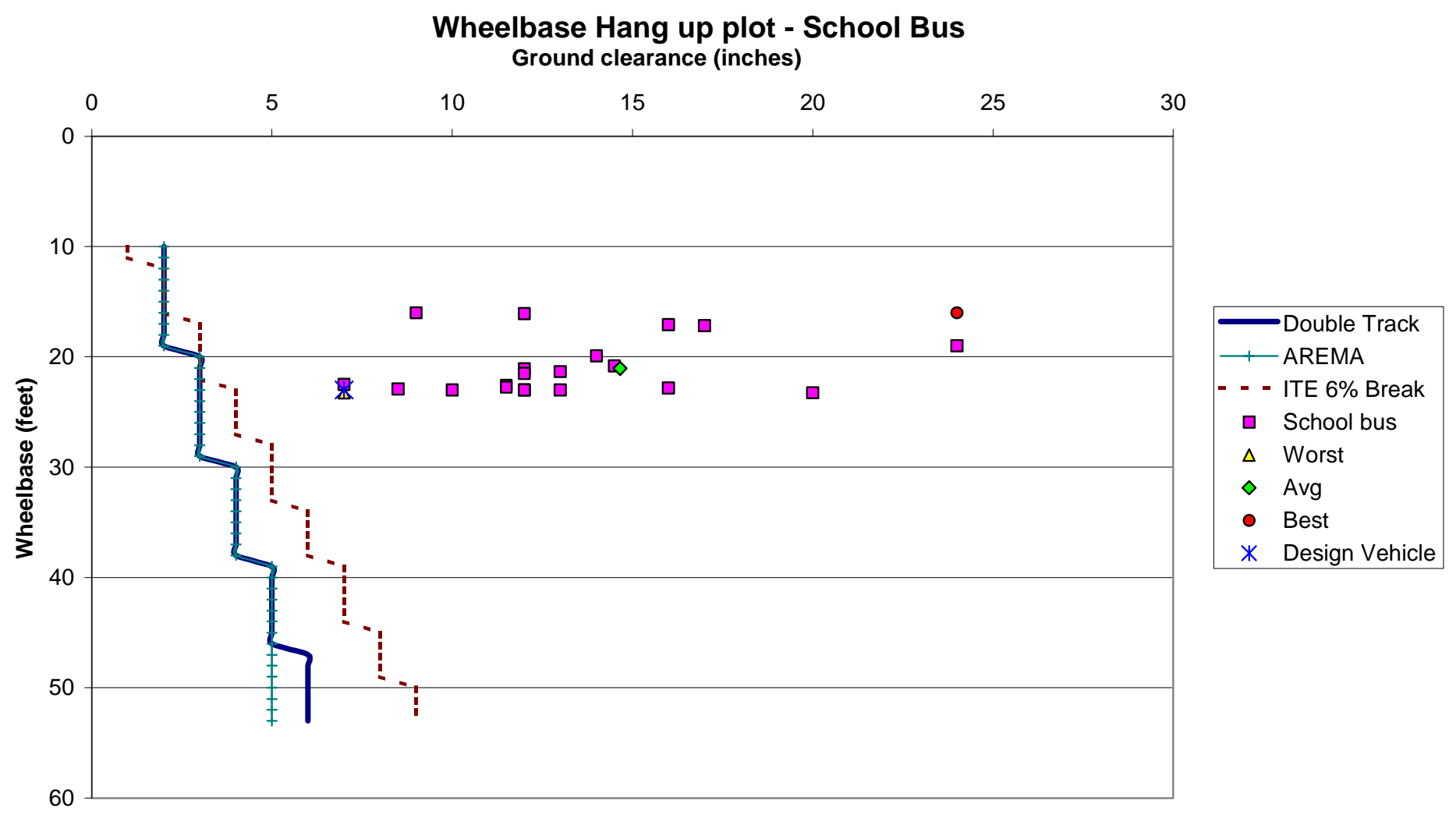


Wheelbase Hang up plot - Single Unit Transit Bus

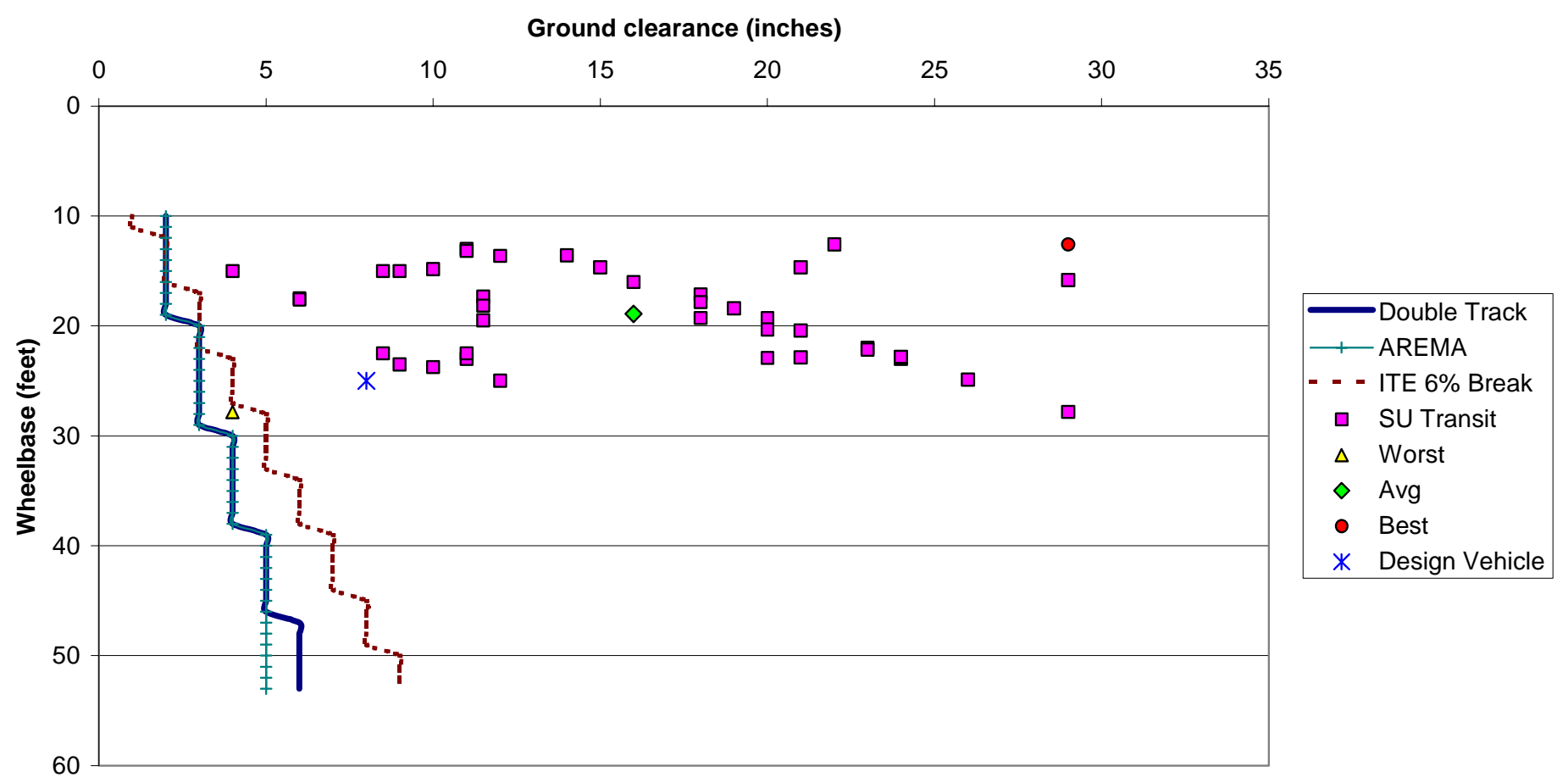




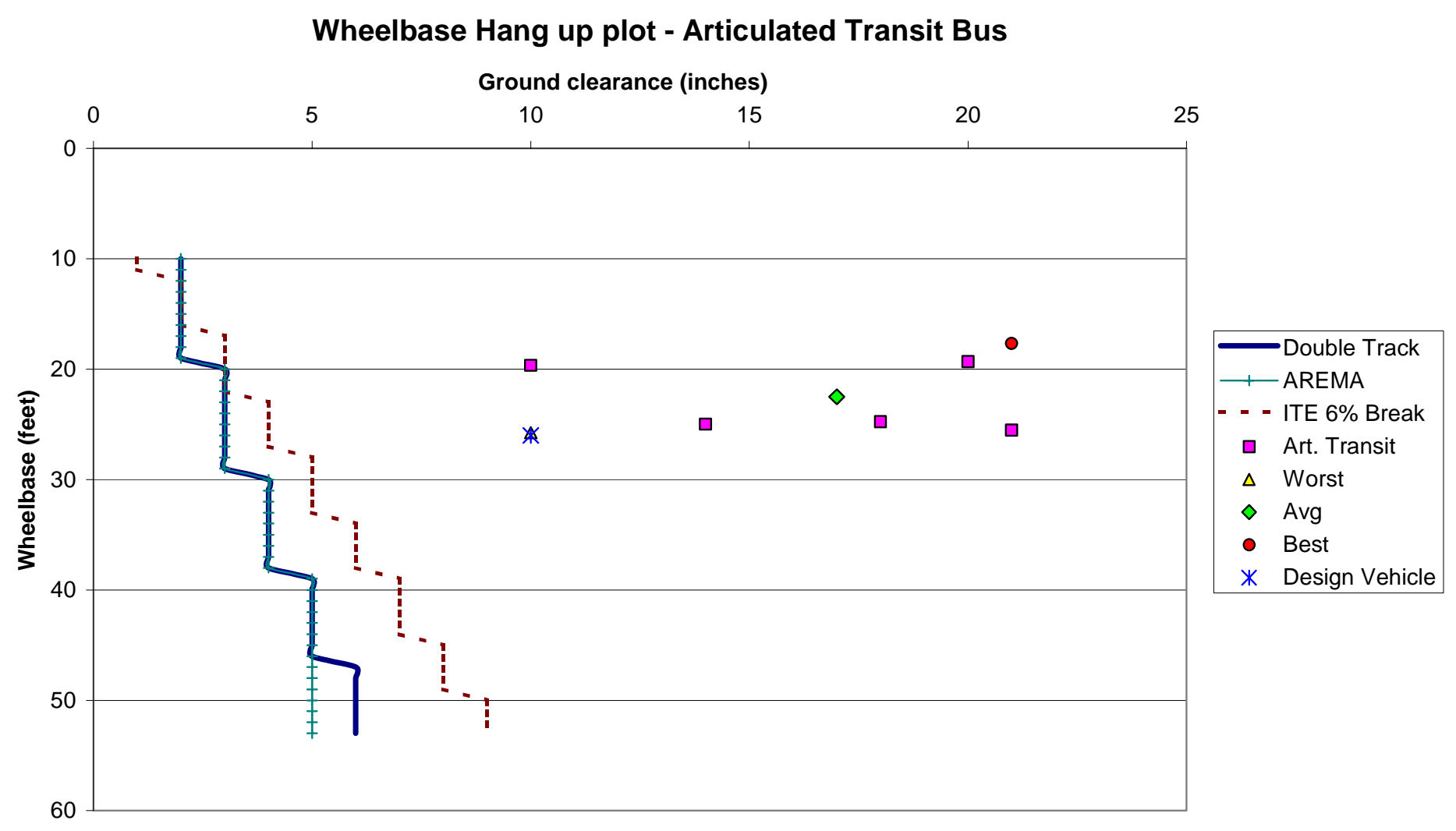


Wheelbase Hang up plot - Motorcoach

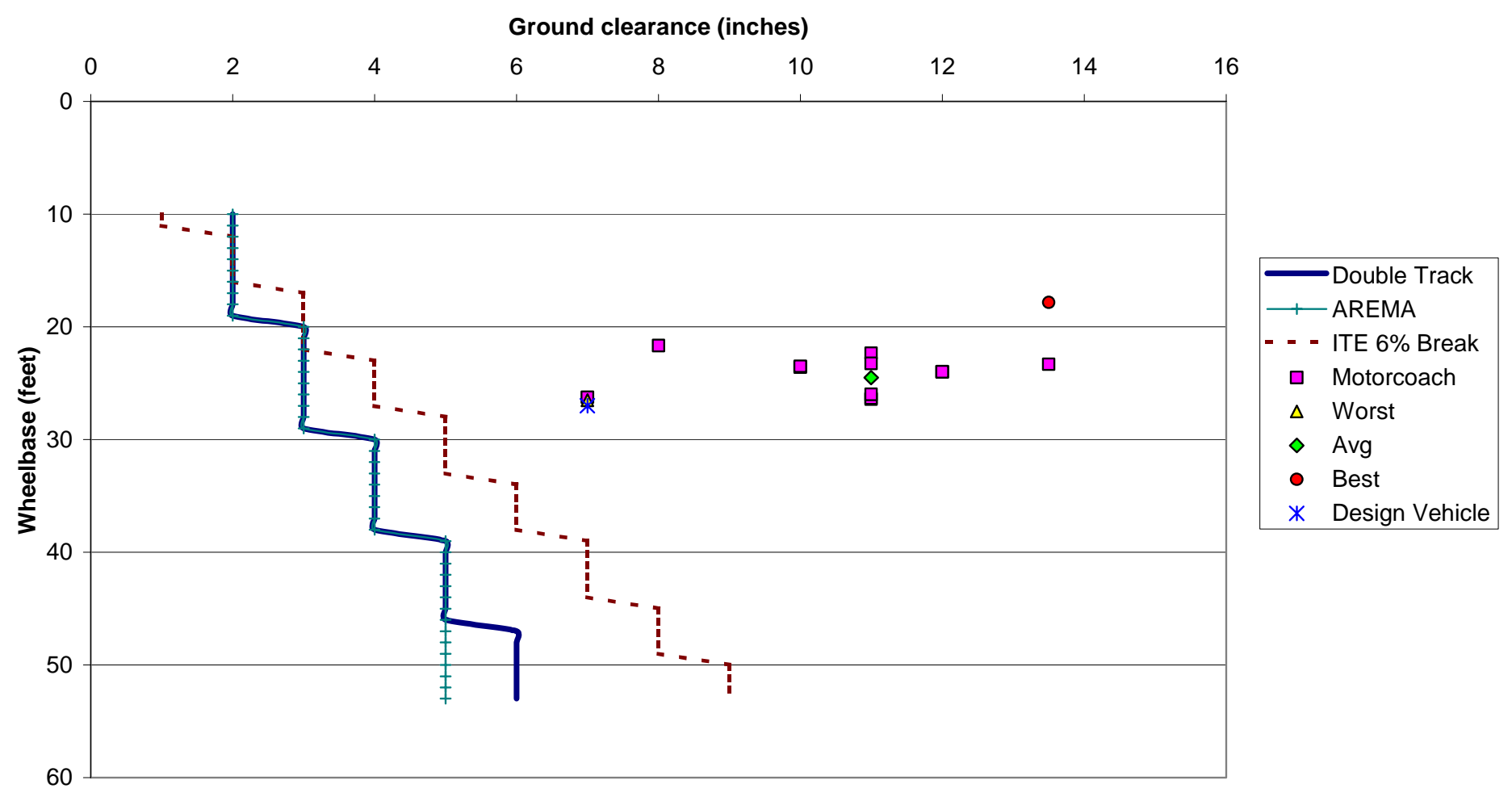




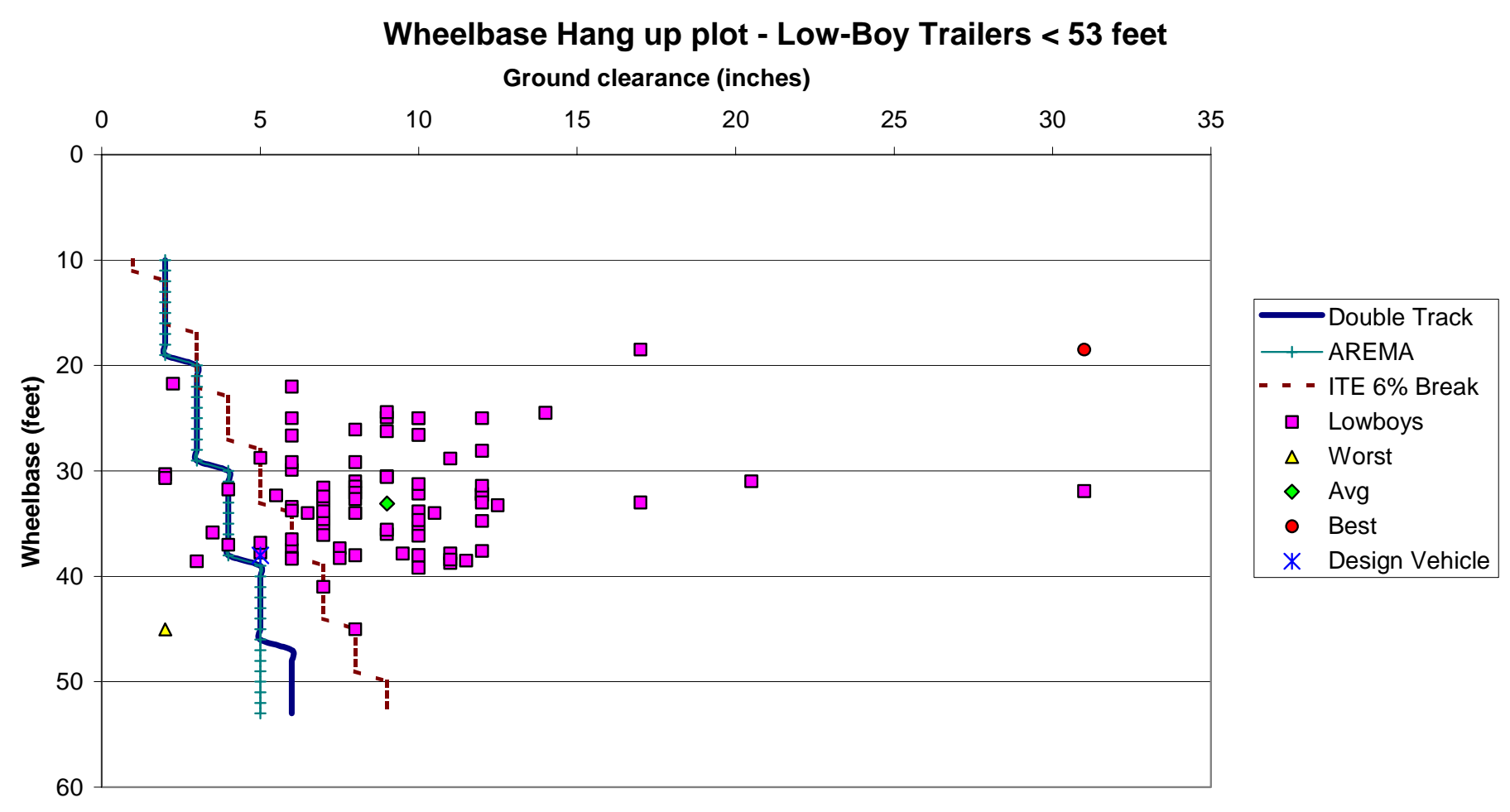




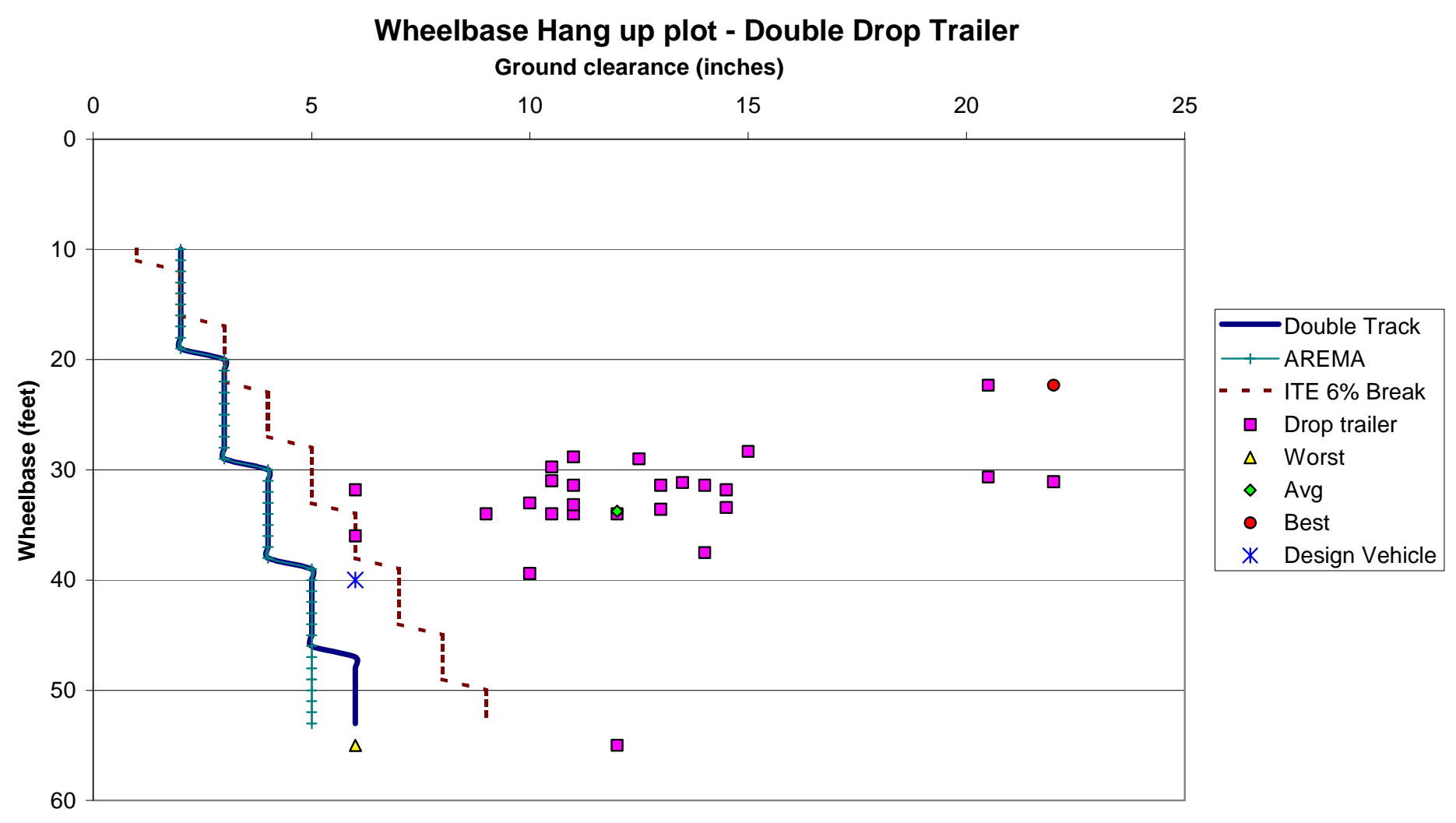


Wheelbase Hang up plot - Car Carrier Trailer

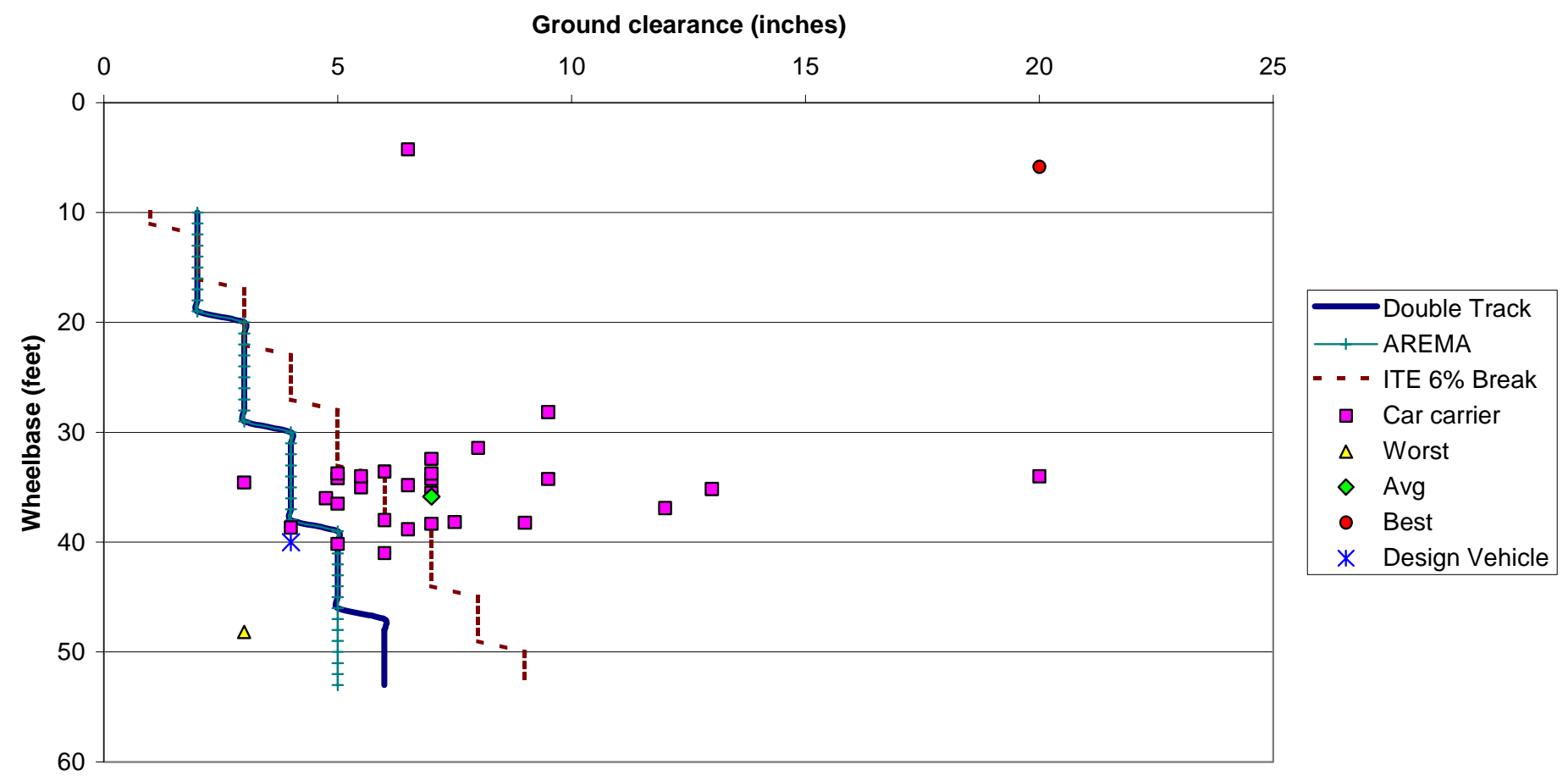




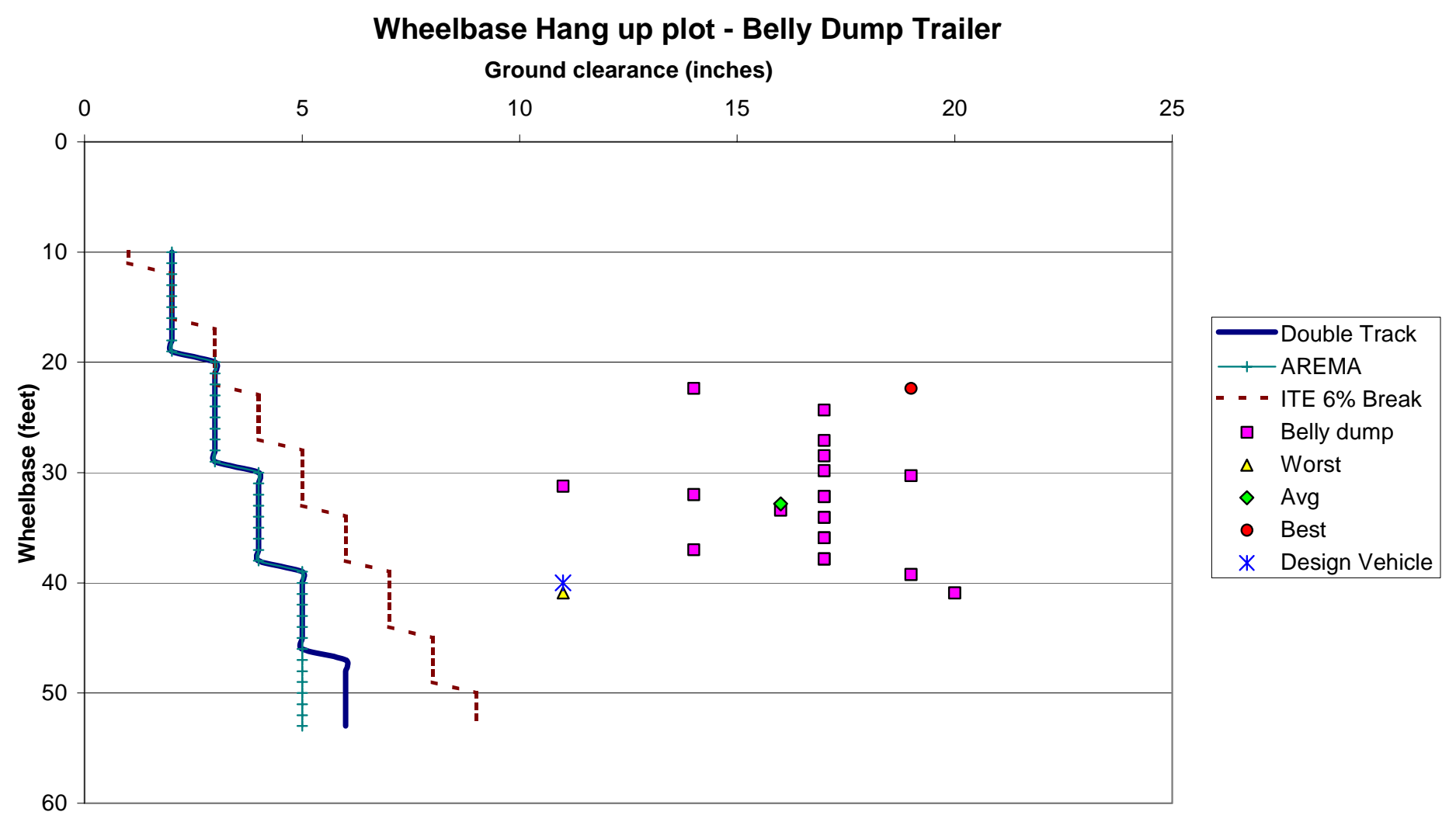


Wheelbase Hang up plot - Passenger Vehicles and Trailers - Private Use

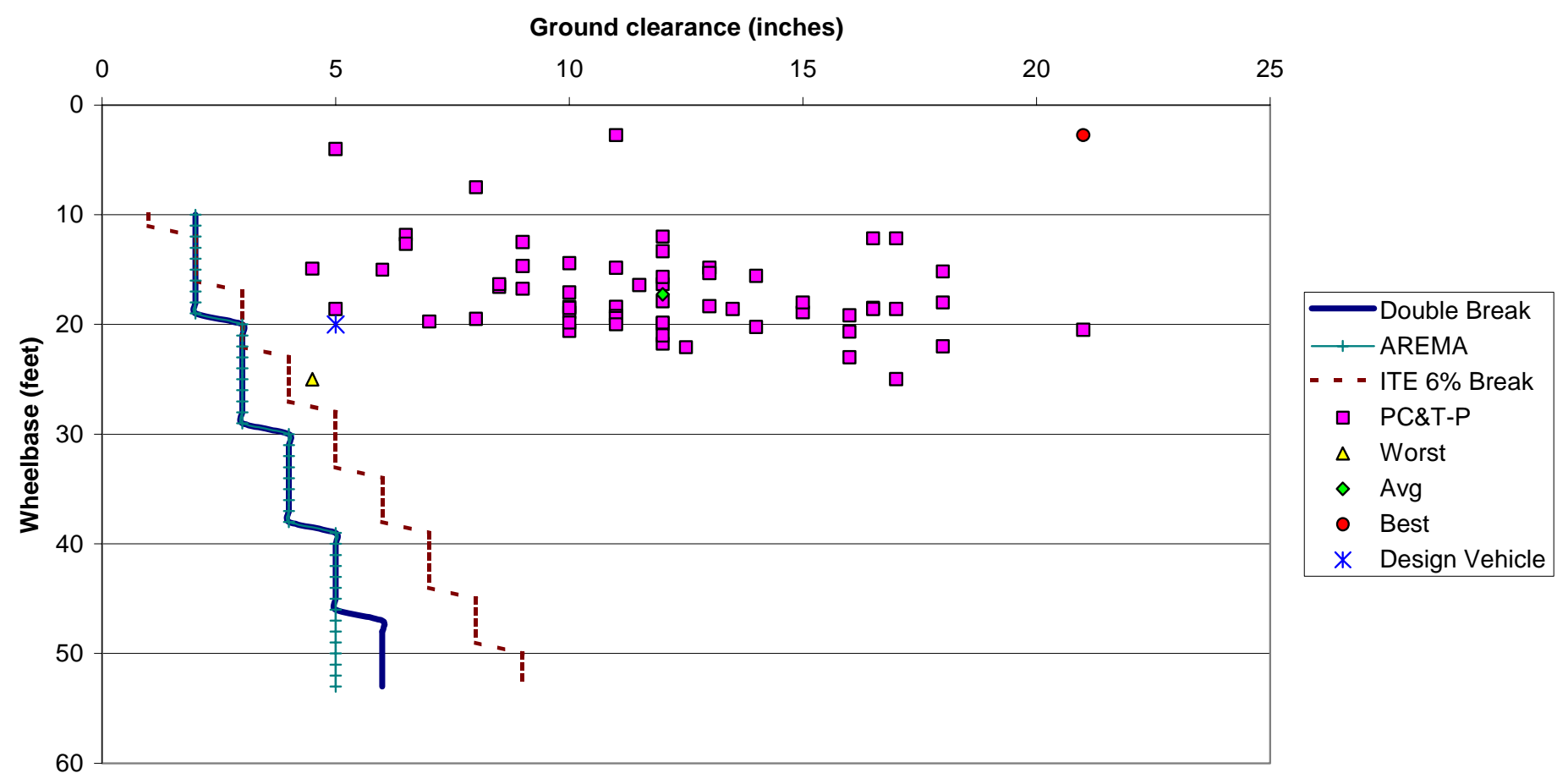


Wheelbase Hang up plot - Passenger Vehicles and Trailers - Commercial Use

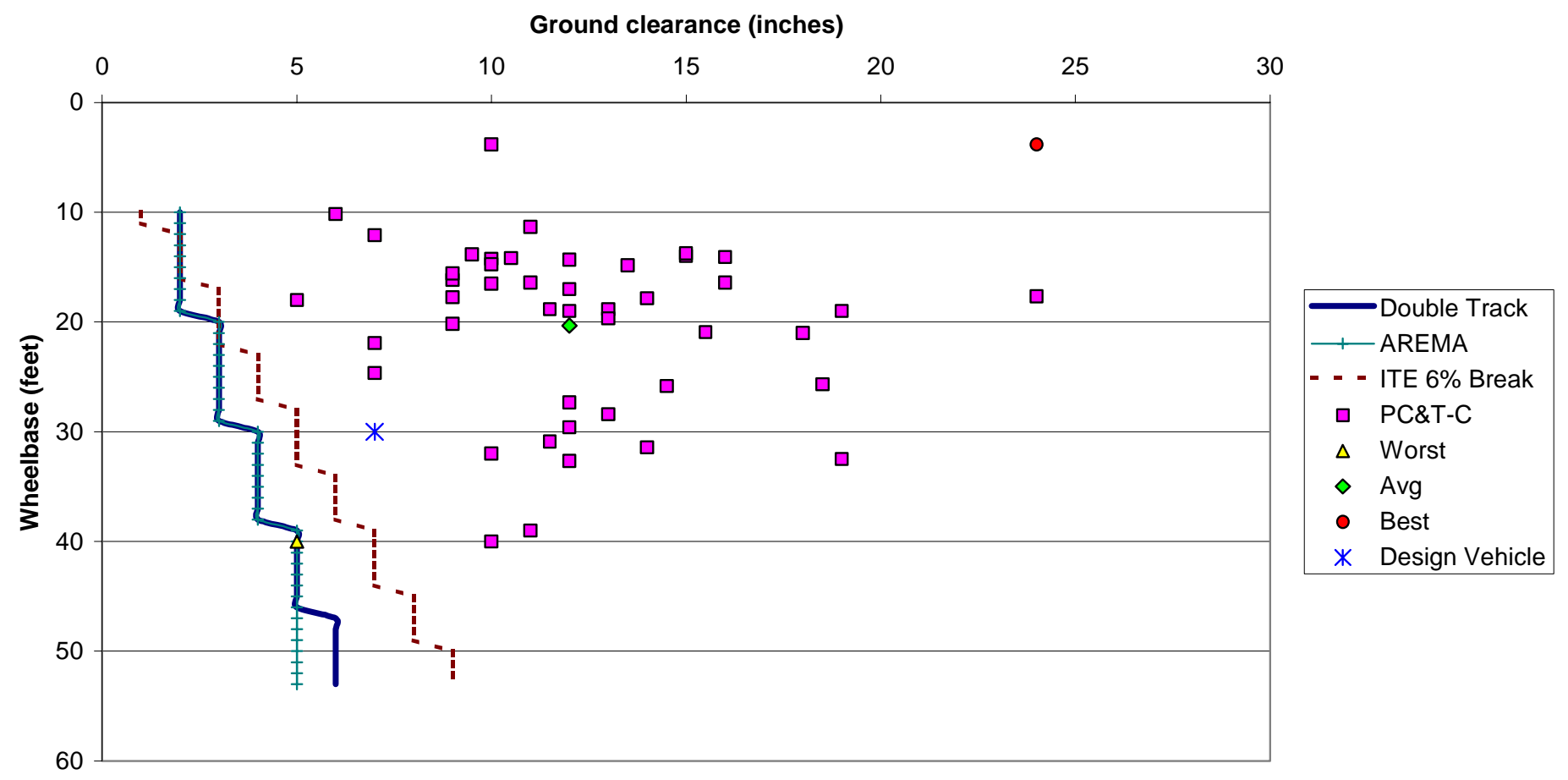




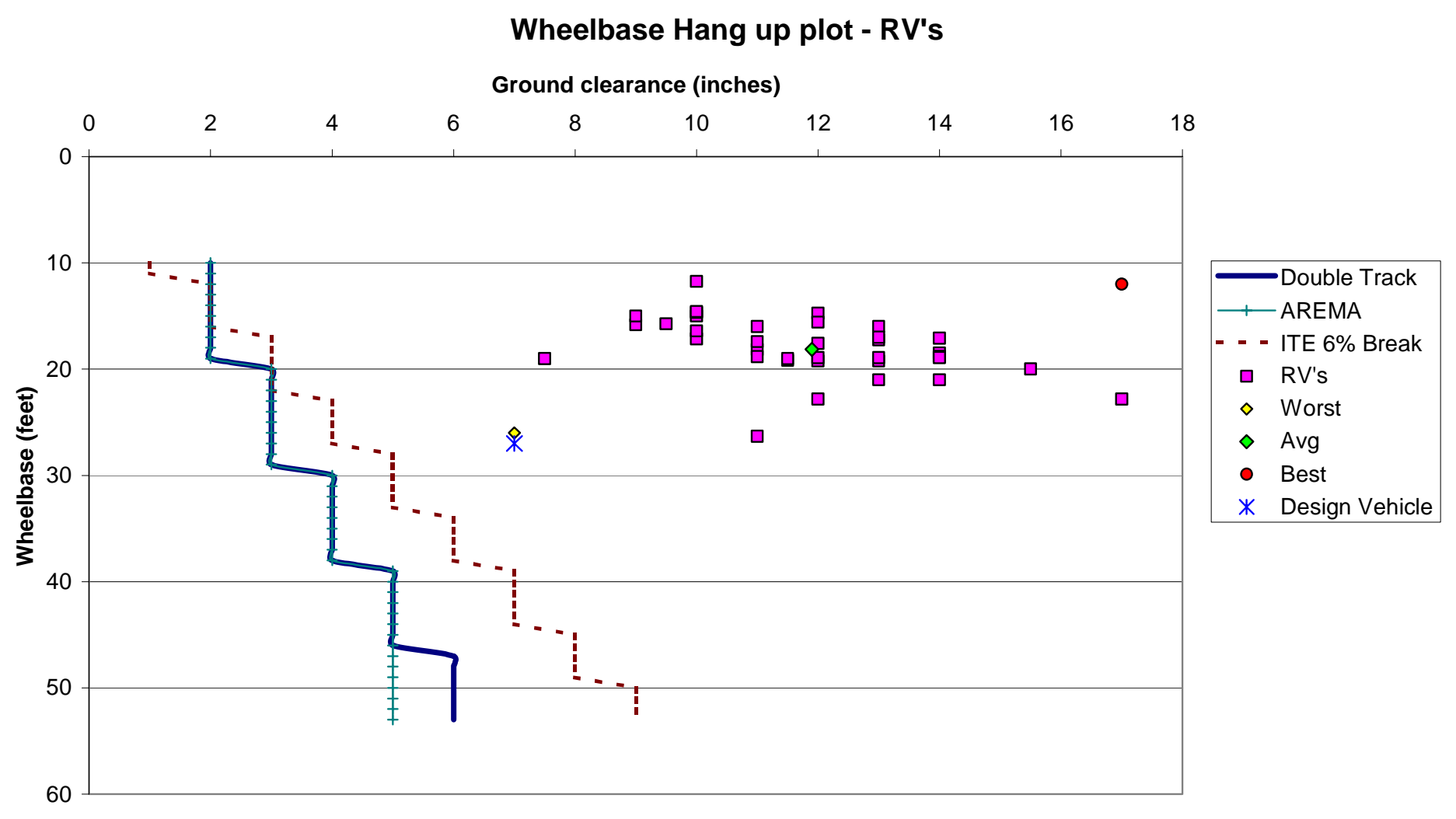


APPENDIX F - Rear Overhang HANGUP Plots 


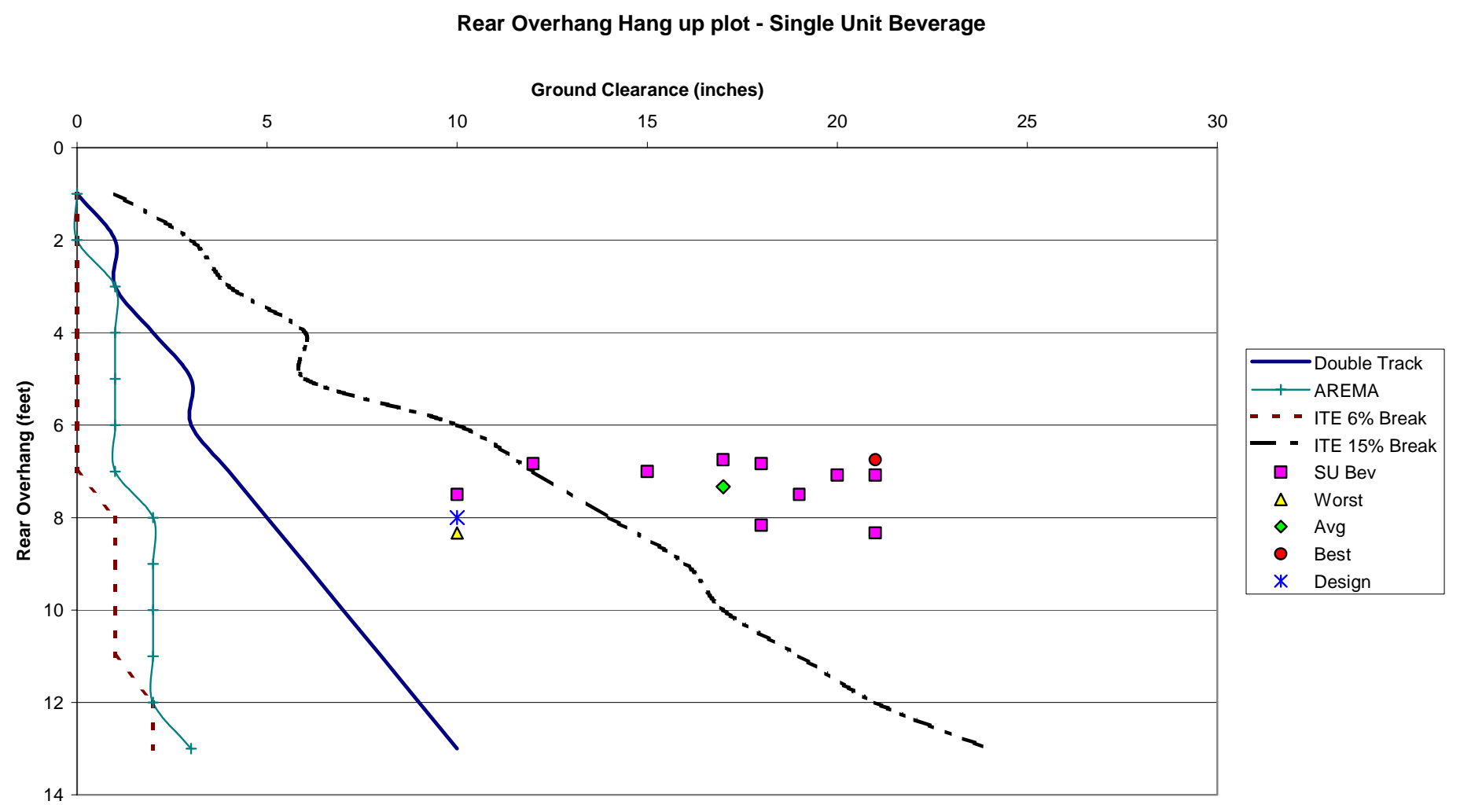


Rear Overhang Hang up plot - Rear-Load Garbage trucks

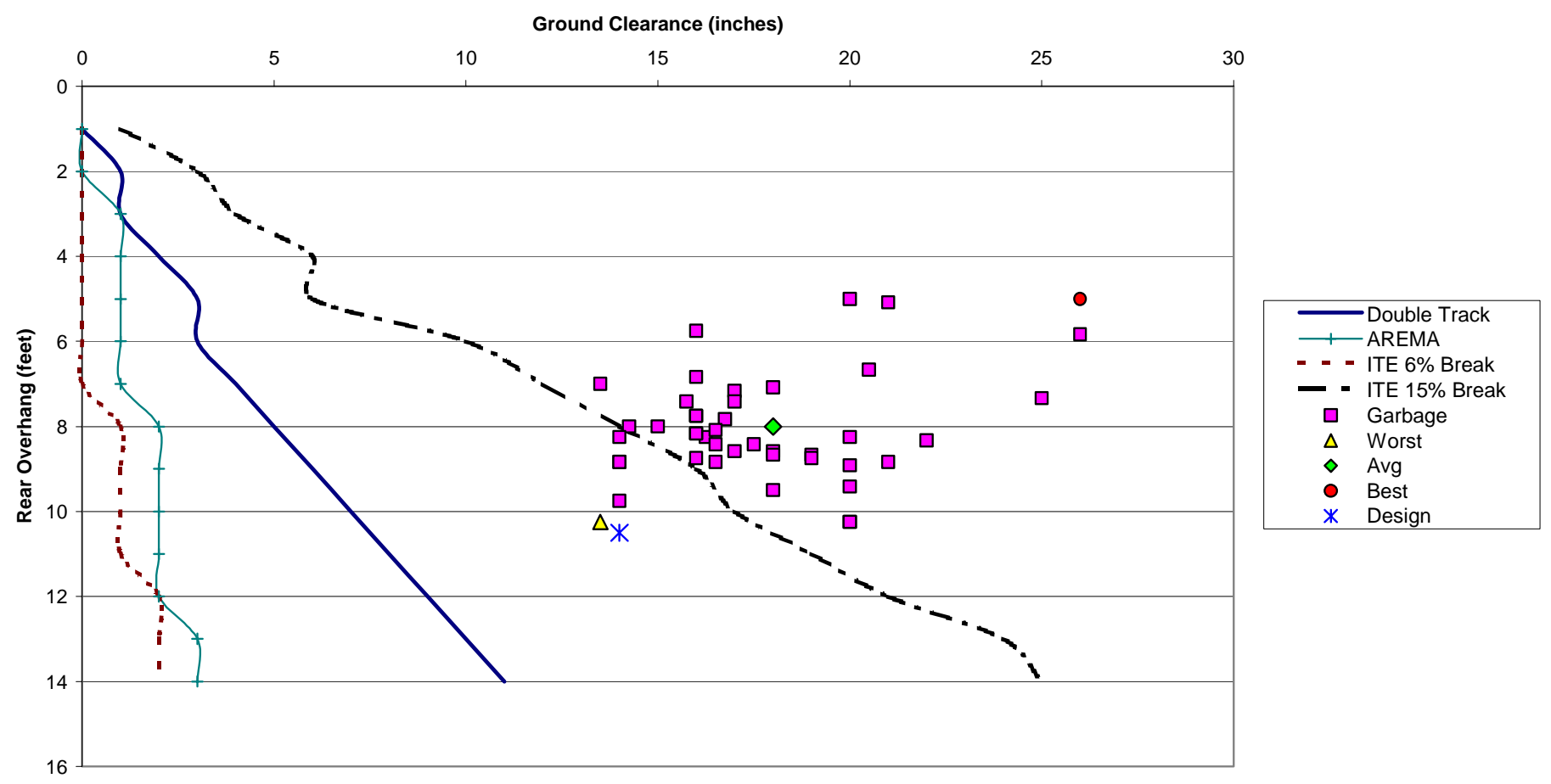




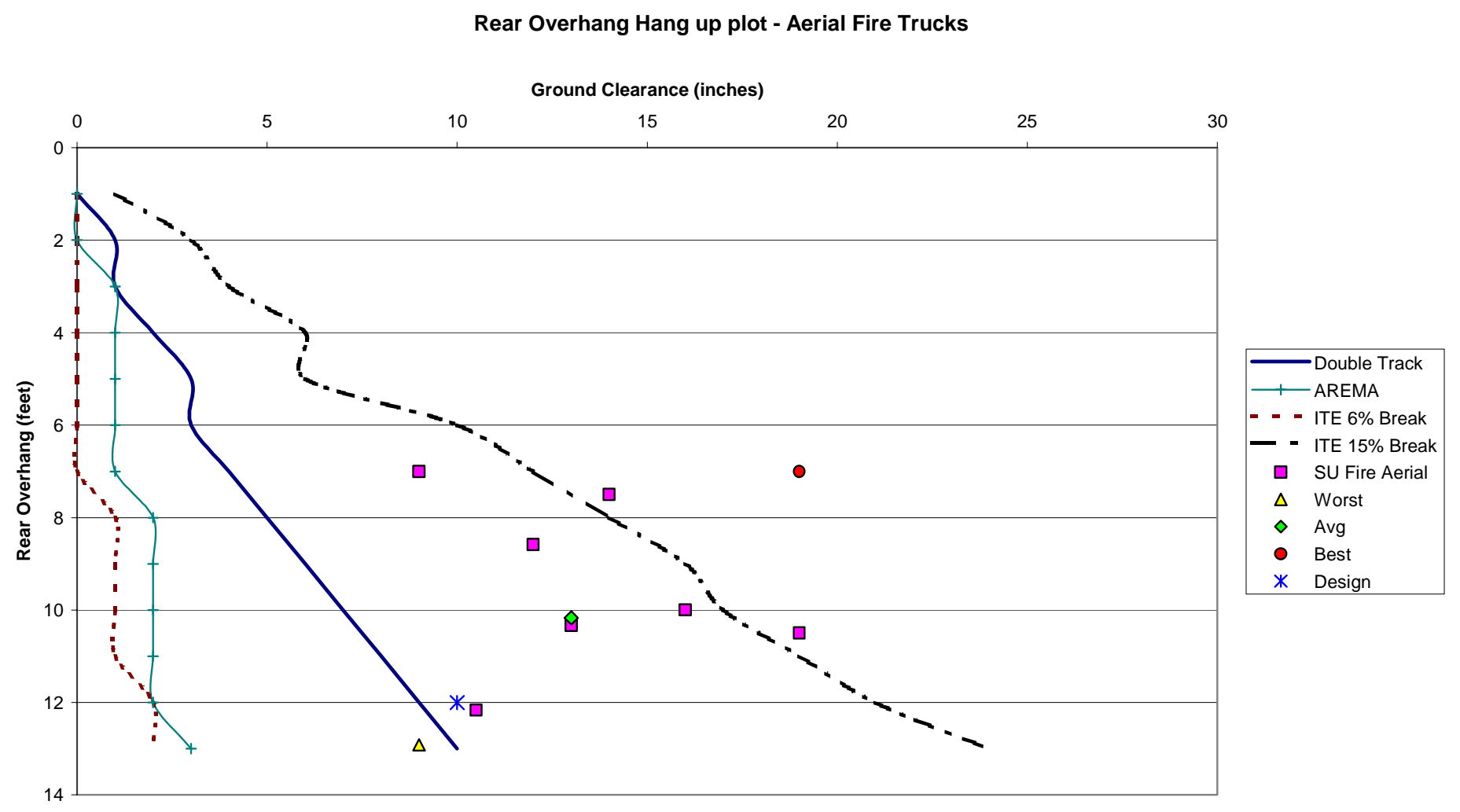




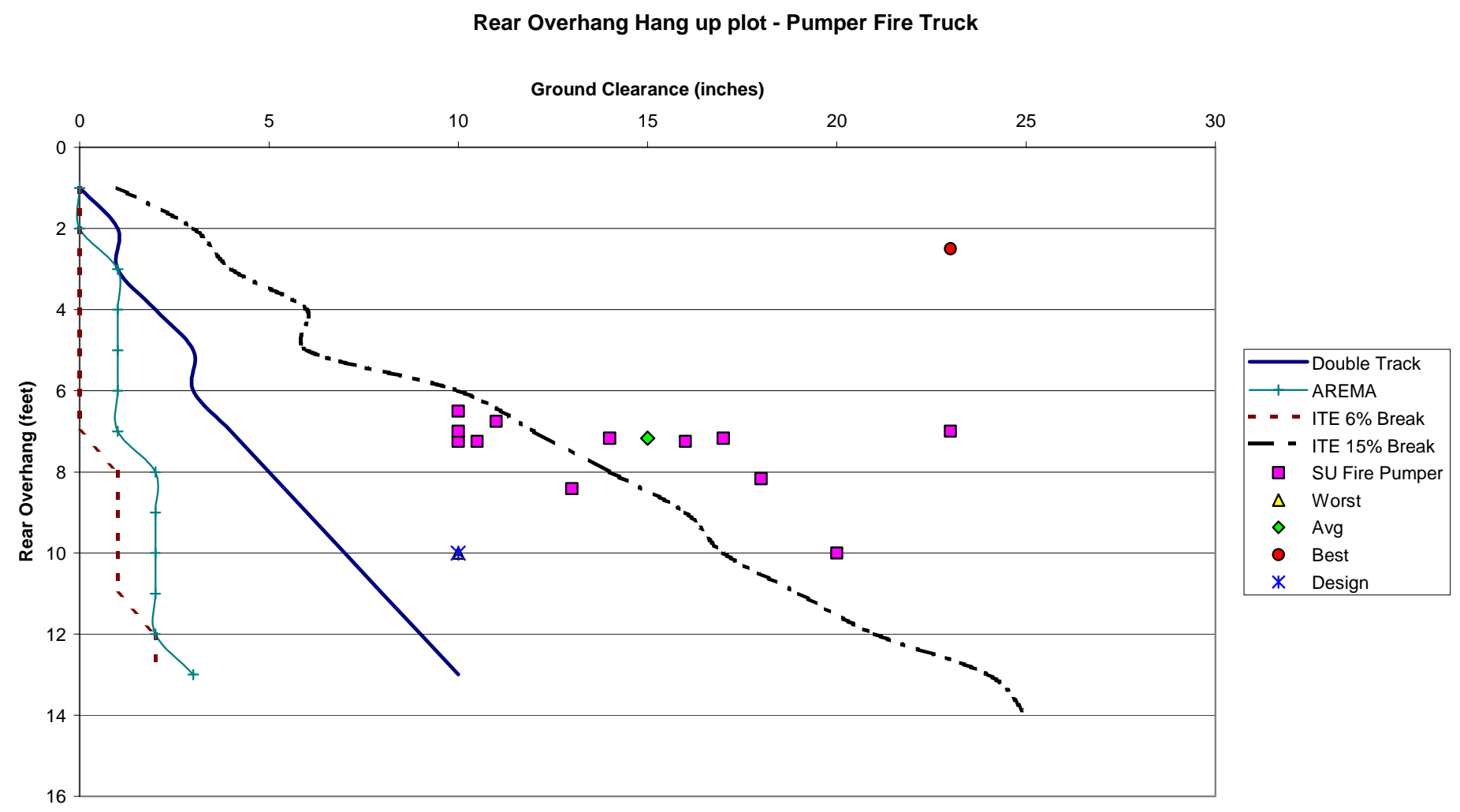




\section{Rear Overhang Hang up plot - Mini bus}

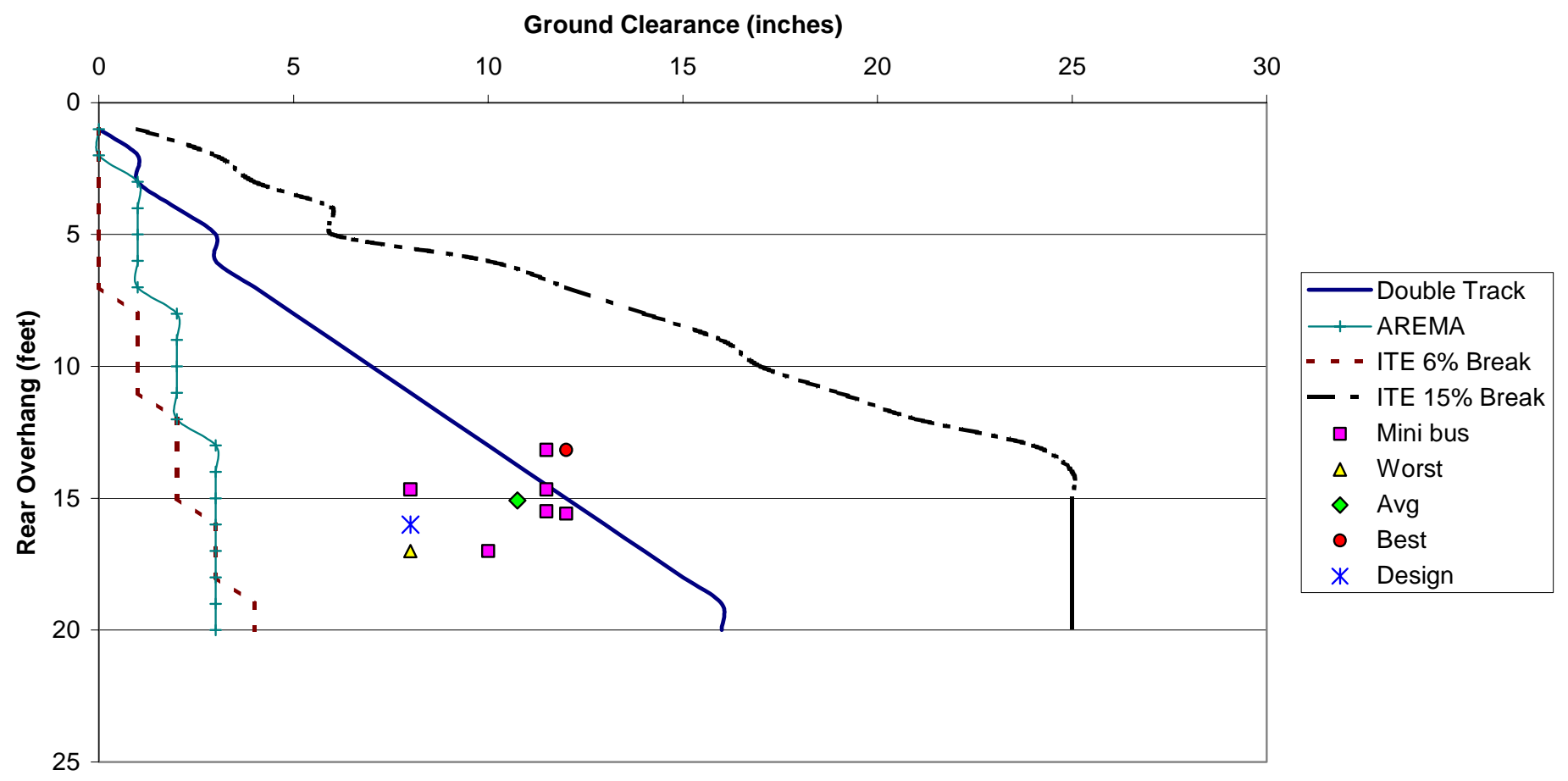


Rear Overhang Hang up plot - School Bus

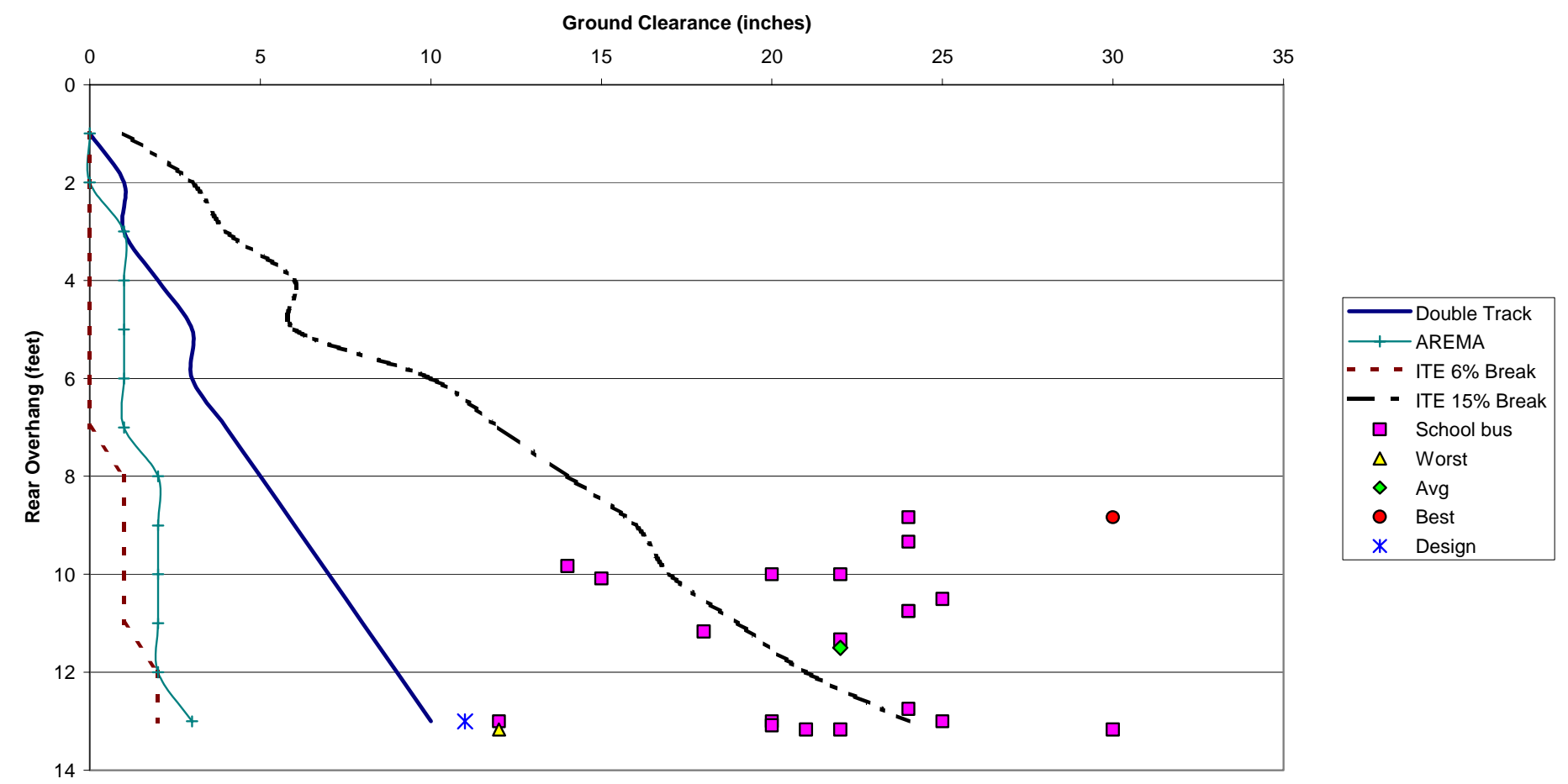


Rear Overhang Hang up plot - Articulated Transit

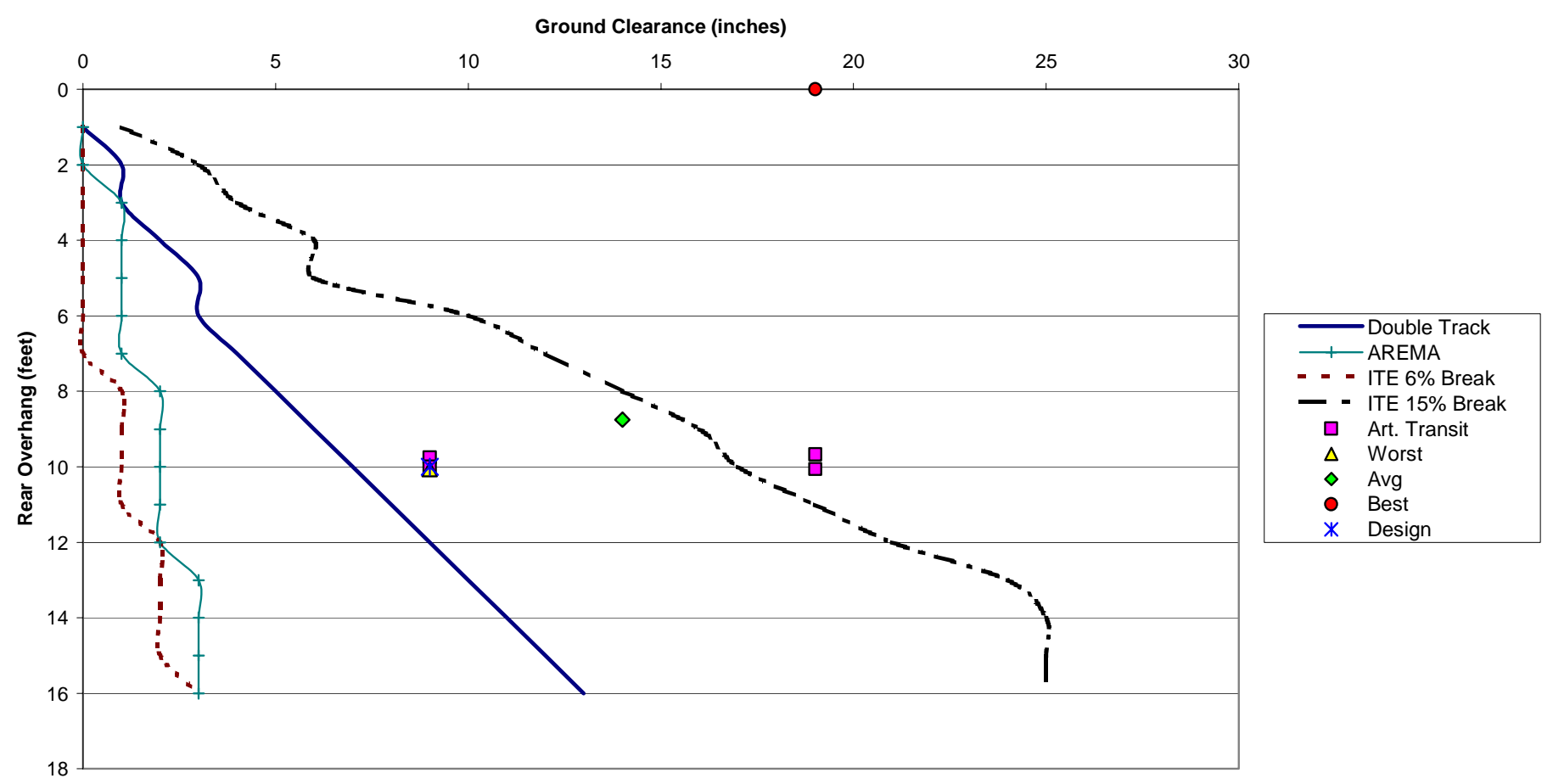




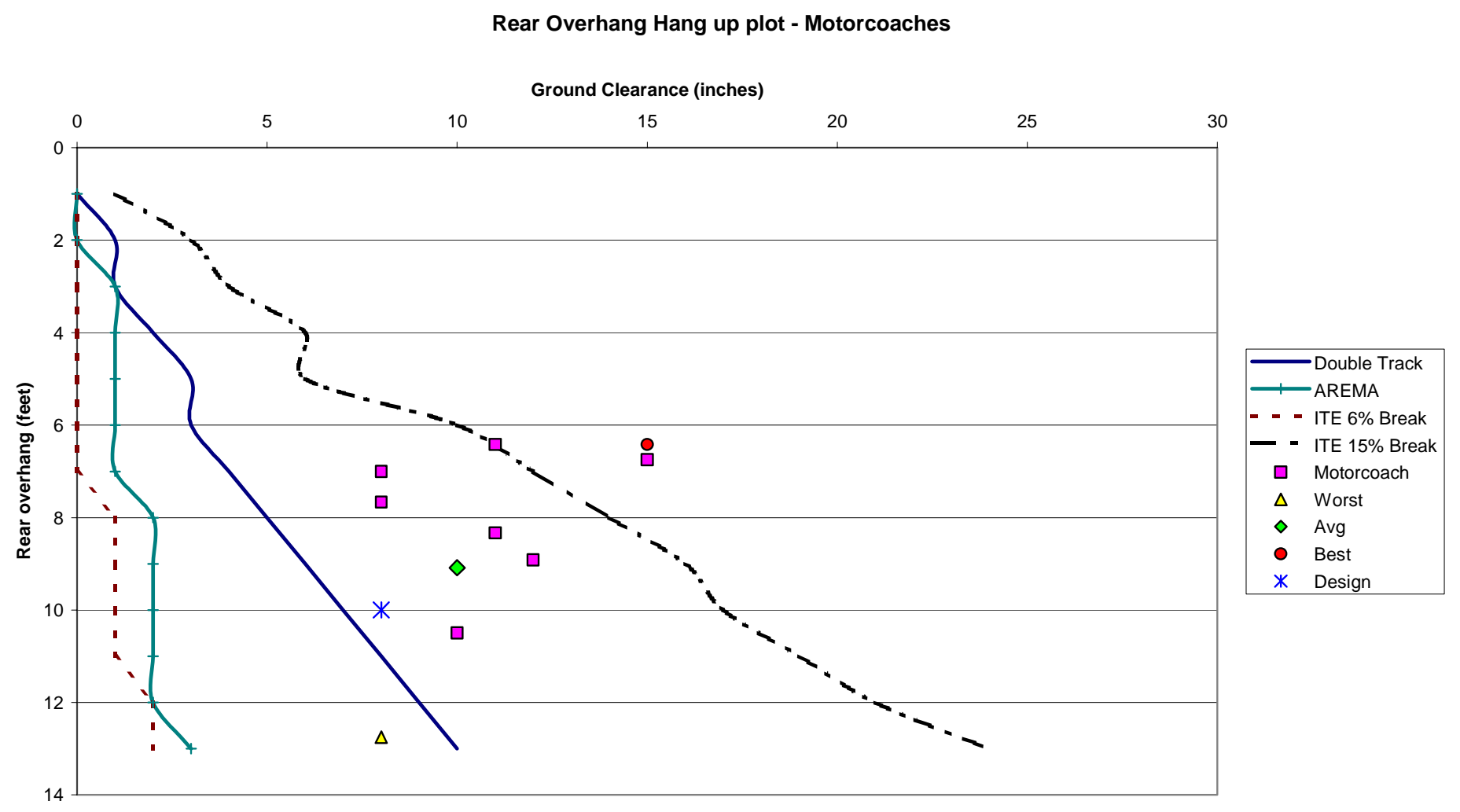




\section{Rear Overhang Hang up plot - Car Carrier Trailer}

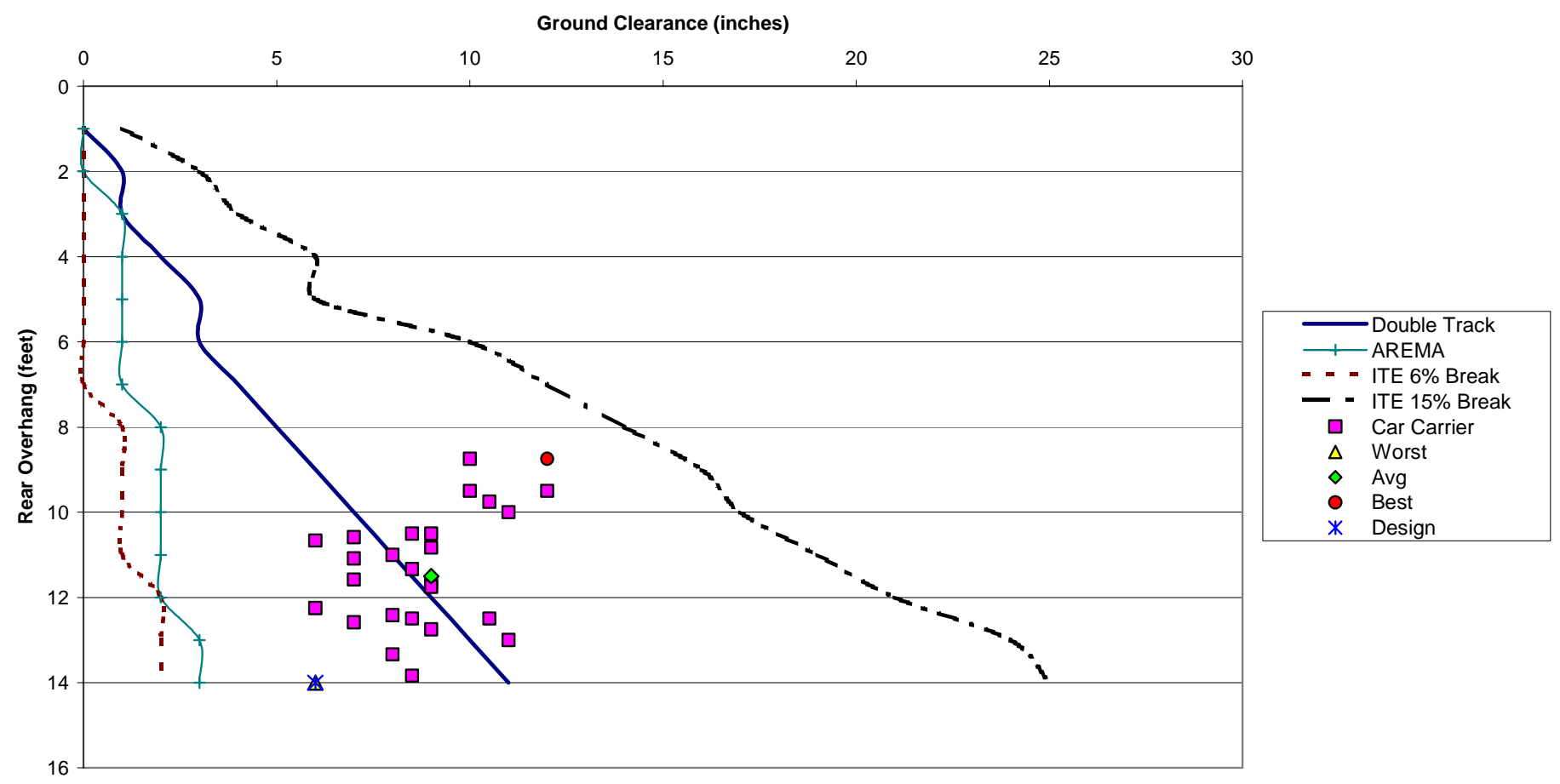


Rear Overhang Hang up - Passenger Vehicles and Trailers - Commercial

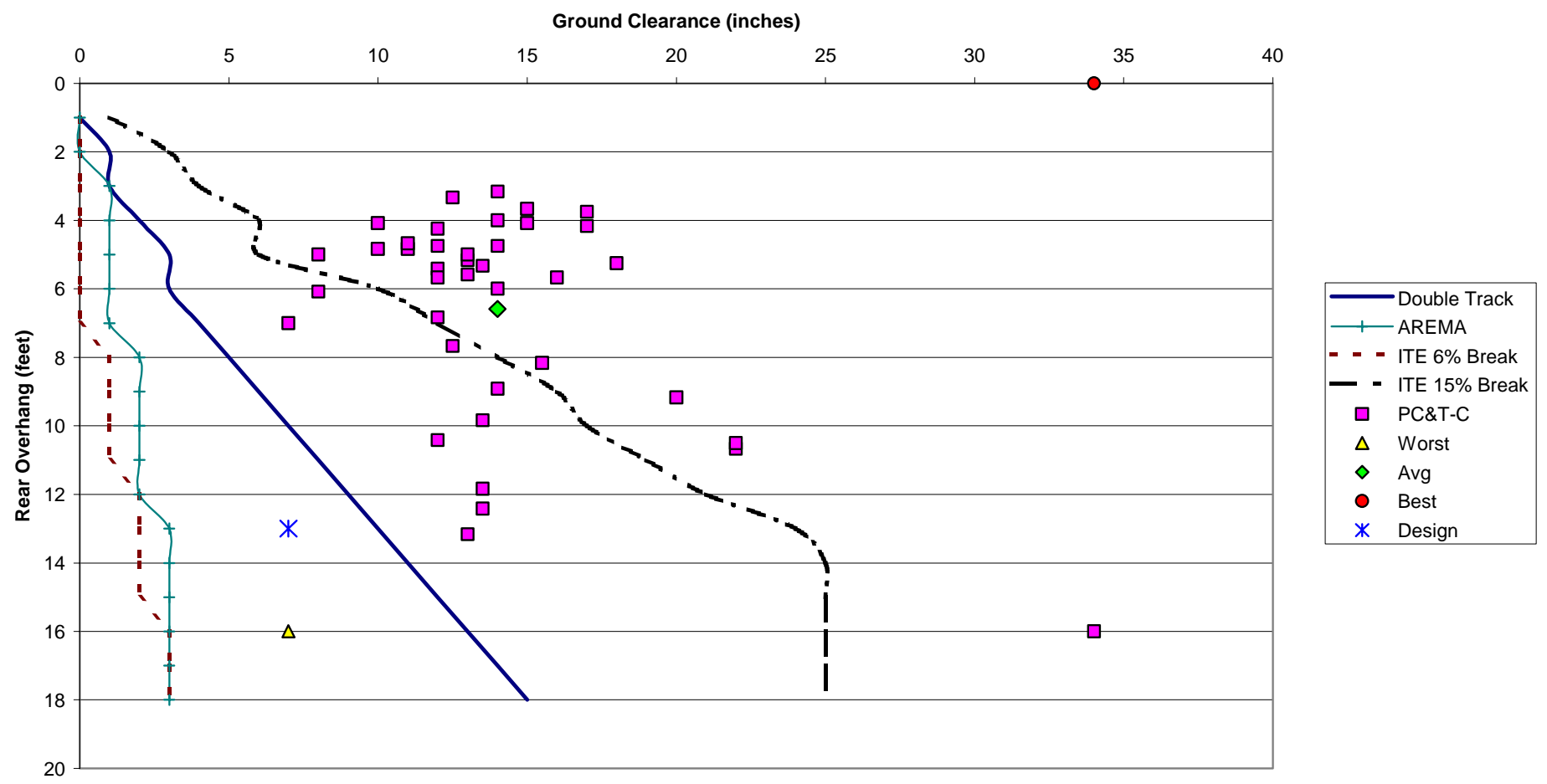


Rear Overhang Hang up plot - Passenger Vehicles and Trailers - Private Use

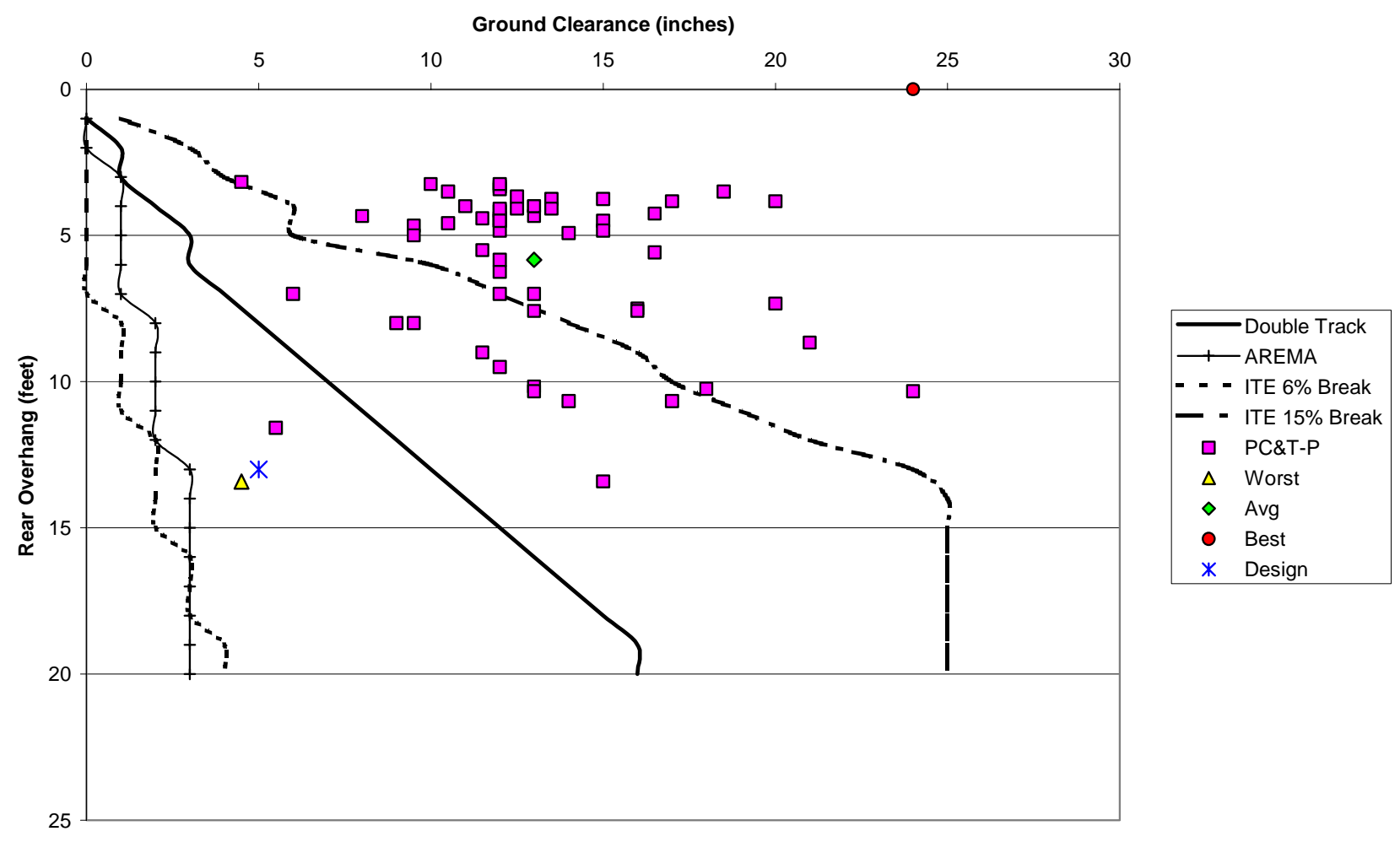




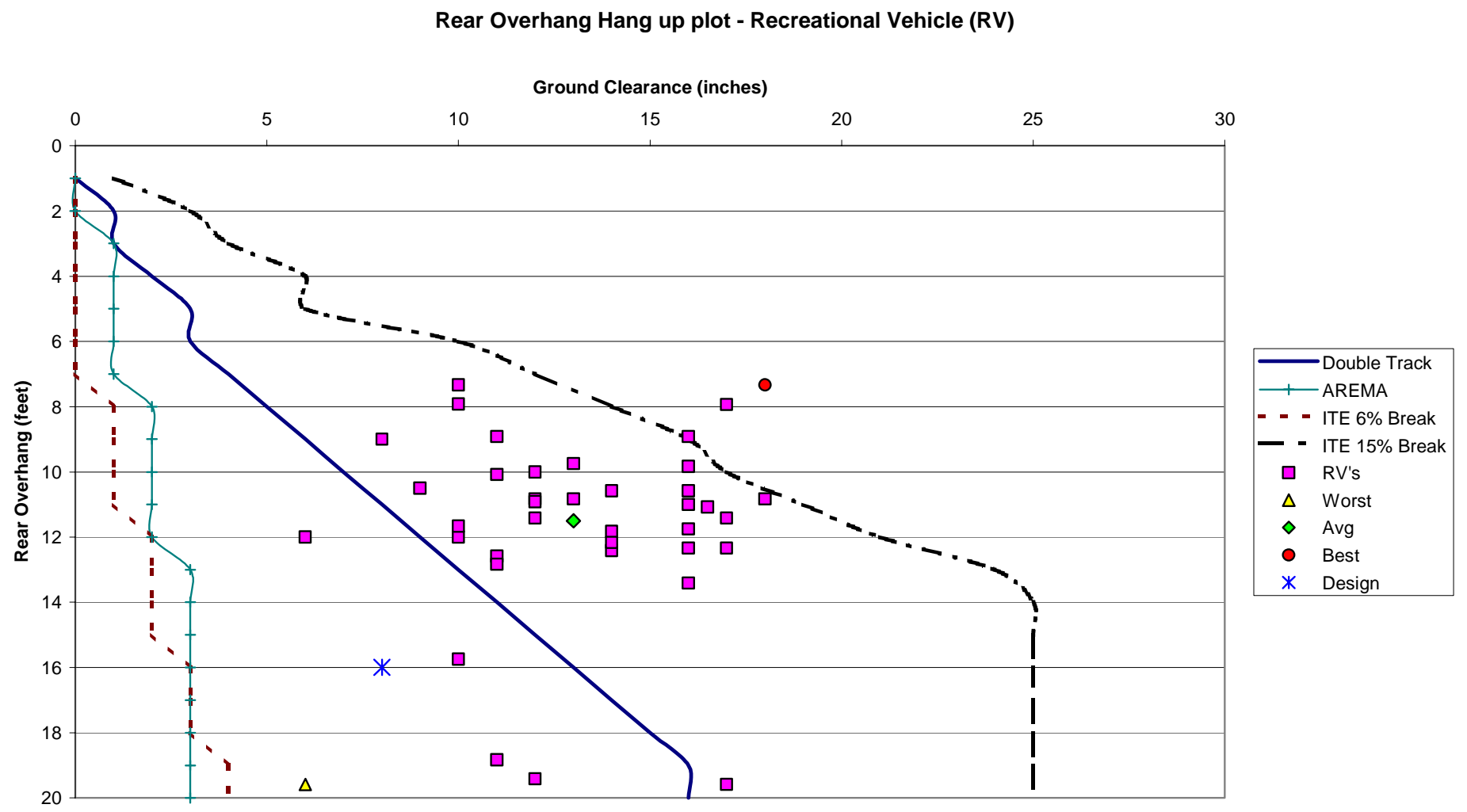




\section{Vita}

Amy Clawson was born in Latrobe, Pennsylvania, on August 9, 1979. She was raised in Blairsville, Pennsylvania, attended Blairsville Senior High School, and graduated in 1997. Amy received her Bachelor of Science in Civil Engineering in 2001 from West Virginia University. Currently, she is a Candidate for the Master's of Science in Civil Engineering at West Virginia University specializing in Transportation Engineering. 